ERNEST DRLANDD LAWRENCE

BERKELEY NATIONAL LABDRATIRY

Energy \& Environment Division

\title{
Energy Analysis Program
}

\section{Annual Report}

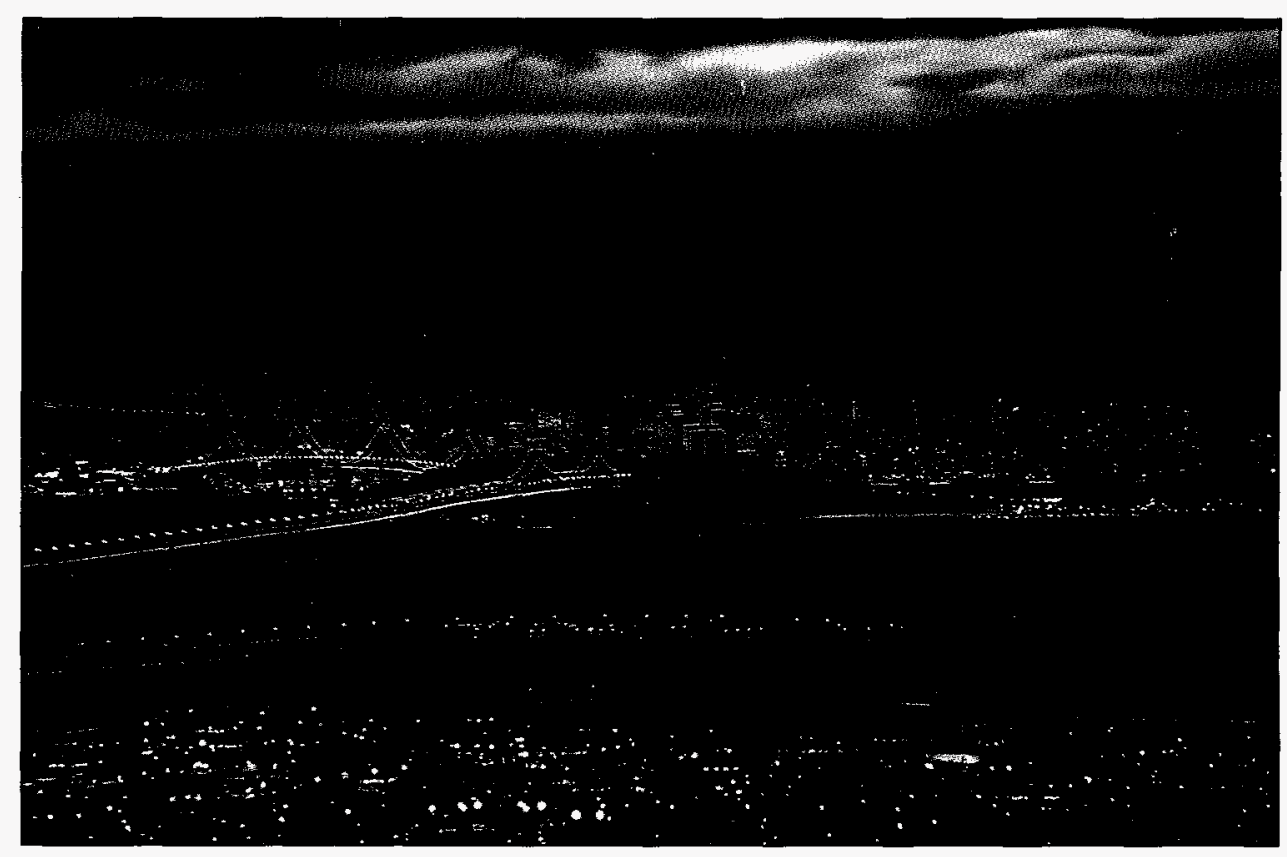

May 1996 


\section{DISCLAIMER}

This report was prepared as an account of work sponsored by an agency of the United States Government. Neither the United States Government nor any agency thereof, nor any of their employees, makes any warranty, express or implied, or assumes any legal liability or responsibility for the accuracy, completeness, or usefulness of any information, apparatus, product, or process disclosed, or represents that its use would not infringe privately owned rights. Reference herein to any specific commercial product, process, or service by trade name, trademark, manufacturer, or otherwise does not necessarily constitute or imply its endorsement, recommendation, or favoring by the United States Government or any agency thereof. The views and opinions of authors expressed herein do not necessarily state or reflect those of the United States Government or any agency thereof.

Cover photograph courtesy of Don Fike.

Available to DOE and DOE Contractors from Office of Scientific and Technical Information P.O. Box 62, Oak Ridge, TN 37831

Prices available from (615) 576-8401

Available to the public from

National Technical Information Service

U.S. Department of Commerce

5285 Port Royal Road, Springfield, VA 22161

Printed on recycled paper using soy-based ink.

Prepared for the U.S. Department of Energy under Contract No. DE-AC03-76SF00098 


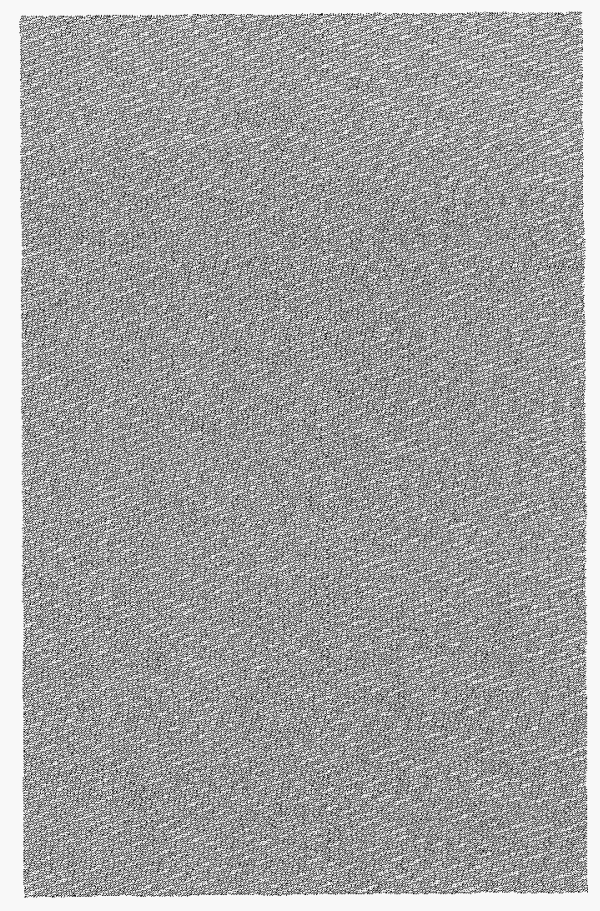

\section{Energy Analysis Program 1995 Annual Report}

Mark D. Levine, Program Head

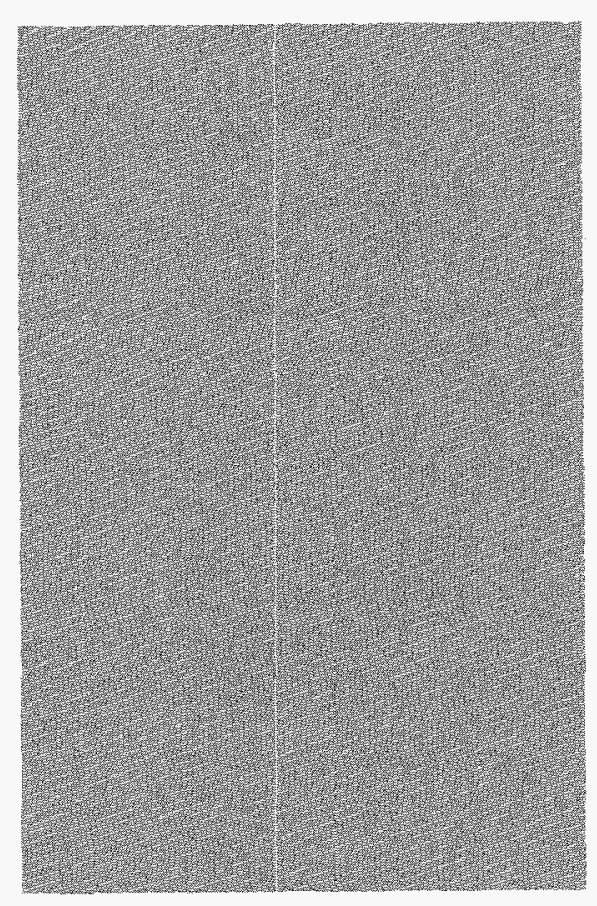

Energy \& Environment Division

Ernest Orlando Lawrence Berkeley National Laboratory University of California

Berkeley, California 94720

(510) 486-5001

Report No. LBL-38354

\section{MASTER}





\section{DISCLAIMER}

Portions of this document may be illegible in electronic image products. Images are produced from the best available original document. 


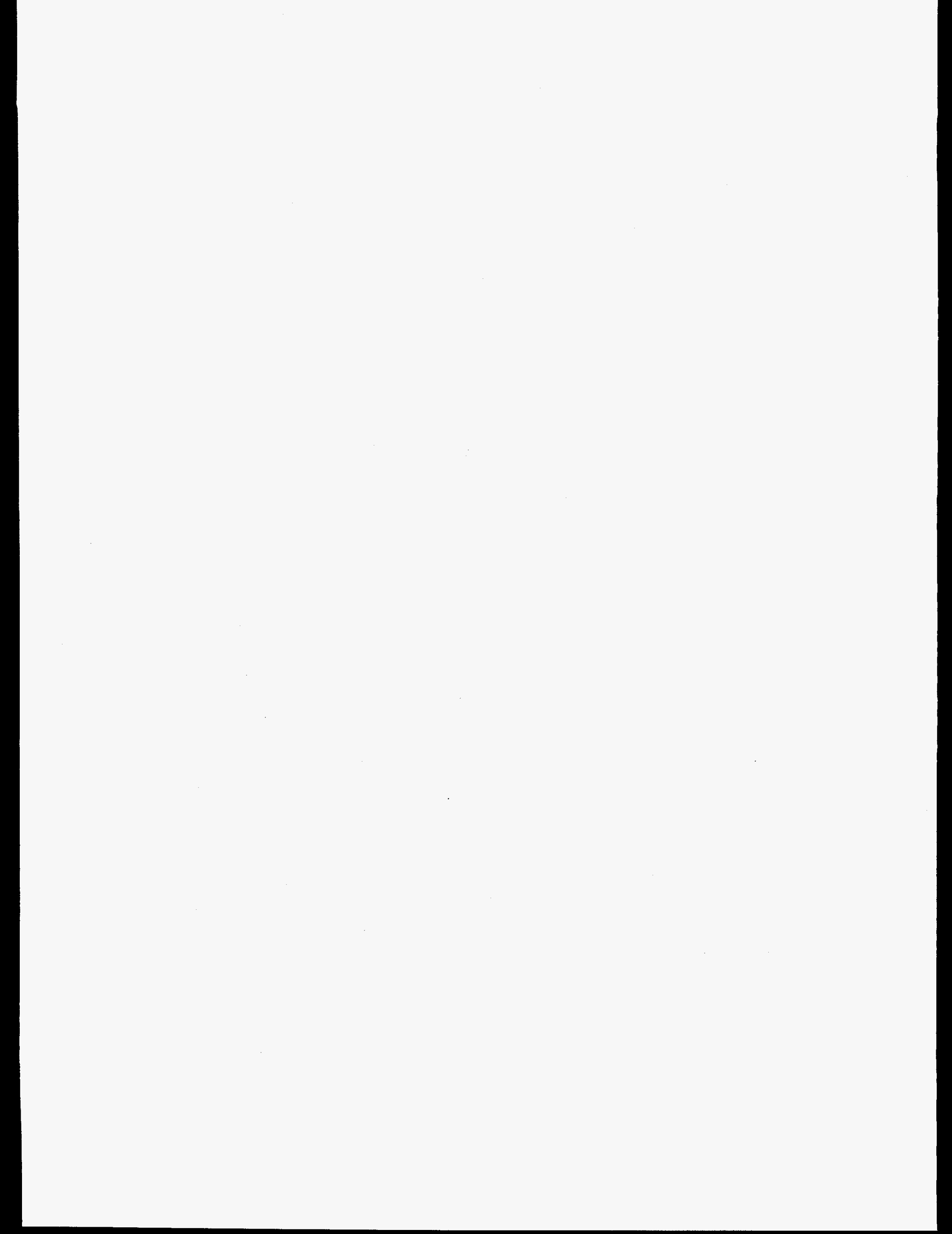




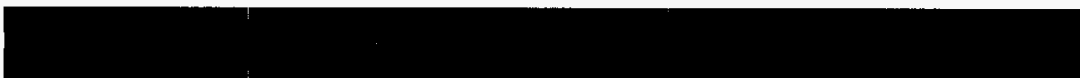

\section{Contents}

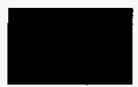

International Energy and the Global Environment $\ldots \ldots \ldots \ldots \ldots \ldots \ldots \ldots \ldots \ldots$

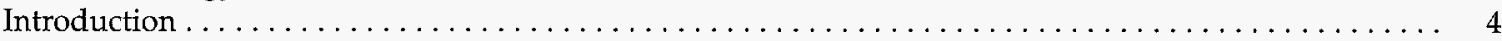

Energy Efficiency Improvement Utilising High Technology: An Assessment of Energy Use

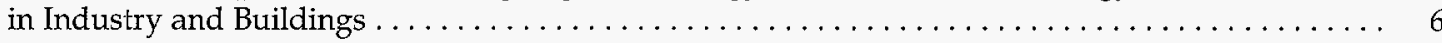

Mitigation Options for Human Settlements: A Report for the Intergovernmental Panel

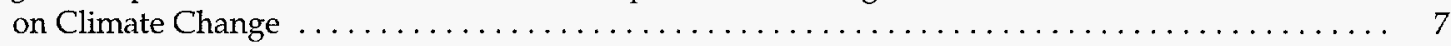

Conducting Greenhouse Gas Mitigation Assessment in Developing and Transition Countries:

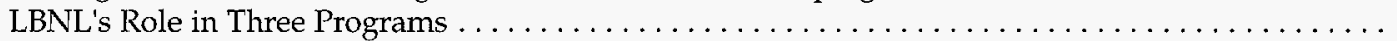

Greenhouse Gas Mitigation Assessment: A Guidebook $\ldots \ldots \ldots \ldots \ldots \ldots \ldots \ldots \ldots \ldots \ldots \ldots \ldots$

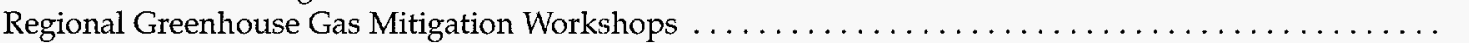

Carbon Flows and Mitigation Options in the Forest Sector $\ldots \ldots \ldots \ldots \ldots \ldots \ldots \ldots \ldots \ldots \ldots \ldots$

The Institutional Needs of Joint Implementation Projects $\ldots \ldots \ldots \ldots \ldots \ldots \ldots \ldots \ldots \ldots \ldots \ldots \ldots$

Energy Use and Carbon Implications in India: Focus on Industry $\ldots \ldots \ldots \ldots \ldots \ldots$

Macro-Economic Implications of $\mathrm{CO}_{2}$ Mitigation for Venezuela: An Evaluation Using a CGE Model .. 16

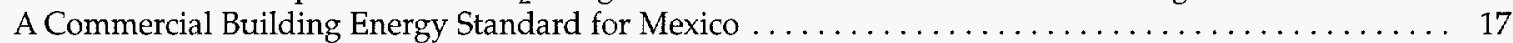

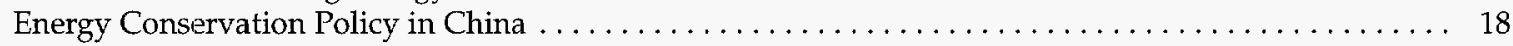

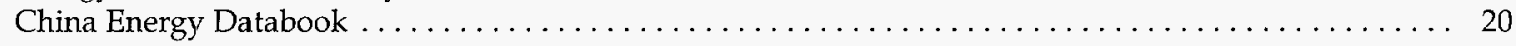

An Economic Approach to Evaluating Cogeneration Projects in China . . . . . . . . . . . . 22

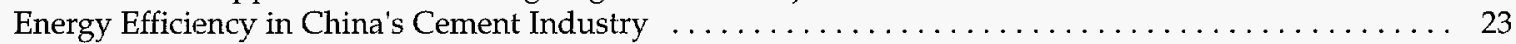

U.S.-China Super-Efficient CFC-Free Refrigerator Project $\ldots \ldots \ldots \ldots \ldots \ldots \ldots \ldots \ldots \ldots \ldots$

An International Collaboration Strategy to Reduce Greenhouse Gas Emissions in China . . . . . . . . 26

Integrated Asisessment: Structural Models of Long-Term Energy Demand . . . . . . . . . . . . . 27

The Evolution of $\mathrm{CO}_{2}$ Emissions from Energy Use in Industrialized Countries: An End-Use Analysis . . 28

Comparisons of Energy Use in Japan and the U.S. . . . . . . . . . . . . . . . . . . . . 29

Household Energy Use in Japan and the U.S. . . . . . . . . . . . . . . . . . . 30

Manufacturing Energy Use and $\mathrm{CO}_{2}$ Emissions in 10 OECD Countries:

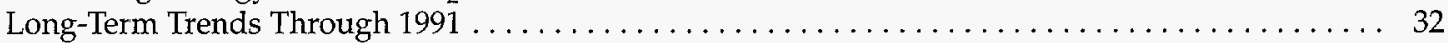

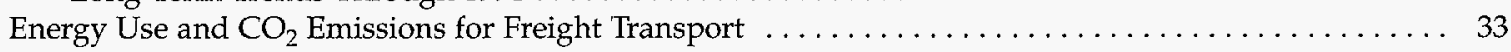

Coming in from the Cold: The Challenge of Providing Affordable Comfort

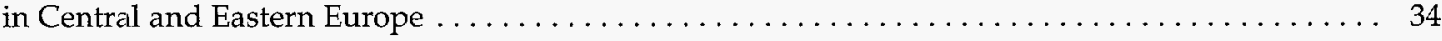

Energy Use and $\mathrm{CO}_{2}$ Emissions in Denmark Through the Early $1990 \mathrm{~s} \ldots \ldots \ldots \ldots \ldots \ldots \ldots$

Monitoring U.S. $\mathrm{CO}_{2}$ Emissions-Restraint Policies Using Energy-Use Indicators $\ldots \ldots \ldots \ldots$

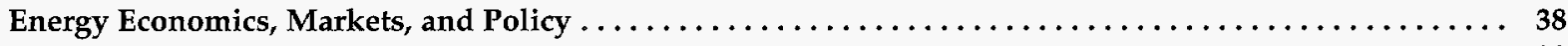

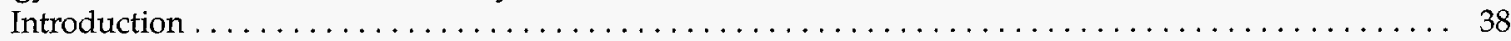

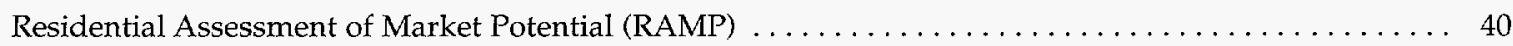

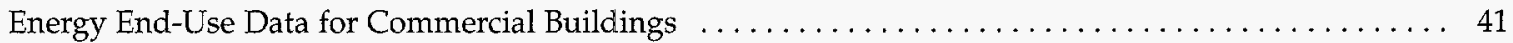

Efficiency Improvements in U.S. Office Equipment: Expected Policy Impacts and Uncertainties $\ldots \ldots \ldots 42$

Energy End-Use Data in the ROADMAP System: A Collaborative Effort . . . . . . . . . . . . 43

Magnetic Fluorescent Ballasts: Market Data, Market Imperfections, and Policy Success . . . . . . . . 44

Transforming Markets for Efficient Chillers and Motor Systems . . . . . . . . . . . . . . 45

Buying Efficient Products: The Federal "Procurement Challenge" $\ldots \ldots \ldots \ldots \ldots \ldots \ldots \ldots \ldots \ldots \ldots$

Uncertainty and Implicit Discount Rates in Energy-Efficiency Investments . . . . . . . . . . . . 47

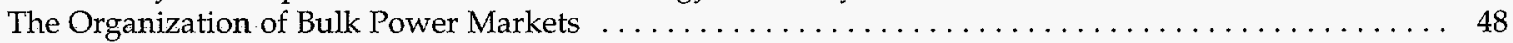

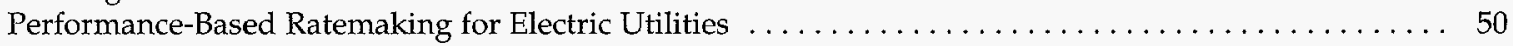

PSE\&G's Standard Offer Program: Evaluation and Transferability $\ldots \ldots \ldots \ldots \ldots \ldots \ldots \ldots \ldots \ldots \ldots$

Money Well-Spent: The Cost and Measured Performance of the Largest Commercial Sector

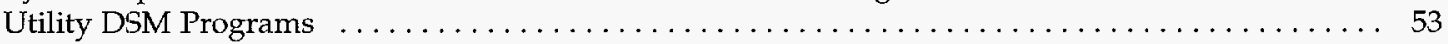

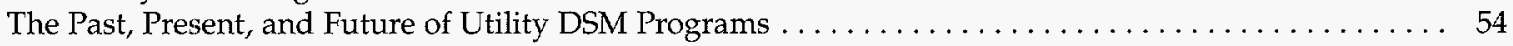

Resource Planning for Gas Utilities: Models and Issues $\ldots \ldots \ldots \ldots \ldots \ldots \ldots \ldots \ldots \ldots \ldots \ldots \ldots \ldots$

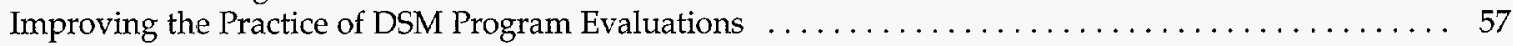

The Performance of the U.S. Market for Independent Electricity Generation . . . . . . . . . . . 58

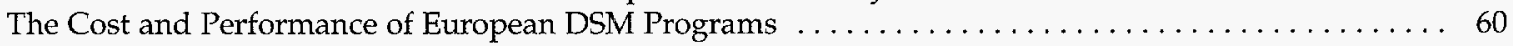

Analysis of Federal Appliance Efficiency Standards $\ldots \ldots \ldots \ldots \ldots \ldots \ldots \ldots \ldots \ldots \ldots \ldots \ldots \ldots \ldots$ 
Engineering Analyses of Appliance Efficiency Improvements $\ldots \ldots \ldots \ldots \ldots \ldots \ldots$ Impacts of Water Heater Efficiency Increases: Variability among Households $\ldots \ldots \ldots \ldots \ldots$ Promoting Water Conservation with State and Local Incentive Programs . . . . . . . . . . 64

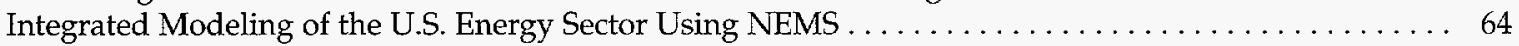

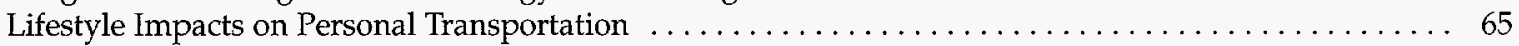
Research to Support the Development of Energy-Efficient, Low-Polluting Automobiles . . . . . . . . 67 Real-World Emissions from Model Year 1993, 2000, and 2010 Passenger Cars . . . . . . . . . . . . . 68

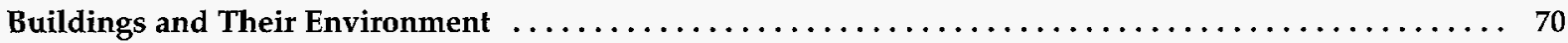

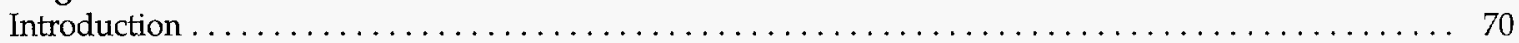

Cooling Our Communities: An Overview of Heat Island Project Activities . . . . . . . . . . . 72

Ozone Air Quality Implications of Large-Scale Albedo and Vegetation Modifications

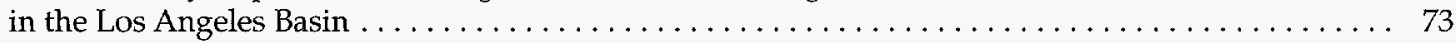

Energy Cost Savings From Cool Roofs in Sacramento, California . . . . . . . . . . . . . . . 74

Modeling the Meteorological and Energy Impacts of Urban Heat Island Control in the U.S. . . . . . . 74

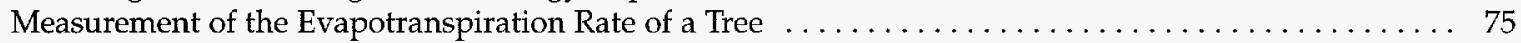

Microclimate Variation in the Suburban Environment $\ldots \ldots \ldots \ldots \ldots \ldots \ldots \ldots \ldots \ldots \ldots \ldots \ldots \ldots$

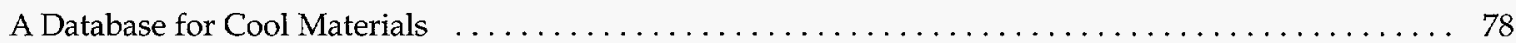

Paving Materials for Heat Island Mitigation $\ldots \ldots \ldots \ldots \ldots \ldots \ldots \ldots \ldots \ldots \ldots \ldots \ldots \ldots$

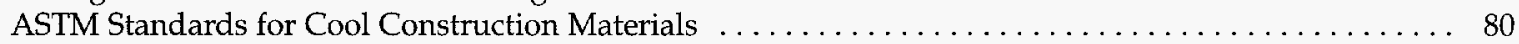

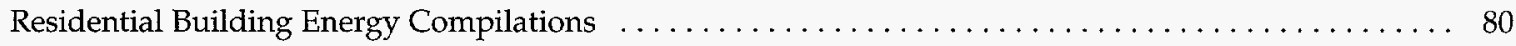

The Cost and Performance of Residential New Construction Programs . . . . . . . . . . . . 81

Designing Compressorless Houses for California Transition Climates $\ldots \ldots \ldots \ldots \ldots \ldots \ldots$

Evaporative Cooling and Other Low-Energy Cooling Strategies in Large Commercial Buildings . . . . 83

Detailed Analysis of an Innovative Evaporative/Radiant Floor Slab Cooling System . . . . . . . . . 84

Computerized Commissioning Tools for Commercial Buildings $\ldots \ldots \ldots \ldots \ldots \ldots \ldots$

Building Performance Evaluation and Tracking Tool $\ldots \ldots \ldots \ldots \ldots \ldots \ldots \ldots \ldots \ldots \ldots \ldots \ldots \ldots \ldots \ldots$

Measured Energy Savings and Performance of Power-Managed Personal Computers and Monitors . . . 87

Energy Use of Ice Making in Domestic Refrigerators $\ldots \ldots \ldots \ldots \ldots \ldots \ldots \ldots \ldots \ldots \ldots \ldots$

Space-Conditioning Energy Requirements in the U.S. Commercial Building Stock . . . . . . . . . . . 89

Estimates of Energy Consumption by Building Type and End Use at Department of Defense Facilities 


\section{Introduction}

This year the role of energy technology research and analysis supporting governmental and public interests is again being challenged at high levels of government. This situation is not unlike that of the early 1980s, when the Administration questioned the relevance of a federal commitment to applied energy research, especially for energy efficiency and renewable energy technologies. Then Congress continued to support such activities, deeming them important to the nation's interest.

Today, Congress itself is challenging many facets of the federal role in energy. The Administration is also selectively reducing its support, primarily for the pragmatic objective of reducing federal expenditures, rather than because of principles opposing a public role in energy.

In this climate it is useful to look at the numerous activities of the Energy Analysis Program to reassess how they still relate to the national interest.

Our largest activity, with more than 30 staff members under the direction of James McMahon and Isaac Turiel, is performing engineering and economic analysis on appliance energy efficiency standards - an effort we have led for the U.S. Department of Energy for the past 15 years. We estimate that the appliance standards already implemented will cut energy demand by one quad per year by the end of the decade, a savings on the order of $\$ 10$ billion per year. They will also reduce the need for more than forty 500-MW power plants. Additional standards under consideration would yield even greater benefits.

Another of our research areas is utility planning and policy. A tremendous array of public policy issuesfrom transmission pricing to the role of utility demand-side management and public goods R\&D in a restructured industry-have emerged as the utility industry enters a new era that is redefining the industry itself. Utility regulatory commissions often do not have the resources to research these issues. Furthermore, many of these issues are best addressed at the national level, especially the development of methodologies relying on quantitative models.

Our work on heat islands has invigorated a whole research area-assess- ment of the causes and mechanisms to mitigate urban heat islands-by demonstrating that reducing the trapping of heat in urban areas can be one of the most significant and cost-effective means of improving urban air quality as well as reducing energy use.

In the field of international energy demand, our multifaceted work continues: analyzing energy demand in developing countries (with special attention to China), Eastern Europe and the former Soviet Union, and the industrialized nations; supporting developing countries on greenhouse gas mitigation; and fostering programs to support activities implemented jointly between the U.S. and developing countries to reduce greenhouse gas emissions.

Federal procurement and marketconditioning policies are two more of the Program's activities. Working with our Washington, D.C. colleagues, we are leading efforts to encourage federal offices to purchase energy-efficient equipment.

In light of uncertain political support for appliance standards and utility analyses as well as the tremendous

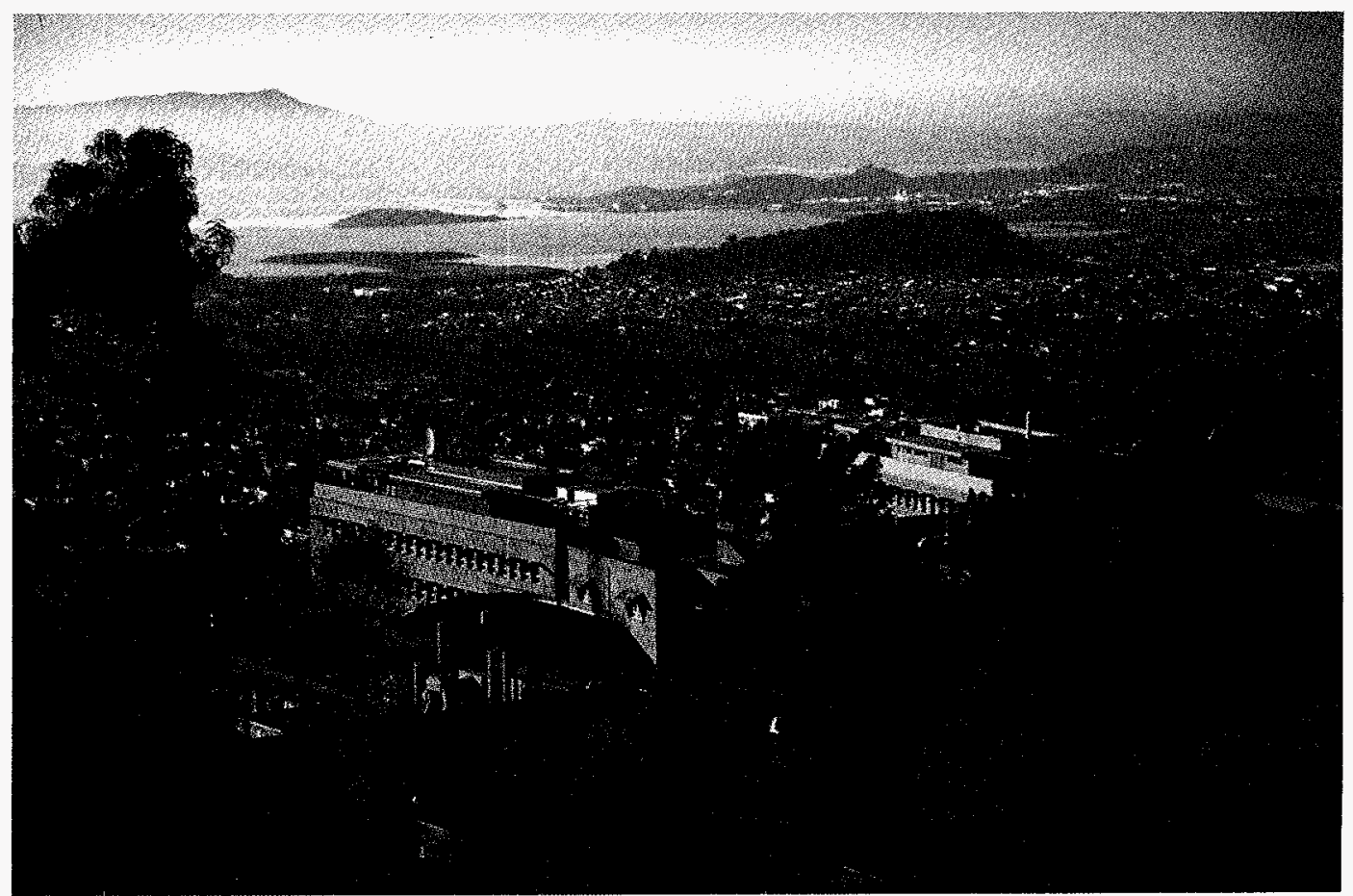


downward pressure on federal budgets to assist or work with developing countries, we have established new initiatives and thrusts for the Program to pursue. These initiatives all build on the work that we now do and extend the work into new areas. We have chosen the following six initiatives as our initial thrust:

- technical support for the energy-efficiency components of international bank loans. Here we support developing countries that have energy-efficiency programs. We envision working with these countries to craft energy-efficiency policies, design capital investments for energyefficiency projects, and train personnel in various aspects of energy efficiency. Steve Wiel is leading this initiative.

- international appliance labeling and standards. Our appliance standards work is being extended to industrialized and developing nations. Jim McMahon is leading this initiative for industrialized countries; Jim and Steve Wiel are actively pursuing this for developing countries.

- global assessment of energy efficiency in buildings, industry, and transportation. This initiative builds on the work performed for the Tokyo World Energy Council in 1995. If funded, it will be a major international collaboration for the World Energy Council meeting in Houston in 1998. A global energy display and analysis laboratory is a logical followup of the global assessment work. In conjunction with international energy analysts, we will produce a state-of-theart energy-efficiency assessment and disseminate that information. Mark Levine is leading this initiative.

- U.S. energy supply, demand, and price modeling. This effort involves LBNL establishing its capabilities to perform independent analyses of a range of energy policy issues using the National Energy Modeling System (developed by the U.S. Energy Information Adminis-

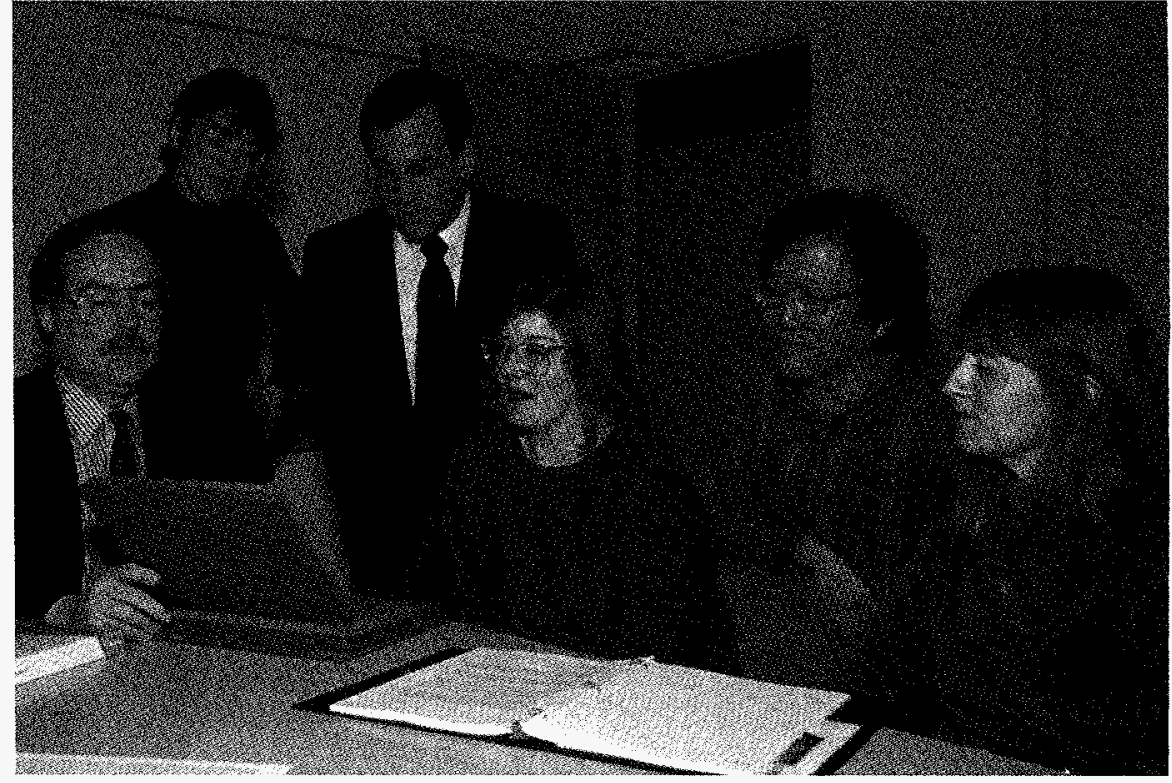

tration) and other modeling tools. Chris Marnay is the leader.

- benefit/cost/risk assessment of regulatory policies. This initiative involves applying the tools developed in numerous analyses within the Energy Analysis Program (including the extensive work on appliance standards) to prioritize investment according to risk in other regulatory policies. Jim McMahon is the leader.

- a multiclient study of energy issues in China. The first effort will study energy demands of transportation in China and the implications for liquid fuel requirements. This work is led by David Fridley.

We are also exploring four other major new initiatives:

- application of our Geographic Information Systems laboratory to energy markets and electric utility applications.

- Presidio Pacific Center: the creation of a training institute fostering sustainable development at the Presidio of San Francisco.

- transportation analysis: the development of data and modeling relating to emissions, air quality, energy efficiency, travel demand, and economics.

- applications of the World Wide Web to energy efficiency: novel applications (e.g., remote monitoring and calculations) and new approaches to information dissemination

As noted, these initiatives build on our work of the past decades, which we continue to stress. We are eager to work with professional colleagues on these initiatives. At this time, more than ever, excellent professional collaborations are needed to address problems of national importance. Inquiries about the initiatives can be made by sending e-mail to us at eap.initiative@lbl.gov.

This year, we have divided the Annual Report of the Energy Analysis Program into three sections, corresponding to the three major thrusts of the Program. These are "International Energy and the Global Environment," "Energy Economics, Markets, and Policy," and "Buildings and Their Environment." A description of our activities over the past year is presented in the following pages. 
Mark D. Levine, Program Head

Stephen Wiel, Deputy Program Head

\author{
Asim Afzal \\ Margaret Agbowo* \\ Hashem Akbari \\ Orpheus Allan* \\ Barbara Atkinson \\ Celina Atkinson \\ Tim Belden. \\ Peter Biermayer \\ Stanley Boghosian \\ Sarah Bretz \\ Andrea Brewer \\ Rich Brown \\ Stephen Brown \\ Yuri Burovski $i^{\dagger}$ \\ John Busch \\ Charles Campbell \\ Nancy Casey-McCabe \\ James Chadam \\ Peter Chan \\ Terry Chan \\ Mark Chao* \\ Pelin Chen ${ }^{\dagger}$ \\ G. Alan Comnes \\ Deborah Connell \\ Paul Craig \\ Mike Cramer \\ William Bart Davis \\ Odón de Buen \\ Mirka della Cava \\ Antonio del Monico \\ Andrea Denver \\ Anthony DeVuono \\ Diana Duhnke \\ Camilla Dunham \\ Mike Eisenberg* \\ Joseph Eto \\ Di Ann Fager \\ Jacco Farla ${ }^{\dagger}$ \\ Debbie Farlow \\ Viviania Fernández
}

*Student Assistant
+Participating Guest
†Group Leader

\begin{tabular}{|c|c|}
\hline Maria Figueroa & Marie-Alice L'Heureux \\
\hline Anthony Fisher & Aaron Lee \\
\hline Diane Fisher & Ronnen Levinson \\
\hline Beth Fishman & Nancy Lewis \\
\hline Ellen Franconi & Jiang Lin \\
\hline David Fridley & Barbara Litt \\
\hline Rafael Friedmann & Xiaomin Liu \\
\hline Sasa Gabersek $^{\dagger}$ & James Logan \\
\hline Chris Ganson & James Lutz \\
\hline Janissa Garcia* & Miriam Mabel \\
\hline Lisa Gartland & Susan Mahler \\
\hline Ted Gartner & Willy Makundi \\
\hline Beth Goldberg & Chris Marnay \\
\hline Charles Goldman & Nathan Martin \\
\hline Todd Goldman ${ }^{\dagger}$ & Eric Martinot \\
\hline William Golove $^{\dagger}$ & Marsha Mathews \\
\hline Roger Gorham ${ }^{\dagger}$ & C. Bartlett McGuire \\
\hline Robert Gramlich & Aimee McKane \\
\hline Steve Greenberg & James McMahon $\ddagger$ \\
\hline Nathaniel Greene & Alan Meier $\ddagger$ \\
\hline Lorna Greening & Stephen Meyers \\
\hline Bjorn Grinden ${ }^{\dagger}$ & Mithra Moezzi \\
\hline Shauna Haines & Patty Monahan \\
\hline Sajid Hakim. & Nandita Mongia $^{\dagger}$ \\
\hline Jeffrey Harris & Puran Mongia ${ }^{\dagger}$ \\
\hline Kristin Heinemeier & Diana Morris \\
\hline Moira Howard & Bruce Nordman \\
\hline Richard Howarth & Richard Norgaard \\
\hline Yu J. Huang & Jeff Ogi \\
\hline Nancy Hurrelbrinck ${ }^{\dagger}$ & Karen Olson \\
\hline Mireya Imazt & Shmuel Oren \\
\hline Katy Janda & Adolfo Palombo \\
\hline Judith Jennings & Prakash Parameswara \\
\hline Frank Johnson & Chris Payne \\
\hline Patricia Juergens & Leena Perälä \\
\hline Edward Kahn $\ddagger$ & Steven Pickle \\
\hline Anton Kast & Mary Ann Piette \\
\hline Marta Khrushch ${ }^{\dagger}$ & Maggie Pinckard* \\
\hline Suzie Kito & Mel Pomerantz \\
\hline Johanna Kollar & Brian Pon \\
\hline Steven Konopacki & Barbara Praetorious $^{\dagger}$ \\
\hline Jonathan Koomey & Lynn Price \\
\hline Florentin Krause & Scott Prudham ${ }^{\dagger}$ \\
\hline
\end{tabular}

Maria Figueroa

Anthony Fisher

Rafael Friedmann

Sasa Gabersek ${ }^{\dagger}$

Chris Ganson

Janissa Garcia*

Charles Goldman

Todd Goldman ${ }^{+}$

William Golove

Robert Gramlic

Steve Greenberg

Nathaniel Greene

Jeffrey Harris

Kristin Heinemeier

Richard Howarth

Yu J. Huang

Nancy Hurrelbrinck

Judith Jennings

Frank Johnson

cia Juergen

Marta Khrushch ${ }^{\dagger}$

Suzie Kito

Florentin Krause
Huimin Qin ${ }^{\dagger}$

John Randolph

Cooper Richey

Judy Roberson

Gregory Rosenquist

Marc Ross

Glenn Saika

Jurgen Salay

Marla Sanchez*

Alan Sanstad

Jayant Sathaye $\neq$

Lee Schipper $\neq$

Lynn Scholl

Agah O. Sezgen

Leslie Shown

Irina Shukman

Jonathan Sinton

Craig Smith

Richard Sonnenblick

Steven Stoft

Haider Taha

Mike Ting

Kenneth Train

Isaac Turiel

Fridtjof Unander ${ }^{\dagger}$

Pravin Varaiya

Edward Vine

Zora Vorackova ${ }^{\dagger}$

Diana Vorsatz

Jeff Warner

Elaine Watt

Carrie Webber

Tom Wenzel

Stephen Wiel

Ryan Wiser

Lorraine Williams

Nancy Wishner

Feng Yang*

Fu Qiang Yang

Chung-Seok Yoo'

Justin Zeitz*

Hui Zhang

Shuyu Zhang 


\section{International Energy and the Global Environment}

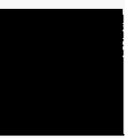

In 1995 not only did we continue much of our previous work in the field of international energy studies, but we also expanded our studies with large efforts in the area of international workshops. We produced reports that were presented at world conferences and updated our China Energy Databook.

\section{- intercountry energy comparisons}

For many years the Energy Analysis Program has played a leadership role in international energy demand analyses. The early work of Lee Schipper, comparing energy intensity among different countries, has given rise to a vast body of literature-much produced by Lee himself-on numerous aspects of intercountry energy comparisons. In this Annual Report, Lee and his colleagues summarize their work of the past year on $\mathrm{CO}_{2}$ emissions from all energy sectors of industrialized countries; manufacturing energy use in industrialized countries; energy and housing in Eastern Europe; and analysis of the structure of energy use in Japan, the United States, and Denmark, with a comparison of the first two. In the coming years, we anticipate that Lee's group will devote considerable effort to international transportation demand and energy issues.

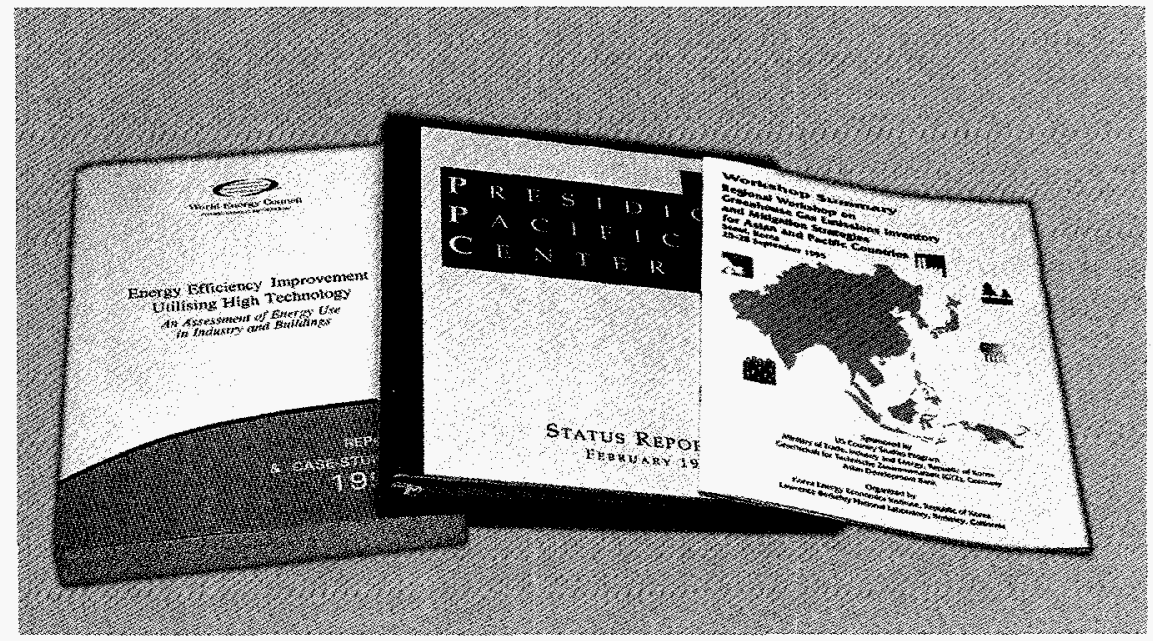

- energy demand and forestry in developing nations

Jayant Sathaye has led a broad range of analyses of energy demand and forestry in developing nations. His collection of data from developing countries, including surveys of energy use as well as data from the network of energy experts from these countries, have been used by numerous organizations as the basis of understanding energy scenarios for the developing world. This year Jayant and colleagues describe carbon flows in the forest sector and methods to reduce carbon emissions, energy use

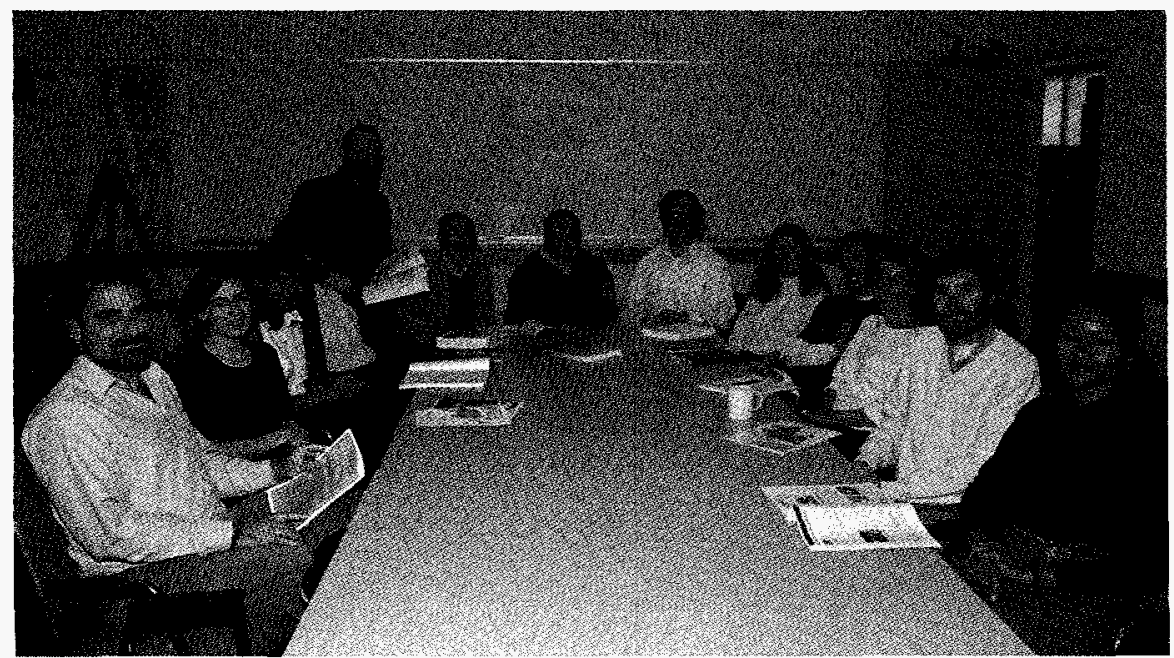

and carbon in India, macroeconomic modeling of reducing the growth of $\mathrm{CO}_{2}$ emissions in Venezuela, and issues associated with joint implementation (between industrialized and developing countries) of greenhouse gas-mitigation projects.

- technical assistance to developing countries to reduce greenhouse gas emissions

Steve Wiel and Jayant collaborated in leading the U.S. effort to provide technical assistance to developing countries in analyzing approaches to reduce greenhouse gas emissions. This effort, which involved more than 50 developing countries, was primarily designed to assist these countries in the preparation of assessments of greenhouse gas mitigation potential and national action plans. The activities included the production of an extensive guidebook on methods to mitigate emissions, two international training workshops, and four regional workshops in which the results of the work in the developing countries were presented.

Steve and Jayant are also collaborating on projects for the U.S. Agency for International Development that support energy efficiency to reduce greenhouse gas emissions in Latin America. Of particular note has been the work on. building energy standards in Mexico. 
- energy efficiency from a global perspective

Mark Levine and colleagues produced two reports on energy efficiency from a global perspective. One report, for the Intergovernmental Panel on Climate Change (IPCC), was on mitigation options for human settlements, with emphasis on energy efficiency in buildings as the major set of mitigation measures. This will be one of four chapters on policy options to reduce greenhouse gas emissions in the final report of Working Group II of the IPCC. The other report was an analysis of energy efficiency in five industrial subsectors (iron and steel, pulp and paper, oil refining, building materials, and chemicals) and in buildings for the major regions of the world. Published as a report of the World Energy Council, this work was presented at the World Energy Congress in Tokyo. Nathan Martin and Lynn Price won Outstanding Performance Awards for this work, the only members of the Energy Analysis Program to be so honored this year.

Mark and Steve Wiel have been leading an effort to establish the Pacific Presidio Center (FPC), an institute promoting sustainable development at the Presidio of San Francisco. The institute, which will focus on countries in the
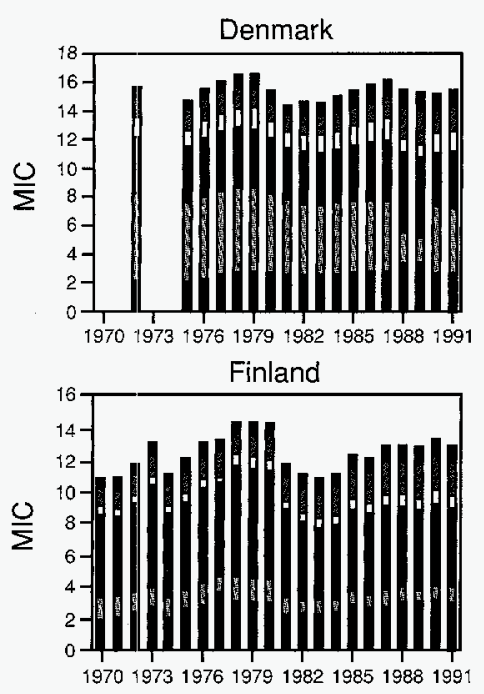

USA

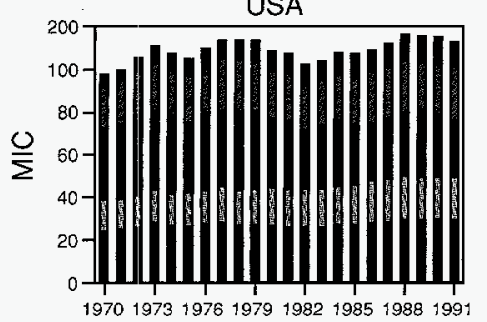

Pacific Rim and South Asia, will provide opportunities for leaders to meet to discuss sustainability, would offer broad training on the subject, would produce and "distribute" a new journal of sustainable development on the World Wide Web, and over time, create a global network of PPC alumni with a "Presidio Perspective" of the world. To date, the PPC has, with partial funding from the U.S. DOE, prepared a feasibility study for the institute, obtained its first private funding, organized two U.S.-Japan workshops on energy, and created an active World Wide Web site called VirtualPresidio.

\section{- China energy studies}

The China energy studies activity, under: the direction of Mark Levine and David Fridley, produced a wide variety of work: an assessment of Chinese energy-conservation policies, an analysis of

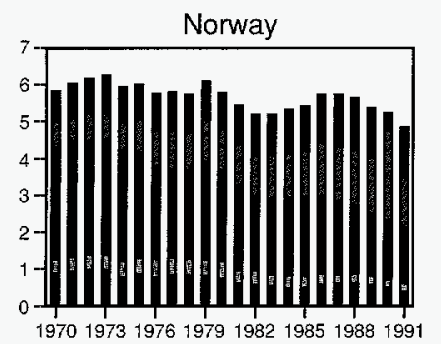

W. Germany

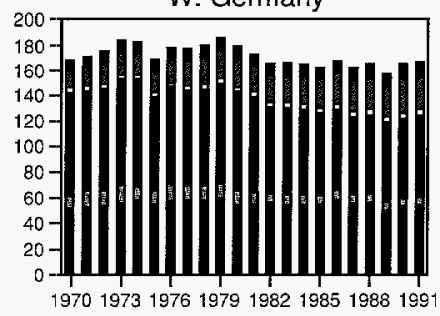

France

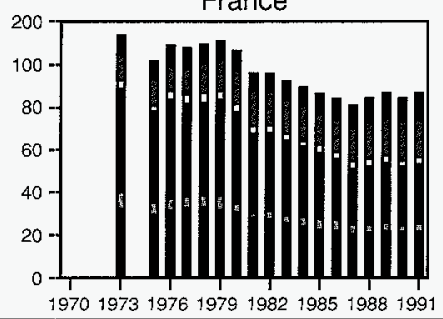

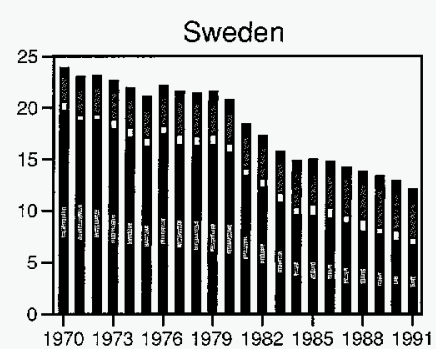

Japan

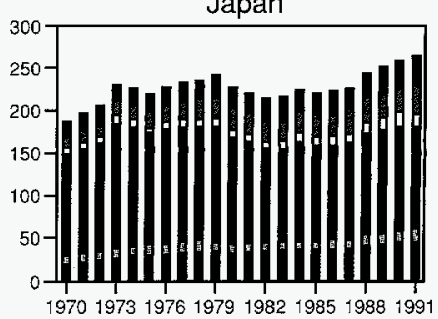

UK

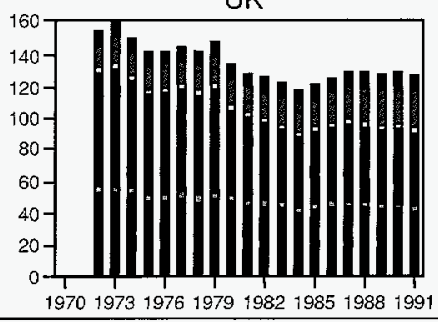

Freight Travel $\square$ Other Industry Manufacturing 騾 Services

Residences 


\section{Energy Efficiency Improvement Utilising High Technology: An Assessment of Energy Use in Industry and Buildings}

M.D. Levine, N. Martin, L. Price, E. Worrell*

The Energy Analysis Program cochaired a key energy-efficiency study that was presented at the 1995 Congress of the World Energy Council (WEC) in Tokyo, Japan. The Congress brought together over 4500 key policymakers, industrial representatives, and researchers to discuss the sustainable production and use of energy. The study was a twoyear research effort involving participants from 10 countries.

This global efficiency analysis reviewed historical trends in energy use and efficiency in five energy-intensive industrial sectors (iron and steel, pulp and paper, chemicals, petroleum refining, and building materials) and in residential and commercial buildings. Together the top five energy-intensive sectors account for about $45 \%$ of total

*Department of Science, Technology \& Society, Utrecht University, Utrecht, The Netherlands. industrial energy use. Three scenarios were developed to estimate future energy use. The report also includes 23 individual case studies of energy-efficient technologies in the two sectors.

Industrial energy use is expected to grow by $1.4 \%$ annually through the year 2020 under a business-as-usual scenario (see Figure). This growth can be slowed to about $0.8 \%$ per year as a result of directed policies and strong price signals that lead to the use of state-of-theart technologies. In a world in which an ecological imperative leads to rapid and widespread use of advanced technology, industrial energy use in 2020 can remain at 1990 levels. In all three of these scenarios, energy demand growth for buildings is about $1 \%$ per year higher than for industry. As a result, the buildings sector is likely to use more commercial energy than all of industry within a quarter of a century unless there are unexpected changes in energyuse patterns.

The report noted that there are three essential requirements for an energy-efficient future: 1) aggressive energyefficiency policies, as well as real increases in energy prices; 2 ) major programs to transfer knowledge, technology, and tools for transforming markets to the developing world; and 3) continued efforts to pursue research and development in technologies and practices to increase energy efficiency in buildings.

\section{Reference}

Levine MD, Martin N, Price L, Worrell E (Lead Authors). Energy Efficiency Improvement Utilising High Technology: An Assessment of Energy Use in Industry and Buildings. London, UK: World Energy Council. 1995.

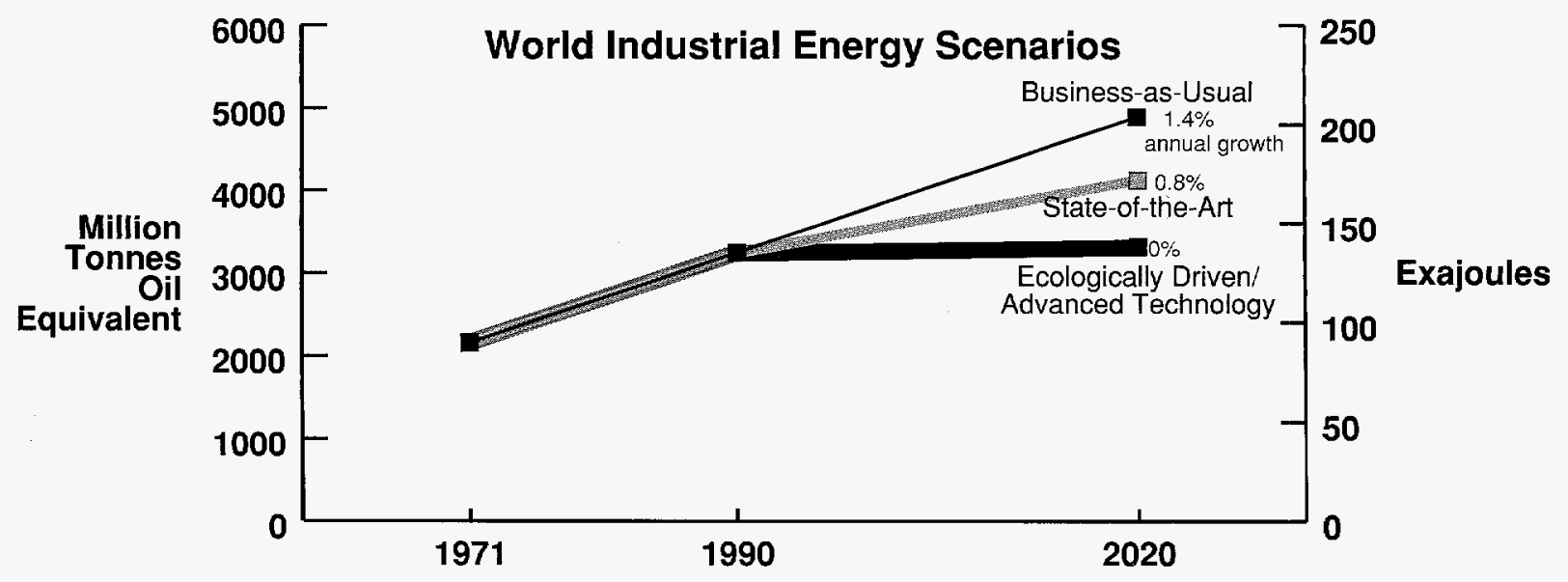

Figure. Results of three scenarios for the industrial sector, 1990-2020. 
Mitigation Options for Human Settlements:

A Report for the Intergovernmental Panel on Climate Change

M.D. Levine, H. Akbari, J. Busch, G. Dutt, K. Hogan, P. Komor,, S. Meyers, H. Tsuchiya,$\$$

G. Henderson, ${ }^{\ngtr}$ L. Price, K.R. Smith ${ }^{\diamond}$ L. Siwie I

This report was prepared for the Intergovernmental Panel on Climate Change (IPCC), the scientific body established by the United Nation's Intergovernmental Negotiating Committee with responsibility for assessing the current state of knowledge related to global climate change. The report provides an assessment of historical trends of greenhouse gas (GHG) emissions from human settlements, analyzes the potential for emissions reductions, identifies various policy options, and discusses future scenarios of energy-efficiency improvements and associated GHG emissions reductions.

The largest portion of GHG emissions in human settlements is in the form of carbon dioxide $\left(\mathrm{CO}_{2}\right)$ from energy use in buildings (including emissions from power plants that produce electricity for buildings), amounting to about 1.7 billion tonnes of carbon. The other three major sources of GHG emissions are methane from urban solid waste (equivalent to 135-275 million tonnes of carbon in the form of $\mathrm{CO}_{2}$ ), methane from domestic and industrial wastewater (200-275 million tonnes of carbon equivalent), and a variety of GHGs produced through the combustion of biomass in cookstoves throughout the developing world (estimated to be 100 million tonnes of carbon equivalent).

In 1990, residential buildings contributed $19 \%$ of total global emissions of $\mathrm{CO}_{2}$ while commercial buildings contributed an additional 10\%. Industrialized countries produced $63 \%$ of global $\mathrm{CO}_{2}$ emissions in 1990, while the former Sovi-

\footnotetext{
*Independent consultant, Buenos Aries, Argentina.

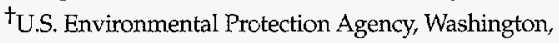
D.C.

†L.S. Congress, Office of Technology Assessment, Washington, D.C.

$\S$ Research Institute for Systems Technology, Tokyo, Japan.

$¥$ Building Research Establishment, London, UK.

${ }^{0}$ East-West Center, Honolulu, HI, USA.

IChina Academy of Building Research, Beijing, China.
}

et Union and Eastern Europe produced $19 \%$ and developing countries produced $18 \%$. Overall growth in emissions of $\mathrm{CO}_{2}$ from buildings was about $2 \%$ per year from 1973 to 1990 . Almost all of this growth took place in developing countries and in the former Soviet Union and Eastern Europe (see Figure).

The potential for the greatest growth in $\mathrm{CO}_{2}$ emissions-in both percentage and absolute terms - is in the developing world, where per capita energy consumption in human settlements is currently very low. Even in the industrialized countries, however, if policies to minimize such emissions are not enacted and rigorously carried out, the already high levels of $\mathrm{CO}_{2}$ emissions can increase. The most significant factors influencing the growth of GHG emissions in human settlements are efficiency of energy use, carbon intensity of fuels used directly in human settlements or to produce electricity, population growth, the nature of development in developing countries, the nature and rate of global economic growth, and implementation of policies that are directed toward fulfilling national commitments to reducing GHG emissions.

Examples of cost-effective technologies that are available to reduce energy consumption and hence $\mathrm{CO}_{2}$ emissions include more efficient space-conditioning systems; improved insulation and reduced air leakage in windows, walls, and roofs; and more efficient lighting and appliances (refrigerators, water heaters, cookstoves, etc.). In addition, measures to counter trends toward higher ambient temperatures in urban areas through increased vegetation and greater reflectivity of roofing and siding materials can yield significant reductions in space-cooling energy requirements in warm climates.

Policy options for reducing the growth of carbon emissions from human settlements include energy-pricing strategies, regulatory programs, utility demand-

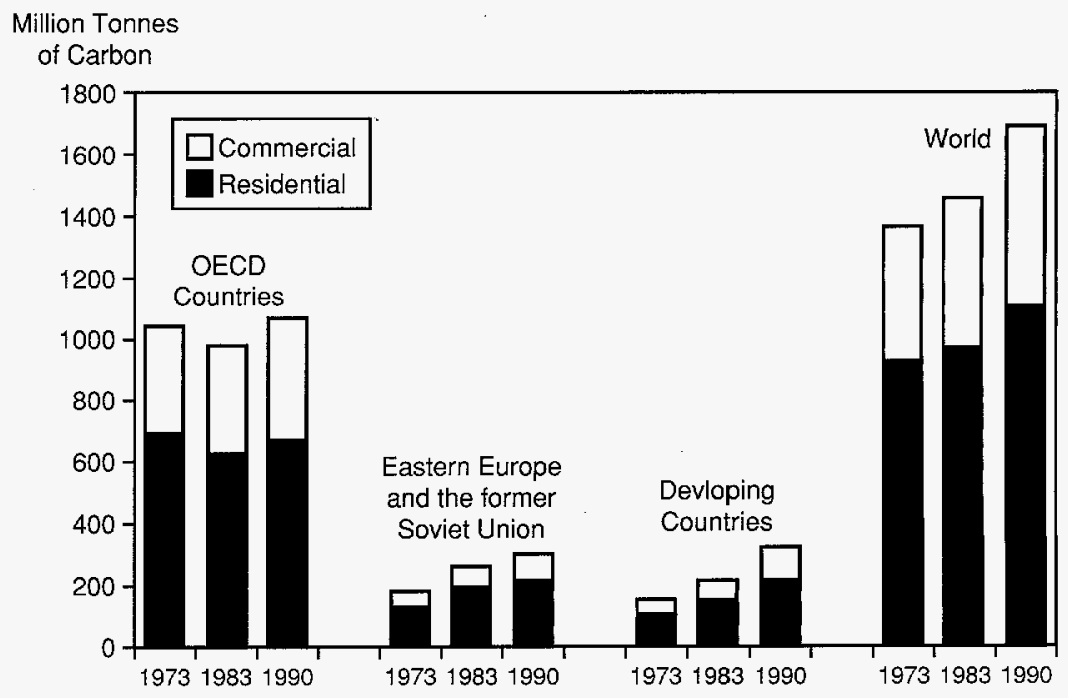

Figure. Carbon emissions from residential and commercial buildings by region, 1973, 1983, and 1990. 
side management programs, demonstration and commercialization programs, and research and development. Each type of program has been carried out, primarily in industrialized countries, and many have achieved significant energy savings. Resources, such as collaborations in training activities and institution building, are especially needed in developing countries.

Many "business-as-usual" energy scenarios postulate a $2 \%$ annual growth in buildings energy use-much like that observed during the past several decades. Aggressive energy-efficiency scenarios for buildings show reductions in overall energy demand growth of 0.5 to $1.0 \%$ per year where energy efficiency alone could contribute about half of the reductions needed to maintain $1990 \mathrm{lev}-$ els of $\mathrm{CO}_{2}$ emissions. Such energy-efficiency scenarios, however, will require strong and significant policy measures, well beyond what has been adopted to date. Scenarios for the longer term that are aimed at increasing the efficiency of energy use while providing needed energy services suggest that radical transformations in the ways energy is used are possible. A plausible case can be made for a society that meets human needs and aspirations that is not nearly as energyand resource-intensive as today's society.

\section{Reference}

Levine $\mathrm{MD}$, et al. Mitigation options for human settlements. In: Climate Change 1995: The IPCC Second Assessment Report, Volume 2: Scientific-Technical Analyses of Impacts, Adaptations, and Mitigation of Climate Change [Watson RT, MC Zinyowera, RH Moss (Eds.)]. Cambridge and New York: Cambridge University Press, 1996 (in press).

\section{Conducting Greenhouse Gas Mitigation Assessment in Developing and Transition Countries: LBNL's Role in Three Programs J. Sathaye, S. Wiel, S. Meyers, W. Makundi, M. della Cava," B. Goldberg, C. Ganson}

The United Nations Framework Convention on Climate Change, signed by more than 150 governments worldwide, calls on parties to the Convention to undertake inventories of national sources and sinks of greenhouse gases (GHGs) and to develop plans for responding to climate change. To assist developing countries and countries with economies in transition to meet this obligation, the U.S. government has spent $\$ 35$ million to support climate change country studies. Fifty-six countries are participating in the U.S. program (see Figure). In addition, other bilateral and multi-lateral donors are also supporting country studies. The Global Environment Facility is supporting a $\$ 9.5$ million Asia Least-Cost Greenhouse Gas Abatement Study (ALGAS)-through the United Nations Development Programme and the Asian Development Bank-and has initiated a $\$ 3$ million country-studies program through the United Nations Environment Programme (UNEP) Collaborating Centre on Energy and Environment at the Risø National Laboratory.

The U.S. Country Studies Program (USCSP) began in 1992 and is managed by personnel from 11 U.S. agencies including the Environmental Protection

*Energy Analysis Program, Washington, D.C. Project Office.
Agency, the Department of Energy, the National Oceanic and Atmospheric Administration, the Agency for International Development, the Department of Agriculture, and the Department of State.

LBNL was selected to lead the technical assistance by a team of experts in the field of mitigation assessment for the USCSP, ALGAS, and UNEP programs. Experts are drawn from various universities, laboratories, and consulting firms.

Studies supported under each of the three programs may address one or more climate change issues of concern to the recipient country, including an inventory of sources and sinks of GHGs, an assessment of vulnerabilities to the impacts of climate change, an evaluation of options to adapt to these potential impacts, an evaluation of options to mitigate net emissions of GHGs, and the development of national measures and strategies and public outreach activities.

We organized two international workshops, in June 1994 and April 1995, which brought together more than 60 scientists and energy policymakers from developing and transition countries participating in country-studies programs. They came to LBNL for hands-on training in techniques and models used for GHG mitigation analy- sis. We prepared a guidance document that was used by workshop participants to learn about techniques for mitigation assessment in the energy, forestry, agriculture, and other sectors.

Workshop participants received two weeks of analytical training composed of lectures and computer demonstrations. They were divided according to their area of expertise - energy, nonenergy, or macro-economic analysis. More than 30 experts provided the detailed analytical instruction at each workshop.

At the end of each workshop, participating countries submitted workplans for GHG mitigation. To provide continuing support to these nations' GHG reduction efforts, we are tailoring specific technical assistance to each country. The program's support is in the form of further training in the use of specific models, site visits to countries, and regional workshops where national representatives discuss the results of their studies.

A similar workshop, which will focus on training, sharing of experiences in mitigation assessment, and developing national mitigation action plans and mitigation projects, is being organized for the ALGAS program for March 1996.

We organized four regional workshops during the summer of 1995 (see 


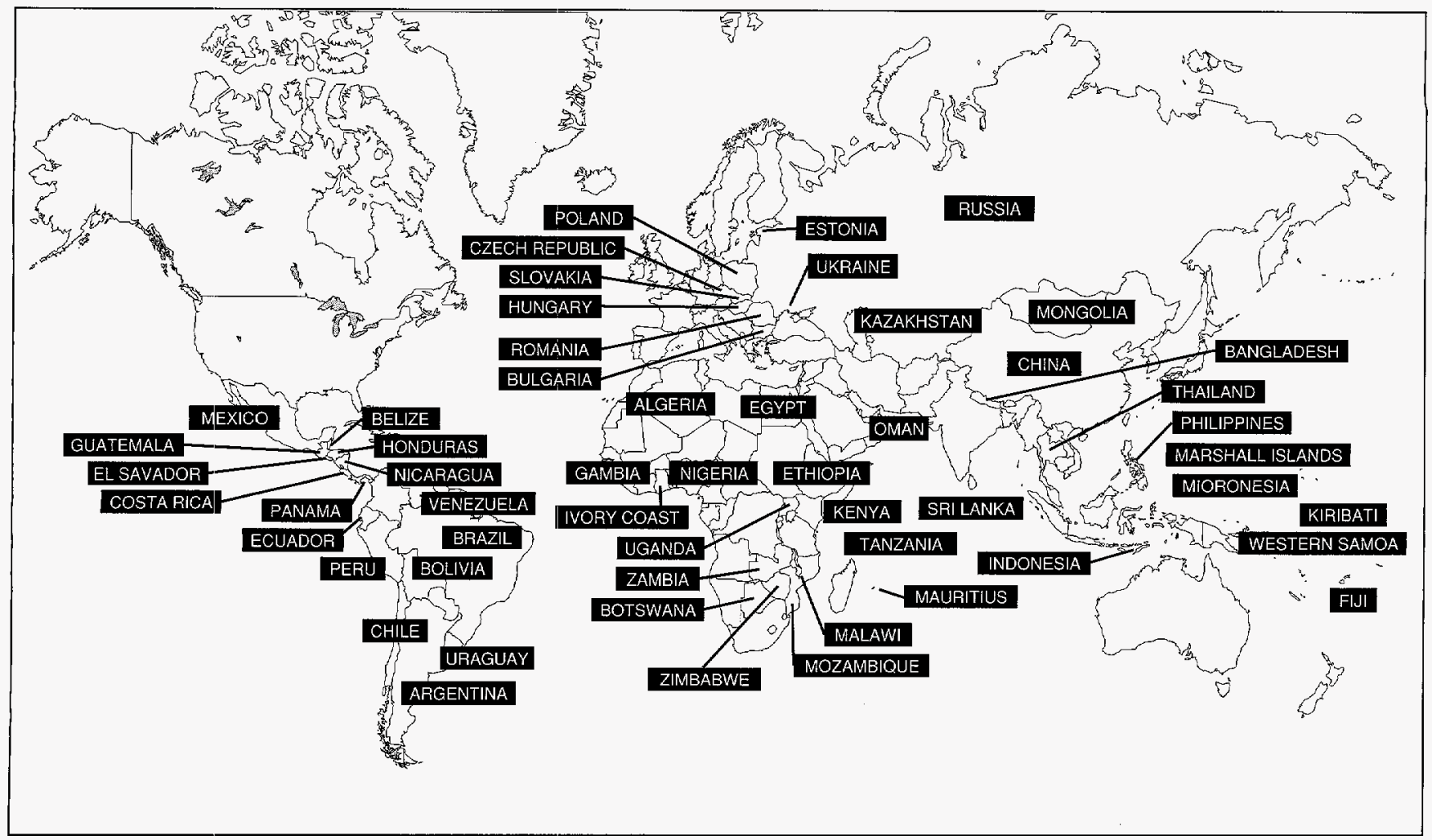

Figure. Participating countries in the U.S. Country Studies Program.

accompanying article). Participants reported the results of their country mitigation assessments at each workshop. The first workshop was held in Warsaw, Poland, in June, followed by another in Cancun, Mexico, in July; Arusha, Tanzania, in August; and Seoul, Republic of Korea, in September. Between 70 and 90 participants attended each workshop. The workshops were co-sponsored by other bilateral and multilateral donors.
Results of each workshop are being published in a special issue of an academic journal.

As the results of the U.S. studies become available, we plan to issue synthesis reports that will compare results across countries and provide a context for the variety of results on the costs and benefits of GHG emissions reduction in energy, forestry, agriculture, and wastemanagement sectors. Results of these studies will be published as they become available throughout 1996.

The USCSP program is now turning its focus to assisting developing and transition countries in the development of national action plans. In FY1996, we will provide technical and other support for the mitigation component of this program.

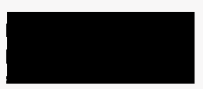

\section{Greenhouse Gas Mitigation Assessment: A Guidebook}

J. Sathaye, S. Meyers, W. Makundi, A. Sanstad, J. Koomey, A. Gadgil*

To support the work of countries that are conducting assessments of greenhouse gas mitigation options as part of the U.S. Country Studies Program (see also accompanying articles), we prepared a comprehensive, detailed guidebook (see Figure 1).

Drawing on the expertise of over

*Indoor Environment Program, Energy \& Environment Division, LBNL.
20 specialists from LBNL, other national laboratories, universities, and other organizations, the Guidebook provides guidance for analysis of mitigation options in energy, forestry, agriculture, and waste management. The book describes the key steps involved in conducting an assessment in the different sectors and also discusses selected models that may be applied to support an analysis.
The Guidebook serves three purposes: to assist countries in making decisions about the scope and methodology for mitigation assessments; to provide countries with guidance and step-bystep instructions on each element of a mitigation assessment (see Figure 2); and to help countries determine which analytical tools are best suited to their needs and describe procedures for applying these tools. The book is pri- 
marily intended for analysts conducting studies at a national level in developing countries and countries with economies in transition, but it is also a useful compendium of information for analysts in other countries. The Guidebook is also of interest to scientists and policymakers involved in the field of global climate change who wish to better understand how a mitigation assessment may be conducted.

\section{Reference}

Sathaye J, Meyers S (Lead Authors). Greenhouse Gas Mitigation Assessment: A Guidebook. Dordrecht, The Netherlands: Kluwer Academic Publishers. ISBN 0-7923-3781-6. 1995.

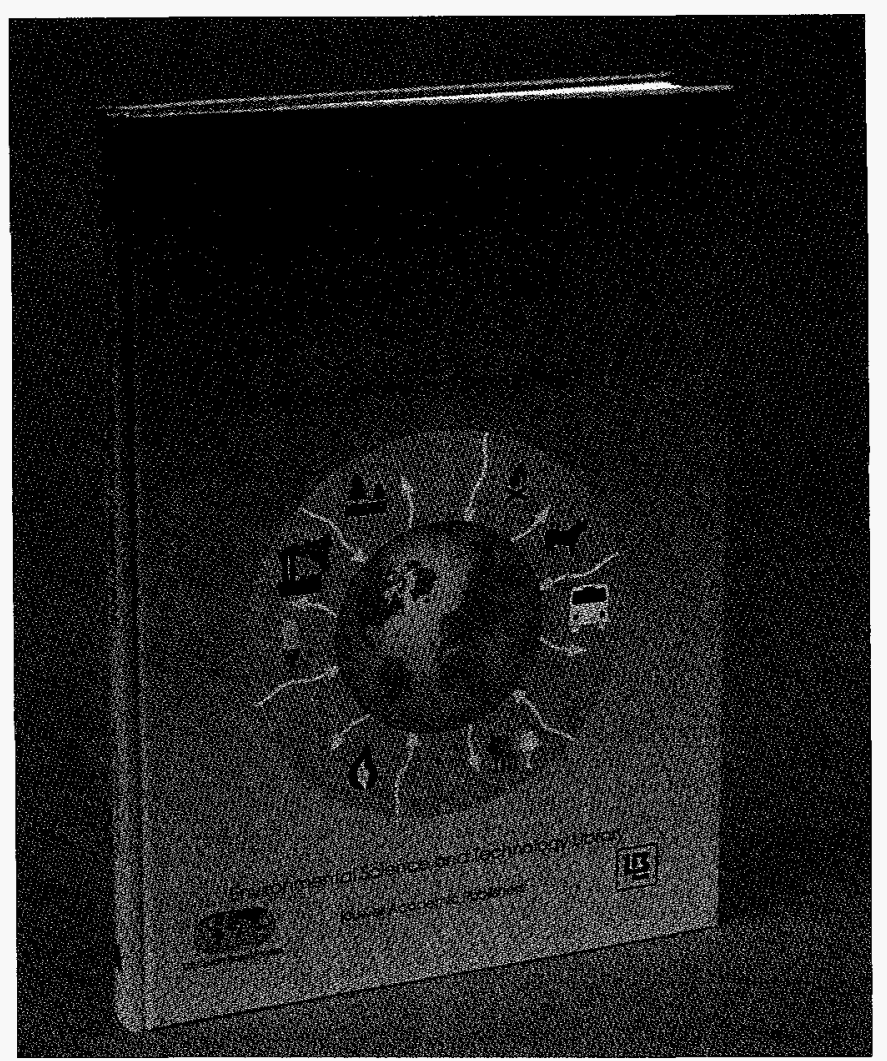

Figure 1. The Guidebook.

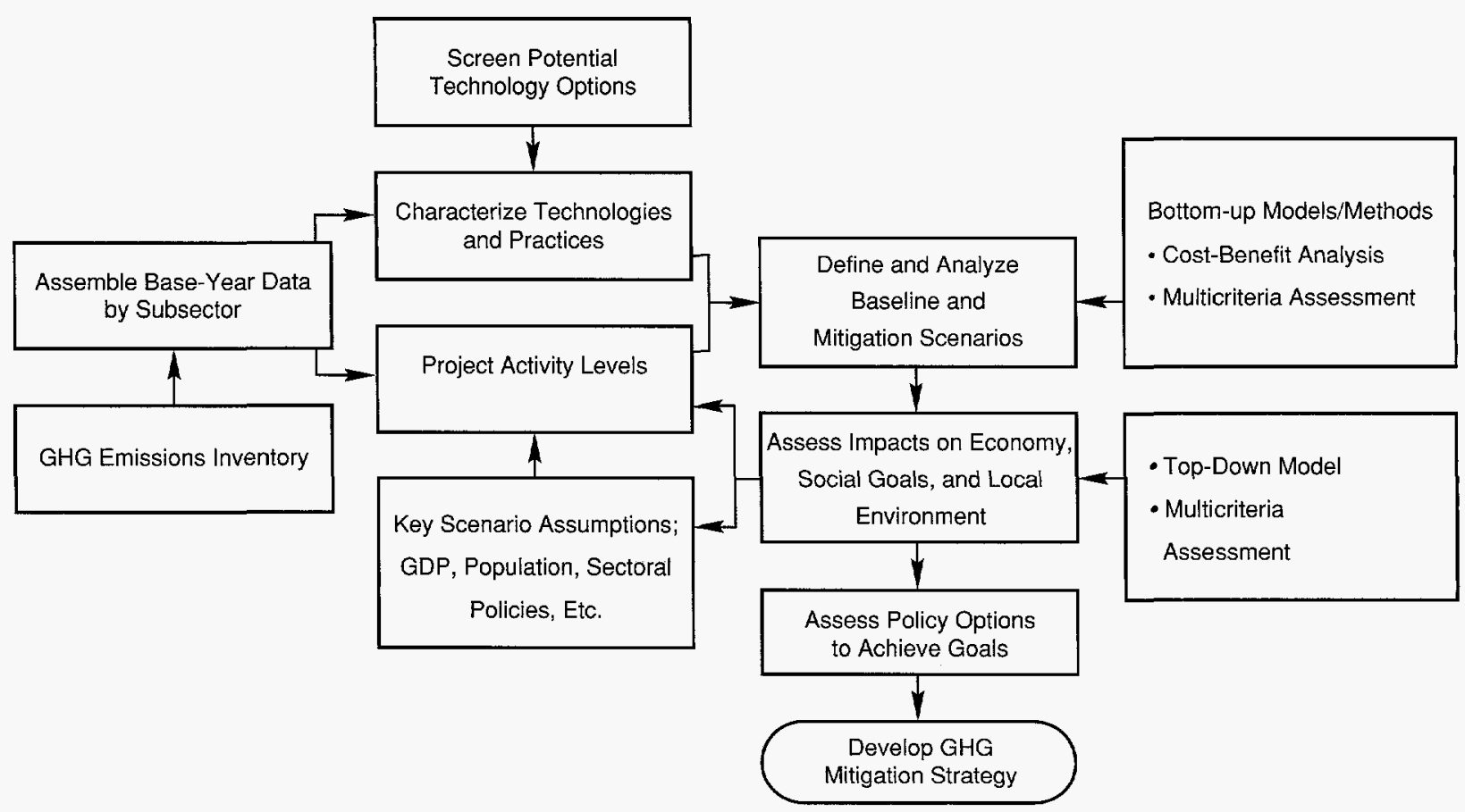

Figure 2. Structure of a sectoral mitigation assessment. 


\section{Regional Greenhouse Gas Mitigation Workshops \\ J. Sathaye, S. Wiel, S. Meyers, W. Makundi, B. Goldberg, M. della Cava*}

Throughout 1995 we organized a series of regional workshops, sponsored by the U.S. Country Studies Program in conjunction with various national, bilateral and multilateral organizations, in Europe, Latin America, Africa, and Asia. The main goal of these workshops was to facilitate the assessment and development of country-specific greenhouse gas (GHG) mitigation options. The workshops provided an international forum for the exchange of information among representatives of countries preparing mitigation strategies, researchers and experts on GHG mitigation options, and policymakers. At the workshops, participants presented results of their mitigation assessments and discussed issues related to the analysis and implementation of mitigation options. Separate working groups were held on energy sector analysis and forest and agriculture sector assessment. The workshops also addressed strategies for implementing mitigation technologies, policies, and programs.

The workshop for East European countries and countries with economies in transition brought together more than 90 scientific and policy experts from 23 countries. A common theme that arose throughout the workshop was the difficulty of conducting analysis oriented toward the future during a period when the economic structure of a country is undergoing a radical transition.

Participants used a variety of models for developing scenarios of GHG emissions and conducting assessments of mitigation options. Because of the problems with data and the inherent limitation of quantitative models, some participants thought that these should be complemented by nonmodel analytical approaches, such as inviting experts and decisionmakers to select and weigh decision criteria against which to assess mitigation options.

Countries recognize that GHG mitigation programs offer opportunities for adopting technologies and measures that have both economic and environ-

*Energy Analysis Program, Washington, D.C. Project Office. mental benefits. The up-front cost of measures is a key concern and the need for innovative financing was highlighted. Measures that are linked to modernization of industry and that help attract joint venture funding are more likely to be adopted.

The workshop for Latin American countries brought together about 60 participants from 13 countries. Paper presentations and group discussions revealed the great potential for improvement in energy efficiency in most Latin American countries-particularly in the energy-production and transportation sectors. The challenge is to ease away from the heavy consumption of the most polluting fossil fuels, especially coal and oil. In the forestry group, it was noted that both Venezuela and Mexico have a huge potential for long-term carbon sequestration.

Participants from Latin American countries felt that the existing institutions were not adequate to accomplish the objectives of the Framework Convention on Climate Change. To foster mitigation options in the forestry and energy sectors, they favored new institutions that are independent, have inputs from different sectors, and are integrated under the framework of "sustainable development."

In Arusha, Tanzania, more than 70 researchers, scientists, scholars, and government officials from 23 countries and organizations participated in the reporting and discussion of regional mitigation assessment results and issues. In Africa, the energy sector is closely linked to the land-use sector in that biomass provides over $70 \%$ of the primary energy consumed in the region. Given such linkages, it was agreed that the mitigation assessment should be treated in an integrated manner.

The mitigation options for biomass energy address efficiency improvements in production, distribution, and utilization of bioenergy. Various programs and initiatives effecting biomass use in the household energy sector already exist in many African countries. These programs, which have been driven by energy supply and developmental policies, should be consolidated and expanded as part of the countries' climate change mitigation policies.

At the workshop in Seoul, Korea, for Asian and Pacific countries, 72 participants from 15 countries and international organizations (see Figure) took part in discussions of their national emissions inventories and mitigation assessments. Most Asian and Pacific countries were well along in developing emissions inventories, and some had begun to identify opportunities to reduce these emissions. Strategies to mitigate GHGs tend to focus on the use of fossil fuels and on forest management. Many countries have implemented energy-efficiency, reforestation, and other forest-related measures. Methane emissions from rice paddies, livestock, and coal mines constitute a significant portion of Asian GHG emission, but the implementation of mitigation options for their reduction is just beginning.

At all four workshops it was concluded that the most effective mitigation. options were those that could be framed in the larger context of sustainable development. Mitigation options that create wealth for the society and provide immediate and visible benefits to the country should be promoted to encourage policymakers to increase their participation and interest in climate change concerns.

We have published summaries of each of the workshops. Selected papers from each workshop are being published in one of four special journal editions.

\section{References}

Sadowski M, et al. (Eds.). Workshop Summary: Methods to Assess Climate Change Mitigation Options for Countries with Economies in Transition. Warsaw, Poland, June 13-16, 1995. Lawrence Berkeley National Laboratory Report No. LBL-38271, 1995.

Gay C, et al. (Eds). Workshop Summary: Regional Workshop on Greenhouse Gas Mitigation Strategies for Latin Ameri- 
can Countries. Cancun, Mexico, July 10-13, 1995. Lawrence Berkeley National Laboratory Report No. LBL-38272, 1995. Also published as Interciencia, Special Issue, September 1995.

Mwandosya $\mathrm{M}$, et al. (Eds). Workshop Summary: Regional Workshop on Greenhouse Gas Mitigation for African Countries. Arusha, Tanzania, August 28-31, 1995. Lawrence Berkeley National Laboratory Report No. LBL38273, 1995.

Lee H, et al. (Eds). Workshop Summary:
Regional Workshop on Greenhouse Gas Emissions Inventory and Mitigation Strategies for Asian and Pacific Countries. Seoul, Korea, September 2528, 1995, Lawrence Berkeley National Laboratory Report No. LBL-38274, 1995.

Imaz M, et al. (Guest Eds.). Interciencia: Special Issue on Greenhouse Gas Mitigation: Strategies for Latin America 1995; 20 (6).

Sadowski M, et al. (Guest Eds.). Environmental Management: Special Issue on Methods for Assessing Greenhouse
Gas Mitigation for Countries with Economies in Transition 1996;20, Supplement 1 .

Mwandosya M, et al. (Guest Eds). Environmental Professional: Special Issue on Greenhouse Gas Mitigation Options for African Countries 1996;18 (May, in press).

Lee $\mathrm{H}$, et al. (Guest Eds). Ambio: Special Issue on Greenhouse Gas Emissions Inventory and Mitigation Strategies for Asian and Pacific Countries 1996;25(4) (June, in press).

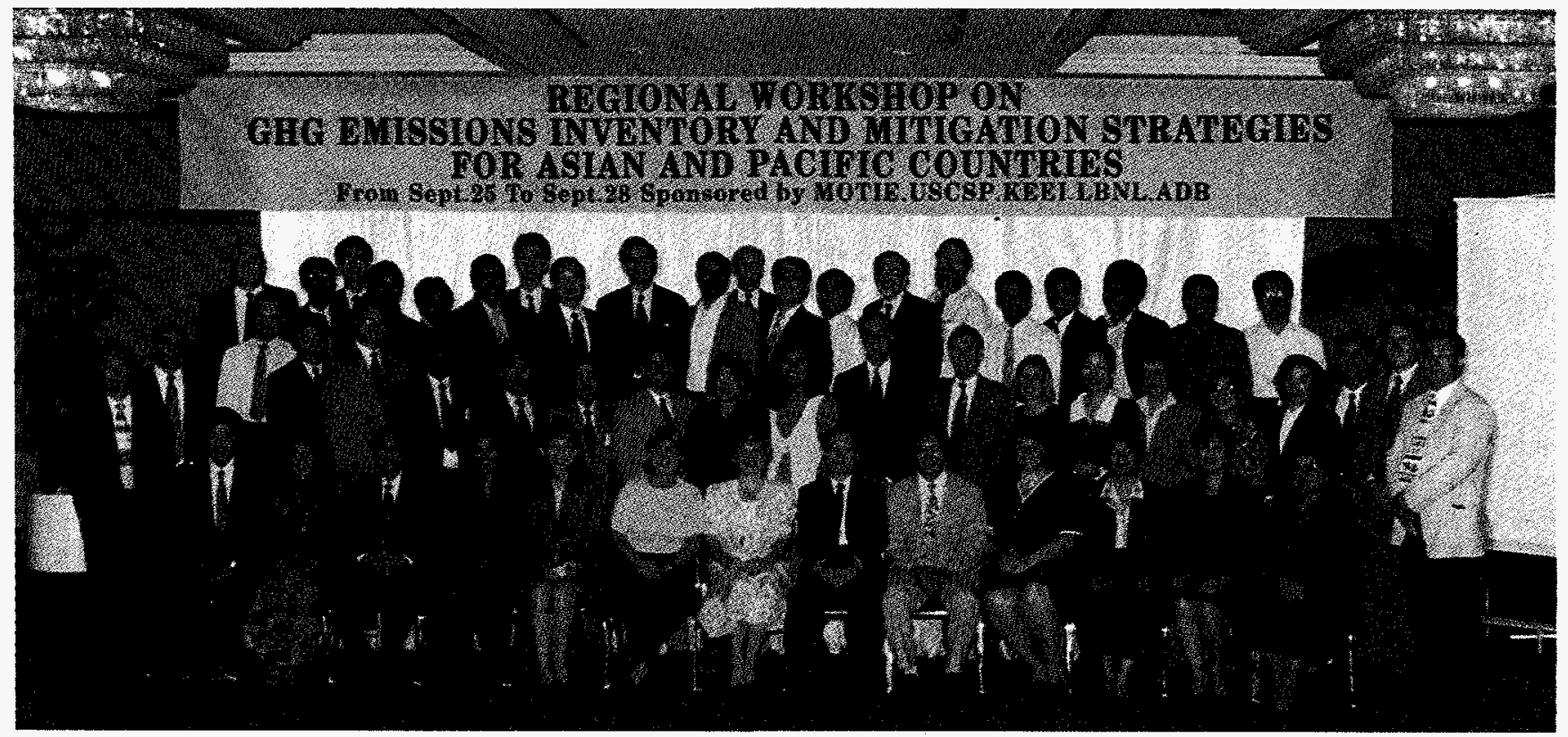

Figure. Participants in the workshop held in Seoul, Korea. 


\section{Carbon Flows and Mitigation Options in the Forest Sector}

W. Makundi, J. Sathaye

Emissions of greenhouse gases (GHGs) from land-use changes in developing countries exceed those from fossil-fuel use. Carbon dioxide emissions from tropical deforestation have been estimated at about $20 \%$ of total global emissions and have the potential for becoming much higher. The forestry sector provides a unique opportunity to sequester carbon from the atmosphere through photosynthesis, with the carbon being stored in woody vegetation, detritus, soils, and long-term forest products. However, the estimates of emissions and sequestration in individual countries vary significantly.

To understand better the role of the forest sector in reducing emissions and sequestering carbon, LBNL developed a common methodology (COPATH) for estimating carbon flows in the forest sector. The model was initially applied in seven countries (the F7 network) that had among the largest percentage of deforestation of moist closed forests. The initial countriesBrazil, Mexico, Indonesia, Thailand, China, India, and Nigeria-were later joined by Malaysia and Tanzania.

Using a common framework, researchers from the individual countries produced results showing that prior estimates of emissions from Brazil, Mexico, and India were overestimated, while those for the other countries were slightly underestimated. Using these data, projections put emissions from the tropical biome between 1.1 and 1.7 billion tonnes of carbon $(\mathrm{tC})$ per year, while the growing stock is projected to sequester about 374 million $\mathrm{tC}$ annually. After estimating emissions, researchers then proceeded to study mitigation measures to stabilize or reduce future GHG emissions.

The F7 group used a common methodology (COMAP), also developed at LBNL, to evaluate mitigation policies for reducing emissions and sequestering carbon (see Figure). This framework involves identifying and screening mitigation options, reconciling land-use distribution under various mitigation scenarios, and estimating and ranking the costs and benefits of each option, using a set of cost-effectiveness indicators. The most attractive mitigation options vary by country depending on the emission profile and opportunities available in the forest sector.

The study showed that, in general, the most cost-effective mitigation options are those that reduce emissions through forest conservation and protection. These options had a cost of less than $\$ 3 / \mathrm{tC}$ for India and Tanzania. The options involving afforestation had higher initial cost, but all had a positive present value at low discount rates,

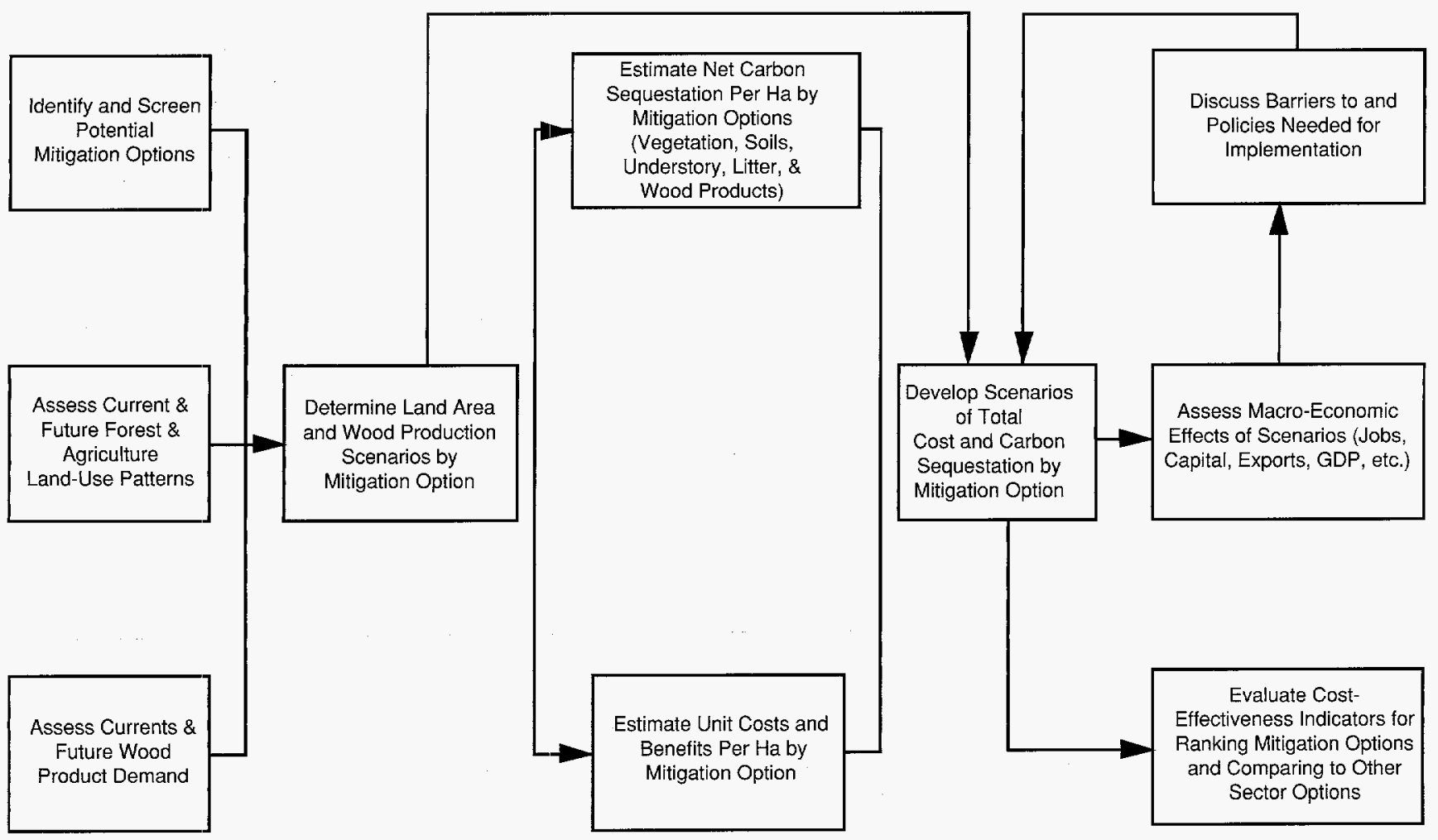

Figure. Comprehensive mitigation analysis process (COMAP) for forestry ( $\mathrm{Ha}=$ hectare). 
ranging from $\$ 3.4 / \mathrm{tC}$ for fuelwood plantations in Tanzania to $\$ 14.16 / \mathrm{tC}$ in sawlog plantations in Brazil. Agroforestry had a benefit of at least $\mathrm{S5} / \mathrm{tC}$ even without including the value of the agricultural product.

The cost-effectiveness of each option was very sensitive to assumptions on product and input prices. When the opportunity cost of land was included, the cost of reducing emissions or sequestering carbon increased substantially-in some cases by as much as $200 \%$. However, the options were less expensive than comparable measures in the forests of temperate countries, and much less expensive than the proposed policies to reduce emissions from the energy sector in developed countries.

The following related topics deserve further research: 1) incorporating non-monetary and intangible costs and benefits into mitigation assessments, 2) developing a framework for evaluat- ing joint implementation opportunities for GHG mitigation, and 3) investigating the role of sustainable forest management on climate change.

\section{Reference}

Sathaye J, Makundi W (Guest Eds). Journal of Biomass and Bioenergy: Special Issue on Forestry and Climate Change 1995; 8(5).

\section{The Institutional Needs of Joint Implementation Projects}

\section{E. Watt, J. Sathaye}

The United Nations Framework Convention on Climate Change (UNFCCC) calls for the implementation of projects to reduce net emissions of greenhouse gases (GHGs). The UNFCCC also suggests that signatories to the Convention may implement policies and measures jointly with other Parties (countries), with the intent that Parties may share the financing and the ensuing GHG benefits from jointly implemented projects. However, because the UNFCCC does not explicitly define joint implementation (JI) or lay down criteria for JI projects, it is unclear what the appropriate roles should be for international or UNFCCC member country institutions. There are several vexing issues, including the governments' allocation of the authority to accept such projects, and the capability of all concerned institutions to monitor, evaluate, and verify the financial and GHG benefits of JI projects.

To gain a better understanding of these concerns, we asked colleagues in five developing countries - China, Egypt, India, Mexico, and Thailand-to evaluate their countries' institutional capacity to handle JI projects. The current postures of these countries toward JI range from an aggressive pursuit of JI projects to a waitand-see approach. We also used information from several pilot JI projects between U.S. and host country institutions that have been developed over the last few years. In addition, we considered the criteria for II projects from the U.S., Australian, and Canadian JI initiatives and the draft criteria from the Intergovernmental Negotiating Committee. We assessed the existing and potential institutional structures for the implementation of JI projects and formulated suggestions for institutional mechanisms that would enhance such implementation. Implementation of a JI project entails tasks ranging from project feasibility studies to acceptance to eventual verification of GHG reductions. Some of the tasks are no different from those for any other investment project. Two are unique to JI projects: 1) gaining host country acceptance for an eligible project, and 2) assessing the project's GHG reduction.

The current trend is toward each country developing its own criteria for project acceptance with some sharing of information among countries. To reduce the array of criteria that investors might face across different host countries, a common set of guidelines, based on existing criteria, could be developed and then used by countries to establish their own acceptance criteria.

Acceptance institutions within the host countries could range from a senior government official specially appointed for this purpose to a panel of members of relevant ministries. No uniform formula for an acceptance institution will work across all countries, and each country would select an appropriate institution. What is important is that the acceptance panel or official have the authority to trade or share GHG credits with the investor country's government on behalf of the host country's government.

The assessment task includes estimating, calculating, and verifying the GHG reduction. This task requires adequate data, analytical methods, and technical skills. Much project-specific data will originate from the project-level teams; however, estimating and calculating the GHG reduction will require appropriate methods and technical expertise. These tasks are best performed by technical experts from private organi- zations, nongovernmental organizations, and universities. The verification task requires the ability to check data sources and the methods used for calculating the GHG reduction.

The assessment task calls for information exchange, training, and verification. An international institution, such as an international JI secretariat, could standardize and disseminate assessment methodologies, train assessors in their use, certify teams performing the GHGreduction verification, and resolve challenges or refer disputes to a tribunal. Development and standardization of methods should be done in concert with experts from research institutions. Assessors should be trained by sector (e.g., forest or energy), since the necessary data sources, methods, and technical skills vary greatly across sectors.

At the First Conference of the Parties in Berlin in April 1995, the participants agreed to voluntary JI projects. In FY96, we plan to work with several countries to address the concerns and issues regarding JI and help establish appropriate institutional processes to foster mutually beneficial use of $J$.

\section{Reference}

Watt E, Sathaye J. The Institutional Needs of Joint Implementation Projects. Lawrence Berkeley National Laboratory Report No. LBL-36453, 1995.

de Buen O, Masera O, Gelil IA, Ravindranath $\mathrm{NH}$, Zhou, D, Li J, Intarapravich D. Perspectives on the Institutional Needs of Joint Implementation Projects for China, Egypt, India, Mexico, and Thailand. Lawrence Berkeley National Laboratory Report No. LBL37031, 1995. 


\section{Energy Use and Carbon Implications in India: Focus on Industry} N. Mongia, J. Sathaye, P. Mongia*

Our objective is to assess the economic impact of alternative $\mathrm{CO}_{2}$ mitigation strategies, which may be adopted by India in the process of implementing its industrialization program. This is an optimization exercise using a multi-sector programming model. We seek to minimize the cost of energy services for a given level of end-use demand.

This work is an extension of an earlier study in which the industrial sector was treated as a single entity. In light of the recent far-reaching changes in industrial policy in India, we feel that, within the overall economy, the industrial sector merits a detailed examination.

In the present study, we retain all non-industrial sectors at their earlier levels of aggregation. The composite industrial sector is disaggregated into seven energy-intensive industries, i.e., steel, cement, aluminum, petrochemicals, paper, fertilizer, textiles, and a residual composite "other industries."

We use process analysis to represent each industry's technology profile. This enables us to specify alternative

\footnotetext{
*University of Delhi, Delhi, India.
}

combinations of inputs to achieve a given level of output. We also quantify levels of $\mathrm{CO}_{2}$ emissions associated with different process choices for given levels of projected demand for end-use service and for industrial products. Data for the specification of process choices were obtained from industrial project reports, technical manuals, manufacturer and trade associations, reports of committees to assess fuel-pricing policies, and from industrial consultants through personal interviews. Energy service requirements in different industries are assumed to be proportional to their output. Levels of output are projected using growth rates implicit in projection exercise in the Seventh Five-Year Plan of India.

We analyze three possible energy scenarios for the years 2005 and 2025: the likely trends scenario, the efficiency scenario, and the low-carbon scenario (see Figure). The last scenario has two sub-options: fuel switching and renewable energy sources. The outcome in each case is contrasted with the values for the base year 1985. For each scenario, the model chooses optimal process combinations and fuel mix of ener- gy supply for each end use which is consistent with given emission-abatement levels. It also reports the cost, investment, and foreign exchange requirements of each scenario. We conduct a sensitivity analysis with respect to the price of crude oil and identify policy options.

In the likely trends scenario, carbon emissions increase from 110 million tonnes of carbon (MtC) in 1985 to 819 $\mathrm{MtC}$ in 2025. In comparison, in the efficiency scenario, emissions are $13 \%$ lower. The low-carbon scenario shows even a greater reduction- $20 \%$ over the likely trends scenario. The incremental cost of mitigation is negative in both of the latter two cases, indicating that mitigation could take place at zero net cost. However, when we take into account investment required for $\mathrm{CO}_{2}$ mitigation, the efficiency scenario emerges as the most economic option.

\section{Reference}

Mongia N, Sathaye J, Mongia P. Energy use and carbon implications in India: focus on industry. Energy Policy 1994; 22(11): 894-906.

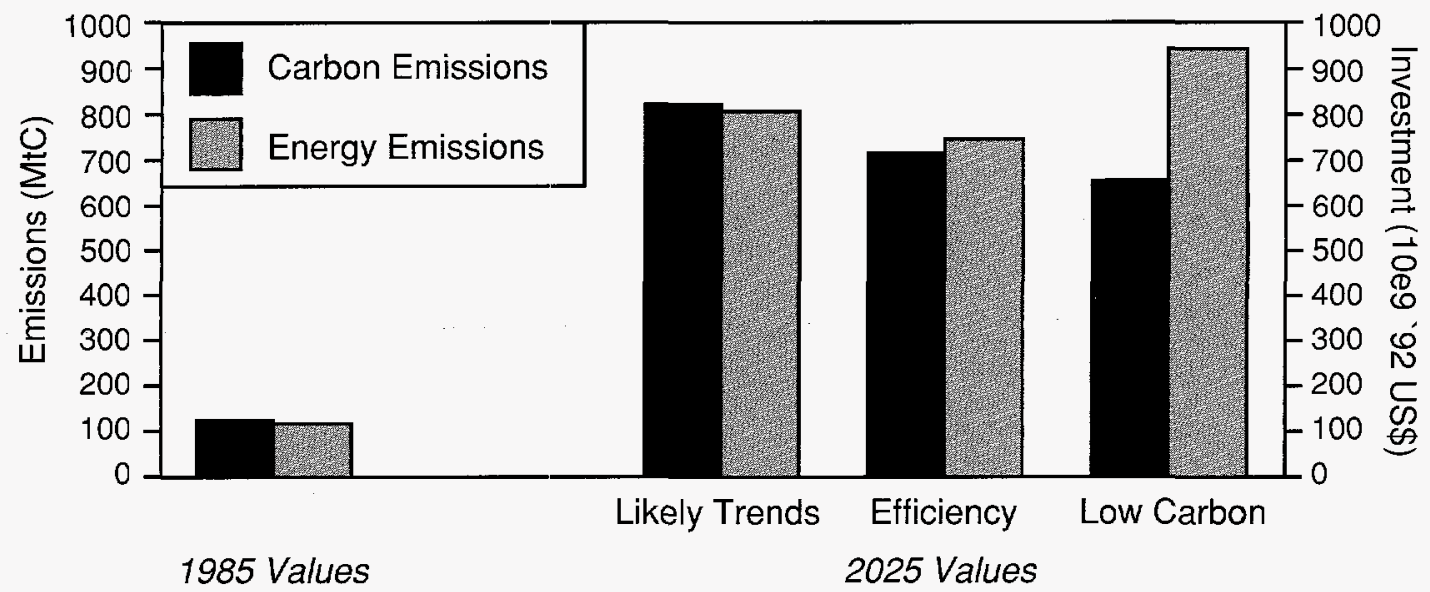

Figure. Carbon scenarios and energy system investment in India. 


\title{
Macro-Economic Implications of $\mathrm{CO}_{2}$ Mitigation for Venezuela: An Evaluation Using a CGE Model
}

\author{
P. Mongia, ${ }^{*}$. Sathaye
}

This project examines the macroeconomic effects of reducing $\mathrm{CO}_{2}$ emissions from the energy sector in Venezuela. It represents an extension and a practical application of our previous work in the construction of a model for analyzing energy-economy-environmental linkages.

Venezuela is heavily dependent on the extraction, refining, and export of oil. However, in-country consumption amounts to almost $25 \%$ of the oil produced. Recent investigations have shown that significant opportunities exist for saving energy-much of which is used inefficiently. These savings would not only help increase oil exports but would also reduce $\mathrm{CO}_{2}$ emissions.

We examined the implications of adopting alternative strategies for reducing $\mathrm{CO}_{2}$ emissions on GDP, sectoral production levels and prices, balance of payments, and employment. The principal strategies investigated were 1) increases in energy prices, and 2) increases in investment in energy efficiency. Alternative ways of increasing

*University of Delhi, Delhi, India. energy prices, i.e., changes in tax/subsidy rates or in profit markup rates, were explored to test the different effects they might have on fuel mix and on total energy consumption. Two ways of increasing investment in energy efficiency were also investigated. In one case, the souce of the increase was through a corresponding reduction in investment in the producing sectors. In the other case, it was through a net infusion of resources into the economy.

The analysis was conducted using the multi-sector computable general equilibrium model, LBL-CGE. A unique feature of this model is that, by incorporating engineering judgments into an economic framework, it allows energy consumption to be sensitive with respect to investments in energy efficiency. To highlight the energy-economy linkages, the economy was divided into six materials-producing sectors (agriculture, light manufacturing, heavy manufacturing, construction, transport, and services) and four energy-producing sectors (oil extraction, natural gas, electricity, and refined oil products). An input-output table of the Venezuelan
$\%$ change relative to base case

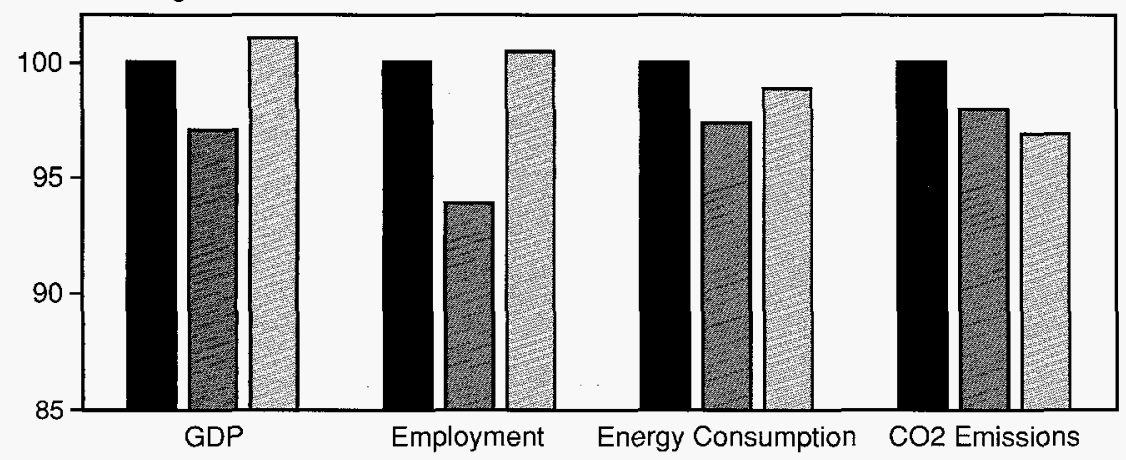

Base Case

Petroleum Tax Increase

Investment in Energy Efficiency Increase

Figure. Results of a policy experiment for Venezuela. economy was made to conform to this level of sectoral aggregation. This table was combined with aggregated national accounts statistics and the energy balance of the Venezuelan economy to form a social accounting matrix. This matrix was used to calibrate the parameters of the model for the base year. Selected policy parameters were changed to study their effect on energy consumption, $\mathrm{CO}_{2}$ emissions, and other macroeconomic variables.

We examined the effects of a doubling of tax on petroleum productswhich would raise their prices by $18 \%$ and compared them with the effects of a $1 \%$ increase in investment in energy efficiency. The results showed that while the former policy was successful in reducing energy consumption and $\mathrm{CO}_{2}$ emissions, these savings were accompanied by reductions in income and employment and an increase in the overall price level. On the other hand, for comparable levels of emissions reductions, income and employment actually increased under the energyefficiency policy strategy. The Figure reflects the case in which funds for energy-efficiency investments come through a reduction in investment in the producing sectors. In the case of a net infusion of resources into the economy, income and employment increase even more.

A major finding of the study is that in comparison to energy price increases, investments in energy-efficiency projects can reduce energy consumption with significantly lower economic welfare losses.

\section{References}

Mongia P, Sathaye J. Macroeconomic implications of $\mathrm{CO}_{2}$ mitigation in Venezuela. Interciencia 1995;20(6):360365.

Mongia P, Sathaye J. A Computable General Equilibrium Model for Energy and Environment Policies in Venezuela. Lawrence Berkeley National Laboratory Report No. LBL-37755, 1995. 


\section{A Commercial Building Energy Standard for Mexico}

Y.J. Huang, J.L. Warner, O. de Buen, S. Wiel, M.D. Levine

The development of a building energy standard is an arduous task in any country. A viable standard must have a well-defined scope, be technically accurate, and fit the technical skills and resources of engineers and building officials. In Mexico, a developing nation, this task is complicated by the shortage of data on building characteristics and climate and the limited understanding of energy-related issues within the building industry.

In 1992 researchers and engineers from the U.S. and Mexico launched a collaborative effort to develop an energy standard for Mexican commercial buildings. We have been heavily involved in this work for the past two years, cooperating with the Comision Nacional de Ahorro de Energía (CONAE) (National Commission for the Conservation of Energy) under the sponsorship of the U.S. Agency for International Development. With technical assistance from LBNL, Mexican officials and engineers completed a draft standard in the spring of 1995 and forwarded it to the Mexican government for final approval.

Since cooling is the primary spaceconditioning energy use in Mexico, the standard had to accurately reflect the changes in cooling loads associated with various conservation measures, accounting for diurnal temperature swings and building thermal lags. The DOE-2.1E building energy simulation program was used to estimate the cooling season averages for equivalent outdoor temperatures and solar heat gains in four locations for which detailed climatic data were available: Mexico City, Mérida, Monterrey, and Mexicali. The simulation results were extended by regression analysis to over 60 Mexican locations based on long-term monthly average climate statistics. In nearly all the Mexican locations examined, window shading had the greatest impact on building cooling loads, followed by roof insulation, with wall insulation providing only modest energy benefits. These results held true for both masonry and steel-frame construction types.
The simulated climatic conditions were used both to set prescriptive requirements for wall and roof insulation (see Figure) and window conductance and shading, and to identify tradeoffs between these prescriptive measures that would result in the same energy budget. These tradeoffs would give building designers greater flexibility in complying with the standard. The use of average equivalent temperatures and solar heat gains also enhanced the standard's appeal by allowing the detailed simulation results to be presented in the form of design load calculations familiar to Mexican engineers and building officials.

A verification analysis indicates that the new Mexican commercial building standard should result in net savings of $\mathrm{N} \$ 48 / \mathrm{m}^{2}$ (US $\$ 8 / \mathrm{m}^{2}$ at the current exchange rate) in direct savings from reduced energy loads alone over the life of the average new office build- ing. The net lifetime savings comprising this national average range from $\mathrm{N} \$ 16 / \mathrm{m}^{2}$ for a masonry building in Mexico City to $\mathrm{N} \$ 114 / \mathrm{m}^{2}$ for a masonry building in Mexicali. Even greater savings should be captured through reductions in heating, ventilating, and air conditioning (HVAC) system size and fan energy consumption in many buildings.

Future work on this project could include enhancements to the current methodology to better correlate simulation results to weather data and the inclusion of other building components, such as HVAC, in the standard.

\section{Reference}

Comisión Nacional para el Ahorro de Energía. Eficiencia energética integral en edificios no residenciales. Norma Oficial Mexicana, NOM-081-1994, Versión Aprobada, Secretaría de Energía, México, 1995.

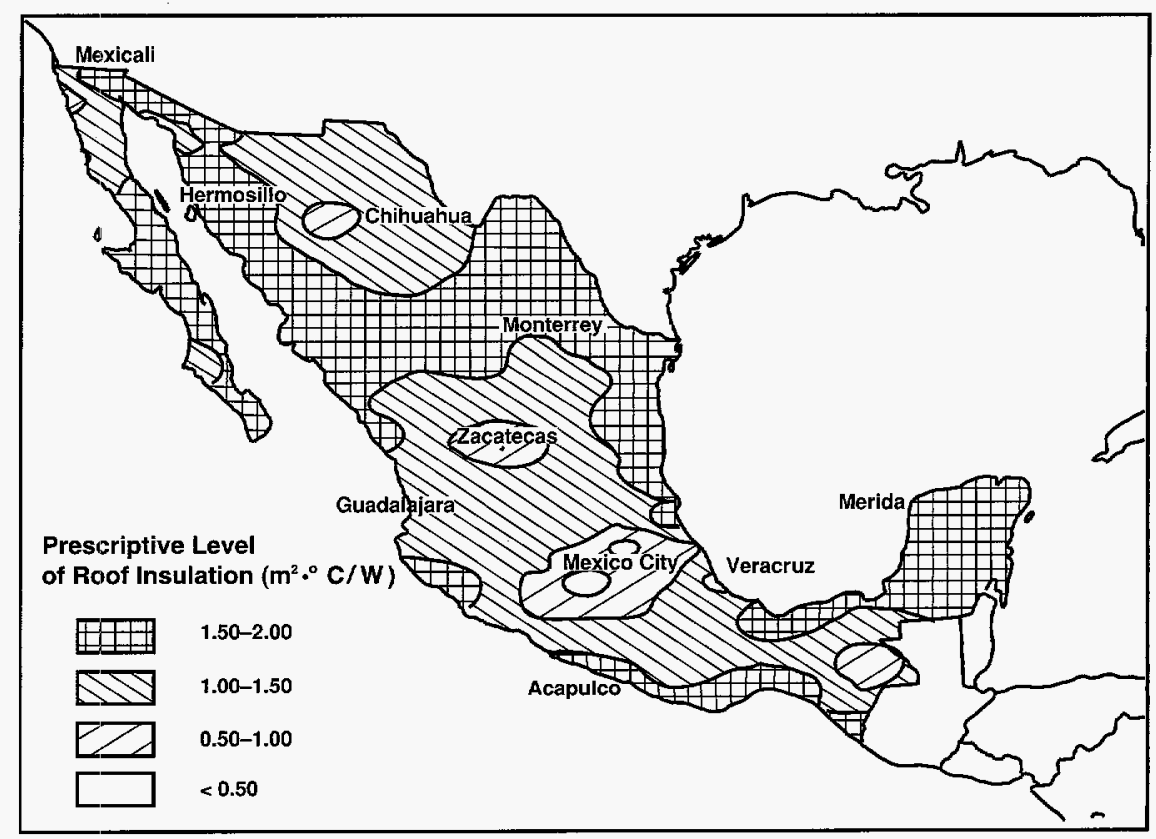

Figure. Prescriptive insulation values for a typical concrete roof in various locations. 


\title{
Energy Conservation Policy in China
}

\author{
Q.Y. Wang, J.E. Sinton, M.D. Levine
}

This work, summarized in a paper written with one of China's foremost experts on energy policy issues, analyzes the development of China's energy conservation policies and regulations, including likely components of the national Energy Conservation Law, to be enacted in 1996. We also examined developments in energy-pricing regimes and the likely influence on energy conservation efforts of recent economic system reforms, e.g., the changes in China's tax system that were implemented in January 1994. We looked at the historic and prospective roles of government as well as various implementation mechanisms, concentrating on an appropriate design for the rapidly evolving economic and political climate.

The organizational structure for conservation extends from the State Council and the powerful central Commissions (i.e., the State Planning Commission, the State Economic and Trade Commission, and the State Science and Technology Commission) through parallel ministerial and regional lines down to the level of local governments and even individual state-owned enterprises (see Figure). Policies and regulations covering energy management through administrative means (particularly energy consumption quotas) and financial incentives (e.g., energy conservation awards), R\&D, and technical services, training, and education have been adopted, implemented, and modified since 1980. Particularly noteworthy was the establishment of the China Energy Conservation Investment Corporation, which currently has an annual budget of 2 billion yuan ( $\$ 240$ US million) exclusively for investing in energy conservation. The acceleration of market economy reforms since 1993, however, has come into conflict with energy conservation work, demanding a thorough revision. Unfortunately, govern-

*China Energy Research Society, Beijing, China. mental functions and attitudes towards policy-making have been slow to change. The central government is currently drafting the Energy Conservation Law, a comprehensive piece of legislation based on experience with and updating of more than 30 pieces of efficiency legislation adopted at the state level over the past 15 years (see Box).

Under the planned economy system, the prices of virtually all energy products are tightly controlled at levels well below marginal cost. During the 1980s, however, portions of output were allowed to be sold at higher, outof-plan prices, creating a multi-track pricing system. While this stimulated energy production to a certain extent, it retained many of the faults of the planned price system and introduced new problems (e.g., by providing opportunities for corruption), and did little to encourage conservation through the price mechanism. In 1993 the government carried out a number of important new reforms in taxation, finance, investment, foreign exchange, and other areas, spurring energy price system reform. After years of controversy and expectation, the goal of reforming energy prices to be set mainly by the market received general approval. Since then the price of coal has been almost entirely freed, and some steps have been taken in many areas to rationalize electricity prices and to introduce pricing schemes that encourage conservation and load shifting. Prices of petroleum products, on the other hand, have come under tighter central control after a brief period of relaxation. In 1994 the prices of energy products increased across the board after the introduction of a valueadded tax, set at $17 \%$ for nearly all products, including energy products.

The government, facing a neverending series of crises as the planned system withers and new institutions for economic guidance are developed, has not yet adequately transformed its system for pursuing energy efficiency. The mainly administrative tools used to encourage efficiency in the past, such as the provision of low interest rates for energy conservation loans and the waiver of value-added taxes on designated energy-conserving equipment, have lost their effectiveness, or even been abolished. A fully functional set of market-oriented financial and other institutions, through which the government can promote efficiency through economic means, is not yet in place. The growing inability of the central government to assert its authority in many areas weakens its ability to enforce mechanisms, like equipment efficiency standards, designed to rectify market failures. Systemic weakness in China's legal structure presents another serious obstacle to enforcement. Reforms have also resulted in what is hoped to be only a temporary weakening in some other basic institutions, such as the statistical collection system.

The biggest challenge at present is for policy-making ideologies, systems, and implementation methods to keep pace with market-oriented reforms. Several key strategies would be particularly useful in transforming China's energy-efficiency system, including:

- Continue to push energy price reforms to reflect the full cost of supply in energy prices and to simultaneously remove subsidies.

- Establish market incentive mechanisms and an energy audit system to replace energy quota management and enterprise energy conservation awards.

- Foster capital markets for energy conservation, technology markets, and competitive markets for energy-conserving equipment.

- Commercialize energy conservation technology service centers.

- Educate and train managers to understand what energy conservation means in the context of the market and how to achieve it. 
Figure. Organizational framework of energy conservation policy and implementation in China.

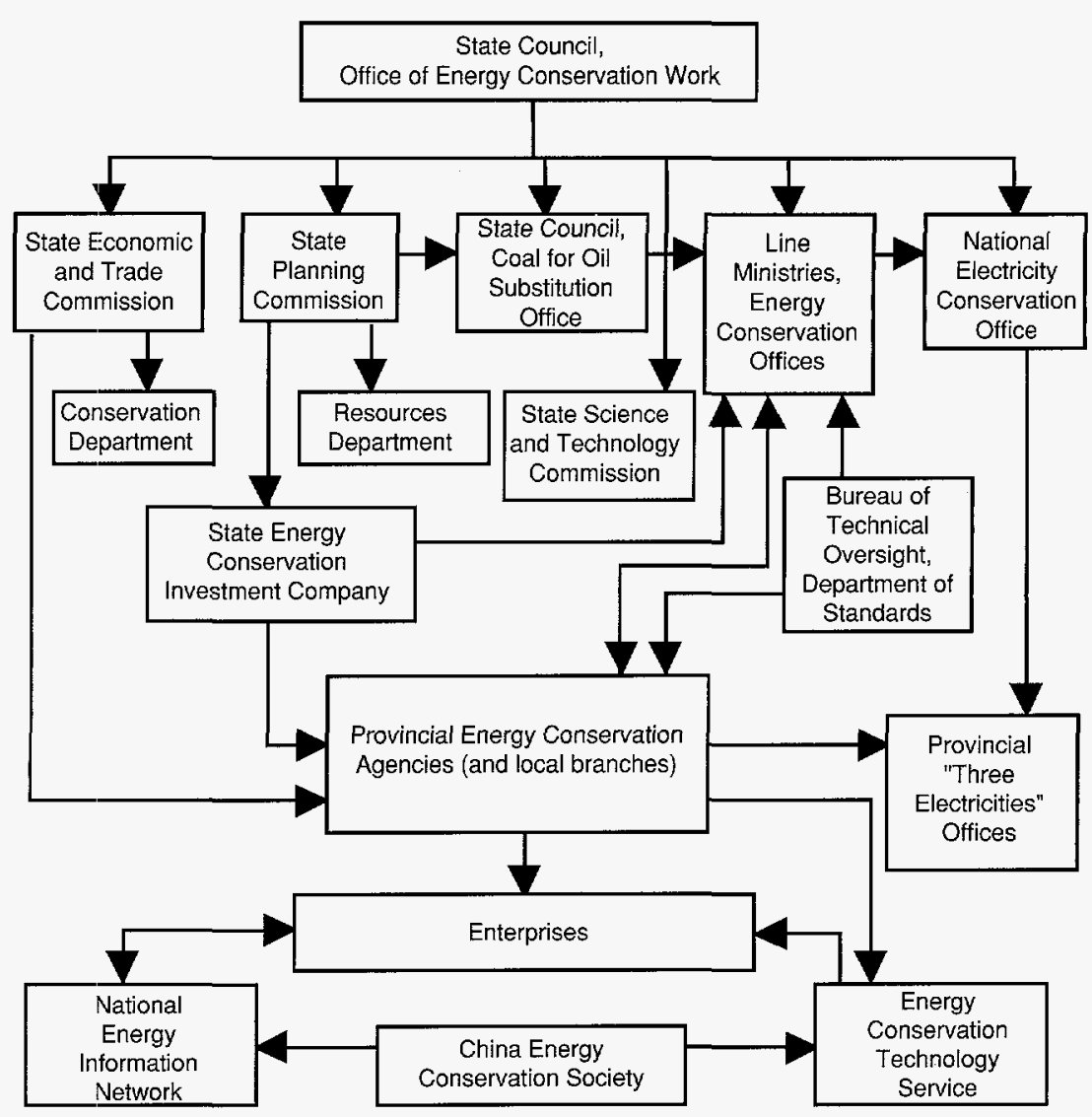

The draft Energy Conservation Law, currently under revision for expected passage in 1996, is intended as a practical guide to implementing conservation policy in the "mixed economy" of the so-called transition period to a market economy, especially through strengthening of economic incentives and energy-conservation supervision. Some of the key provisions (some of which may be omitted from the final Law) in its draft form were:

- Major energy users will be required to hire energy managers who have passed a national examination.

- Mandatory energy audits of major energy users by qualified outside experts will gradually be phased in.

- All feasibility studies for new fixed asset investment projects will have to include a section on energy conservation.

- Specific energy consumption quotas (a tool of the planned economic system) for certain products will be retained.

- Mandatory energy-efficiency standards for equipment (e.g., electric motors and motor vehicles) will gradually be implemented.

- Financial incentives for energy-efficiency research, development, demonstration, and investment projects will be redesigned and implemented.

Box. China's proposed Energy Conservation Law. 
China Energy Databook

J.E. Sinton, D.G. Fridley, F.Q. Yang, M.D. Levine, Z.P. Jiang, ${ }^{*}$ X. Zhuang," K.J. Jiang, ${ }^{*}$ X.F. Liu ${ }^{*}$

This project, a collaborative effort with the Energy Research Institute of China's State Planning Commission, resulted in the publication in 1992 (and revision the following year) of the most comprehensive collection of Chinese energy statistics that has so far appeared in English, the China Energy Databook. No other reference volume dedicated to China's energy system contains a similar variety and quality of material. The updated and expanded 1996 version is even more valuable than the first, since China ceased publication of its China Energy Statistical Yearbook with the 1991 edition.

The volume is organized into 10 chapters, covering energy resources, production, investment, consumption, energy-consuming activities, energy prices, imports and exports, environmental indicators, international comparisons, and socioeconomic data. Each chapter consists of a summary article, annotated data tables, graphs, and in many cases maps. It contains information exclusively in the public domain, but much of it comes from limited circulation sources and is difficult to obtain even within China. The annotations to the data series, which are sometimes absent from Chinese sources, make the Databook especially helpful.

Since publication of the original Databook, China's energy supply mix has undergone little change, with coal still providing $74 \%$ of primary commercial energy. The structure of coal output has continued to change; from 1980 to 1993 , the share of small rural mines went from 18 to $42 \%$. As in the past, less than $20 \%$ of total coal output is washed, virtually all at large state-owned mines. Petroleum output has stagnated; the

*Energy Research Institute, State Planning Commission of China, Beijing, China. large Eastern fields can barely maintain output levels, and large reserves in the Northwest will likely not be exploited on a large scale until well into the next century. Natural gas output was also flat for many years, but is now set to rise quickly as large new offshore and onshore fields come on-line. Electricity output growth, mainly from new thermal power plants, has been explosive, averaging $10 \%$ annually since 1990 .

Information in the Databook also shows that China's energy-consumption patterns (see Figure) have recently undergone changes that may foreshadow larger alterations in the future. While coal still dominates both the primary and end-use consumption mixes, its share is declining, as oil imports grow to meet incremental domestic demand and as an increasing fraction of coal goes for thermal power generation. Electricity is growing faster than any other end-use energy source, and only lack of supply is preventing it from growing even faster. Natural gas use has leveled off, primarily because supplies have been limited, but will rise significantly in the near term.

The dominance of industry in the sectoral end-use mix has actually strengthened. Direct coal use in industry has been giving way to indirect coal use, as the share of electricity rises. We find it remarkable that household energy use has dropped during recent years, since the decline in coal use (due to increased efficiency of coal use and fuel switching) has more than offset accelerating electricity use (which grew 16\% annually between 1985 and 1992). Commercial sector energy use is rising fastest and now exceeds China's huge agricultural sector. Transportation energy use is rising nearly as fast, as swelling vehicle fleets require more fuel; this sector now uses nearly as much oil as industry.

Rising stocks of appliances and motor vehicles indicate that there will be no deceleration of energy demand from the household and transportation sectors. Continued strong growth in the output of major industrial products, paralleling rates of economic growth, suggests that industry's dominance in energy use will continue. Technical efficiency gains, then, will be key to slowing growth in overall energy use. Energy intensity figures for a variety of industrial products show that China has made significant progress in improving the efficiency of energy use in certain sectors, and that it still has much to do to achieve levels typical in developed countries.

One key to stimulating efficient use of energy is the freeing of energy prices to market levels, and statistics on coal, oil, and electricity prices (featured in a newly added chapter of the Databook) show that much progress has been made in this area. Coal prices have been freed since 1993; since then they have risen and leveled off but show significant regional variation. Oil prices, on the other hand, remain tightly controlled, after an abortive attempt at partial decontrol starting in 1992. Electricity prices have risen several times over in many areas and are expected to continue increasing. Some areas have already instituted peak pricing.

We plan to issue further revised editions to the Databook at intervals of two to three years, incorporating new data as they become available.

\section{Reference}

Sinton JE, et al. (Eds.) China Energy Databook. Lawrence Berkeley National Laboratory Report No. LBL-32822, Rev. 3. 1996. 


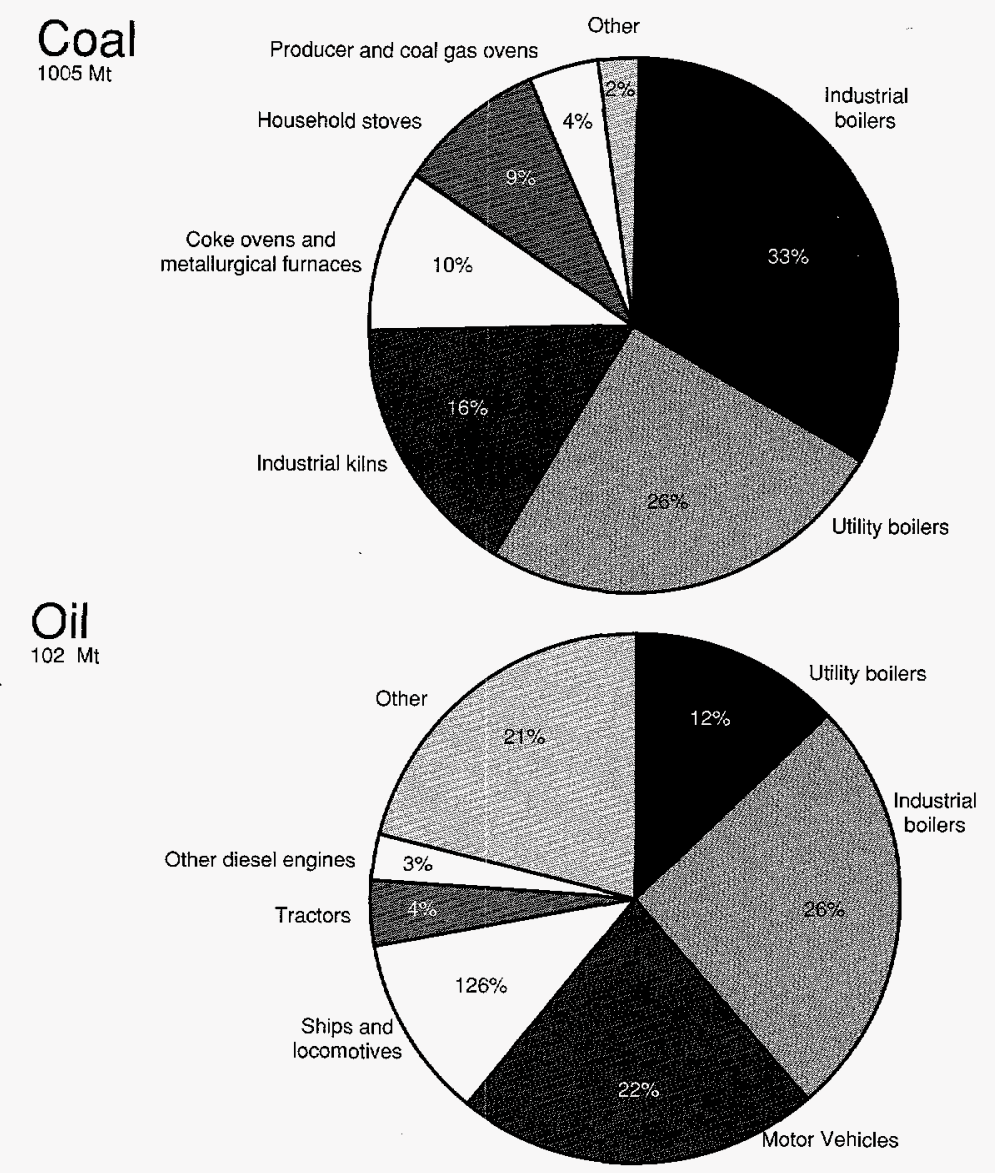

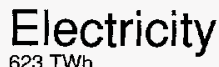

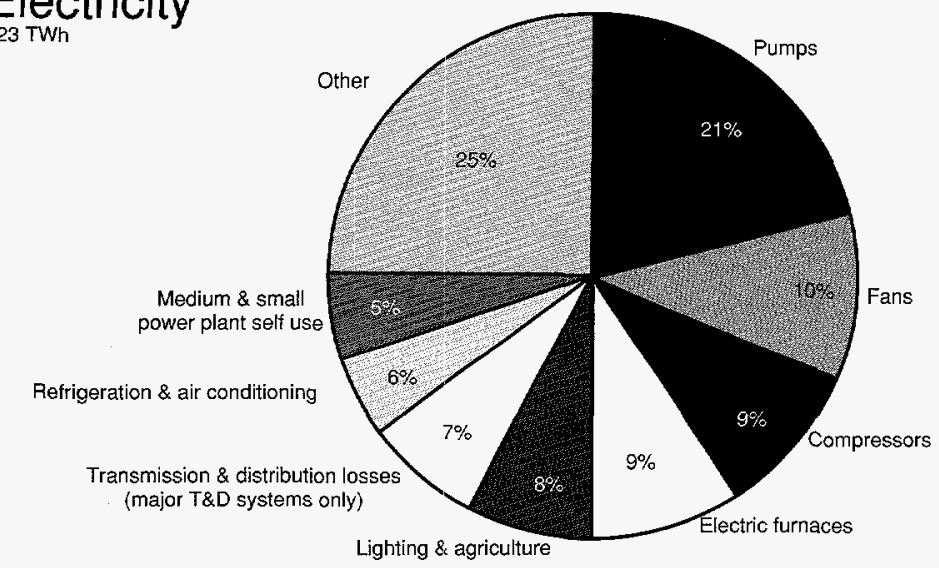

Figure. Estimated energy consumption by end use. 


\section{An Economic Approach to Evaluating Cogeneration Projects in China}

F.Q. Yang, M.D. Levine, J. Naeb*

This study is being carried out in support of an upcoming 1996 DOE-sponsored workshop aimed at matching U.S. investors with Chinese cogeneration projects. The purpose of the study is to identify trends and opportunities, ascertain technological levels, evaluate policies, assess environmental impacts, and provide tools for quantifying investment risks. A report entitled Cogeneration Development and Market Potential in China is being produced for the workshop. In addition, a project-evaluation spreadsheet tool is undergoing final preparation and will be used to evaluate cogeneration projects presented at the workshop.

Strong electricity demand, energy conservation efforts, and environmental concerns are the major forces driving Chinese cogeneration development. Although China wants to add $10 \mathrm{GW}$ of

*Private consultant, Oakland, CA. new cogeneration capacity by the year 2000 , and $40 \mathrm{GW}$ by 2020 , its recent macroeconomic policies aimed at the diversification of funding sources have meant that local governments are faced with limited capital availability. The Chinese market for electricity demand is in no way homogenous, with the relatively depressed Northeastern region suffering from over-capacity while the rapidly growing Southeast coastal region is falling further behind in meeting electricity demand. The primary motivation for efforts at environmental improvement is the alleviation of local pollution problems. However, the Chinese government has identified cogeneration as a key technology in their efforts to reduce greenhouse gas emissions.

Small to medium in-plant projects in such industrial sectors as paper and cement or district economic development zones in electricity-poor and rapidly growing provinces provide the best opportunities for a good return on investment. Local governments in these areas are relatively flexible and generally supportive in the determination of tariff rates. Although these smaller plants are not the optimal choice, they are well suited to current economic and technological conditions in China. China lacks large-scale (>200 MW) boiler and turbine technologies as well as advanced coal-gasification, fluidized-bed, scrubber, and control technologies.

Several risks whose minimization is crucial to the success of cogeneration plants include: macroeconomic and institutional conditions such as electricity and heat tariff rates, energy supply, fuel prices, tax credits, depreciation rates, international exchange rates, and technological factors such as load variation, heat load estimation accuracy, operating hours, self-use electricity rates, and long construction

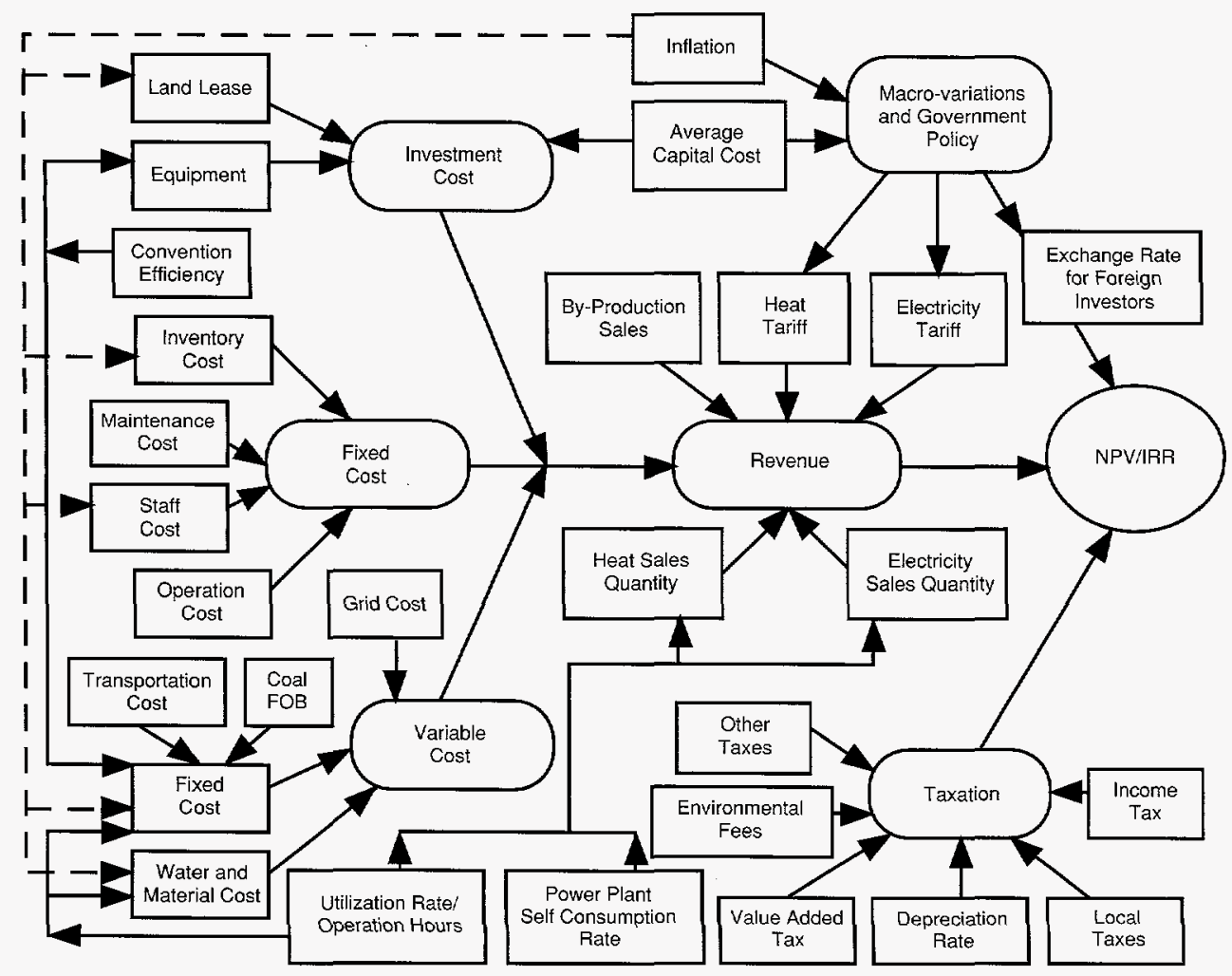

Figure. Economic evaluation approach for cogeneration projects. (NPV = net present value; IRR = internal rate of return.) 
periods. Government policies have strong impacts on utility rates, taxes, and loan interest rates. The Figure illustrates the factors involved in the economic viability of cogeneration projects.

Risk minimization can be accomplished via long-term fuel supply and delivery contracts, utility purchase and backup agreements, payment guarantees, implementation of cost-control methods, heat and electricity pricing rates that are tied to inflation, and shared risk for exchange rate variations.

Although cogeneration projects can be cost-effective in reducing greenhouse gas emissions, the Chinese government needs to further strengthen legislative regulations on cogeneration development in order to overcome institutional barriers. Favorable policies such as deregulation of tariffs, particularly heat tariffs, are essential for encouraging both domestic and foreign investors to enter cogeneration markets. Government decision-making mechanisms, procedures, and pricing formulations need to be made more transparent, with relevant information made available to prospective investors.

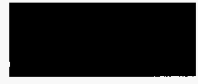

\section{Energy Efficiency in China's Cement Industry} J.E. Sinton

Since 1990, cement output in China has more than doubled to $400 \mathrm{Mt}$ per year (see Figure), and the country's more than 7000 plants now rnanufacture one-quarter of the world's total cement. Continued rapid growth in output is virtually certain, since the current construction boom in China shows no signs of abating. Accounting for nearly $5 \%$ of China's total commercial energy use, cement is one of the most energy-intensive industrial products to manufacture. Production equipment is long-lasting, so current investment patterns will exert a strong influence on China's overall energy-consumption levels and associated environmental impacts far into the future. To date, China's economic reforms have helped promote adoption of more efficient equipment, but in important cases the reforms are also contributing to a growing preference for a cement-manufacturing technology that, if widely adopted, would worsen fuel efficiency in this crucial industry.

An ongoing field research project on the Chinese cement industry (see also the Energy Analysis Program 1994 Annual Report) combines an analysis of trends in the cement industry as a whole with detailed case studies of energy efficiency and investment decision-making at a variety of plants. These plants typify the major classes of ownership and manufacturing technologies. A particular focus is the impact of China's decade-and-a-halfold process of economic reforms in investment and operations and the consequences for energy efficiency.

Average cement fuel intensity, i.e., the amount of fuel burned in kilns per unit of clinker (which is then ground into cement), has declined since the early
1980 s because of improvements in the various production technologies and changes in equipment structure. (Electricity intensity, which has increased, is not discussed in this article.) The Chinese government has spent considerable effort developing and disseminating mecha- nized and otherwise improved versions of vertical (or shaft) kilns and in retrofitting nonmechanized vertical kilns. Improving the average efficiency of large dry-process rotary kilns reflects growing mastery of the design and operation of preheater and precalciner rotary kilns.

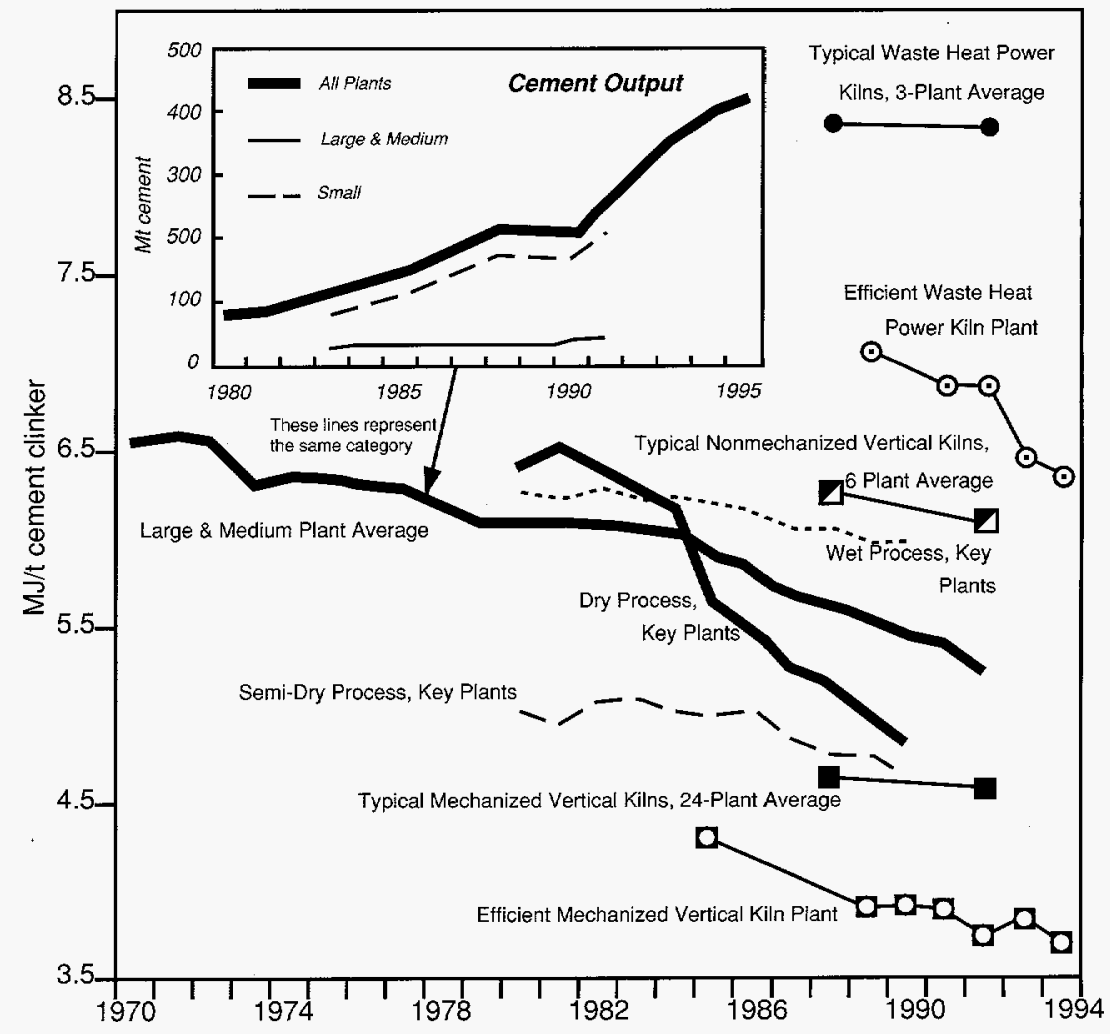

Figure. China: Cement clinker fuel intensities (MJ per metric ton) and cement output (million metric tons). "Key plants" are the approximately 60 largest state-run cement plants in China, all of which use rotary kilns. "Large and medium" plants typically produce over $300 \mathrm{kt}$ cement annually and represent a mix of rotary and mechanized vertical kilns. "Small" plants typically produce under $300 \mathrm{kt}$ annually and use mainly mechanized vertical kilns, although many continue to use nonmechanized vertical kilns. 
There has even been some gain in fuel efficiency in China's aging stock of wetprocess kilns, which still account for the largest part of rotary kiln cement output. Contrary to what might be expected, the typical fuel efficiency of new small-scale cement plants, virtually all of which use mechanized vertical kilns, is often as good as or superior to that of new rotary kilns (although product quality is poorer). By far the largest increments in new production capacity have come from these small plants (see Figure), implying a concomitant drop in the industry's average fuel intensity.

This trend is broadly in line with the long-term drop in energy intensity that the Chinese economy has demonstrated since the late 1970s. Many observers have suggested this is attributable to economic reforms of the past 15 years, which encourage the adoption of more energyefficient production techniques and equipment. Some of our field research case studies have borne this out. Adoption of more energy-efficient technologies, however, was usually motivated by concerns about output levels and product quality, and only secondarily by energy issues. Indeed, many respondents stated flatly that they would not undertake investment projects that only promised improved fuel performance. Under most circumstances, attainment of the primary goals was consistent with achieving efficiency improvements. Only in rare cases was acquisition of efficient equipment driven primarily by a desire to bring down energy costs.

In an important class of cases, however, the incentives currently facing newly empowered local decisionmakers have led to the selection of the most fuelinefficient production technology, i.e., long kilns with waste heat power generation, which have fuel intensities comparable to those of wet-process kilns. Tail gases from the kilns (which are used to preheat kiln feed in advanced rotary kilns) are used to generate electric power. Compared to alternative investments, i.e., equivalent capacity in vertical or preheater/precalciner kilns and central power generation, such plants are inefficient. If, for instance, the coal needed to produce one ton of cement in a vertical or preheater kiln is subtracted from that needed to produce the same amount in a waste heat power generation kiln, and the balance is allocated to power generation, the resulting heat rate is often twice as high as average central power plant heat rates.

Because electricity prices are perceived to be rising faster than coal prices, and because continuity and quality of supply are much more critical issues for electricity than for coal, plant leaders are typically more attuned to electricity issues. The absence of secure central electricity supplies encourages self-generation. There are thus strong incentives to substitute coal for electricity, which is possible through adoption of the waste heat power generation kiln. Such kilns are also becoming more attractive because, like other rotary kilns, they are capable of producing the high-quality cement that is in serious shortage; vertical kilns can only produce lower quality cements, the markets for which are much closer to saturation. Such kilns will most likely represent a growing portion of new cement production capacity over the next several years.

Future work will quantify the impacts of various technologies on energy use and pollutant emissions as well as identify ways to increase the penetration of efficient cement-manufacturing technologies given the economic and technical environments facing local decisionmakers.

\section{Reference}

Liu F, Ross M, Wang S. Energy efficiency in China's cement industry. Energy-The International Journal 1995;20(7):669681.

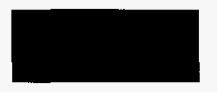

\section{U.S.-China Super-Efficient CFC-Free Refrigerator Project D.G. Fridley}

Over the last decade increasing affluence, particularly among China's urban households, has underpinned a remarkable rise in residential electricity use. Between 1985 and 1993, total residential electricity consumption rose from 22.25 to 72.99 TWh. This growth averages $16 \%$ per year, compared to total electricity consumption growth of $8.9 \%$ per year over the same period. Although residential use remains a small percentage of national consumption compared with other developing countries, its share has nearly doubled - to $12 \%$ of the total-since 1985.

The major factor propelling this growth in demand is the rapid increase in household electronics and appliance ownership, particularly of refrigerators, washing machines, color televisions, rice cookers, sewing machines, fans, radios, and audio equipment. In 1985, only $7 \%$ of urban households owned a refrigerator, $17 \%$ a color television, and $48 \%$ a washing machine; by $1993,57 \%$ of urban families owned a refrigerator, $80 \%$ had purchased a color television, and washing machines were found in $86 \%$ of households. The surge in refrigerator ownership alone has contributed significantly to rising residential demand for electricity; based on an average consumption of $1.1 \mathrm{kWh} /$ day, refrigerators now account for $25 \%$ of total residential electricity use, compared to just $8 \%$ in 1985.

In the next decade, refrigerator ownership is expected to continue its strong growth as new markets open in rural areas and urban penetration rises. No fewer than 70 million new refrigerators will be added to the existing stock, which will result in an additional 28 TWh of annual energy demand if no improvements in average energy efficiency are made. This demand would necessitate the construction of some $4860 \mathrm{MW}$ of new power generation capacity at a cost estimated, in 1993 terms, at nearly SUS2 billion. This financial burden will be accompanied by a substantial increase in $\mathrm{CO}_{2}$ emissions from power plants. In addition, as an Article 5 country under the Montreal Protocol, China is not obliged to phase out the use of chlorofluorocarbons (CFCs) until 2005; thus, the projected hugh increase in refrigerator ownership is important for the questions of greenhouse gases and ozone protection.

Home refrigerators were virtually unknown in China before the economic reforms of the late 1970 s, but in the early 
and mid-1980s, more than 200 production lines were imported from abroad, and by 1990 , total production capacity had reached 13.5 million units per year, all based on CFC-12 refrigerant and CFC-11 foam-blowing agent. In 1989, the U.S. Environmental Protection Agency (EPA) toured a number of Chinese refrigerator factories and an agreement was reached with China's National Environmental Protection Agency to explore options for CFC substitutes and to improve energy efficiency. This cooperative project eventually included the Beijing Household Electric Appliance Institute, the National Council of Light Industry, the Haier Refrigerator Factory in Qingdao, Shandong, the University of Maryland, and Liebherr, a German refrigerator manufacturer. The first stage of the project, with support of bilateral Montreal Protocol Facility funding, involved replacing CFCs with hydrocarbons in the Haier factor. The second stage, currently underway with LBNL technical project management, focuses on implementing energy-efficiency measures and designing a program to replicate the results throughout the sector.

The goal of the project is to demonstrate the technical and commercial viability of a CFC-free refrigerator with $50 \%$ energy savings and to transform the market to produce these models. After years of research and testing, a series of design changes resulting in a $50 \%$ reduction in energy use over the base model were agreed upon and implemented in Haier's 222-liter prototype model. Starting with a base model consuming on average $1.364 \mathrm{kWh} /$ day, the impact of each of the measures was modeled with the EPA Refrigerator Analysis model. This combination of measures was chosen on the basis of proven application and ease of implenentation, in order to minimize technical and commercial risks. They include:

- Thicker thermal insulation. Fifteen $\mathrm{mm}$ of insulation were added to the outside of both doors, and $23 \mathrm{~mm}$ were added to the outsides of the sides, the back of the cabinet, and the outside of the bottom. To accommodate this the prototype used the cabinet of the next larger model size with an inner liner of the 222-liter model. The modeled reduction in energy consumption over the base model was $16 \%$.
- Convert refrigerants. The prototype was tested using HFC-134a and a wide variety of additional alternative blends as substitutes for the original CFC-12 refrigerant, but later, R600a (isobutane) was adopted with consideration of its zero ozone-depletion potential status. This substitution alone accounted for a $5 \%$ decrease in energy consumption. The EPA model indicated an overly generous $12 \%$ reduction (this has since been corrected). Experience in Germany, where isobutane is widely used, shows that in practice direct conversion from CFC -12 to isobutane provides only $3-4 \%$ improvement in efficiency.

- High-efficiency compressor. The original CFC-12 compressor with a 1.1 coefficient of performance (COP) was replaced by an imported hydrocarbon compressor using R600a with a COP of 1.45. This switch provided $22 \%$ savings over the base model.

- Modification of gasket. A new gasket flange design reduced the heat flow though this region of the cabinet. Tests had shown that gasket heat flow accounted for about $20 \%$ of total heat flow into the fresh food compartment; this modification reduced energy consumption by $5 \%$.

- Switch foam-blowing agents. To complete the conversion from CFCs, cyclopentane was substituted for CFC11 as the foam-blowing agent. Owing to the difference in thermal conductivity of cyclopentane compared with CFC-11, this step resulted in a $3 \%$ increase in energy consumption.

- Optimize system. With the switch to hydrocarbons, the system design was optimized to match the thermal load of each compartment better; this involved increasing the surface area of the condenser and evaporator and resizing the compressor. These measures added $3 \%$ in efficiency.

The cumulative impact of these measures can be seen in the Figure. Field testing currently underway in Beijing, Shanghai, and Guangzhou has demonstrated energy savings on the order of $40 \%$, even in the more severe operating conditions within Chinese households. It is expected that redesign based on field test results and increased experience in manufacturing energy-efficient models will lead to achievement of the $50 \%$ goal.

We are now working to replicate the results of the Haier experience, including programs for labeling and standards, marketing, manufacturer incentives, technical outreach, and training, throughout the refrigerator sector. These measures are designed to overcome the commercial, technical, and market barriers to the acceptance of CFC-free energy-efficient refrigerators among manufacturers and consumers. The long-term implications of success are striking: assuming a 50\% market penetration of energy-efficient modelsover 10 years, at least 35 million tonnes per year of carbon emissions will be avoided, in addition to 31 million tonnes of carbon equivalent avoided through conversion from CFCs, thereby saving US $\$ 1$ billion in investment costs in new power plants.

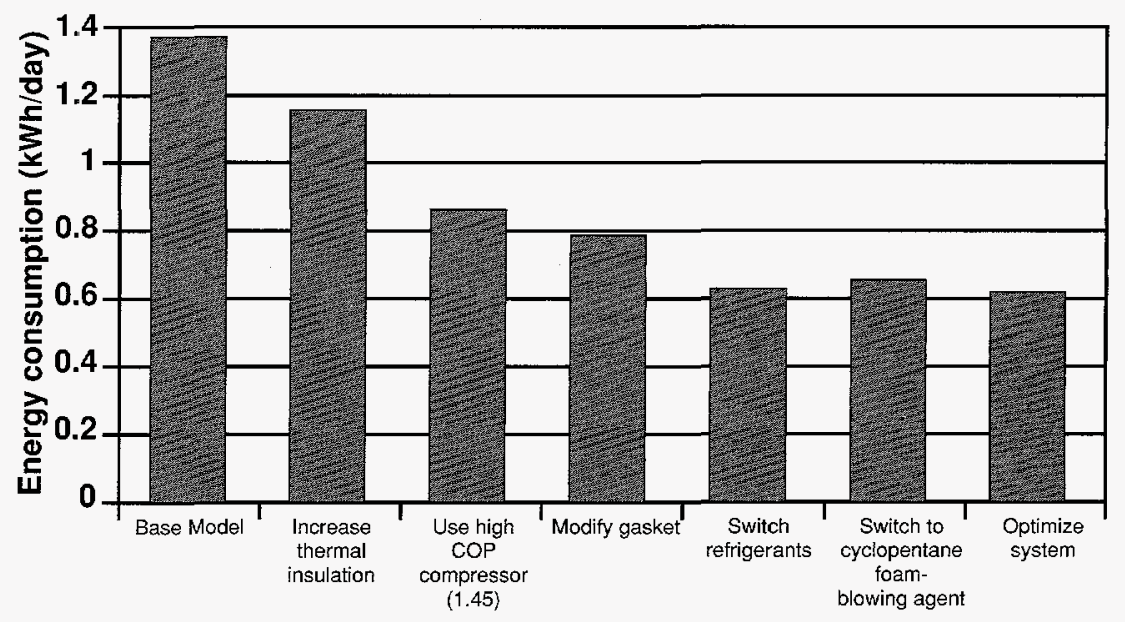

Figure. Base model refrigerator modifications and energy savings. 


\title{
An International Collaboration Strategy to Reduce Greenhouse Gas Emissions in China
}

\author{
F.Q. Yang, M.D. Levine
}

China ranks second in the world both as an energy producer and as an emitter of greenhouse gases (GHGs). The most recent demand forecasts made in China show that primary energy demand in the years 2000 and 2020 will reach 1.7 and 2.8 billion tons of coal equivalent (tce), respectively; but with an aggregate primary energy supply of 1.4 (2000) and 2.5 billion tce (2020), an energy shortage may last a long time. This shortfall will result in a significant increase in energy imports, particularly oil, to satisfy domestic demand and to assure an adequate energy supply to support the government's ambitious economic goals.

China's energy consumption is based primarily on coal, which has the highest rate of $\mathrm{CO}_{2}$ emissions per unit of useful energy delivered. In the next decades, rapid economic expansion will result in even higher emission levels. This is shown in Figure 1, which is based on our forecast for $\mathrm{CO}_{2}$ emissions up to 2020 . In the business-as-usual scenario, $\mathrm{CO}_{2}$ emissions in the year 2020 will be twice those of 1993. Concern over the amount of emissions has led to growing emphasis on the use of advanced technologies and cost-effective measures in both energy development and energy conservation. In spite of the substantial government effort to promote energy conservation, the lack of capital, advanced technology, and fully developed market mechanisms still restrict the implementation of these measures.

Widespread opportunities exist for collaboration between China and the U.S. on energy and environmental issues. We have examined a special program, the U.S. Department of Energy's Activities Implemented Jointly (AIJ) program, which was designed to promote the flow of private capital from the U.S. in support of $\mathrm{CO}_{2}$ reduction or sequestration activities in China and other developing countries, and to overcome capital and technological constraints. As shown in Figure 2, unlike other capital flows, which separate government and private sector actions, AIJ involves government efforts to stimulate the private sector to engage in activities that reduce or sequester greenhouse

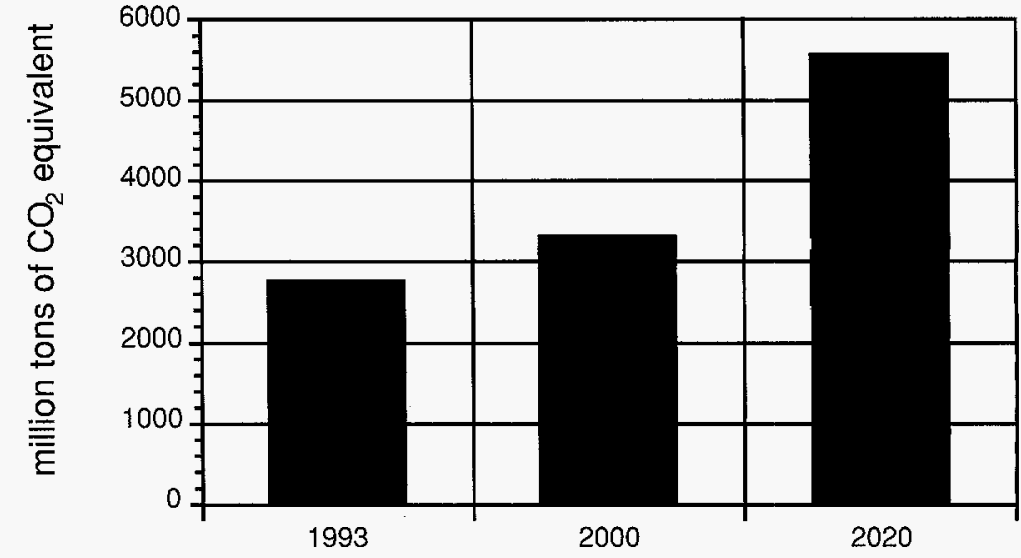

Figure 1. China's $\mathrm{CO}_{2}$ emissions forecast.

gas emissions. AIJ involves a wide range of possible arrangements between interests in the U.S. and China. The significant potential of $\mathrm{AIJ}$ is based on the understanding that joint implementation provides an opportunity to reduce emissions at a lower global cost than would be possible if each country acted alone.

We have conducted research in support of the AIJ program, and we have worked with the Chinese officials and relevant professional personnel. In contrast to the original concept of joint implementation in which investor and host country would share the "credit" for $\mathrm{CO}_{2}$ sequestered or avoided, we found that the Chinese government felt that, in the AIJ pilot phase, the credit issue should not be addressed. China would like to participate in the pilot phase of AIJ on a

voluntary and equitable basis, although the Chinese government felt that in the pilot phase, credit should not be allowed for GHG reduction. The Chinese government welcomes foreign investors in AIJ projects. AIJ pilot projects should be both economically and environmentally sound.

The State Science and Technology Commission (SSTC), the State Planning Commission, the Ministry of Foreign Affairs, the National Environmental Protection Agency, and the Chinese Meteorological Administration are now jointly involved in the administration of $\mathrm{AIJ}$ through an operations office. It appears at this time that SSTC will carry out overall coordination in the pilot phase.

The Chinese government expressed a preference for the types of projects eligible for selection as pilot $\mathrm{AIJ}$ projects;

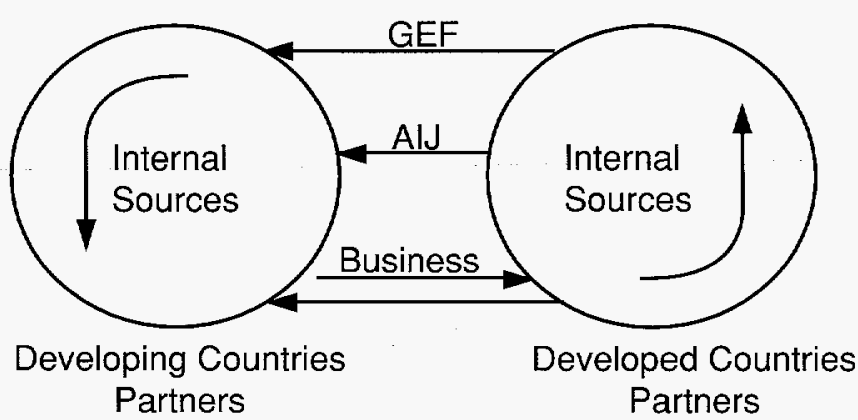

Figure 2. The role of AIJ in capital flows for GHG emissions reduction (GEF = Global Environmental Facility, United Nations). 
among these are promotion of energy efficiency (building materials, industrial boilers, electric motors, and water pumps), cogeneration, wind power generation, clean coal technology, solar photovoltaics, coal bed methane, and munic- ipal waste-fired power plants. We have proposed 18 possible AIJ projects and have evaluated their potential for followup steps. We will continue to make efforts to maintain close contact with U.S. and Chinese governments on AlJ progress and speed up processing of AIJ implementation. We will also contact American and Chinese private sector firms in areas of mutual interest and benefit for both the U.S. and Chinese government

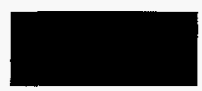

\section{Integrated Assessment: Structural Models of Long-Term Energy Demand}

\section{L.A. Greening, L. Schipper, P. Wilcoxen, * W.B. Davis, A. Sanstad}

This multi-year project involves the reconciliation of "top-down," or macroeconomic, energy models with more disaggregated, technology-specific "bottom-up" modeling techniques. The motivation for this work stems from the need to develop an understanding of both the economic and non-economic factors that drive energy consumption and carbon dioxide emissions in the absence of constraints on energy usage or carbon emissions. Macroeconomic models currently in use for the forecasting of both energy demand and future levels of carbon dioxide rely on assumptions of exogeneously defined parameters such as changes in "autonomous energy efficiency improvements" (AEEI). Exogeneously defining the crucial factors that impact energy-consumption patterns precludes adjusting for consumer behavioral responses to changes in either energy prices or economic growth. Further, these

*Department of Economics, University of Texas at Austin. types of models have been developed at such levels of aggregation that they fail to capture explicitly technological innovation, changes in product mix and energy services, or changes in overall economic activity.

The project, entitled "Structural Models of Long-Term Energy Demand: Understanding the Long-Term Prospects for Carbon Dioxide Emissions," brings together a staff of experienced researchers in a number of sub-specialities in economics. The overall goal of this project is to incorporate the demand for energy services and introduce endogeneously defined parameters such as AEEI into the update of the Jorgenson/Wilcoxen Computable General Equilibrium (CGE) model for the U.S.

The Jorgenson/Wilcoxen model is probably the most disaggregate CGE model in existence at this time and captures many of the high-level sectoral effects that impact energy demand and energy prices. The production side of the Jorgenson/Wilcoxen model disaggre- gates the economy into 35 industries, each of which is represented by an econometrically estimated, tier-structured cost function. At the top tier, output is taken to be a function of inputs of capital, labor, energy, and materials (KLEM). Energy, in turn, is a function of inputs of primary and secondary energy commodities (coal, crude and refined petroleum, gas, and electricity). A similar approach is used for the model's 672 consumer groups (differentiated by demographic characteristics). For energy analysis, however, a better approach would be to represent sector-level energy demand in terms of energy services instead of energy goods. This will be done through the estimation of econometric energy service modules to replace the energy-demand functions now in the Jorgenson/Wilcoxen model.

As part of the first year's effort, we completed a comparison of current energy-usage decomposition index methods and then developed an indexing method that is more robust in forecasting and modeling frameworks. A parametric
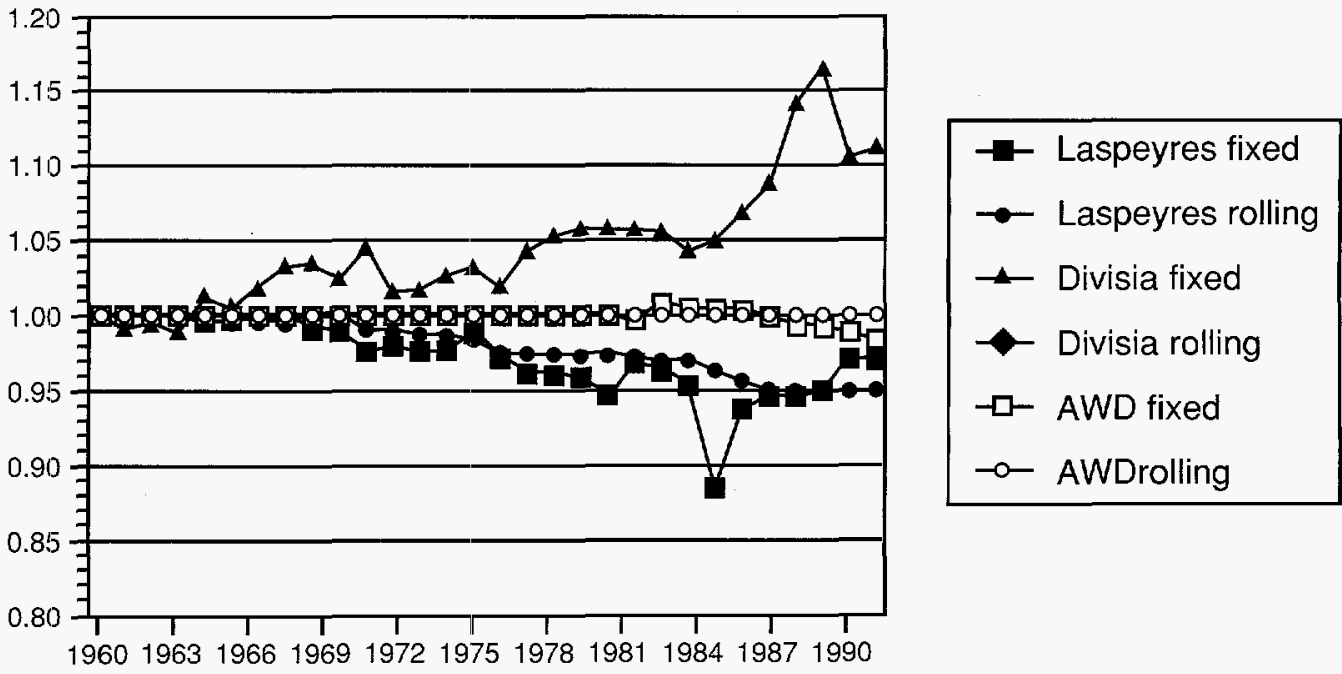

Figure. Residuals for six indices: Primary energy in U.S. manufacturing ( $A$ WD $=$ adaptive weighting divisia). 
divisia decomposition specification that is sufficiently general to subsume all previous decomposition methods was applied to data from the manufacturing sector for 10 countries with the result that either a simple average rolling base year or adaptive weighting rolling base year divisia decomposition method performs best under several criteria. The Figure illustrates the comparison of the residual term for all six methods; as illustrated here, both preferred methods generally have a zero residual term. The 10 countries analyzed are Denmark, Finland, France, West Germany, Italy, Japan, Norway, Sweden, the U.K., and the U.S. This parametric framework has been extended to a decomposition of $\mathrm{CO}_{2}$ emissions from this sector for these same countries. Declines in aggregate $\mathrm{CO}_{2}$ emissions for these 10 countries for the period 1971 to 1991 range from less than $40 \%$ to more than $70 \%$ and may be primarily attributed to decreases in energy intensity, i.e., increases in the average product of ener- gy. Both the rolling base year adaptative weighting divisia decomposition and refinements to previous assumptions regarding the energy balances and carbon emissions coefficients are being applied to other sectors, including transportation, freight, and residential energy end use, for the 10 countries.

For the remainder of the first year of this project, one or two intermediate steps remain to be completed for the reconciliation of the "top-down/bottom-up" modeling approaches. One is to develop estimates of elasticities of the aggregate energy intensity and the $\mathrm{CO}_{2}$ decomposition indices with respect to changes in energy prices and income. The sum of these individual elasticities for each component may be utilized either as a parameter in the Jorgenson/Wilcoxen model or with the output of the model to forecast changes in the various factors underlying energy consumption. This approach provides the vehicle for tests of energy-capital complementarity and technological embodiment.

During the first year, we also expect to begin the effort to specify and estimate improved energy sector models. Generally, the change will be to model the demand for energy services, treating energy consumption as derived demand, rather than estimating the demand for energy commodities directly. This approach more closely represents actual behavior and more explicitly recognizes the tradeoffs between increased investment (in energy efficiency) and energy consumption. As a result of these refinements to the Jorgenson/Wilcoxen CGE model, links of high-level effects on industries will be made to low-level changes in energy-service demands; further links may be made between changes in energy prices and industry-level effects. The primary benefit from this project will be that the model should produce more realistic and detailed energy sector results. As a result, a broader array of energy policies may be examined.

\section{The Evolution of $\mathrm{CO}_{2}$ Emissions from Energy Use in Industrialized Countries: An End-Use Analysis} L. Schipper, P. Monahan, M. Ting, L. Scholl, F. Unander, ${ }^{*}$ M. Khrushch, W. Golove

We examine the long-term evolution of $\mathrm{CO}_{2}$ emissions from economic activity or by end use from 1973 through 1991 in 10 OECD countries. These countries account for nearly $80 \%$ of commercial primary energy use in the OECD and over $35 \%$ of worldwide energy use. Analysis was conducted for five sectors of final demand: households, services, manufacturing, travel, and freight. Within the household sector, we analyzed space- and water-heating, cooking, lighting, and six electric appliances; within manufacturing, six individual branches (and a residual branch), and within travel and freight up to five modes of transport depending on the country. Typically absent are activities accounting for some 10-15\% of total $\mathrm{CO}_{2}$ emissions from energy use. Data limitations (principally for the

*Institute for Energy Technology, Kjeller, Norway. ${ }_{\text {OECD }}=$ Organization for Economic Cooperation and Development. The countries are Denmark, Finland, France, West Germany, Italy, Japan, Norway, Sweden, the U.K., and the U.S.
U.S.) forced us to omit analysis of "other industry" (agriculture, mining, and construction). The losses incurred in converting primary inputs to district heat and electricity were allocated to end uses.

Between 1973 and 1991 aggregate $\mathrm{CO}_{2}$ emissions from the sectors (including emissions from producing electricity and district heat) fell or barely rose in all but one country. Relative to GDP, total emissions fell strongly everywhere. The main elements of this decline were improvements in energy efficiency, fuel switching, and, in a few countries, shifts away from production of raw materials. In many countries, emissions from consumer activities (households, personal transportation, and portions of the service sector) fell less than other sectors. But by the late 1980 s the rate of decline in emissions relative to GDP slowed, because improvements in both efficiency and fuel switching slowed.

Differences in national emissions per capita arise out of differences in overall GDP per capita, structure, ener- gy intensities, and fuel mix. In general, we can say:

- Differences in GDP per capita explain some of the differences in per capita energy use and per capita $\mathrm{CO}_{2}$ emissions over a wide range of income, but are less important among the countries considered here.

- Differences in the structure of economies, relative to GDP, are the most important reason why there are differences among countries in $\mathrm{CO}_{2}$ emissions per unit of GDP arising from energy use.

- Differences in fuel mix are about equally as important as differences in economic structure in accounting for differences in $\mathrm{CO}_{2}$ emissions per unit of GDP.

- Differences in energy efficiency rank after these factors in contributing to differences in per capita $\mathrm{CO}_{2}$ emissions.

- Differences in the severity of the climate also contribute to differences in $\mathrm{CO}_{2}$ emissions because climate is a strong determinant of energy use for 
space-heating and, to a lesser degree, space-cooling.

The decomposition of national $\mathrm{CO}_{2}$ emissions by changes in sectoral activity, structure, energy intensities, fuel mix, and utility fuel mix follows our previous work. From the decomposition of emissions changes in each sector we formed economy-wide totals representing the separate effects of any one component on each sector.

Increased activity (population growth, economic growth in both the service and manufacturing sectors, and increased mobility of people and goods), led to emissions increases in all countries. In general, none of these individual sectoral factors grew more rapidly than GDP. As a result, the ratio of $\mathrm{CO}_{2}$ to GDP fell "without anyone trying." That is, growth in the economy itself led to lower $\mathrm{CO}_{2}$ intensity of the GDP.

Changes in the structure within individual sectors increased $\mathrm{CO}_{2}$ emissions, ranging from $35 \%$ in Finland and
$23 \%$ in Japan to only $4 \%$ in the U.S. and $0 \%$ in Norway. In general, structural changes in manufacturing had only small effects, except in West Germany, the U.S., Japan, and the U.K., where such changes alone reduced emissions more than $10 \%$ from manufacturing. The shift toward trucks for freight raised emissions in almost every country. In all countries, structural changes in the household and travel sectorsmore comfort and appliances in larger homes, more car travel-increased $\mathrm{CO}_{2}$ emissions significantly. This effect on emissions from consumers grew roughly with GDP.

Lower primary energy intensities--improved energy efficienciesreduced emissions in every country. The deepest cuts occurred in the U.S., West Germany, and Denmark, where emissions fell around $30 \%$ because of the drop in final energy intensities.

Final fuel mix worked toward lower emissions where final consumers moved away from coal to gas (U.K.,
France, and to some extent West Germany). But the increased share of electricity in the fuel mix of the residential, manufacturing, and services sectors lead to increased emissions in Denmark, Japan, West Germany, the U.K. (for services and manufacturing), and the U.S. The 1973 carbon release from electricity and district heat in these countries was greater than that from the fossil fuels replaced. Changes in utility fuel mix led to lower emissions in all countries, because electricity production itself became less $\mathrm{CO}_{2}$-intensive.

This type of analysis will be used to analyze $\mathrm{CO}_{2}$-reduction plans of individual countries and compare them with historical trends in each country. And we will examine some recent strategies invoked by public or private authorities that have led to measurable reductions in $\mathrm{CO}_{2}$ intensity and emissions. Finally, we will carry out a formal estimation of some of the causes of the historical reduction in $\mathrm{CO}_{2}$ emissions we have observed.

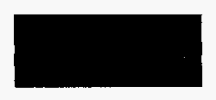

\section{Comparisons of Energy Use in Japan and the U.S.} L. Schipper, B. Litt, N. Kiang

It is commonly stated that Japan produces almost the same GDP/capita as the U.S., but uses considerably less energy to produce it. This comparison implies that energy use in Japan is more efficient. More detailed comparisons, however, suggest that only some differences of energy intensities can be accounted for by efficiency. The rest are brought about by "structural" factors, i.e., different mixes of activities and output. Our new comparison reflects an effort to understand the household and transportation sectors of Japan (see also the next article) as well as new calculations of manufacturing energy use. The year of the comparison was constrained because the latest year for which data for manufacturing are available for the U.S. is 1991.

This comparison is accomplished as follows. First, we break Japanese and U.S. final and primary energy use into a large number of uses or activities, for which we associate both an activity indicator and an energy intensity. Then, for each end use, we calculate energy use for each country like it had the other country's per capita activity, or, in the case of manufacturing, the other country's share of GDP attributable to manufacturing. The comparison uses each country's actual mix of different industries in manufacturing. Agriculture, mining, and construction are not included in this comparison because there are no data for the U.S. after 1985. We calculate primary energy use for each of these activities by multiplying electricity by the ratio of primary energy consumed to electricity consumed in the economy. Where energy intensities from the other country are used in a calculation, we take that country's ratio of primary energy to electricity as well.

The Figure decomposes the two countries' ratios of primary energy use to GDP in six sectors. Differences in the activities in each economy account for at least as much of the difference in the ratio of energy to GDP. This can be seen by noting in the Figure that switching the U.S. energy intensities for those of Japan reduces the U.S. ratio less than does substituting Japanese structural parameters into the U.S. energy calculation. Similarly, using U.S. structural features for the calculation of the Japanese ratio boosts Japan's value more than does substituting U.S. energy intensities. We emphasize that this comparison is a static comparison, ignoring what would have to occur if one country's households and enterprises were to assume characteristics of the other.

In fact, Japanese manufacturing energy intensities remain significantly below those of the U.S. But the Japanese auto fleet (including mini-cars) uses only $10 \%$ less fuel $/ \mathrm{km}$ than do autos (and household light trucks) in the U.S. And Japanese homes use only half as much heat, per square meter and degree day, as those in the U.S., primarily by heating fewer hours to lower temperatures. But the Japanese travel only $40 \%$ as much, per capita, by car as do Americans, and enjoy only half as much 
household space as Americans do. These two elements of the comparison contribute the most to the observed differences in the ratio of aggregate energy to GDP. Thus it would be improper to suggest that "Energy use in Japan is $X$ times more efficient than in the U.S." on the basis of the differences in the ratio of energy use to GDP. More generally, our work continues to show that the ratio of energy use to GDP is not a suitable measure of energy efficiency. In FY1996 and 1997 we will explore how the long-term changes in the structure of energy use affect the relationship between GDP and energy use.

\section{Reference}

Kiang N, Schipper L. Energy trends in the Japanese transportation sector. Transport Policy 1995;2(4, in press).

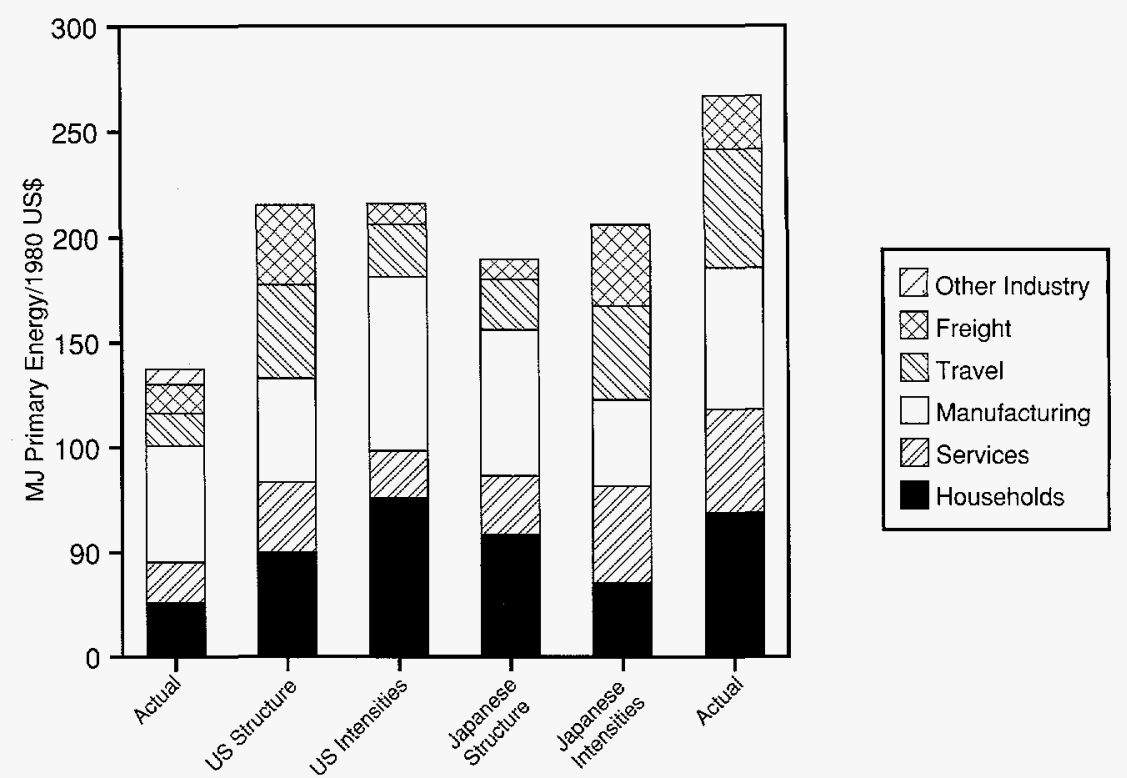

Figure. U.S. and Japanese primary energy/GDP ratios, 1991.

\section{Household Energy Use in Japan and the U.S. L. Schipper, B. Litt, H. Nakagami, ${ }^{*}$ Y. Nagata, ${ }^{+}$C. Murakoshi, ${ }^{*}$ A. Meier}

Perhaps the most difficult sector of energy use in Japan to compare with that of other countries' is the residential sector. This year, in collaboration with Japanese researchers, we have studied this sector in detail and compared it with its U.S. counterpart. By disaggregating household energy use and applying appropriate normalization factors, we illuminated the reasons for the differences in energy use. While still low compared to that of the U.S., Japanese residential energy use has increased steadily over the past 30 years. As the structure of Japan's residential sector becomes more like that of the U.S., Japanese residential energy use per person is expected to continue to increase.

We reviewed major sources of data for residential energy use and housing and appliance characteristics for both countries, adjusting data where necessary to enable comparison. We calculated struc-

\footnotetext{
* Jyukankyo Research Institute, Tokyo.

${ }^{\dagger}$ Central Research Institute of Electric Power Industry, Tokyo.
}

tural factors and intensity factors, as defined in the Table.

The Japanese intensities for all end uses except lighting are significantly lower than those of the U.S. Even in this detailed comparison, some important structural factors are not included due to a lack of representative national data. Such factors include the intermittent heating and relatively low indoor temperatures in Japanese houses, the relatively small capacity of many appliances, and the use of ambient temperature water for clotheswashing. If normalizing for such differences in levels of amenities were possible, the difference between residential energy intensities would certainly shrink significantly. The structure-intensity model does not include the influence of the different energy prices in the two countries. An econometric analysis that incorporates energy prices and disposable income but uses less detailed structure and intensity information is being done for this project by Jyukankyo Research Institute in Tokyo.

The Figure shows residential energy use per person for Japan, the U.S., and for hypothetical places with Japanese intensities and U.S. structure, and with U.S. intensities and Japanese structure. A person in Japan uses less than one-third of the final energy used by someone living in the U.S. But if Japan's residential sector had the same structure as that of the U.S., Japanese residential energy use would increase by a factor of two. Similarly, if the U.S. residential sector had the same structure as that of Japan, U.S. residential energy use would decrease by a factor of two. Although the U.S. uses more than three times the residential energy per capita of Japan, only half of this difference is due to intensity differences. The remaining half is due to structural differences.

\section{Reference}

Schipper L, Nakagami H, Litt B, Nagata Y, Murakoshi C, Meier A. Comparison of Residential Energy Use in Japan and the U.S. Lawrence Berkeley National Laboratory Report No. LBL-38007, 1996. 
Table. Structure and intensity definitions for end uses, and Japan and U.S. intensities.

\begin{tabular}{|c|c|c|c|c|c|}
\hline \multirow{2}{*}{$\begin{array}{l}\text { End-Use } \\
\text { Categories }\end{array}$} & \multirow{2}{*}{$\begin{array}{l}\text { Structural Level } \\
\text { Definitions }\end{array}$} & \multirow{2}{*}{$\begin{array}{l}\text { Intensity } \\
\text { Definitions }\end{array}$} & \multirow{2}{*}{$\begin{array}{l}\text { Intensity } \\
\text { Units }\end{array}$} & \multicolumn{2}{|c|}{ Intensity Levels (1993) } \\
\hline & & & & Japan & U.S. \\
\hline Space heat $\left(E_{s h}\right)$ & $\begin{array}{l}\text { Heated floor area } \\
\text { per capita } x \mathrm{HDD}^{\mathrm{a}}\end{array}$ & $\begin{array}{l}E_{\text {sh }}{ }^{b} \times \mathrm{HDD}^{-1} \\
\times(\text { heated floor area) }\end{array}$ & $\mathrm{KJ} \mathrm{m}^{-2} \mathrm{HDD}^{-1}$ & 100 & 170 \\
\hline Water heat $\left(\mathrm{E}_{\mathrm{wh}}\right)$ & 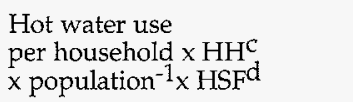 & $\begin{array}{l}E_{W h} \times(\text { liter hot } \\
\text { water use })^{-1}\end{array}$ & $\mathrm{KJ} \mathrm{I}^{-1}$ & 180 & 270 \\
\hline Cooking $\left(\mathrm{E}_{\mathrm{ck}}\right)$ & HH $\times$ pop. $^{-1} \times$ HSF & $\mathrm{E}_{\mathrm{ck}} \times \mathrm{HH}^{-1}$ & GJ $\mathrm{HH}^{-1}$ & 3.4 & 4.2 \\
\hline Cooling $\left(\mathrm{E}_{\mathrm{cl}}\right)$ & Cooled floor area per capita ${ }^{e}$ & $\mathrm{E}_{\mathrm{Cl}} \times$ cooled floor area ${ }^{-1}$ & M] $\mathrm{m}^{-2}$ & 26 & 80 \\
\hline Lighting $\left(E_{1}\right)$ & Floor area $x$ pop..$^{-1}$ & $\mathrm{E}_{1} \times$ floor area $^{-1}$ & $\mathrm{KJ} \mathrm{m} \mathrm{m}^{-2}$ & 24 & 26 \\
\hline Other appliances & $\begin{array}{l}\text { Diffusion = \# of each } \\
\text { major appliance per capita }\end{array}$ & $\begin{array}{l}\text { Unit energy consumptions } \\
\text { of appliances and } \\
\text { miscellaneous energy } \\
\text { per capita } \\
\text { refrigerator, } \\
\text { freezer, } \\
\text { clothes washer, } \\
\text { dryer, } \\
\text { dishwasher } \\
\text { miscellaneous }\end{array}$ & $\begin{array}{l}\mathrm{kWh} \\
\mathrm{kWh} \\
\mathrm{kWh} \\
\mathrm{kWh} \\
\mathrm{kWh} \\
\mathrm{GJ}\end{array}$ & $\begin{array}{l}700 \\
\text { na } \\
47 \\
480 \\
\text { na } \\
4.2\end{array}$ & $\begin{array}{l}1200 \\
1000 \\
100 \\
900 \\
160 \\
6.4\end{array}$ \\
\hline
\end{tabular}

Notes:

a. heating degree days (HDD), base $18^{\circ} \mathrm{C}$.

b. $\quad E_{i}$ is the total energy used in a country for the ith residential end use.

c. number of households $(\mathrm{HH})$.

d. household size factor (HSF) reflects the empirical observation that water heating and cooking energy use increases with the square root of the number of household members. This factor is used only when comparing structures of two different countries or two times for the same country. $\left.\mathrm{HSF}=\sqrt{(\mathrm{pop} \cdot 1} / \mathrm{HH} \mathrm{H}_{1}\right) / \sqrt{ }\left(\mathrm{pop} \cdot 2 / \mathrm{HH}_{2}\right)$. e. calculated from diffusion of room and central air conditioners.

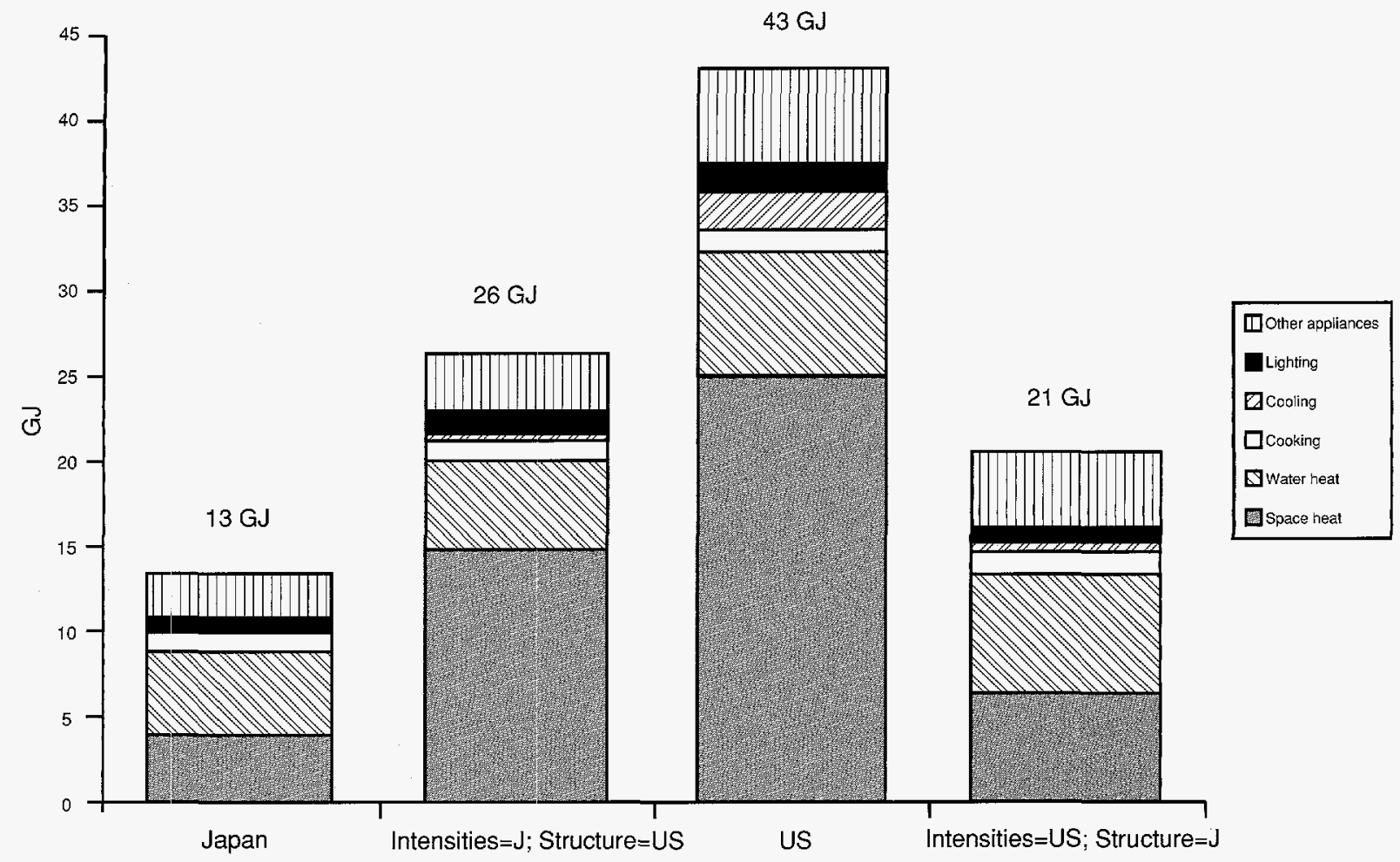

Figure. Residential energy use for Japan, the U.S., and two hypothetical countries. 


\title{
Manufacturing Energy Use and $\mathrm{CO}_{2}$ Emissions in $10 \mathrm{OECD}$ Countries: Long-Term Trends Through 1991
}

\author{
L. Schipper, F. Unander, ${ }^{*}$ M. Khrushch, M. Ting, L. Perälät
}

Our objective was to quantify the components of changes in energy use and $\mathrm{CO}_{2}$ emissions for seven manufacturing subsectors in 10 OECD countries. $¥$ This objective extended our previous work by adding Denmark and Finland, by including food as a separate energy-consuming sector, and by using improved data covering more years. Our methods and data sources were similar to those of previous work, but we have made refinements based on improvements carried out by each country's statistical authorities.

From 1973 to 1991, per capita energy use for manufacturing in the ten countries barely changed, increasing only in Finland, and $\mathrm{CO}_{2}$ emissions fell in all countries. Yet per capita output was higher in most countries, from between $13 \%$ (Sweden) and $63 \%$ (Japan). Surprisingly, energy use and

*Institute for Energy Technology, Kjeller, Norway.

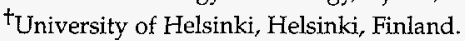

†OECD = Organization for Economic Cooperation and Development. The countries studied are Denmark, Finland, France, West Germany, Italy, Japan, Norway, Sweden, the U.K. and the U.S. output moved in opposite directions over this period. Even more surprising, in $1992 \mathrm{CO}_{2}$ emissions from manufacturing were lower in all but three countries, and by the early 1990s emissions per capita or per unit of manufacturing output were well below their 1973 levels. Figure 1, which shows the origin of emissions in each country by major end uses, relative to total output, contains much of the story.

This remarkable change in energy use resulted from changes in many underlying components. These same components, which affect energy consumption, also affect $\mathrm{CO}_{2}$ emissions as measured by aggregate carbon intensity $\left(\mathrm{CO}_{2}\right.$ emissions per unit of value added $)$.

We found that:

- Changes in the mix of output (structural change) that favored less energy- or $\mathrm{CO}_{2}$-intensive industries were important in only three countries (U.S., Japan, and West Germany) in restraining energy use (by 10-15\%) and emissions (by 15-20\%).

- Changes in sub-sectoral primary energy intensities reduced energy use

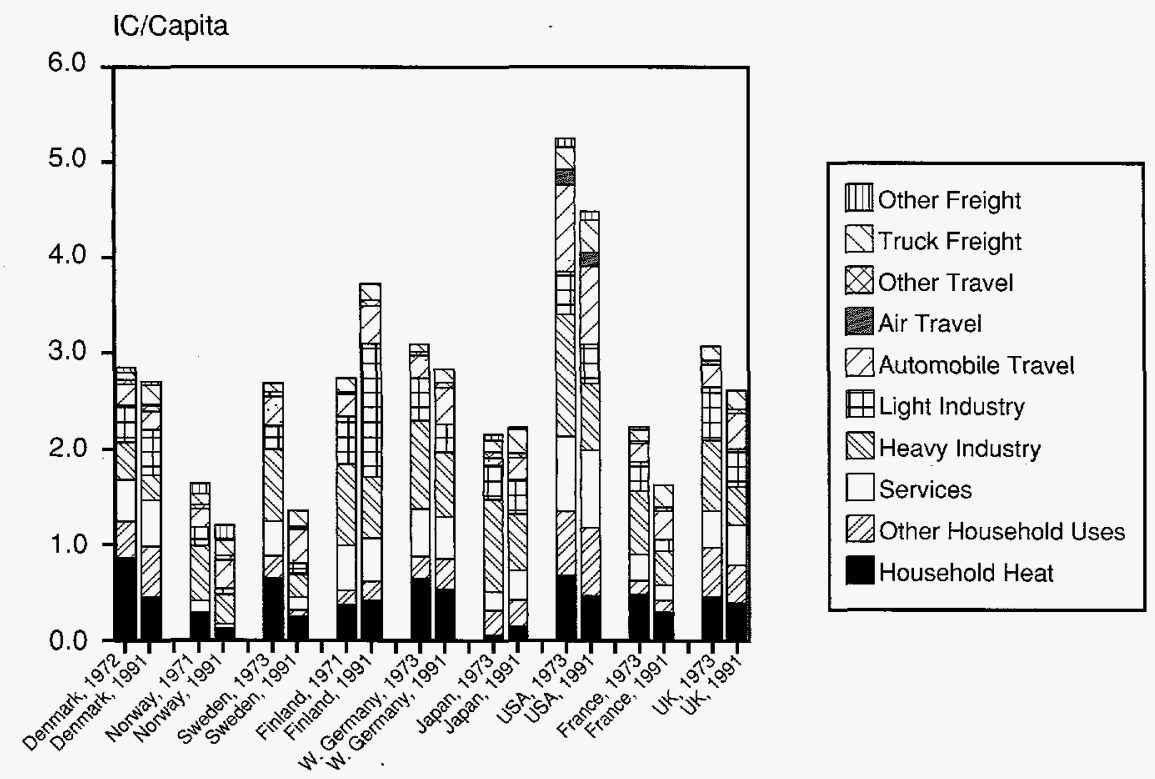

by $15-35 \%$.

- Changes in structural output and energy intensities reduced $\mathrm{CO}_{2}$ emissions. The $\mathrm{CO}_{2}$ intensity of electricity production fell in nearly every country. And the final fuel mix in general moved toward more natural gas and less coal or oil, reducing $\mathrm{CO}_{2}$ emissions further.

- Aggregate carbon intensity fell markedly in every country.

These factors are contrasted better in Figure 2. There we show 1991 per capita $\mathrm{CO}_{2}$ emissions from all of manufacturing in several ways, always with the 1973 value $=100$. "Activity" shows how much emissions increased because of climbing output. "Structure" shows that for most countries, shifts in product mix alone reduce $\mathrm{CO}_{2}$ emissions. "Energy Intensity" shows significant reductions in emissions in every country. Changes in the final fuel mix increased emissions by modest rates in half the countries. In contrast, changes in electric utility fuel mix reduced emissions, particularly in countries with low-carbon sources of electricity like nuclear, hydro, or biomass. Combining all fuel and intensity effects into "Carbon Intensity" shows that the ratio of emissions to a unit of output fell dramatically in every country.

These findings are significant for two reasons. First, they show that in general $\mathrm{CO}_{2}$ emissions from manufacturing fell principally because of energy saving in that sector. Other factors reenforced this declining trend. Since energy intensity seems to fall more the more output grows, the wedge between $\mathrm{CO}_{2}$ emissions and output is large, leading to restraint in emissions. This means that if trends continue, $\mathrm{CO}_{2}$ emissions from manufacturing should continue to lag significantly behind output.

In the coming year, we will refine methods, data, and assumptions and explore the causes of the changes in energy intensities and $\mathrm{CO}_{2}$ emissions using inferential statistical techniques.

Figure 1. Total carbon emissions per capita by major end use. 


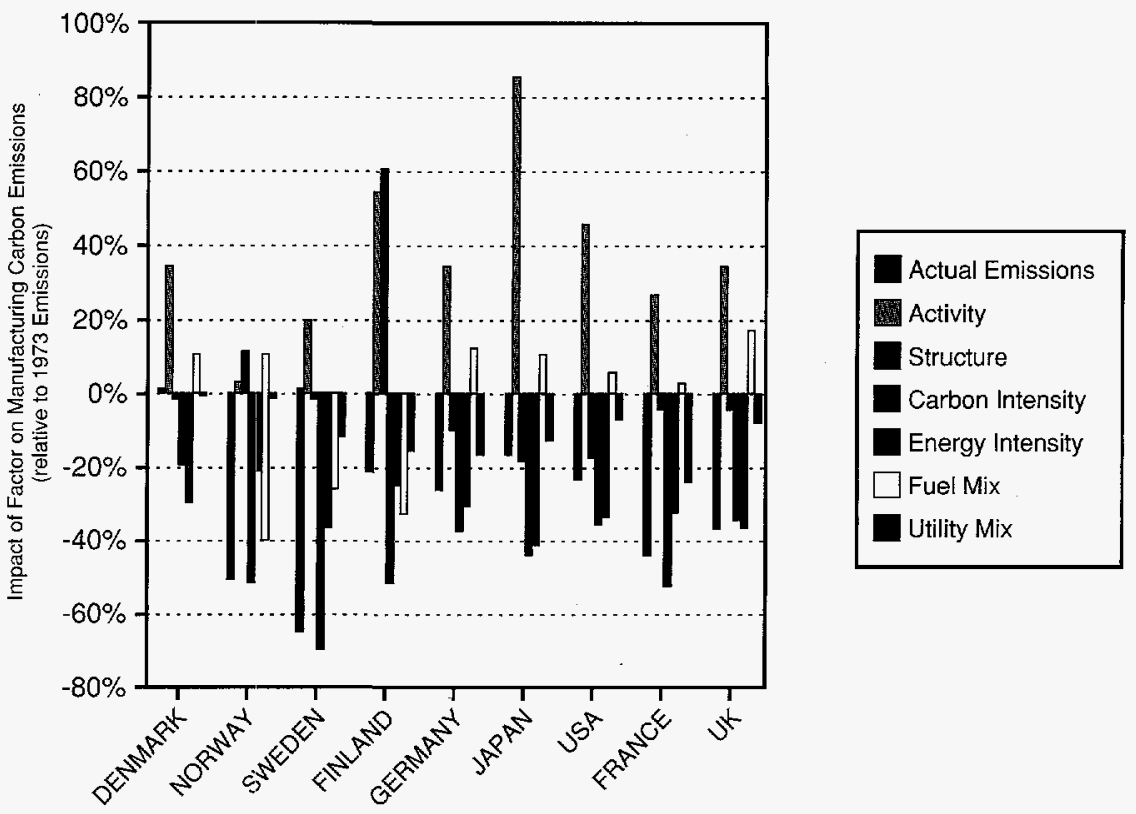

Figure 2. Impact of activity, structure, and intensity on manufacturing carbon emissions as a percentage of change from 1973.

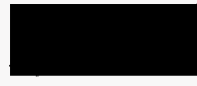

\section{Energy Use and $\mathrm{CO}_{2}$ Emissions for Freight Transport}

\section{Schipper, L. Scholl}

We reviewed trends in domestic freight activity and energy use by mode in ten industrialized countries from the early 1970 s to 1993 , disaggregating total energy by freight mode (rail, inland shipping, truck, air) and by fuel. We found that domestic freight haulage increased at slightly less than GDP over the long term, with very closely correlated short-term variations. Comparing the energy intensities of different modes over time and among countries, we found that in all countries trucks were significantly more energy intensive than other modes, while a two-to-one difference in trucking energy intensity exists between countries. On average, more energy was required to move one tonne one kilometer in 1993 than in 1970 because of the increasing role of trucks in freight hauling. Trucks dominate freight hauling (except in the U.S. and Norway) and the energy intensity of trucking increased in half the sample countries (see Figure). Because of high energy intensities, energy for trucking dominates freight energy consumption.

To study changes in overall energy use, we carried out a decomposition of changes in energy use for freight since 1973. Increased freight haulage lifted energy use everywhere. Modal shifts increased energy use in each country by 5 to $30 \%$. Energy intensities for freight (weighted by 1973 modal shares) decreased in half the countries studied. Still, when all these factors were com- bined, we found that energy use for freight increased in every country on a per capita basis and increased relative to GDP in the U.S and Europe. In general, freight volumes, in tonne- $\mathrm{km}$, increased less rapidly than GDP, but the combination of shifts toward trucks and, for many countries, increased energy inten-

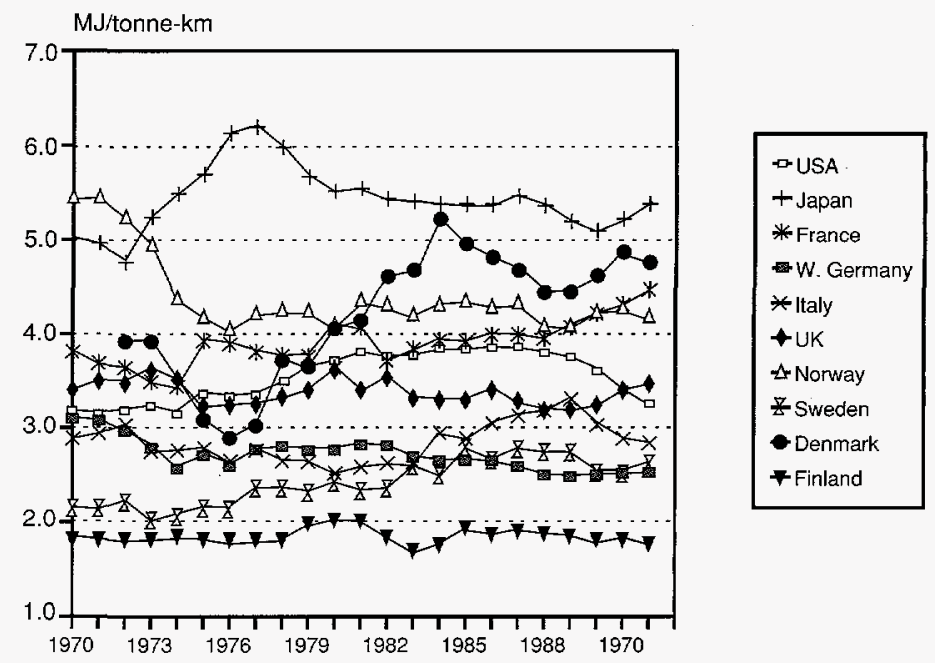

Figure. Energy intensities of trucking. 
sity of trucking, led to overall energy use for freight keeping pace with GDP.

We carried out a similar decomposition of $\mathrm{CO}_{2}$ emissions, one of the many environmental problems associated with freight. Results were similar to those for energy, because almost all freight energy is from oil products, whose emissions vary only slightly among themselves. Indeed, the share of $\mathrm{CO}_{2}$ emissions from freight was rising in every country we studied.

The evolution of emissions from freight leads to a dilemma. Freight activity, modal mix, and-in half the countries studied-energy intensity all contributed to greater $\mathrm{CO}_{2}$ emissions from freight. In contrast, emissions from households, services, manufacturing, and, for the U.S., travel, were restrained significantly by lower energy intensities and in many cases by fuel substitution. The trends underying the increase in emissions from freight have scarcely weakened in the 1990s, and may be strengthened by increased trade. Given this strong performance of freight output, restraining or reducing emissions from freight will be particularly difficult unless a radical change in freight handling or a suitable fuel low in net $\mathrm{CO}_{2}$ emissions can be found.

In future work we hope to study how the kinds of goods shipped and the distances they move affect freight mode and energy use, and how these factors have changed over time.

\section{Coming in from the Cold: The Challenge of Providing Affordable Comfort in Central and Eastern Europe}

\section{Schipper}

Rapid economic reform in most sectors of Central and Eastern European (CEU) economies has had a profound impact on energy use there. While economic restructuring is rapidly changing energy use in some sectors, energy use for housing has changed slowly once the shocks of higher prices or cutbacks in supply worked their way through to individual households. Affordable comfort now rests on such factors as the financial pressures felt by both house- holds and the state, local, and private entities that buy and distribute fuels, or on the health and environmental costs associated with solid fuels (including shale and peat) or high-sulfur residual oil. These factors, coupled with the possible return to the cold winters that have been absent since 1988, give the matter some urgency. Our work concluded a four-year effort to better understand energy use in homes in this emerging region.

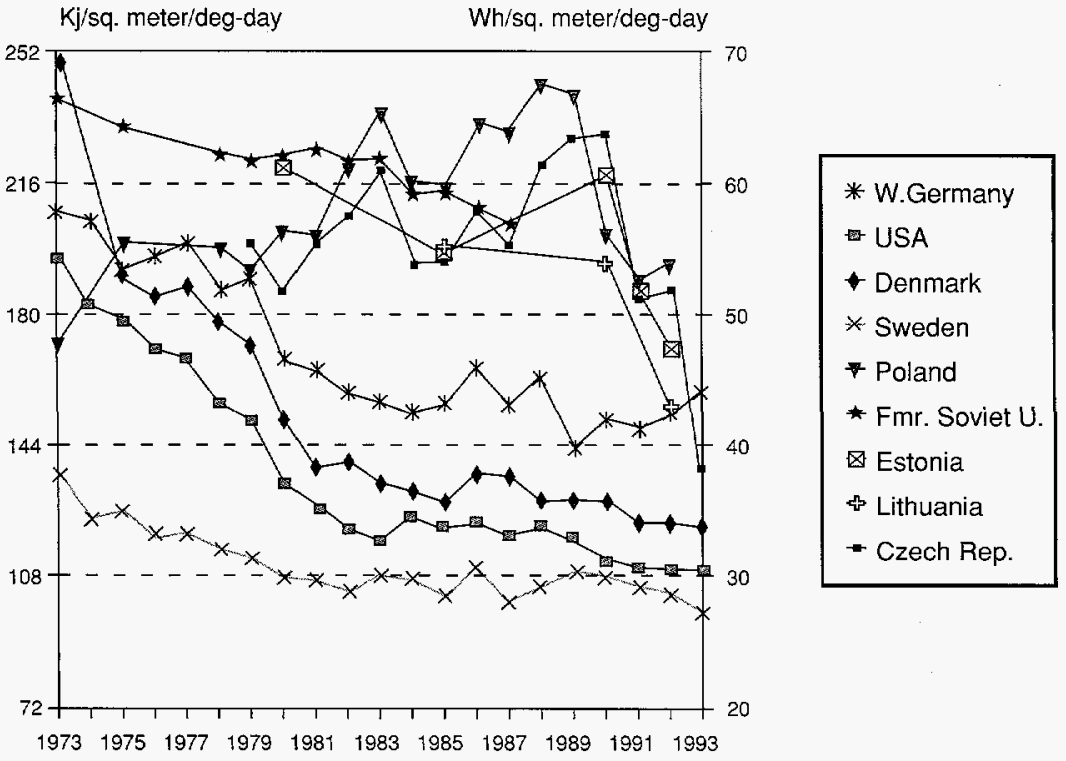

Figure. Residential space-heating intensities (useful energy).
The Figure shows space-heating intensity, normalized to climate, in a variety of CEU countries since the mid1970s, as well as in several other countries for comparison. The CEU countries portrayed have had the highest heating intensities. The level of heating in CEUs was high because of poor insulation, lack of controls, lack of cost meters (in about half the Eastern European stock), and low energy prices.

The decline in heating intensity for CEU households was painful. The sudden drop in Poland occurred as the coal market was privatized and consumers reacted to skyrocketing real prices by buying less coal. In Estonia and Lithuania, the cutbacks occurred on the supply side, as Russian deliveries of oil and gas to large boilers were interrupted or made unaffordable by huge price hikes. In none of the countries do drops in household energy use signify improvements in efficiency, e.g., better thermal insulation, better heating equipment, more controls, or the impacts of metering of heat in flats. In Poland, the decline was almost exclusively due to falling coal demand, prompted by very rapid increases in coal prices. In the Eastern European countries, real energy prices fluctuated wildly but generally increased by as much as a factor of ten or more, forcing heating costs to the second or third largest item in the family budget.

The efficiency of space heating can and will improve, but improvement faces many challenges: 
- Technical challenges: Low levels of building, heating, electronic, and control technologies; near impossibility of metering the heat released into individual apartments.

- Economic challenges: Lack of private funds (mainly a result of the economic chaos of the early 1990s), which prohibited families from retrofitting apartments or tenants from improving entire buildings; energy prices that remain low in many markets; profound difficulties arising from the high share of dwellings with collective, unmetered heating.

- Social and institutional challenges: New and uncertain arrangements in housing ownership, lack of mortgages and lending laws; primitive market for owned and rental housing; lack of financial intermediaries that can use large public or private funds (as well as funds provided through multinational lenders) to lend monies to renovate buildings; inexperience of tenant or owner organizations in borrowing money to undertake retrofits; difficulty in forging agreements among tenants on how to share the gains from reduced heating bills; lack of maintenance organizations that could carry out retrofits; lack of skills among building trades for carrying out responsible retrofits.

- Political challenge: The difficulty facing local and national governments who must raise energy prices and rents to cover costs yet pacify the large number of families not yet participating in the renewal of economic growth.

\section{References}

Martinot E, Schipper L, Khrushch M. Energy demand and efficiency in Estonia: Structure, potential, and policies. Energy Policy 1995;23(3):217233.

Schipper L, Martinot E, et al. The Structure and Efficiency of Energy Use in a Reforming Economy: The Case of Estonia. Lawrence Berkeley National Laboratory Report No. LBL-35542, 1994.

Meyers S, Schipper L, Salay J. Energy use in Poland: An international comparison. Energy The International Journal 1994;19(6):601-617.

Meyers S, Salay J, Schipper L. Energy use in a transitional economy: The case of Poland. Energy Policy 1994;22(8):699-713.

Schipper L, Martinot E. Decline and rebirth: Energy demand in the former USSR. Energy Policy 1993;21(9):969977.

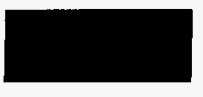

\title{
Energy Use and $\mathrm{CO}_{2}$ Emissions in Denmark Through the Early 1990s
}

\author{
L. Schipper, M. Khrushch, F. Unander, ${ }^{*}$. Ting, O. Sezgen
}

This work updates an earlier analysis and international comparison of energy use in Denmark and other countries carried out for the Danish government in 1992. We found that Denmark experienced the greatest declines in space-heating energy intensity of any of the OECD countries we analyzed and about average declines in the energy intensities in manufacturing. The energy intensity of personal transportation (travel) did not fall, while that for freight actually increased. Overall, energy users in Denmark reduced energy intensities-saved energy-at the greatest pace of all the countries we analyzed through 1989, but, as the update showed, the pace of energy saving slowed after that time.

Between 1989 and 1992, the pace of the decline in energy intensities in Denmark slowed more than elsewhere. Specifically, the intensity of freight continued to increase, while those for travel and other industry (agriculture, mining, and construction) reversed slightly. Intensities for the household sector continued to fall. Those for manufacturing

*Institute for Energy Technology, Kjeller, Norway. and services were approximately constant. The recent developments suggest that energy-saving efforts aimed at the sectors showing stagnation or reversal

must be redoubled if these sectors are to contribute further to $\mathrm{CO}_{2}$ emissions restraint and if Denmark is to resume its lead in energy savings. Furthermore, the

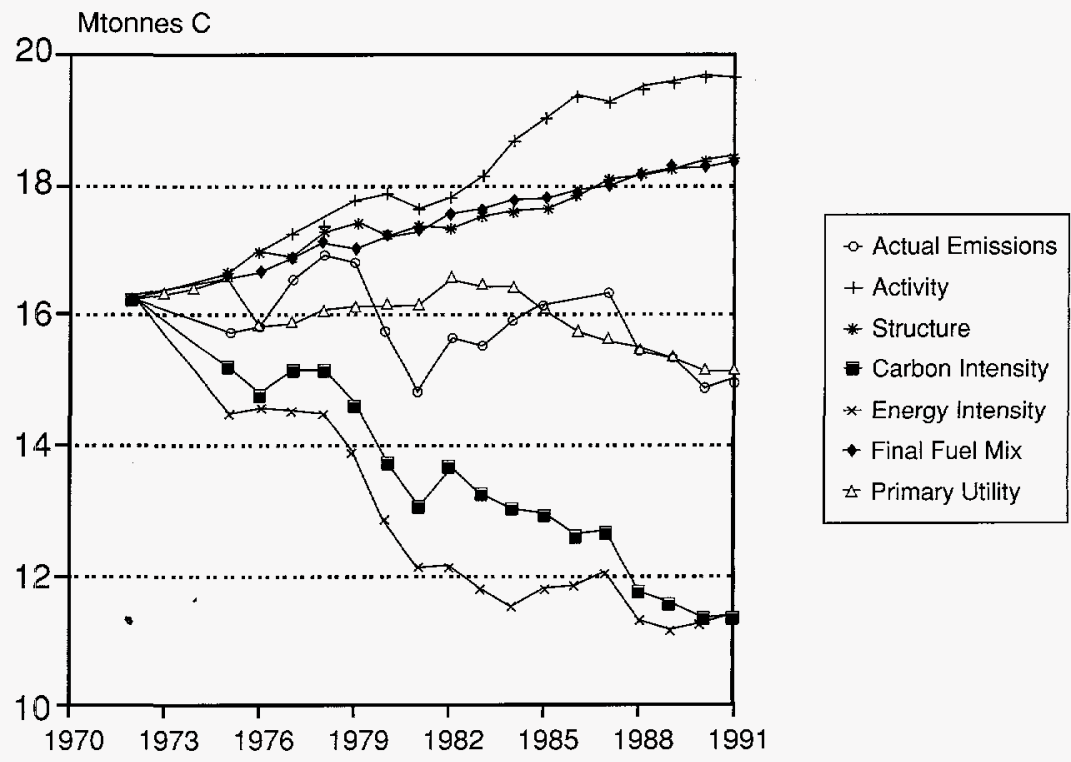

Figure. Impact of changing activity, structure, and intensity on Danish carbon enissions. 
successes of savings in the residential, services, and manufacturing sectors have reduced the importance of these three relative to transportation; future improvements in the transportation sectors will weigh more heavily than they did in our 1972-base weightings.

As part of a larger project for the U.S. Environmental Protection Agency, we analyzed the underlying factors shaping $\mathrm{CO}_{2}$ emissions in Denmark and other OECD countries. Here we applied the factoralization method used in previous projects. To better isolate the factors behind these aggregate trends, we performed the same decomposition on emissions as we did for energy and have added additional multiplicative terms to describe carbon intensity. These two factors are the most important ones for authorities to consider since these factors are the ones most likely to be subject to $\mathrm{CO}_{2}$-mitigation policies.

As in previous calculations of energy, the impact of each component or effect on sectoral carbon emissionsholding the other effects constant at 1972 values-was evaluated. These impacts were then summed (in terms of tonnes C) across sectors for each effect to give their total impact on total carbon emissions. The Figure shows for each effect how emissions were affected by that component. By summing the effect on each sector we can compare that component's impact on 1973 energy use with actual 1973 energy use, and with actual 1991 use for reference. The results in the Figure show that the activity effect (overall measure of sectoral output or activity) raises emissions greatly, as both GDP and population grew. The structure effect (mix of products or activities within a sector) also gives rise to increased emissions. The results for carbon intensity (emissions per unit of activity) decreased over the time period, although there was a slight upward trend in emissions from 19761978. The primary utility effect $\left(\mathrm{CO}_{2}\right.$ emissions per unit of final electricity or district heat) stayed quite flat over the time period and alone had an insignificant role in emission trends as changes in primary fuel mix only marginally lowered the carbon content of electricity. Because of this, the final fuel mix effect (emissions per unit of final energy, holding utility fuels constant at 1973 mix) gives rise to increased emissionsdespite strong fuel-switching away from oil-due to increased electrification in the manufacturing and services sectors and increased use of district heat in the residential sector. The energy intensity effect, however, lowers emissions dramatically over the time period ( $>35 \%$ reduction from 1972 levels) and dominates the trend in overall carbon intensity. We can conclude, then, that Denmark's total $\mathrm{CO}_{2}$ emission rates have been kept in check wholly by reductions in energy intensities.

The main contributors to energy intensity's downward pull on total emissions were residences and services followed by manufacturing. As mentioned earlier, space-heating intensity improvements in residences account for the bulk of the intensity declines in that sector. In manufacturing, the main contributors to overall intensity improvements were the chemicals and food subsectors, both of which decreased their energy/unit value-added ratio substantially (66\% and $31 \%$ decrease from 1972 values, respectively). We cannot pinpoint the services subsectors or end uses that contributed most to energy intensity declines due to lack of proper data; however, it seems likely that space-heating technology and subsequent intensity changes in this sector mirrored that in residences.

The scale of energy intensity reductions in Denmark is remarkable. However, just as noteworthy are the lack of intensity improvements in the transportation sectors. Emissions from transportation grew at rates that have overtaken the declines from other sectors. Considering that the structure and final fuel mix terms for these sectors have remained basically unchanged over the study period, the only reasonable outlook for future transportation emissions is one of continued growth.

Because most of the Danish $\mathrm{CO}_{2}$ reduction occurred through reductions in energy intensities, Denmark faces excellent prospects for further reductions in emissions. This is because unlike many other countries, Denmark has the opportunity to substitute natural gas for coal in power production and a continued gradual substitution of gas for direct uses for space heating as well as in district heating plants. With a carbon tax in place, Denmark fully expects to approach its year 2000 goal of returning emissions to their 1990 level.

\section{References}

Schipper L, Howarth R, Andersson B, Price L. Energy use in Denmark: An international perspective. $\mathrm{Natu}$ ral Resources Forum 1992;17(2):83103.

Sezgen O, Schipper L. Comparison of Commercial Sector End-Use Energy and Electricity Use in OECD Countries: Growth of Electricity Use. Lawrence Berkeley National Laboratory Report No. LBL-36999, 1995.

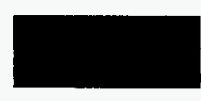

\section{Monitoring U.S. CO} L. Schipper, W. Golove

In 1993, President Clinton proposed The Climate Change Action Plan (CCAP) with the intent to restrain U.S. carbon dioxide $\left(\mathrm{CO}_{2}\right)$ emissions. In response, the U.S. Environmental Protection Agency asked us to assess whether the impact of such actions on emissions could be reliably measured.
Our analysis focused on measuring the underlying components of $\mathrm{CO}_{2}$ emissions and their changes over time, in order to sort out those changes sparked by policies from those occurring autonomously.

We studied U.S. energy consumption for the period 1960-1991 by sector (residential, services, travel, freight, and manufacturing), by fuel type and, in many cases, by end use. We used Laspeyres indexing techniques to understand the importance of three key factors: activity, structure, and energy intensities. We quantified sectoral $\mathrm{CO}_{2}$ emissions, and performed the same 
indexing analysis, adding an evaluation of the impact of changes in three further factors: the mix of fuels utilized, changes in the efficiency of electricity generation, and carbon intensities. The Figure shows the impact of each of these six factors on U.S. $\mathrm{CO}_{2}$ emissions. Each factor's impact is calculated by using the actual values for each year of that factor, while holding the other factors constant at 19173 values.

We found that for the economy as a whole, increased activity alone (more people, more travel, more freight, more manufacturing and service output) would have led to approximately 50\% higher levels of annual $\mathrm{CO}_{2}$ emissions. Structural changes alone would have led to slightly higher levels of emissions. However, the overall impact of changes in the structure and levels of activity still left the economy with a declining ratio of emissions to GDP. Indeed, actual emissions from the specific sectors evaluated in this study showed a negligible increase as did total emissions. The impact on emissions of changes in activity and structure was offset primarily by a large decline in energy intensity in each sector. The impacts of shifts in fuel mix and utility mix were small over this period, but contributed to offsetting the changes in activity and structure.

These findings have important implications for the future. Clearly changes in three factors-energy intensities, fuel mix, and utility fuel mixwill continue to reduce $\mathrm{CO}_{2}$ emissions from the U.S. economy. But activity, and to some extent structural change, are likely to oppose this restraint. Through the early 1990s, the overall impact of change was to hold emissions from the sectors we studied to close to their 1973 level, but now emissions are rising primarily because the restraining influence of energy intensity is weaker. The challenge for policymakers ready to commit the U.S. to further restraint or reductions in $\mathrm{CO}_{2}$ emissions is twopronged: they must both rekindle the decline in energy intensity and stimu- late switches away from the most $\mathrm{CO}_{2}$ intensive fuels (coal and to some extent oil). These changes must be accomplished in a fashion that offsets the strong influence of population growth and increased economic activity.

Given the available data, discerning the impacts of the CCAP is problematic. Moreover, even if the present trend in intensities and fuel mix are combined with all of the policies in the CCAP, these effects together seem unlikely to offset the basic growth in activity and structural trends in the economy today. Given current trends, the policies proposed in the CCAP are unlikely by themselves to lead to a return to $1990 \mathrm{CO}_{2}$ emissions levels. Thus, the problem is not whether the CCAP will or will not succeed, only that its impact will not be large enough to overcome the other changes occurring.

\section{Reference}

Schipper L, Golove W. Climate Restraint: Energy Use, Energy Efficiency, and $\mathrm{CO}_{2}$ Emissions-Measuring Progress in the United States. Lawrence Berkeley National Laboratory Report No. LBL-38041, 1995.

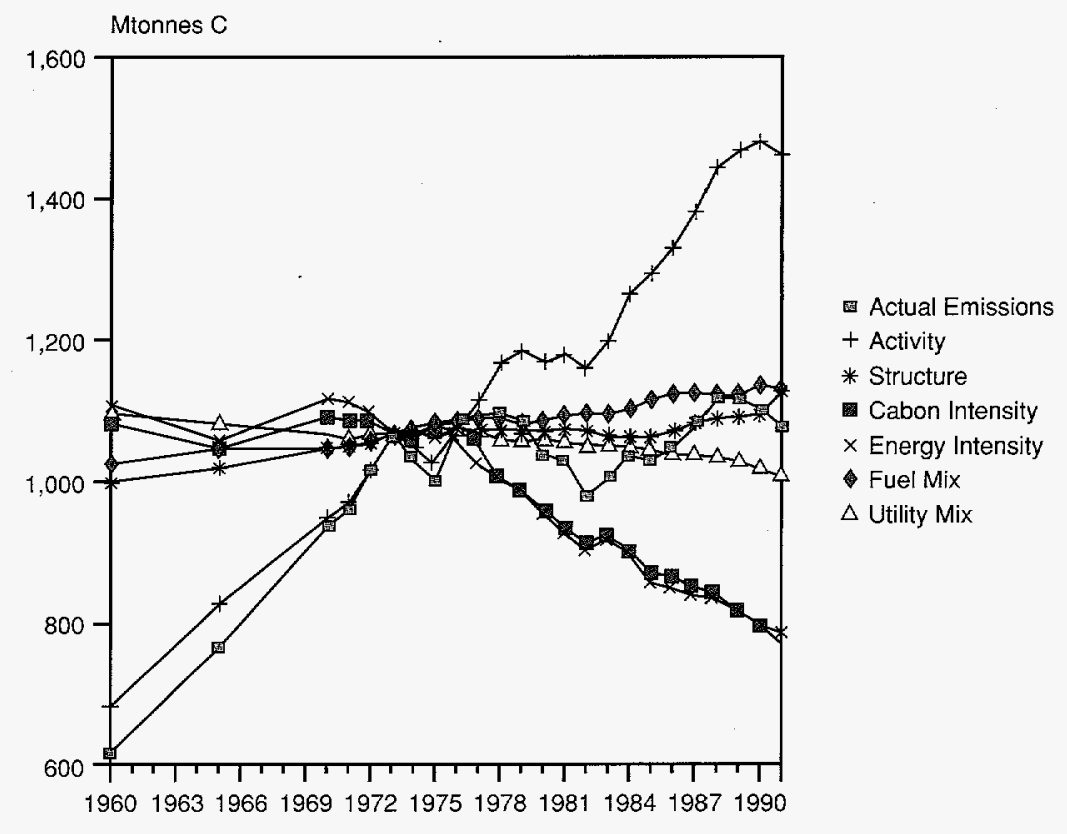

Figure. Impact of six factors on U.S. carbon emissions. 


\section{Energy Economics, Markets, and Policy}

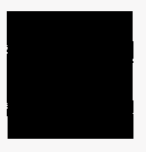

During the past year the work in energy economics, markets, and policy groups was appropriately divided into six related activities: 1) appliance standards analysis, under the leadership of Jim McMahon and Isaac Turiel, 2) assessment of utility demand-side management programs, with work by Joe Eto, Chuck Goldman, Ed Vine, and colleagues, 3) analysis of key issues facing a utility industry in transition, led by Ed Kahn, 4) analysis of markets for energyefficient products, led by Jon Koomey, 5) development of government "marketpull" programs for energy-efficient products, under the direction of Jeff Harris, and 6) transportation analysis, carried out by Lorna Greening and others.

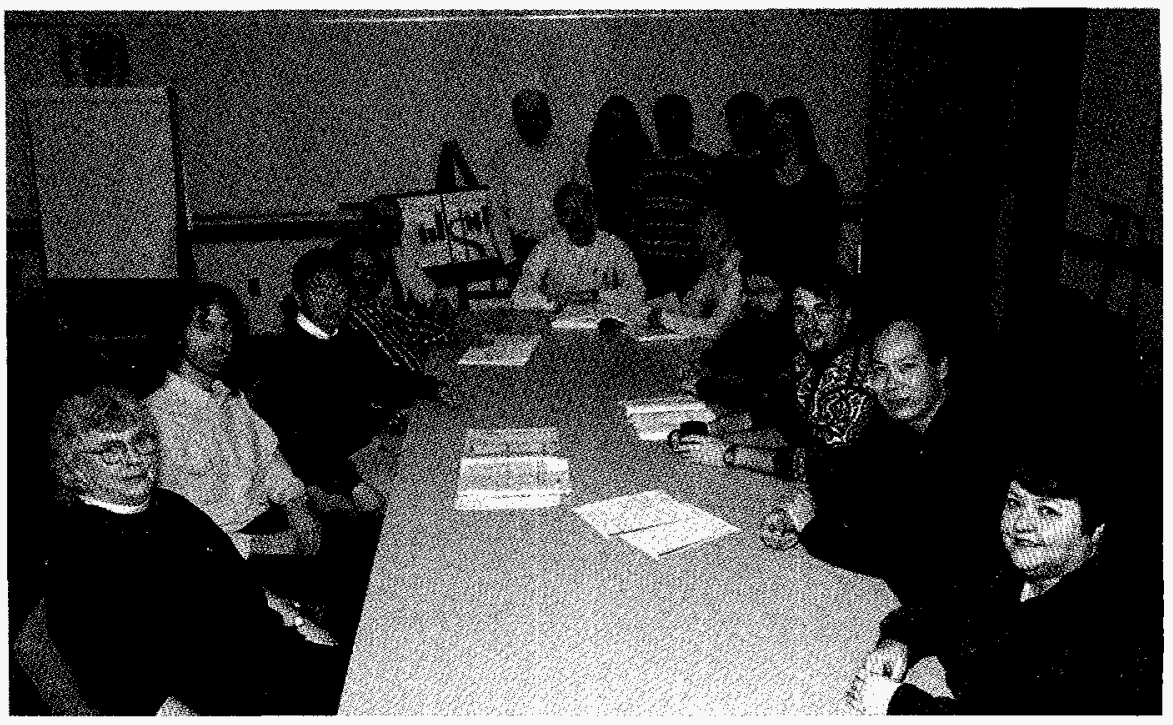

- appliance and lighting standards analysis

Two years ago, the U.S. Department of Energy instructed LBNL to shift from analyzing a few (typically three) appliance types at a time in support of a single rulemaking to simultaneously analyzing all 13 major appliances in support of multiple regulations all under development on overlapping schedules. This past year, that capability was put into practice with 1) the provision of technical support to the refrigerator consensus standards group and the completion of the analysis of the impacts of a negotiated rulemaking on

refrigerators; 2) the re-analysis of proposed standards for eight products (including room air conditioners, water heaters, and fluorescent light ballasts); and 3) the assessment of the impacts of updates to standards on central air conditioners, heat pumps, clothes washers, clothes dryers, and dishwashers.

- assessment of utility demand-side management programs

An important product has been a detailed assessment of the cost and measured performance of the largest commercial-sector demand-side management (DSM) programs. This analysis,

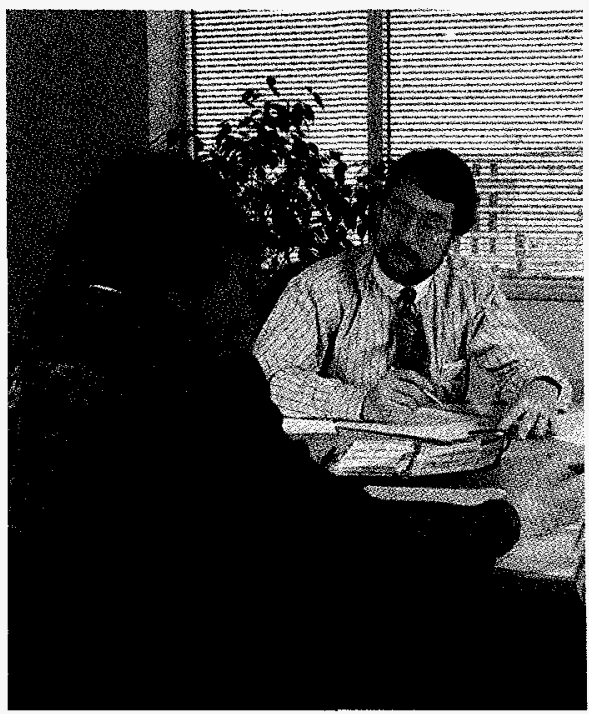

based on higher-quality data than have been used previously in such studies, indicated that these DSM programs performed well economically, with an average cost of saved electricity of 3.24 per kilowatt hour. Other work in this area investigated ways of improving DSM evaluations, addressed issues of the future of DSM in a rapidly changing utility industry, and assessed the experience of European DSM programs.

- analysis of key issues facing a utility industry in transition

This year we addressed the complexities of open access in bulk power markets and how it can be achieved; performance-based ratemaking for utilities; measures of competitiveness of the market for independent electricity generation; a case study of the role of electricity service companies (ESCOs) as electricity service providers; and models for gas utility planning. We have also been active observers of, and occasional participants in, the process of restructuring the California utility industry.

- analysis of markets for energy-efficient products in the U.S.

Examples of major results of ourwork analyzing U.S. markets for energy-efficient products include the development and application of a set of models and associated data to assess the market potential in specific geographic 


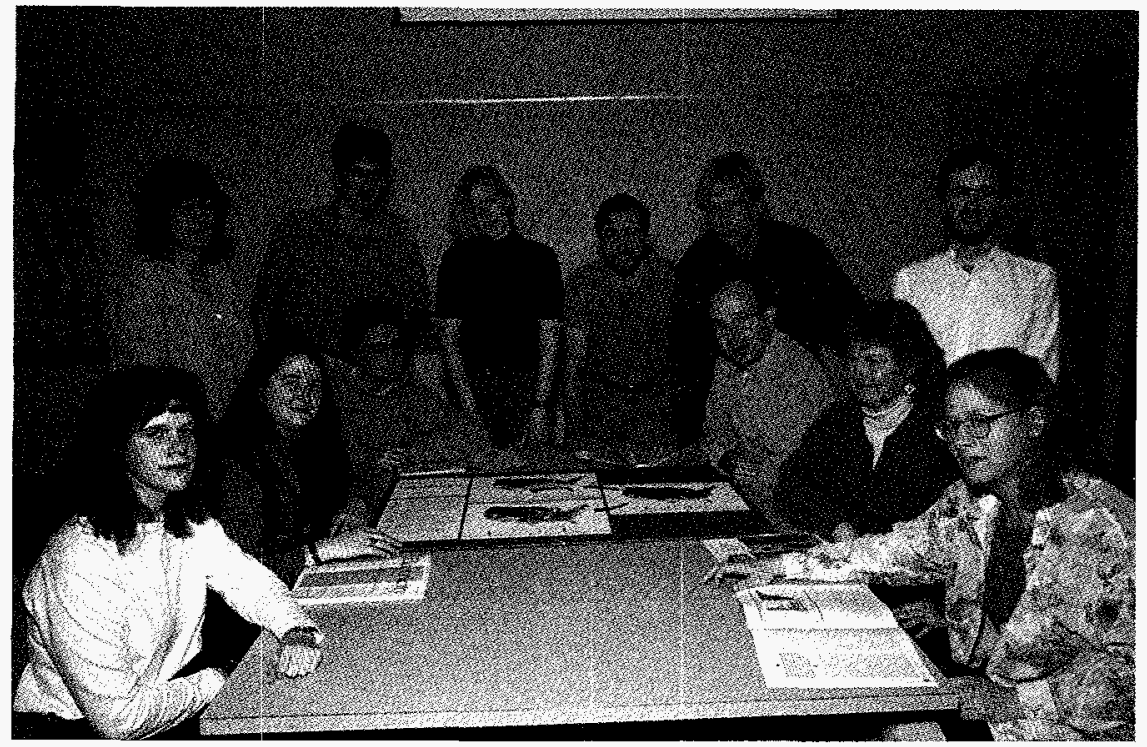

purchased and supporting DOE in its design of overall federal efforts to increase the purchase of energy-efficient chiller and motor systems.

\section{- transportation analysis}

Transportation studies of automobile emissions led to the important finding that emission controls in certain (less expensive) models have a higher probability of failure than others. The result suggests that a significant portion of the problem of highly polluting automobiles might be addressed at the point of manufacture rather than in the service station. If ongoing research reinforces this finding, new, less costly approaches to reducing auto emissions could be developed.

Other transportation analyses dur-

areas, a compilation of technology data (including costs and performance) for all major commercial sector end uses, and a collaboration with Pacific Northwest National Laboratory to create data displays that can be used to answer key questions related to energy efficiency in buildings;

- development of government "market-pull" programs for energy-efficient products

"Market-pull" programs have focused on providing support to the federal government in its efforts to increase its purchases of more efficient products. Such work has included supporting the General Service Administration and the Defense Logistics Agency in developing approaches that will assure that energy-efficient products are

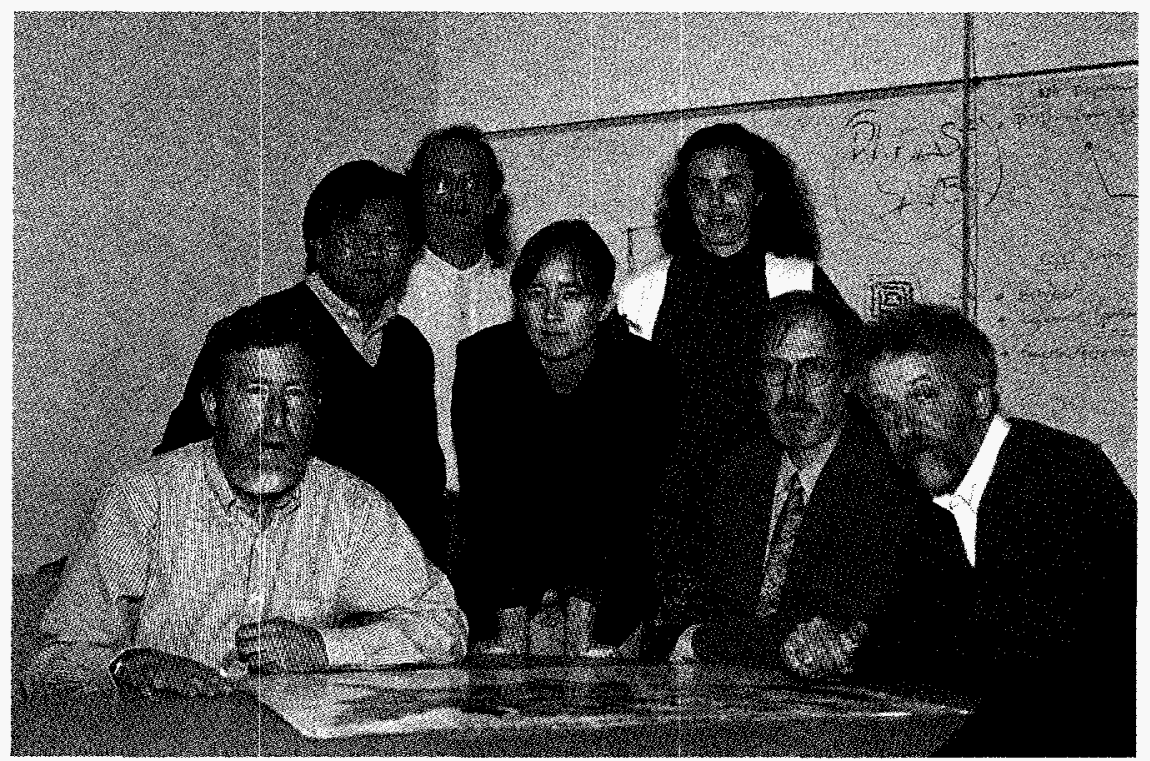

ing this past year included major travel surveys of the U.S. and six European countries and the application of a model of automobile transportation demand in California (CALCARS) to assess impacts of introducing zero-emissions vehicles.

A new area of transportation study begun during the past year involves the application of the National Energy Modeling System (NEMS) to study electric utility policy issues. We anticipate a growing activity applying NEMS to energy policy issues in the coming years. We are also exploring two other new areas for the future: benefit/cost/risk assessment of environmental regulations and international programs and policies to promote energy efficiency in appliances. 
Residential Assessment of Market Potential (RAMP)

\author{
R. Brown, J.G. Koomey, C. Atkinson, S. Bretz, J. Roberson, C. Webber, M. Moezzi, J. Kollar, M. Pinckard
}

The purpose of the Residential Assessment of Market Potential (RAMP) project is to assist the U.S. Environmental Protection Agency (EPA) in designing programs that help meet the residential-sector greenhouse gas stabilization goals of the Climate Change Action Plan. The results of RAMP research facilitate the design of voluntary, "market-pull". programs, which reduce pollution by accelerating the penetration of new or under-utilized energy-efficient technologies for most residential end uses.

The RAMP team is responsible for assessing the market potential of such energy-efficient products as groundsource heat pumps, condensing gas furnaces, and a variety of home appliances. The policymakers who implement the efficiency programs then use this information to design programs that target the most attractive market segments. The EPA can use RAMP research to promote efficiency through several program mechanisms such as product labeling, home builder initiatives, Home Energy Rating Systems (HERS) and Energy-Efficient Mortgages (EEMs), partnerships with realtors and financiers, and utility-sponsored incentive programs.

To assess the market for energyefficient technologies using the residential market assessment methodology, we first focus on how residential products are purchased and used, the existing market infrastructure for efficient products, and the market barriers to increased market penetration of these products. We use existing survey data and conduct informal interviews to gather data pertaining to the functioning of markets. We then apply a detailed model, based on geographic information system (GIS) analysis, to identify market segments in which efficient technologies are technically feasible, costeffective, and acceptable to consumers. The advantage of the GIS is that it can incorporate data (e.g., climate data, utility rates, building thermal characteristics, and equipment saturations) at several different levels of regional detail and produce results in map format that are easy to understand and act upon. Our market-assessment model uses individual household data from DOE's

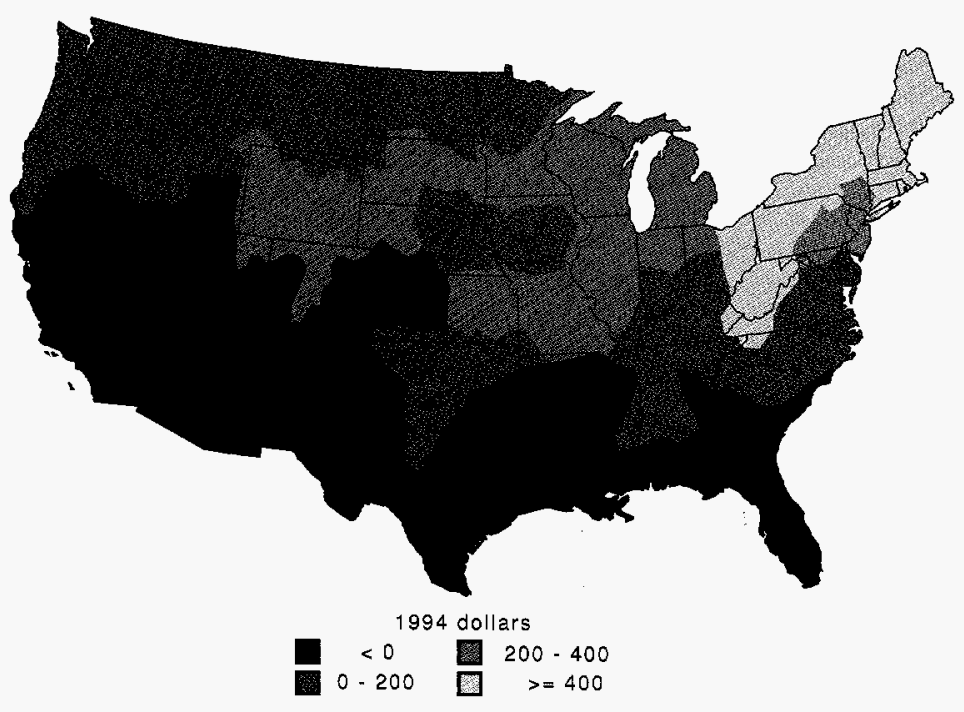

Figure. Life-cycle cost savings per household for a condensing gas furnace compared to a standard gas furnace. Assumes 18-year lifetime, $7 \%$ discount rate, and $\$ 800$ incremental purchase price.

Residential Energy Consumption Survey (RECS) and the American Housing Survey as well as summary data from the 1990 Census.

The key feature of RAMP analysis is that research results are disaggregated as much as possible to distinguish the market potential among regions, house types, demographic groups, and other market segments. Within each market segment, we estimate the potential for efficient technologies to save energy and prevent pollution in terms of both a business-as-usual scenario and a scenario in which various programs are implemented to promote these technologies.

RAMP analysis can be used to answer such important questions as:

- Which households are better or worse off as a result of energy-efficiency performance standards?

- Where is a particular energy-efficient product most cost-effective from the perspectives of the consumer, utility, and society?

- Which customers should be targeted for a particular energy-efficient product?

- Where is the best place for a utility to locate a pilot energy-efficiency program?

- Based on regional cost-effectiveness, how efficient should an appliance be to be eligible for promotion or rebate?

- In a given area (e.g., neighborhood), how many households own particular appliances, and how many are likely to buy replacements or new appliances in the next few years?

- Where is the housing construction market most active and what are the associated opportunities for promoting energy-efficient technologies in new homes?

One specific way in which we have applied the market assessment model is to assist program managers in designing a pilot program to promote the sale of efficient heating and cooling equipment. We used the GIS model to determine the regions in which energy- 
efficient heating and cooling products are most cost-effective. The Figure illustrates the national analysis results for the life-cycle cost savings for a condensing gas furnace compared to a standard gas furnace.

We narrowed the potential areas for launching the program by identifying metropolitan areas with sufficient energy-efficiency market infrastructure and other favorable factors (such as utility program activity). We then identified neighborhoods with favorable demographic and housing characteristics (e.g., a high percentage of households in a given census tract with old furnaces). The results of this screening process were used to target a direct mail campaign and to help local HVAC contractors target their marketing efforts.

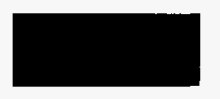

\section{Energy End-Use Data for Commercial Buildings J.G. Koomey, O. Sezgen, E. Franconi, M.A. Piette, C. Richey}

In the past, assessments of the impacts of federal energy policies in the commercial sector have been limited by the lack of a consistent data set characterizing equipment usage, building shell characteristics, energy use, and the costs of achieving particular efficiency levels. Over the last three years, we have created a highly detailed, comprehensive, and consistent data set for energy end uses that accounts for approximately $90 \%$ of the primary energy consumed in the commercial sector.

This data set was originally developed for use in the Electric Power Research Institute's (EPRI's) Commercial End-Use Planning System (COMMEND 4.0), but it is also useful for other analysis efforts and forecasting models. Consequently, we have summarized the building and equipment data in five LBNL reports that characterize the use of the following technologies in commercial buildings: 1) space-conditioning equipment, 2) lighting equipment, 3) office equipment, 4) water heaters, and (5) low- and high-temperature refrigeration. The data provided in these reports are intended to support energy end-use forecasting models for the commercial sector. These data come from a variety of sources, including DOE, EPRI, LBNL, and the U.S. Bureau of the Census. A brief description of each report follows.

\section{Space Conditioning}

This report characterizes the space-conditioning technologies found in commercial buildings and develops cost-efficiency data for these technologies. The report also characterizes the annual and peak space-conditioning requirements for the building stock.

Prototype simulations using the
DOE-2 building energy analysis program were used to generate data related to the efficiencies of shell measures, heating, ventilating, and air-conditioning (HVAC) systems, and utilization systems (controls and economizers). Eleven building types, two vintages (new and existing), and five climates were used to represent the U.S. commercial building stock for this purpose.

An example of the kind of detail available from our analysis is found in the Figure, which disaggregates commercial-sector electricity consumption for cooling by equipment type. This information is highly useful to policymakers, who are designing programs to promote the purchase and use of energy-efficient cooling equipment in the commercial sector.

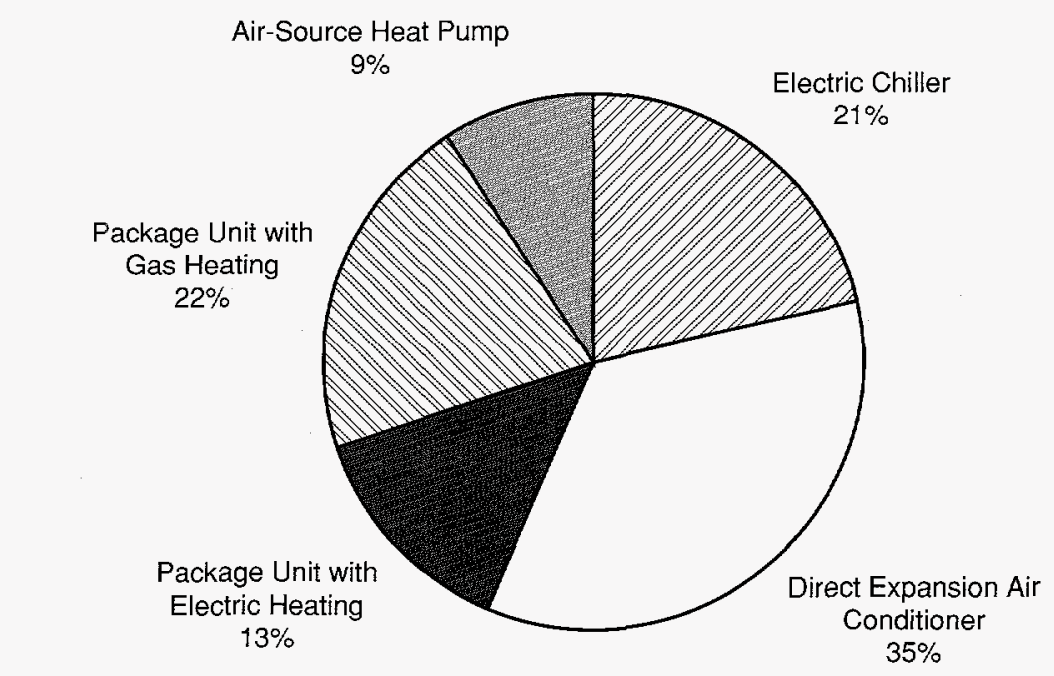

Figure. Commercial sector cooling electricity by equipment type (1993).

\section{Lighting}

This report characterizes the lighting technologies found in commercial buildings, develops cost-efficiency data for these technologies, and characterizes current lighting-utilization patterns and lighting level requirements. In addition, the report characterizes the interactions between lighting and space-conditioning end uses in commercial buildings in the U.S.

\section{Office Equipment}

This report describes a detailed end-use forecast of office equipment energy use for the U.S. commercial sector. Our analysis is based on a spreadsheet model that explicitly treats changes in power and usage for all relevant equipment types. This analysis is 
described in more detail in the next article in this Annual Report.

\section{Refrigeration}

This report characterizes the commercial floorstock in terms of refrigeration requirements and technology saturations and develops cost-efficiency data for these refrigeration technologies.

\section{Water Heating}

This report characterizes the commercial floorstock in terms of water heating requirements and technology saturations. The report also develops cost-efficiency data for these water-heating technologies.

\section{References}

Sezgen O, Franconi EM, Koomey JG, Greenberg SE, Afzal A. Technology Data Characterizing Space Conditioning in Commercial Buildings: Application to End-Use Forecasting with COMMEND 4.0. Lawrence Berkeley National Laboratory Report No. LBL-37065, 1995.

Sezgen O, Huang YJ, Atkinson BA, Eto JH, Koomey JG. Technology Data Characterizing Lighting in Commercial Buildings: Application to End-Use Forecasting with COMMEND 4.0. Lawrence Berkeley National Laboratory Report No. LBL-34243, 1994.

Koomey JG, Piette MA, Cramer M, Eto JH. Efficiency Improvements in U.S.
Office Equipment: Expected Policy Impacts and Uncertainties. Lawrence Berkeley National Laboratory Report No. LBL-37383, 1995.

Sezgen O, Koomey JG. Technology Data Characterizing Refrigeration in Commercial Buildings: Application to End-Use Forecasting with COMMEND 4.0. Lawrence Berkeley National Laboratory Report No. LBL-37397, 1995.

Sezgen O, Koomey JG. Technology Data Characterizing Water Heating in Commercial Buildings: Application to EndUse Forecasting. Lawrence Berkeley National Laboratory Report No. LBL$37398,1995$.

\section{Efficiency Improvements in U.S. Office Equipment: Expected Policy Impacts and Uncertainties J.G. Koomey, M. Cramer, M.A. Piette, J.H. Eto}

Over the past 10 to 15 years, as personal computers and associated peripherals have become widespread, office equipment has become an important source of load growth for electric utilities. For both utilities and governments concerned with long-term energy planning, reliable estimates of future growth in office equipment energy consumption are essential.

In the last year, we completed a detailed end-use forecast of office equipment energy use for the U.S. commercial sector. The forecast is based on a spreadsheet model that explicitly accounts for changes in power and usage for each equipment type and disaggregates forecasting results in terms of both equipment and building type. The equipment types we considered in our analysis included mini-computers, mainframes, point-of-sale terminals, fax machines, copiers, serial printers, laser printers, monitors, and the central processing units (CPUs) of personal computers (PCs). Building categories included office, retail, school, warehouse, hotel, hospital, restaurant, grocery, and miscellaneous. The data used in our analysis came from various sources including recent surveys of office equipment ownership and usage, industry forecasts, trade press assessments, personal communications with industry participants, the Environmen- tal Protection Agency's Energy Star requirements, and DOE's Energy Information Administration's Annual Energy Outlook 1995.

We calculate unit energy consumption (UEC) for each type of equipment based on the estimated power levels and hours of usage. Equipment densities are consistent with current and future commercial-sector floor stock and industry projections of equipment sales. The UECs are then multiplied by the equipment densities and projected floor area in a given year for a given building type to get the total energy use by building type and equipment type.

The Figure shows UECs for PC CPUs and monitors and provides a clear example of the kinds of results we produce for the equipment types listed above. A computer is in active mode when it is being used; standby mode represents an intermediate state which attempts to conserve power but provides instant recovery; suspend mode has the lowest power level and requires a longer recovery time than the standby mode. The declining UEC for PC CPUs is attributable to reductions in the power drawn by microprocessors and peripheral desktop machines. These improvements have been driven by the desire of manufacturers to fit more peripherals into smaller spaces-an effort that requires heat reductions and thus efficiency improvements. In contrast to the CPUs, the baseline UEC of monitors in 2005 shows an increase relative to the 1990 stock. This increase in UEC is attributable to the widespread shift toward the use of color, as well as larger, screens.

Relative to the Energy Star UECs for both PC CPUs and monitors, the advanced scenario shows a reduction of about $75 \%$ in energy consumption. Because the advanced scenario does not consider costs, it represents an estimate of what is technically possible rather than what is practical or cost-effective.

\section{References}

Koomey JG, Piette MA, Cramer M, Eto JH. Efficiency Improvements in U.S. Office Equipment: Expected Policy Impacts and Uncertainties. Lawrence Berkeley National Laboratory Report No. LBL-37383, 1995.

Piette MA, Cramer M, Eto JH, Koomey JG. Office Technology Energy Use and Savings Potential in New York. Completed for the New York State Energy Research and Development Authority and Consolidated Edison by Lawrence Berkeley National Laboratory, Contract \#1955-EEEDBES-93. Lawrence Berkeley National Laboratory Report No. LBL36752, 1995. 


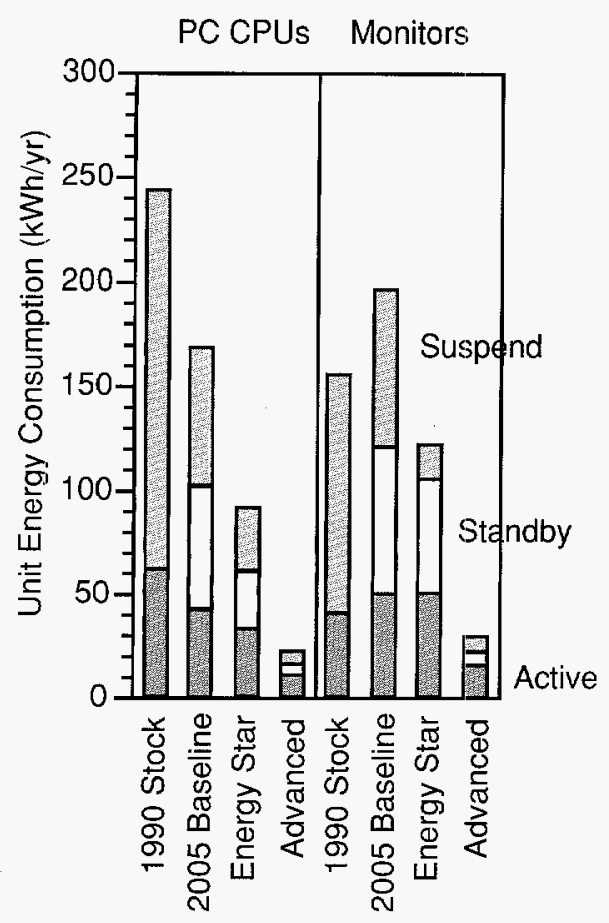

Figure. Unit energy consumption for CPUs and monitors.

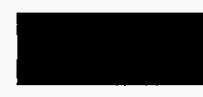

\section{Energy End-Use Data in the ROADMAP System: A Collaborative Effort \\ J.G. Koomey, A. Nicholls,* D. Eike, and B. Kinzey*}

One of the primary challenges for analysts is to make their data and results accessible to policymakers. Too often, data that have been laboriously created and compiled remain hidden inside large reports rather than being used by the people to whom they would be most useful. In order to address this problem, researchers at Pacific Northwest National Laboratories (PNNL) and LBNL have combined PNNL's expertise in programming and graphic presentation of data and LBNL's expertise in compiling energy end-use data to create a software tool called "ROADMAP." In the ROADMAP program, data are organized and compiled in a way that allows policy analysts who are not computer

*Pacific Northwest National Laboratories, Washington, D.C. Office. experts to easily extract relevant information.

Collaboration between PNNL and LBNL on the ROADMAP project has been highly successful because it builds upon each laboratory's traditional strengths. This software tool was designed for analysts at the U.S. DOE's Office of Building Technologies (OBT); OBT analysts are often called upon to answer questions from congressional staff, to defend budget requests, and to design new initiatives to meet congressional and executive mandates. Because PNNL's office in Washington, D.C., is responsible for providing day-to-day support to OBT analysts, PNNL staff members are particularly aware of the type of information that is most important to OBT and the format in which it is most useful. In contrast, LBNL has a wealth of data on residential and commercial energy use and equipment. Together, PNNL and LBNL are able to compile much valuable data and present it in a way that is useful to OBT decisionmakers.

The first data set entered into the ROADMAP system was DOE's Energy Information Administration's (EIA's) widely used Residential Energy Consumption Survey (RECS) data. During the past year, PNNL has also created a userfriendly electronic version of EIA's Commercial Building Energy Consumption Survey (CBECS) data. Using the ROADMAP system, a user can now extract data from CBECS that are not available in the published reports. For example, cross tabulations of the data can be obtained with a few mouse clicks, allowing the user to answer questions such as, "How many square feet of commercial floorstock are operated for less than 30 hours per week and have total energy-use intensities greater than 100 kBtus per square foot?" The Figure shows a sample screen from the ROADMAP software tool.

In addition, after discussion with PNNL about particular issues that are important to OBT program managers, LBNL created data sets that can be used to answer the following questions:

- What are the likely impacts of current and potential government policies on the electricity use of office equipment?

- How can one best characterize the interaction between space-conditioning energy savings and different types of lighting systems in commercial buildings?

- What are the lessons to be learned from the example of energy-efficient magnetic ballasts, a highly costeffective technology that was slow to be adopted in the market place?

In the upcoming year, our goal is to work with PNNL to identify other specific areas of interest to OBT staff members and to develop relevant data sets. In addition, we plan to make the ROADMAP data accessible via the Internet. 


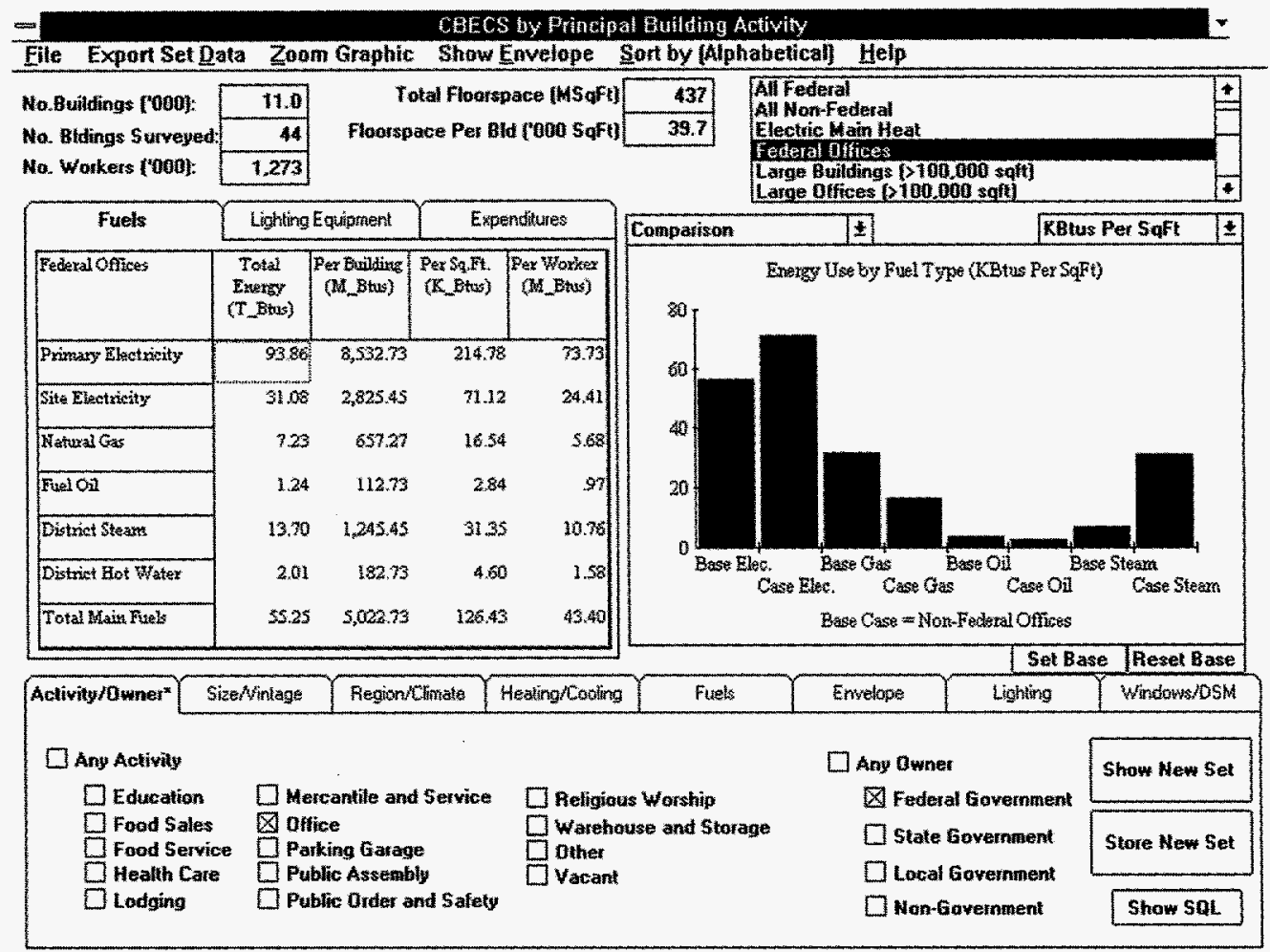

Figure. Sample screen from the ROADMAP software tool.

\title{
Magnetic Fluorescent Ballasts: Market Data, Market Imperfections, and Policy Success
}

\author{
J.G. Koomey, A.H. Sanstad, L.J. Shown
}

Many economists argue that standard techniques of engineering-economics have been inappropriately used to assess the performance of the market for energy efficiency. Taking account of such criticisms, we have developed an engineering-economic approach to identify imperfections in this market and to justify policy interventions therein. Using this approach, we examine energy-efficient magnetic ballasts, a cost-effective technology that was remarkably slow to be adopted in the marketplace. We conclude that the under-adoption of efficient magnetic ballasts is a strong indicator of economic inefficiency in the market.

To calculate the economic return delivered by efficient magnetic ballasts, we used market data on ballast cost from the U.S. Bureau of the Census. We combined these capital costs with a large sample of operating costs and electricity prices for the more than 5000 commercial buildings in DOE's Commercial Buildings Energy Consumption Survey (CBECS). We used survey data to determine ballast lifetimes in the commercial sector. To simplify the presentation of results, we sorted the entire set of CBECS buildings into three operating hour bins: "low usage" comprises the $30 \%$ of buildings with the lowest operating hours, "average usage" comprises the middle $40 \%$ of the buildings, and "high usage" comprises the $30 \%$ of the buildings with the highest operating hours.

The Figure shows the real internal rates of return (IRRs) foregone by consumers choosing inefficient over efficient F40 and F96 magnetic ballasts. Even in the worst case (low usage, F96 ballasts), these IRRs are much higher than typical returns for other consumer capital investments. In fact, even when we split the buildings into ten operating hour bins, the worst case (F96 ballasts in the lowest operating hour bin) yields a real internal rate of return of $31 \%$. Sorting the data by IRR, we found that the overwhelming majority of commercialsector floor area (99\%) is associated with IRRs of greater than $20 \%$ real.

We reviewed historical shipments and market shares of efficient ballasts and found that the growth in efficientballast market shares during the 1980s is exactly accounted for by the states that imposed standards. This striking coincidence of market shares suggests that the growth in shares over the eight-year period would not have occurred without standards, despite the high returns available to private investors from investment in the more energy-efficient 
technology. In this case, the imposition of minimum efficiency standards for ballasts resulted in net economic benefits to ballast users and to society.

This combination of superb rates of return, exact equivalence of service delivered, and market reluctance to purchase the more efficient technology provides strong evidence that market imperfections inhibited the adoption of efficient ballasts. Although we cannot identify the precise nature of these imperfections, we discuss possible explanations in terms of such factors as adverse selection, principle agency problems, and the flow and processing of information by both consumers and firms.

\section{Reference}

Koomey JG, Sanstad AH, Shown LJ. Magnetic Fluorescent Ballasts: Market Data, Market Imperfections, and Policy Success. Lawrence Berkeley National Laboratory Report No. LBL-37702, 1995. Also presented at the Annual Conference of the Western Economics Association, San Diego, CA, July 6-9, 1995.

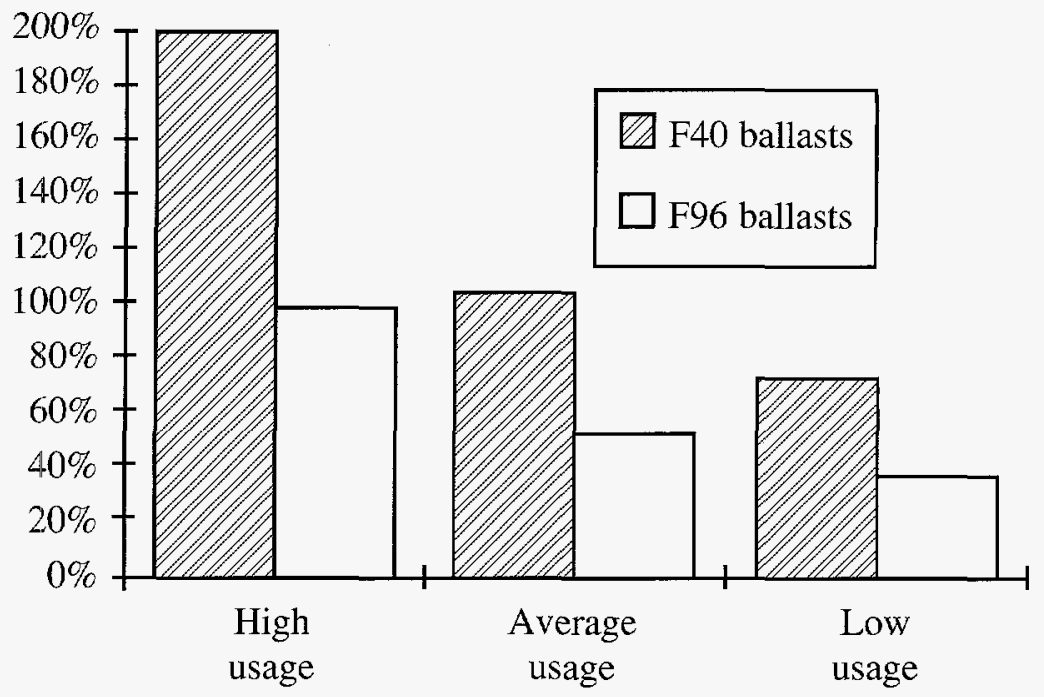

Figure. Real internal rates of return for purchasing efficient magnetic ballasts in the U.S. commercial sector (circa 1989), based on market data.

\section{Transforming Markets for Efficient Chillers and Motor Systems A. McKane, J. Harris*}

Our continuing work for the U.S. Department of Energy's Federal Energy Management Program (DOE/FEMP) is focused on using the purchasing power of the federal government to achieve market pull for energy-consuming equipment. These activities, conducted both in our Washington, D.C., office and here at the Berkeley Lab, have led to the identification of two new areas of concentration: electric chillers and motor systems. Electric chillers and motor systems warrant special attention because of their energy savings potential, customized applications, likelihood of repair rather than replacement, and the importance of system interaction.

Chillers are typically long-lived (25 years or more) and represent a significant capital investment. Chiller retrofit and replacement is at an all-time high in response to requirements of the

\footnotetext{
*Energy Analysis Program, Washington D.C. Project Office.
}

1987 Montreal Protocol to stop the production and restrict the use of ozonedepleting refrigerants (chorofluorocarbons or CFCs). This environment creates an opportunity for all building owners, including the federal government, to achieve substantial energy savings that will accrue for many years.

The U.S. federal government spends over $\$ 4$ billion in energy costs annually for its own facility operations. Included in these costs is the operation of approximately 4000 chillers, nearly half of which operate at efficiencies no better than $0.8 \mathrm{~kW} /$ ton, and may be as poor as $1.1 \mathrm{~kW} /$ ton. Replacement chillers are commonly available with efficiencies in the 0.5 to $0.6 \mathrm{~kW} /$ ton range. The energy savings from replacing watercooled chillers larger than 100 tons in federal facilities is estimated to be $\$ 75$ million annually, or $\$ 1.4$ billion present value over their 25-year life.

Since capital dollars for chiller replacements are extremely limited, DOE has been exploring ways to contain costs for its own facilities as well as other federal agencies while still moving forward in meeting the requirements for CFC phaseout. One method of cost containment is a Basic Ordering Agreement organized through the General Services Administration (GSA) that would allow individual federal purchasers to take advantage of quantity pricing and streamlined specification. processes, for a projected cost savings of over $\$ 75$ million. DOE Defense Programs have taken the lead in working with GSA and chiller manufacturers to arrange such an agreement.

As part of our work for DOE / FEMP, we are coordinating with Defense Programs and GSA to ensure that chillers purchased through the Basic Ordering Agreement meet or exceed the intent of Executive Order 12902 and the 1992 Energy Policy Act. These mandates 
direct federal agencies to purchase "best-practice" energy-efficient products-those in the upper $25 \%$ of the market based on energy efficiency. By focusing federal purchasing on highlyefficient chillers, this coordination effort assures federal facilities maximum energy savings while still providing an adequate selection of equipment.

Our work with the DOE Office of Industrial Technology's Motor Challenge Program concentrates on the efficiency of motor systems used for industrial applications. Motor systems consume about $70 \%$ of the electrical energy used in the U.S. industrial sector. Emphasis on motor efficiency in recent years has led to passage of efficiency standards, to become effective in 1997, for most common types of motors. This is extremely important, since the cost of energy consumed by a motor during its useful life typically far exceeds its acquisition cost. However, there are also significant system-level opportunities for energy savings that are frequently overlooked.

The Office of Industrial Technologies estimates that improvements in motor efficiency represent approximately $18 \%$ of total potential energy savings for motor systems, with the remaining savings opportunities in the motormechanical subsystem (41\%), process optimization (33\%), and electrical distribution correction $(8 \%)$.

Through a series of conferences and round tables with industrial customers, distributors, and manufacturers, Motor Challenge has identified substantial gaps in the type, quality, and knowledge of system performance information available to industrial customers. Motor Challenge has identified a major market transformation tool in the development of sophisticated, demanding buyers of highly efficient motor systems.

Our work with Motor Challenge is designed to address information gaps and assist buyers through the development of educational, training, and evaluation materials. This will involve extensive contacts with industry and industry trade associations to ensure that the materials developed are properly targeted for the industrial end user. We will also be providing the lead in coordinating Motor Challenge initiatives with those of utility companies and energy firms active in the Consortium for Energy Efficiency. The Consortium is a utility-sponsored non-profit organization, co-funded by DOE and the U.S. Environmental Protection Agency, that develops innovative "market-pull" programs.

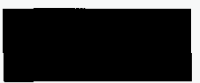

\section{Buying Efficient Products:
J. Harris, ${ }^{*}$ A. McKane, ${ }^{*}$ F. Johnson*}

For most energy-related products, the U.S. government is the biggest customer in the world. Federal agencies spend over $\$ 10$ billion per year on energy-related products, in operating existing facilities, new construction, and as part of renovations or energy retrofit projects. By focusing its buying power on the most efficient products available, the federal government can lead or reinforce market demand for energy efficiency. Purchasing by states and local governments, collectively, can multiply the federal government's market impact by a factor of three to five. Coordination with utility demand-side management programs will reinforce this marketpull strategy for efficient products.

At a time of limited budgets for energy efficiency within the government and utility sectors, the coordinated use of purchasing power requires little or no added spending-relying mainly on expenditures that will occur anyway. Unlike capital-intensive retrofit projects, many energy-efficient products and individual equipment purchases have paybacks of a year or two.

Changes in both policy and day-

\footnotetext{
*Energy Analysis Program, Washington D.C. Project Office.
}

to-day practices are needed to redirect government purchasing toward today's best energy-efficient practice and to establish the federal market as an entry point for even more advanced technologies. Federal purchasing of energy-efficient products was authorized under the 1992 Energy Policy Act, subsequent Policy Letters from the Office of Management and Budget, and a series of Executive Orders on federal energy management and environmentally preferred products. An Executive Order signed in March 1994 directs federal agencies to purchase "best-practice" energy-efficient products (i.e., those in the upper $25 \%$ of the market, or at least $10 \%$ more efficient than federal standards).

To implement the Executive Order, DOE has co-sponsored an "Energy Efficiency and Resource Conservation Challenge" (see Figure). This program encourages federal agencies to change their buying patterns across the board, including direct purchases from commercial sources, products acquired from the supply agencies-the Defense Logistics Agency (DLA) and the General Services Administration (GSA), and indirect purchases as part of construction or service contracts. In September
1995, 22 federal agencies, representing about $95 \%$ of federal purchasing, signed the interagency "Procurement Challenge."

The participating agencies are committed to help lead the way toward energy-efficient purchasing, through "best-practice" buying or by purchasing advanced technologies just beginning to appear on the market. As they implement the Challenge, agencies will contribute to a government-wide goal of saving nearly $\$ 1$ billion in annual energy costs.

In its Washington D.C. office, LBNL provides technical and project management support to DOE's Federal Energy Management Program for a government-wide initiative to capture this largely untapped opportunity for market transformation. We help identify opportunities, design procurement initiatives, develop technical recommendations for Federal purchase of "bestpractice" products, coordinate with other programs, and monitor implementation.

Through our technical support role, we assist GSA and DLA in developing a coding system that clearly identifies which of the products available through the federal supply system meet 
the DOE efficiency recommendations. The aim is to make it easy for procurement officials and individual buyers to locate such products through catalogs, GSA schedules, and the new on-line "electronic commerce" systems. DOE, in its own operations, is directing all facility managers and contractors to set an example by specifying and purchasing energy-efficient and water-conserving products. The Department and its national laboratories account for more than one-tenth of all (non-military) government facilities and over one-fourth of energy use.

LBNL also assists DOE in a related effort to identify new, energy-saving products and technologies for which federal purchases offer a potential entry market. This work draws on our related analyses for the federal appliance and equipment standards, as well as on our technical expertise in lighting, building components (windows, duct systems, high-albedo roof coatings), and equipment and controls.

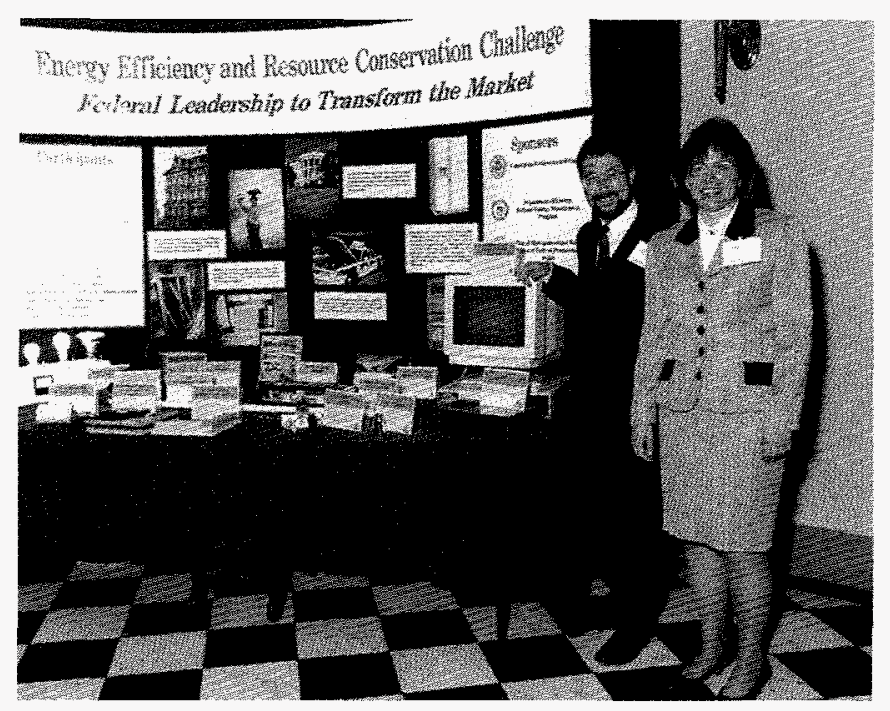

Figure. At a recent White House ceremony to sign the DOE-sponsored Procurement Challenge, staff from the EAP Washington Office demonstrate a few of the energy-efficient products now being purchased and installed in federal facilities.

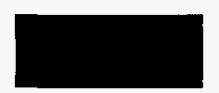

\section{Uncertainty and Implicit Discount Rates in Energy-Efficiency Investments} A.H. Sanstad

Numerous empirical studies have shown that many consumers reveal implicit discount rates for energy-efficiency investments that substantially exceed market interest rates for borrowing or saving. This pattern has been cited as key evidence of an energy-efficiency "gap" and has been used to justify policies promoting energy efficiency. Conversely, some energy economists have sought to explain these high implicit discount rates in terms of rational behavior and well-functioning markets, thereby obviating such policies.

One such explanation draws on recent developments in the theory of finance pertaining to investment under uncertainty. According to this line of research, high implicit discount rates for energy efficiency merely reflect rational "hurdle rates" applied by consumers. These hurdle rates exceed market interest rates because of consumers' uncertainty regarding future returns from investments in energy efficiency and because such investments are "irreversible," that is, cannot be easily or costlessly undone once they are undertaken. Consequently, there is a quantifiable "option value" associated with delaying investment, resulting in high implicit discount rates.

We argue, however, that this explanation falls well short of explaining high implicit discount rates in energy-efficiency investments. These rates have been measured at upwards of $25 \%$ for a range of consumer energy end uses. Applications to date of the "option value" model, however, predict hurdle rates in the range of only $7 \%$. Extending this model to account for much higher hurdle rates shows that, even when the "option value" is accounted for, consumers must be applying very high rates of time discounting to reveal implicit discount rates in the range reported in the literature. The technical reason is that, in the model, the option value is a function not only of uncertainty and irreversibility but also of the consumer's discount rate.

A further issue in the option value model is its assumption that delaying purchase is costless. Industry data show, to the contrary, that a majority of consumers purchase energy-using appliances under circumstances in which delay does have a cost, such as foregoing the service provided by the unit. We incorporate costly delay into the basic option value model and show that with this enhancement the predicted hurdle rate is indeed lowered. The next step in this research will be to numerically extend the basic model with estimates of the cost of delay in purchase.

\section{References}

Sanstad AH, Blumstein C, Stoft SE. How high are option values in energy-efficiency investments? Energy Policy 1995; 23(9):739-743.

Sanstad AH. Investments in energy-efficiency under uncertainty and irreversibility with costly delay. Presented at the Annual Conference of the Western Economics Association, San Diego, CA, July 6-9, 1995. 


\section{The Organization of Bulk Power Markets}

\author{
E.P. Kahn, S. Stoft
}

Introduction

There is a significant demand for increased electricity trade in the U.S. today. It comes from electricity marketers, who hope to profit from trade opportunities, and large industrial consumers, who seek lower rates through direct access. The federal response to this demand began with the Energy Policy Act of 1992 and continues with Federal Energy Regulatory Commission (FERC) actions, most recently the March 1995 Mega-NOPR.* There are also state initiatives for retail access, such as the California Public Utilities Commission (PUC) proposal of April, 1994. This activity all calls into question the current functioning of the bulk electricity market. Responding to the demand for increased trade implies major restructuring of the electricity industry. We address issues associated with changes in the structure of the bulk power market.

\section{International Experience with Restructuring}

The restructuring process in electricity encompasses three general elements. First, vertically integrated firms are reorganized to separate generation. from the transmission and distribution assets. We call this functional restructuring. It includes both divestiture of generation and a re-orientation of the transmission function to facilitate increased. competition. Because the organization of the competitive process can be so varied, we refer to generation competition as a separate stage. Finally, there has frequently been a privatization element associated with electricity restructuring. In most countries outside of the U.S., electricity industry reform originates from a situation of public ownership.

Table 1 summarizes the restructuring process in a number of countries. It shows both the varying extent of imple-

*FERC's Promoting Wholesale Competition Through Open Access Non-discriminatory Transmission Services by Public Utilities, Recovery of Stranded Costs by Public Utitities and Transmitting Utitities. Proposed Rulemaking and Supplemental Notice of Proposed Rulemaking, Docket Nos. RM95-08-000 and RM9407-001. mentation and the substantially different starting point of the U.S. Because of private ownership in the U.S., functional restructuring is linked to stranded cost recovery. Once the possibility of expanded competition arises, private investors need assurance of cost recovery for assets that would become economically obsolete, if they are going to cooperate with such a transition. The cases of Spain and Alberta (Canada), where private ownership has a long history, involve recent functional restructuring but limited competition to date.

Constraints may limit electricity restructuring. Where technology involves environmental or economic externalities, such as hydro or nuclear generation, there is likely to be public ownership, because private markets cannot easily internalize all of the associated externalities. These cases may pose potential barriers to privatization. Other important constraints include the nature of local fuel markets and the strength of the transmission network. Competitive electric markets are facilitated by competitive fuel markets. Where coal mines are vertically integrated with generation plants, the competitive situation may be complicated. In many countries, natural gas plays an important role facilitating competition by lowering the barriers to entry. Gas- fired combined-cycle plants are relatively simple to build and operate, have low capital costs and very high thermal efficiency. Where a well-developed natural gas infrastructure exists, competition will be more robust. The transmission network is the vehicle through which electricity competition occurs. The stronger this network is, the smaller the limitations of network congestion. When the network is congested, markets are geographically separated, limiting competition.

International restructuring experience will offer few large lessons for the U.S., because none of these situations involves both the pervasive private ownership and the highly fractionated nature of the U.S. electricity industry. In Chile, Argentina, and the U.K., a centralized pool operates the wholesale market, with all trade going through the pool. These pooling institutions were formed from pre-existing national utilities. A bilateral trading regime dominates the Norwegian market, but it depends upon an uncongested transmission network, and is facilitated by a pre-existing framework of pooling and marketing institutions. Australian interstate trading experiments promise greater market decentralization than the pool cases, made simpler by the presence of few market centers.
Table 1. How you proceed depends upon where you start.

$\begin{array}{llll}\begin{array}{l}\text { Country } \\ \text { UK, Chile, } \\ \text { Argentina, } \\ \text { Victoria (Aust.) }\end{array} & \begin{array}{c}\text { Functional } \\ \text { Restructuring }\end{array} & \begin{array}{c}\text { Generation } \\ \text { Competition }\end{array} & \text { Privitization } \\ \text { Norway } & & \\ \text { N\&W (Australia), } \\ \text { New Zealand }\end{array}$


The importance of private ownership is that it makes functional restructuring more complex than where government enterprises are involved exclusively. Where restructuring involves writing down the value of uneconomic assets, governments can accomplish this more easily than if private investors must be compensated. The large number of relatively small utilities in the U.S. power network means that the formation of pools would also involve complicated financial compensation procedures.

Ensuring "Open Access" Will Likely Require an Independent System Operator

Achieving open access in electricity markets is the objective of the FERC's Mega-NOPR. But fully competitive market models, both in the bilateral and the spot-market form, rely on an Independent System Operator (ISO) to accomplish this effect. FERC attempts to achieve it without the benefit of an ISO. Open access must solve the problem of excess demand for transmission to preserve reliability, and the FERC's Mega-NOPR allows this only through a predetermined tariff and non-price rationing. Because of the complexities of transmission, non-price rationing cannot be accomplished in a non-discriminatory fashion by an interested party. This leaves the predetermined tariff as the only tool for preventing excess demand. But for this to be almost perfectly effective, as is required by reliability, the tariff rnust be so high as to prevent even moderately efficient use of the grid.

\section{Summary of the Bilateral vs. Spot Market Debate}

A few broad principles have emerged from recent debates and experience both in the U.S. and other markets. These include:

- a general agreement that price transparency is desirable,

- a broad (but not universal) consensus that an ISO is necessary to facilitate increased trade,

- an increased skepticism about vertical economies, and

- a consensus that market distortions should be minimized.
The two competing market models, spot market pools vs. bilateral trade, would implement these principles differently, as summarized in Table 2.

The ISO function involves a much broader range of actions in the Pool model than in the Bilateral model. The reason is that the Pool ISO is dispatching the power system based on sellers' prices, whereas the Bilateral ISO is an information broker who facilitates the trading decisions of others. The different conceptions of the ISO are reflected in all of the other market model attributes in Table 2.

Price transparency facilitates competition by making the value of power clear to participants, but the notion means different things in the two models, because price formation differs in each. When the Grid Merchant is the central clearinghouse, the resulting prices at any network node are the short-run marginal cost (SRMC) at that node. Where no congestion exists, there is effectively a single market clearing price for any given period of time. In the Pool model, price variance results from the time differentiation of SRMC, not from any variance at a given time. The Bilateral trade model is more compatible with price indices averaged over inherently longer time horizons than the Pool model. These indices are averages of many Bilateral contract prices. The potential biases in price reporting will also differ in each model. In the Pool model, there is some arbitrariness in SRMC determination. In the Bilateral model, sampling error may distort price indices.

The question of vertical economies is quite unsettled. Both competitive models inherently question the role of vertical economies. In neither case, however, is it clear that divestiture of generation will be required for unbiased functioning of bulk power trade. There appears to be less emphasis on vertical economies in the Pool model, if only because of the international precedents,

Table 2. Market model summary.

\begin{tabular}{lll} 
& Pool & Bilateral \\
ISO Function & Grid Merchant & Information Broker \\
Price Transparency & Short-run & Index \\
& Marginal Cost & \\
Vertical Economies & Less Important & More Important \\
Contract Performance & Financial & Physical \\
\hline
\end{tabular}

where electricity restructuring along pool lines has been accompanied by vertical separation. The Bilateral model also seems more consistent with a vertical structure, because it is closer to current U.S. industry structure and practice. The increasing occurrence of utility mergers may end up raising market power questions in either of these models. The traditional arguments for vertical economies in a monopoly structure may turn out to look like access barriers in a competitive model.

Finally, contract performance standards differ in the two models. Given that the Pool ISO is a Grid Merchant through whom all physical transactions clear, the only role for contracts is financial. Indeed, a physical performance standard, where seller must physically deliver to buyer, is incompatible with the Grid Merchant concept. In the Bilateral model, on the other hand, physical performance is the essence of commercial relations. It embodies the mutual commitment of the parties to trade. Physical performance as the cornerstone of a Bilateral trade market may impose some complexity on the ISO, but proponents argue that this is feasible.

\section{Future Research}

Many questions are raised by the prospects for a more competitive bulk power market. We list a few of them:

- Which model is most compatible with the FERC Mega NOPR?

- Which model has the largest transactions costs?

- How will reliability be affected by increased competition?

- Which model has the greater potential for abuse of market power?

- Is vertical separation necessary?

\section{Reference}

Kahn E, Stoft S. Organization of Bulk Power Markets: A Concept Paper. Lawrence Berkeley National Laboratory Report No. LBL-37508, 1995.
Contract Performance

Financial

Physical 


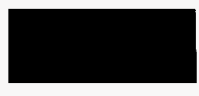

\section{Performance-Based Ratemaking for Electric Utilities}

\author{
G.A. Comnes, S. Stoft, N. Greene, L. Hill ${ }^{*}$
}

Performance-based ratemaking (PBR) is regulation that strengthens the financial incentives of electric utilities to lower rates or costs or improve nonprice performance relative to traditional regulation (cost-of-service, rate-of-return [COS/ROR] regulation). PBR typically reduces the frequency of rate cases by employing external measures of cost to set rates or revenues. For several reasons, plans for PBR are being developed for many for electric utilities in the U.S. U.S. electric utilities are undergoing a restructuring where generation services, once thought to be a monopoly, are being deregulated. Further, electric utilities are providing new services such as information services and demand-side management. These trends place stress

* Oak Ridge National Laboratory, Oak Ridge, TN. on the process of setting rates for a utility's remaining competitive services. PBR is seen as a way to provide utilities with a greater incentive to take productivity-improving actions, to price flexibility to meet competition, and to reduce regulatory costs.

In this project, we have collected and reviewed 11 electric utility plans for PBR. Six of these plans have been adopted and the others are being proposed. The most common types of plans in the sample are price caps and revenue caps. Price caps set maximum prices for monopoly utility services for long periods of time without regard to the utility's own costs. Price caps are often indexed over time using the formula commonly known as the "consumer price index (CPI) minus $X^{\prime \prime}$ formula.
This formula sets prices each year as a function of the previous year's prices, inflation, and a productivity offset (X).

Revenue caps require utilities to keep their nonfuel revenues below a pre-specified cap. The cap is adjusted over time for inflation and productivity (like a price cap) and is also usually adjusted for changes in the number of utility customers. Four plans in our sample are revenue caps.

Among other things, we examined the degree to which utility PBR plans enable utilities to stay out of rate cases. This is one of the simplest and most powerful ways that PBR can encourage utilities to improve performance because it allows them to keep a portion of the cost savings of any productivityimproving actions. In our sample of util-

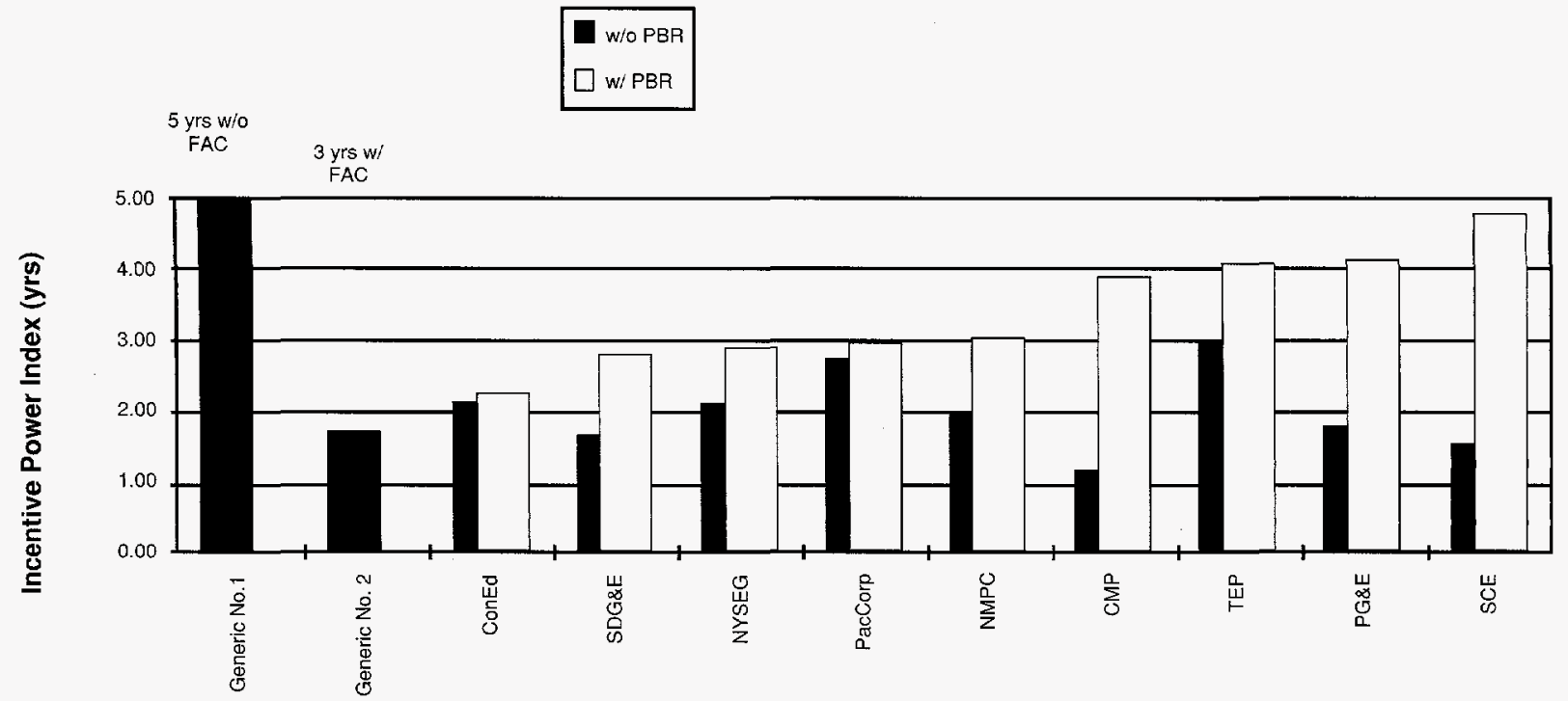

Key to Figure:

Generic 1

Generic 2

ConEd

SDG\&E

NYSEG

PacCorp

NMPC

CMP

TEP

PG\&E

SCE

\author{
Five-year rate case cycle on all rates \\ Consolidated Edison Co. of New York \\ San Diego Gas \& Electric Co. \\ New York State Electric and Gas \\ Pacificorp (California retail operations) \\ Niagara Mohawk Power Co. \\ Central Maine Power \\ Tucson Electric Power Co. \\ Pacific Gas \& Electric Co. \\ Southern California Edison
}

Three-year rate case cycle on nonfuel costs, automatic pass-through of fuel costs

Figure. Index of Incentive Power. 
ities, the median time between rate cases increased from three to five years. It appears that longer PBR terms are infeasible due to the inability of the state regulatory commission and the utility to credibly commit for longer periods of time.

We also assessed the overall effects of PBRs as compared with business-asusual regulation. Our assessment, which we call the Incentive Power Index (see Figure), is based on the overall degree to which the utility's profits are at risk. We compare each utility to itself without PBR and to two "generic" utili- ties: one with 1) no fuel adjustment clause (FAC) and rate cases every five years; and 2) base rate cases every three years and a full FAC. Overall, we find that most PBRs in our sample represent an improvement in profitability over the utility's status quo and represent an improvement compared to generic utility No. 2. Few utilities come close to generic utility No. 1, however. The highest scoring plan that has been implemented is CMP's (higher scoring plans, TEP, PG\&E, and SCE, are still in the proposed stage). On a relative basis, the plans at CMP, PG\&E, and SCE show the highest increase in likely profitability relative to the status quo. Two plans show little increase in expected profitability in comparison to the "withoutPBR" case: ConEd and PacifiCorp.

\section{Reference}

Comnes GA, Stoft S, Greene N, Hill L. Performance-Based Ratemaking for Electric Utilities: Review of Plans and Analysis of Economic and Resource Planning Issues. Lawrence Berkeley National Laboratory Report No. LBL-37577, 1995.

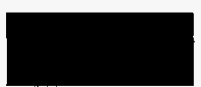

\section{PSE\&G's Standard} C.A. Goldman

U.S. utilities continue to experiment with innovative approaches to acquiring demand-side resources. In May 1993, Public Service Electric and Gas (PSE\&G), the largest investorowned utility in New Jersey, initiated the Standard Offer program. In this program, PSE\&G offers long-term contracts with standard terms and conditions to project sponsors, either customers or third-party energy service companies (ESCOs), on a first-come, first-serve basis. The design includes posted, time-differentiated prices which are paid for energy savings that will be verified over the contract term $(5,10$, or 15 years) based on a statewide measurement and verification $(\mathrm{M} \& \mathrm{~V})$ protocol.

\section{Policy Perspective}

From a policy perspective, the program is interesting for several reasons: 1) the program scope is quite broad and the potential size (150 MW) is significantly larger than any current utility program that relies primarily on ESCOs to market and deliver energy services, 2) participation by PSE\&G's subsidiary, Public Service Conservation Resources Corporation (PSCRC), raises important competition policy issues in emerging energy services markets, and 3) the Standard Offer concept is being considered as an option to preserve the energy-efficiency services industry during; electric industry restructuring and reform.

\section{Objectives}

We were retained to perform an independent evaluation of the Standard Offer program. The major objectives of our evaluation were to assess market response and customer satisfaction, analyze program costs and costeffectiveness, review and evaluate the utility's administration and delivery of the program, examine the role of PSE\&G's energy services subsidiary (PSCRC) in the program, and discuss the potential applicability of the Standard Offer concept given increasing competition and the prospect of industry restructuring.

\section{Market Response}

After 18 months (through December 1994), PSE\&G received commitments from 35 project sponsors (16 ESCOs and 19 customer sponsors) for a total of about $40 \mathrm{MW}$ from more than 1,050 facilities. About $9 \mathrm{MW}$ were operational. The market response is significantly less than the original program target of $150 \mathrm{MW}$.

Various types of lighting measures $(66 \%)$ and electric-to-gas conversions of space and water heating equipment and industrial processes (17\%) are the most popular measures. Nonlighting measures represent $75 \%$ of the savings from customer-sponsored projects, while lighting measures represent
$75 \%$ of the savings from projects sponsored by ESCOs.

Many ESCOs note that the program has been a "harder sell" than anticipated to customers. Factors that adversely affected participation included poor or uncertain economic conditions in New Jersey, customer perceptions that the program is too complex and risky, and stringent contract provisions.

\section{Program Costs and Cost-Effectiveness}

Total resource costs for the Standard Offer program, levelized over the contract term of each facility, average $6.8 \% / \mathrm{kWh}$ overall, which is about $74 \%$ of the utility's then avoided supply costs (see Table). Total resource costs vary somewhat by market segment, averaging $6.6 \% / \mathrm{kWh}$ for projects in the large commercial/industrial (C/I) market and about $8 \notin / \mathrm{kWh}$ for projects in the small $\mathrm{C} / \mathrm{I}$ market.

Costs incurred by the utility average about $6.14 / \mathrm{kWh}$ for the program

Table. Summary of program costs.

\begin{tabular}{cc}
\hline & $\begin{array}{c}\text { Number of } \\
\text { Facilities }\end{array}$ \\
\hline Overall program & 1041 \\
Type of Project Sponsor & \\
ESCOs-Large C/I & 239 \\
ESCO-Small C/I & 868 \\
Customer Sponsors & 34 \\
\hline
\end{tabular}


overall. Payments from host customers account for less than $10 \%$ of the total resource costs in large $\mathrm{C} / \mathrm{I}$ facilities and average about $26 \%$ for small C/I customers.

The Standard Offer program has a benefit/cost $(B / C)$ ratio of about 1.6 from a societal cost perspective.

\section{Role of Utility's ESCO}

The New Jersey Board of Public Utilities' (BPU's) DSM policies were intended to expand the energy-efficiency market by providing financial incentives to utilities. In approving the formation of PSE\&G'S energy services subsidiary, PSCRC, and allowing it to operate in PSE\&G's service territory, the BPU was well aware of possible conflicts of interest and the potential for abuses.

In a relatively short time (i.e., less than three years), PSCRC has become a significant player in the local energy services market and it appears to have been successful in its role of providing capital investment services to other ESCOs and customers. PSCRC-sponsored projects account for about $43 \%$ of the program's committed savings.

PSCRC's financial support and backing has provided an important stimulus to the energy services infrastructure in New Jersey as a number of new ESCOs and other types of service providers have entered the market. However, PSCRC's efforts to facilitate projects sponsored by other ESCOs have been less successful.

On balance, the existence of PSCRC has done more to increase the viability of a local energy services industry that promotes performance contracting/financing services than to impede it. Significant regulatory oversight and monitoring role will be required to ensure the development of a robust and competitive energy services industry and to ensure that ratepayer investments in DSM contin- ue to be prudently managed by PSE\&G.

\section{Transferability of Standard Offer Program Concept}

In discussing the transferability of the Standard Offer to other utilities, it is important to distinguish between the underlying concept and the PSE\&G program because the pilot has been shaped by policy and design choices made by PSE\&G, New Jersey's regulators, and interested parties. The most important of these were the broad market scope of the program (e.g., new and existing $\mathrm{C} / \mathrm{I}$ buildings and residences), the decision to allow an ESCO affiliated with the host utility to participate directly, and the approach to savings verification.

The initial results in New Jersey suggest that the Standard Offer concept appears to work best in C/I markets in either retrofit or planned replacement situations. Direct participation by an ESCO that is affiliated with the host utility also created additional program implementation and monitoring challenges for PSE\&G and the New Jersey BPU. Incentive mechanisms that place the utility on both sides of the transaction (i.e., buyer and seller) necessitate additional regulatory scrutiny to minimize problems that inevitably arise from perceived or actual conflicts of interest. If other states adopt the Standard Offer concept, regulators should seriously consider alternative approaches that offer opportunities for financial incentives to utility shareholders (e.g., sharing of net resource benefits produced by a program) or institutional arrangements that minimize potential conflicts of interest (e.g., having an independent agency administer the program if the host utility's energy services affiliate participates directly).

\section{Role of Standard Offer in More Competitive Environment}

Many analysts have argued that the reality (or even the threat) of electric utility industry restructuring presents a fundamental challenge to the continuation of large-scale, ratepayerfunded utility DSM programs. One option for the continuation of energyefficiency services is the Standard Offer concept. An attractive aspect of this concept is that it could be managed by a statewide agency or consortium empowered to acquire various types of energy-efficiency resources in pursuit of societal objectives. The statewide consortium could define standard terms and conditions for entities that wish to provide verified energy savings; costs of administering and delivering the program, including incentive payments to project sponsors, could come from a variety of sources, including, for example, a broad-based fee or system benefits charge. The Standard Offer concept is attractive to ESCOs because it provides a natural fit with the way they market and develop projects. The concept is also compatible with notions of "customer choice" because it maximizes customers' choice of service providers and theoretically places fewer constraints on their choice of acceptable end-use efficient technologies. For those state public utility commissions and utilities looking to preserve and/or stimulate the energyefficiency services industry during a period of restructuring and regulatory reform, the Standard Offer concept merits consideration in certain market segments.

\section{Reference}

Goldman CA, Kito SM, Moezzi, M. Evaluation of Public Service Electric \& Gas Company's Standard Offer Program. Lawrence Berkeley Laboratory National Laboratory Report No. LBL-37157, 1995. 


\title{
Money Well-Spent: The Cost and Measured Performance of the Largest Commercial Sector Utility DSM Programs
}

\author{
J. Eto, S. Kito, L. Shown, R. Sonnenblick
}

Utility demand-side management (DSM) activities are at a crossroads. After five years of unprecedented growth, during which aggregate DSM spending increased nearly four-fold to almost $\$ 3$ billion in 1994, utilities and public utility commissions are now reexamining their roles and obligations in improving customer energy efficiency. Issues that need to be carefully considered include the magnitude and value of uncaptured energy-efficiency opportunities, the extent of utilities' obligations to serve, and the maturity of the energy services infrastructure. We feel strongly that evidence on the actual performance of utility DSM program should be an integral part of the discussion. Ideally, this evidence will help us answer the questions: What have utilitysponsored energy-efficiency DSM programs cost? Have they been cost-effective? What explains variation in program costs?

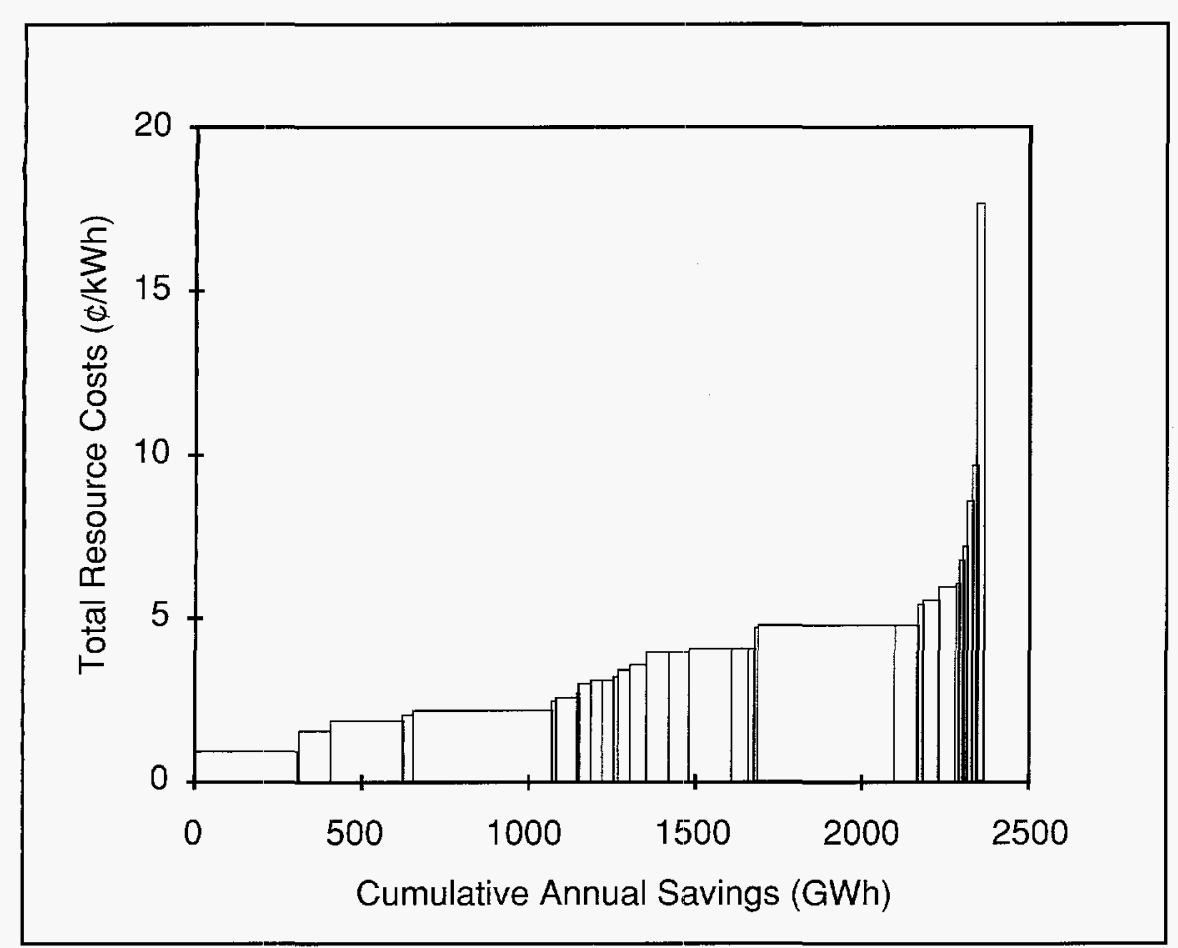

Figure. The total cost and measured performance of the largest commercial sector DSM programs. Individual DSM programs are ordered from the least expensive to the most expensive. The width of the columns corresponds to the size of the programs as measured by annual GWh saved.

In 1995, we completed a study examining the actual performance of the largest commercial sector energy-efficiency DSM programs. Our goal was to develop consistent and comprehensive information on the total societal cost of energy savings delivered through these programs. We focused on the commercial sector because the energy-efficiency opportunities available there are thought to be large and highly costeffective. We focused on programs run in 1992 because post-program evaluations of the 1992 programs were the most recent ones consistently available when we began our study in late 1994.

The $\$ 377$ million that sponsoring utilities spent on the 40 programs we examined represents nearly a third of total 1992 industry spending on DSM energy-efficiency programs. The programs accounted for more than half of the sponsoring utilities' 1992 DSM energy-efficiency budgets. annul GWh saved.
The majority of programs (30) offered rebates, but there are also a number of direct installation programs (10). Several programs featured loan or financing options although rebates constituted the bulk of the programs' activities. While the majority of programs (26) offered a variety of efficiency measures, energy savings from lighting measures $(70 \%)$ represented the largest contributor to overall savings.

The total societal cost of energyefficiency DSM programs includes customer-paid measure costs, utility-paid measure costs, and utility administrative costs. Administrative costs include directly assignable costs, overhead, measurement and verification (generally incurred in years subsequent to the program year evaluated), and shareholder incentives. The measured performance of energy-efficiency DSM programs requires annual savings estimates developed through post-program evaluations of program performance and estimates of the economic lifetime of measures.

The savings-weighted mean cost for our 40 programs is $3.2 \phi / \mathrm{kWh}$. Utility administrative costs account for $25 \%(0.8 \% / \mathrm{kWh})$. Measure costs, split between utility and participants, account for $44 \%(1.4 \% / \mathrm{kWh})$ and $31 \%$ $(1.0 \% / \mathrm{kWh})$, respectively. The Figure shows that the weighted average is dominated by large and inexpensive programs and that the most expensive programs are comparatively small.

The savings-weighted total resource cost (TRC) benefit-cost ratio of avoided costs to program costs is 3.2 , indicating that, on the whole, the programs are highly cost-effective. This high TRC benefit-cost ratio suggests that on an aggregate basis, the programs would remain cost-effective even under today's lower avoided costs. However, 11 of the programs have TRC ratios of less than 1.0, indicating they are not cost-effective. These 11 non-cost-effective programs account for $12 \%$ of the total cost of the programs.

What makes some programs cost less than others? Looking at the least expensive, several features stand out. 
First, the programs were very large, measured either by total savings or by number of participants. Second, all were rebate, as opposed to direct installation, programs. Third, they include some of the older, possibly more mature programs in the sample. Fourth, because the programs tended to report incremental measure costs, they appear to have targeted equipment replacements, rather than retrofits.

The most expensive programs also have some common features: They are small as measured by total savings and appear to be somewhat newer compared to the entire sample. Both factors suggest that these programs are not fully mature, that fixed costs are being spread over a smaller base of savings, and that one might expect improved performance in future years. Finally, they include more direct installation programs, for which full measure costs would be reported.

For a final look at the data, we used multiple regression techniques to conduct a series of exploratory analyses of the costs for the programs. The regressions lent additional support for our earlier findings that: 1) direct installation programs have been more expensive than rebate programs; and that 2) larger programs (in absolute size and savings per participant) have been less expensive. However, our regression results were by no means definitive. Taken together, the two explanatory variables account for less than $30 \%$ of the observed variance in the results. Our work indicates that, when all the costs and savings are accounted for, electric utilities have run large and overall very cost-effective DSM programs. Hence, while utility interest in running DSM programs may be at a turning point, the ability of utilities to run good programs can no longer be questioned. This fact underlies the importance of future energy-efficiency policies that seek to maintain, transfer, or otherwise preserve these benefits in tomorrow's restructured utility industry.

\section{Reference}

Eto J, Kito S, Shown L, Sonnenblick R. Where Did the Money Go? The Cost and Performance of the Largest Commercial Sector DSM Programs. Lawrence Berkeley National Laboratory Report No. LBL-38201, 1995.

\title{
The Past, Present, and Future of Utility DSM Programs
}

\author{
J. Eto , E. Hirst, ${ }^{*}$ C. Goldman, S. Wiel
}

During the past several years, more and more electric utilities have been running demand-side management (DSM) programs. These programs improve the efficiency with which customers use electricity and affect the timing of that use (e.g., to shift it away from high-cost times). Today, the electricity industry is in the midst of a major restructuring. No one yet knows what the final form and regulation of the electricity industry will look like. Currently, utilities are increasingly using DSM to retain customers, to increase market share, and to improve customer service as ways to enhance profitability. In the future, regulated, local distribution companies are likely to continue to deliver energy-efficiency services to customers, as will a host of unregulated energy service companies (some of them utility affiliates), equipment vendors, and power marketers. These changes in DSM program orientation and delivery suggest that DSM in the future will be very different from the past. What, in particular, are the implications of these changes for the historic justifications used by regulators to encourage utilities to run these programs in the past?

Government officials, policy analysts, consumer groups, environmental organizations, and others offered many reasons in the late $1970 \mathrm{~s}$ and early $1980 \mathrm{~s}$ to justify requirements that electric utilities help their customers become more energy-efficient:

- Defer construction of new, large, expensive, and polluting power plants.

- Reduce the adverse environmental effects of electricity production and transmission.

- Compensate for distortions in electricity prices. Retail prices, which were based on embedded costs, were typically below avoided supply costs. Thus, the price signal being sent to consumers told them to over-consume.

- Reduce dependence on foreign oil to generate electricity.

*Oak Ridge National Laboratory, Oak Ridge, TN.
- Compensate for the absence of government programs and standards intended to improve efficiency of electricity use.

- Overcome market barriers that prevented customers from adopting cost-effective energy-efficiency practices and measures.

- Recognize that electric utilities were in a unique position and have a least-cost planning obligation to help their customers improve efficiency of energy use.

In 1995, we conducted a study that examines the continuing relevance of these justifications in light recent changes.

Today's avoided costs are much lower than those of 15 years ago because natural gas prices are low, many utilities have excess capacity, and wholesale power markets are becoming actively competitive. All else equal, lower avoided costs reduce the amount of DSM that remains cost-effective. On the other hand, advances in energy-efficient technologies and DSM-delivery methods suggest that, even under lower avoided costs, there remain significant opportunities to save more electricity at lower acquisition costs. Some utilities have demonstrated that they can successfully run low-cost DSM programs and we expect that they will, in principle, be able to continue to acquire cost-effective DSM resources in the future.

The un-internalized environmental costs associated with electricity production and transmission remain a continuing source of concern and an important justification for programs to improve energy efficiency. Recent studies of the environmental damages associated with electricity production show lower values than those previously developed. However, whether these estimates are more accurate than earlier ones or whether they merely reflect the substantial uncertainties associated with quantification and monetization of environmental damages is unclear. It is clear that new power plants are much cleaner than old ones and that growth 
in electricity use is offsetting these technological gains for some emissions. At the same time, governments may impose further restrictions on emissions of nitrogen oxides, small particulate matter, and air toxics. Finally, emissions of carbon dioxide (a key contributor to global warming) are now not controlled at all and thus mitigating them represents an important continuing justification for energy-efficiency programs.

Although government appliance standards and building codes have had major effects on electricity use, utility DSM programs are often a key element in making government standards and codes work well. That is, there are important synergistic effects between utility and government efforts to improve energy-efficiency.

Finally, debates about the appropriateness of government intervention in energy-service markets (either directly through codes and standards or indirectly through mandates to utilities) continue unabated. While the scope of these debates has narrowed somewhat in recent years, they are still often dominated by fundamentally irreconcilable differences in values about the relative competitiveness and role of regulation in these markets. It is probably safe to say that neither markets nor regulators are perfect and that the appropriate balance cannot be established by fiat, but rather must be based on detailed examination of the workings of particular markets, end uses, perceived market barriers, and participants in these markets.

In summary, we believe the historic rationale for public policies to improve customer electricity use remains unchanged-there remain significant opportunities to increase economic efficiency and reduce the environmental effects of electricity production and transmission. At the same time, we recognize that the role of electric utilities as an instrument to achieve the goals of these public policies is being challenged by the likely erosion of the monopoly franchise. DSM programs, however, are in no danger of disappearing, as utilities begin to take advantage of their strategic importance for the survival of the firm in an increasingly competitive electricity market. However, the remaining question is whether there is a need for additional public policies to ensure market-based outcomes reflect societal interests.

Four regulatory policy issues figure centrally in this process:

- Will regulated utilities (in the limit, distribution entities) have planning and operating incentives embedded in rate-setting formulas or processes that are consistent with the public interest in energy efficiency?

- What criteria will public utility commissions (PUCs) use to review utility-proposed use of ratepayers funds for DSM programs if the primary purpose of these programs is customer value rather than resource value? Which programs should be funded by utility shareholders rather than by customers?

- Will regulatory efforts to check market-power abuses by utilities or their subsidiaries operating in energy-

\section{Resource Planning for Gas Utilities: Models and Issues J.F. Busch, G.A. Comnes}

Gas utilities and state regulatory commissions have ongoing responsibilities to conduct resource planning, but the task is complicated as a result of industry and federal government actions that have restructured the natural gas industry. Our goal is twofold: 1) to illustrate the types of resource planning methods and models used in the industry, and 2) to illustrate some of the key tradeoffs among types of resources, reliability, and system costs. To this end, we developed a gas utility prototype that contains a simplified, but reasonably representative, model of a typical U.S. gas distribution utility (Figure 1). With this utility prototype, we analyzed several types of resource planning issues using a commercially available gas dispatch and resource planning model (the Sendout $($ model of EDS Utilities Division, Atlanta, GA).

One of the resource planning problems we examine is optimal investment in underground storage. Storage is a key strategic resource in a utility's resource portfolio. In the last several years, many utilities and regulatory commissions have reevaluated commitments to storage resource options in service markets help these markets mature and become fully competitive?

- To the extent that markets, rather than vertically integrated utilities, make end-use and supply-resource choices, how, if at all, will PUCs assess the consistency of these choices with the public interest? How will inconsistencies in these choices be addressed?

\section{References}

Hirst E, Eto J. Justification for ElectricUtility Energy-Efficiency Programs. Oak Ridge National Laboratory Report No. ORNL/CON-419, 1995.

Eto J, Kito S, Shown L, Sonnenblick R. Where Did the Money Go? The Cost and Performance of the Largest Commercial Sector DSM Programs. Lawrence Berkeley National Laboratory Report No. LBL-38201, 1995.

light of federal policy changes that unbundle storage from pipeline service and deregulate storage pricing. As a result of pipeline open access and changes in rate design, incremental storage investments is being considered by many gas utilities.

Our utility prototype initially possesses 210 terajoules (TJ) per day (200 thousand decatherms per day (MDTh/day)) of storage, which represents approximately $16 \%$ of the prototype utility's peak load. This level was considered representative of typical U.S. utilities. Using typical costs for storage service, we computed total system costs at alternative levels of storage capacity. For our prototypical utility, we found that 593 TJ per day (565 MDTh/day), or about $55 \%$ of the system's peak, was optimal storage (Figure 2). At that level, present value system costs of the utility prototype decrease $9 \%$ from the base case. Storage is a costeffective resource because it provides peak-day deliverability at lower fixed costs than its alternatives-usually pipeline capacity. Our study illustrates the appropriate method for evaluating this resource. We also consider the 
impact on optimal investment as a result of changing assumptions, such as the cost of storage.

In addition to the examination of new storage resources, we look at arrangements whereby the gas utility buys back gas from interruptible customers during periods of peak demand (known as buyback contracts), generic resource evaluation using avoided costs, and optimal reliability for residential and small commercial customers.

In general, we found resource planning models to be well-suited for answering a variety of questions that are relevant to today's utilities. The purpose of this study was not to give answers or prescribe detailed methods but, instead, to provide the reader with a better understanding of alternative methods, to assess the efficacy of resource planning models, and to point out the important tradeoffs among resources and costs when planning for a gas utility.

\section{Reference}

Busch JF, Comnes GA. Resource Planning for Gas Utilities: Using a Model to Analyze Pivotal Issues. Lawrence Berkeley National Laboratory Report No. LBL-37717, 1995.

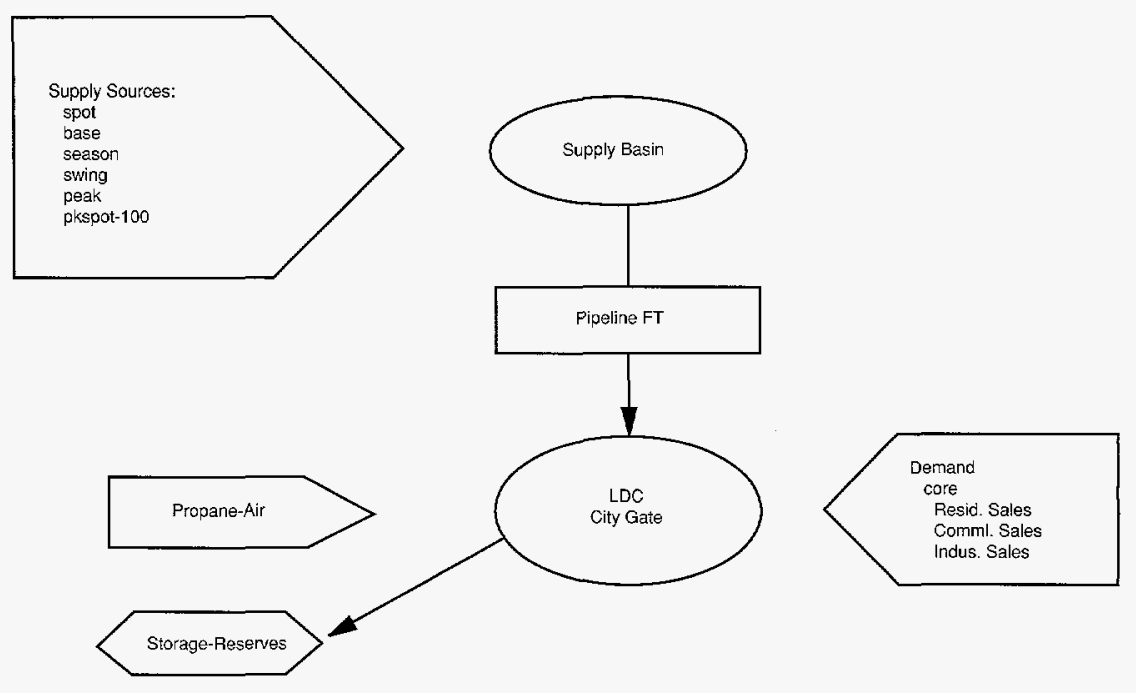

Figure 1. Network diagram for a prototypical local distribution company (LDC). (FT= firm transportation.)

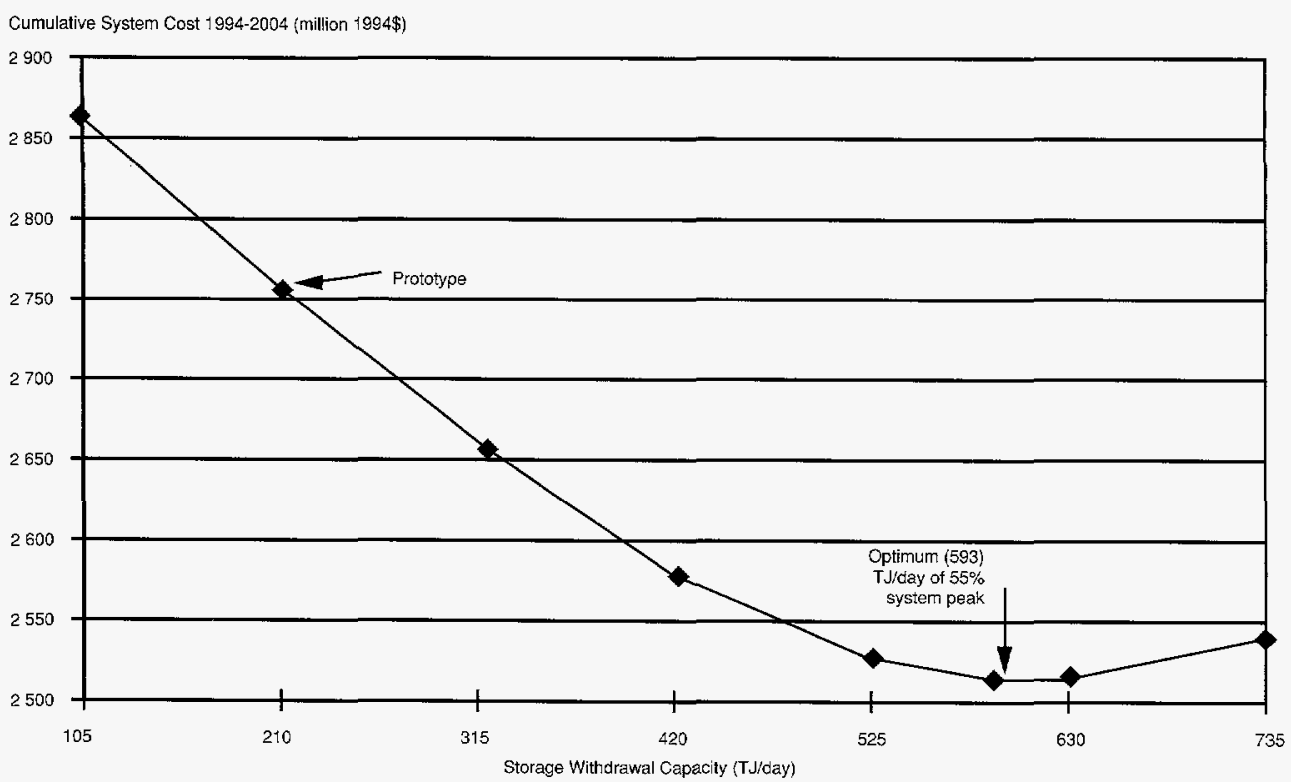

Figure 2. Optimal storage withdrawal capacity. 


\section{Improving the Practice of DSM Program Evaluations}

R. Sonnenblick, J. Eto

The prudence of utility demandside management (DSM) programs hinges on their performance, yet evaluating performance is complicated because the energy saved by DSM programs can never be observed directly but only inferred. Utilities currently rely on a variety of methods, drawn from a variety of disciplines, including engineering, statistics, social psychology, and economics. Given the relative newness of utility DSM programs, it is not surprising that no consensus has emerged on a single best evaluation method.

We recently completed a study examining current practices in the evaluation of commercial sector lighting DSM programs. The study frames and begins to answer the following questions: 1) How well do current evaluations perform in improving our confidence in the measurement of energy savings produced by DSM programs? 2) In view of this performance, how can we best allocate limited evaluation resources to maximize the value of the information they provide?

We reviewed three classes of methods for estimating annual energy savings: tracking database (sometimes called engineering estimates), end-use metering, and billing analysis. We assessed the accuracy and precision of each method and constructed trade-off curves to represent the cost of increases in accuracy and precision. We then examined the methods in light of the even greater uncertainties that exist in current estimates of DSM program measure lifetimes. Finally, we demonstrated a decision-analytic approach for improving future evaluations using the information we developed along with a clear specification of the objective of the evaluation (e.g., program cost-effectiveness).

Based on a small sample of studies in which we could directly compare tracking database estimates of savings to end-use metering, we found considerable variation in bias and precision. Because evaluators, without additional evaluation information, have no means of estimating the bias and precision of their tracking database estimate, we concluded that tracking database estimates alone are not reliable. Among the computational ele- ments used in tracking databases (i.e., number of measures installed, change in load per measure, and hours of operation), we found hours of operation were the largest contributor to bias and imprecision in annual savings estimates.

Although end-use metering offers the promise of being the most accurate method for estimating lighting energy savings, we found that contemporary end-use metering studies are often limited due to their high cost. While sampling issues associated with selecting sites for metering were often explicitly addressed, we found that some studies failed to account for HVAC/lighting interactions, were biased because short-duration metering could not identify seasonal changes in building operation, and may not be representative due to the limited number of circuits typically metered within a given building.

In evaluating the popular Statistically Adjusted Engineering or SAE billing analysis model, which introduces sitespecific engineering estimates of savings, we confirmed the magnitude of a wellrecognized but under-appreciated limitation of the method, namely, that its reliability depends strongly on the quality of the initial engineering estimate of savings (see Figure). We found that the SAE model did not perform as well as simpler time-series regression methods. This is a major finding of our study and, if confirmed by subsequent application of our methods to a wider range of situations, represents a particularly sobering conclusion for the evaluation community, which has come to rely heavily on this modeling approach.

We also found that inclusion of comparison groups in time-series regression analyses of billing information can greatly improve the precision of annual savings estimates, at moderate costs. When the DSM program reduces customer consumption by a small amount ( $4 \%$ in our simulation), incorporating nonparticipant data improves the precision of savings estimates by a factor of three. For programs that save a larger proportion of customers' electricity consumption, the improvement is smaller but still significant.
The value of DSM programs depends on both annual savings and the economic lifetime of the measures. We caution that the current practice of simply estimating equipment measure lifetimes based on expert judgment may be highly unreliable. We have demonstrated that measure lifetimes are a significant uncertainty, comparable in magnitude to uncertainties currently considered in other evaluation activities. In many cases, the uncertainty associated with measure lifetime estimates is, in fact, larger than the uncertainty of annual savings estimates.

How much one should spend acquiring DSM evaluation information depends on how much the information is worth relative to its costs. We found that the 90/10 precision standard often required of evaluations may only rarely be cost-justified from the standpoint of confirming program cost-effectiveness. We found that relative precision in the range of $90 / 50(50 \%$ relative precision at a $90 \%$ confidence interval) was sufficient to confirm the cost-effectiveness of the majority of programs from a recent sample of 20 commercial lighting programs. Only programs with total resource cost ratios very close to one require more precise estimates to allow confident assertions of cost-effectiveness.

For a decision to continue funding a program based on cost-effectiveness, the amount to spend on evaluation depends on 1) a subjective estimate of the chances that the program is actually not costeffective, in the face of any evaluation results, and 2) an estimate of the resources that could be misallocated to the program in the following year. We represented the decision to fund as being based on a) a mean evaluation estimate of cost-effectiveness, or b) an estimate of cost-effectiveness that includes imprecision. The difference between a) and b) is the value of including uncertainty in the program screening decision. The product of 1) and 2) is the expected value of future misallocated resources.

The introduction of competitive forces in the industry is creating substantial pressures for utilities to control costs. Formal decision-analytic approaches to 
ration DSM program evaluation costs offer the potential to guide cost-control decisions in a systematic and defensible fashion that maximizes the value of evaluation expenditures. Application of these approaches, however, requires detailed information on the performance of evaluation methods. This information is not yet widely available. We recommend increased effort by future evaluation efforts to report intermediate findings, especially on precision, so that the industry can develop a more comprehensive and reliable base of information upon which to ground these decisions.

\section{References}

Sonnenblick R, Eto J. A Framework for Improving the Cost Effectiveness of DSM Program Evaluations. Lawrence Berkeley National Laboratory Report No. LBL-37158, 1995.

Eto J, Vine E, Shown L, Sonnenblick R, Payne C. The Cost and Performance of Utility Commercial Lighting Programs. Lawrence Berkeley National Laboratory Report No. LBL-34967, 1994.

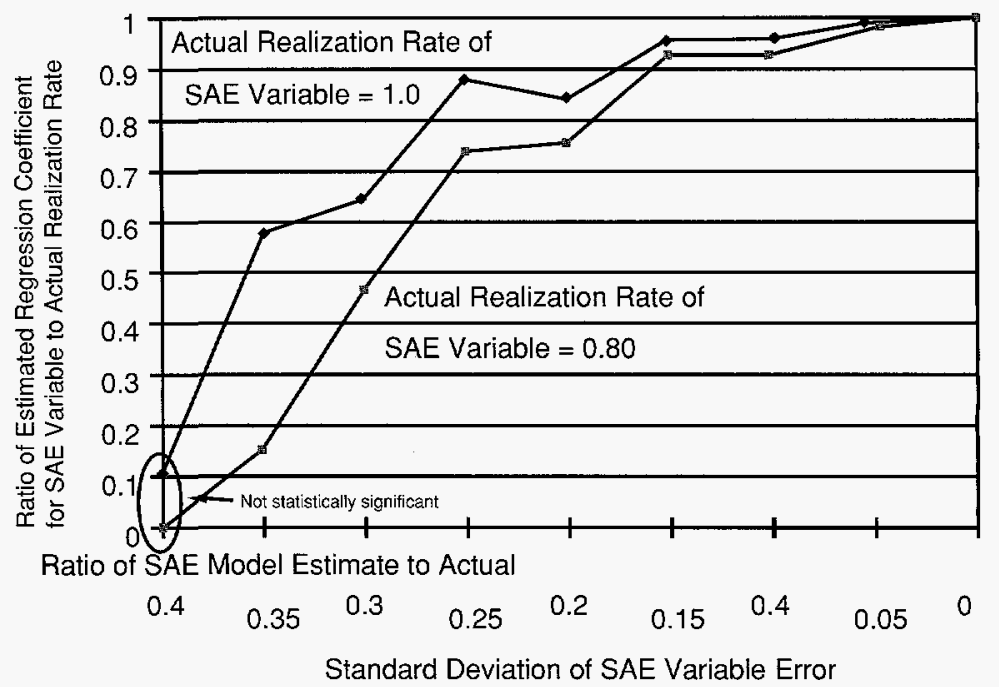

Figure. Bias in SAE model realization rate depends on quality of engineering estimates. The SAE model is a regression approach that relies on an engineering estimate of energy savings as one of its explanatory variables. The estimated coefficient is called a realization rate and is interpreted as a correction factor to the original engineering estimate. Our work demonstrates that, in practice, the SAE model is subject to significant bias due to errors in variables. Thus, even when an unbiased estimate of savings is used (see upper curve), the model dramatically underestimates the coefficient (in principle, it should always equal 1.0) whenever the standard deviation of the SAE variable error is greater than about 0.25 .

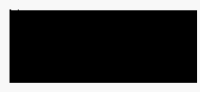

The Performance of the U.S. Market for Independent Electricity Generation G.A. Comnes, E.P. Kahn, T.N. Belden

In 1993 , total capacity of private power producers in the U.S. was 60.8 GW; approximately $8 \%$ of the U.S. total. Private power developers are currently making annual net additions to generation plants comparable to those of vertically integrated electric utilities. Most of the power generated from private developers is still sold to electric utilities at administratively determined prices based on avoided costs. However, most new contracts for private power are acquired via bidding or some other type of competitive process.

We examine recent evidence on the economic performance of the competitive segment of the U.S. independent electricity generation market. We use a sample of power purchase contracts for 26 independent power facilities that have been acquired competitively beginning in 1987. The sample facilities total $6354 \mathrm{MW}$ in size. The major project types are: natural gas cogeneration and/or combined cycle ("nonpeakers"), (20); natural-gas fired combustion turbines ("peakers"), (2); coal-fired steam (3); and wind turbine (1).

We standardize the price formulas of the contract sample to produce levelized nominal prices. Levelization is necessary because there is a wide variation in the way contracts allocate revenues over time. Annual project costs are computed using a common set of assumptions including general-price inflation and fuel-price escalation rates. Then the net present values (NPV) of the projects are computed. Projects with different vintages (start dates) are adjusted for inflation to a common base year of 1994. Then the project NPVs are annualized with a standard annuity formula using a nominal discount rate representative of the typical weighted average cost of capital used by electric utilities for economic evaluation. Prices are separated into capacity $(\$ / \mathrm{kW})$ and energy $(\$ / \mathrm{kWh})$ components, as well as aggregated to total price $(\$ / \mathrm{kWh})$, typically using a capacity factor of $80 \%$, a representative target for baseload projects which are the most common type in our sample.

With prices levelized and adjusted to a common base year, we may compare prices systematically. The Figure shows total price at two capacity factors (40\%, and $80 \%$ ). The three coal projects have an average price of $\$ 0.092 / \mathrm{kWh}$ at $80 \%$ capacity factor. The gas nonpeakers show a wide price range. Their average price is $\$ 0.069 / \mathrm{kWh}$ (the low price is $\$ 0.045 / \mathrm{kWh}$ and the high is $\$ 0.095 / \mathrm{kWh}$ ). Surprisingly, the two gas combustion turbine (peaker) projects have very competitive prices, an average of $\$ 0.056 / \mathrm{kWh}$ at the relatively high capacity factor of $80 \%$. The wind project's price is $\$ 0.056$ at a projected annual availability of $36 \%$. Wind power is not 
firm, so its cost cannot be directly compared to the others without some adjustment for additional reliability costs.

The apparent superiority of the gas peakers over a wide range of capacity factors is surprising. Gas peakers, with their low capacity costs but relatively higher heat rates, traditionally fill a niche at low annual capacity factors. Our analysis shows that peakers are among the cheapest gas-fired resources at a capacity factor of $40 \%$ and are competitive with gas nonpeaker projects at an $80 \%$ capacity factor, although there may be reliability issues at these high output levels.

We examine price performance with a statistical analysis of the 23 intermediate and baseload contracts (excluding the two peakers and the wind project). We consider a price determination model of the general form:

$$
\text { price }=\alpha \bullet \operatorname{cost}+\beta \bullet \text { value }
$$

The basic hypothesis is that the more competitive the market, the greater $\alpha$ would be relative to $\beta$. In general, we would expect value, or willingness to pay, to decrease in importance as a product becomes more competitive.

Estimating the equation directly is not feasible since neither cost nor value are directly observable. We developed a set of proxies for cost and value. Proxies for cost include those that reflect differences in project location, local input prices, technological factors such as fuel type and scale economies, changes in the economic environment, and the contract duration. Proxies for value include a measure of opportunity cost, dispatchability, and exposure to fuel cost fluctuations.

Most of the cost proxies are straightforward. Froxies for value are slightly more subtle. The most difficult issues involve fuel costs. Since our sample is dominated by gas-fired projects, we view the local delivered price of coal as a proxy for the opportunity cost facing buyers. If the utility did not buy a gas-fired project, the main alternative would have been coal-fired generation. Choosing gas means that coal technology was more expensive. We cannot easily measure the full cost of coal-fired alternatives, so we use local delivered coal fuel prices as a proxy for the full cost. We consider the local delivered price of natural gas, however, as a cost factor, again because the sample is dominated by gas-fired projects.

A number of the cost proxies are statistically significant. In particular, scale economies exist over the $1.0 \mathrm{GW}$ capacity range of the sample; lowering purchase price by $\$ 0.010-0.013 / \mathrm{kWh}$. The choice of coal technology raises price by $\$ 0.010-0.014 / \mathrm{kWh}$. Longer terms contracts (those 10 years longer than the average) lower total price by $\$ 0.005-0.008 / \mathrm{kWh}$. Projects in the Northeast add $\$ 0.012-0.014 / \mathrm{kWh}$ to price relative to other U.S. locations.

Of the value proxies, only local delivered coal prices are consistently significant. At the sample mean, the contribution of this term to total price is $\$ 0.060-0.066 / \mathrm{kWh}$. Coal price explains over $80 \%$ of the variation in the sample's total price. Therefore value, measured by this proxy, appears to play a strong role in price determination.

Our small sample makes it difficult to draw strong conclusions. Nonetheless, we make the following observations. First, despite our ex ante expectation to the contrary, prices did not fall as a result of increased competition. Variables that measured the date of

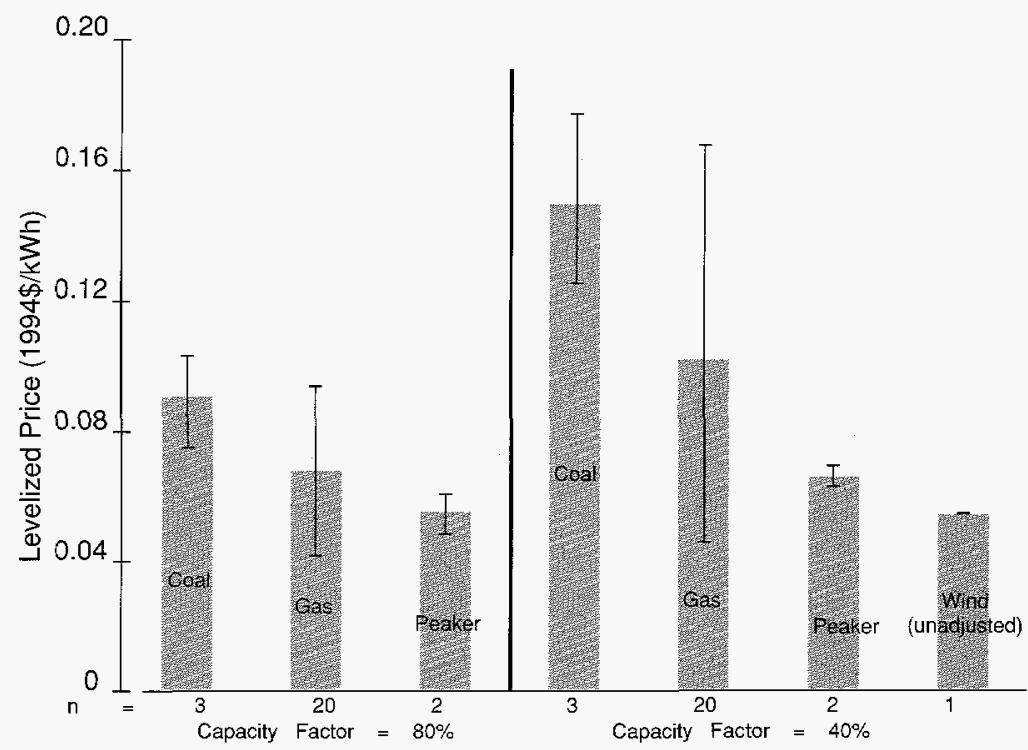

Figure. Levelized price by technology type. Note: Shaded bars indicate group averages; line bars indicate group max/min values. contract execution or expected commercial operation date were not significant in our regressions. Second, we did not observe electricity prices converging to one price as might be expected in a competitive market. This heterogeneity in price, which we are unable to explain in terms of cost variation, may indicate a lack of robust competition. Third, one of our value proxies, local delivered coal prices, was the most significant variable in our regressions, explaining $80 \%$ of the sample mean price. The strength of this variable in the regressions suggests a lack of robust competition.

Our results indicate that the U.S. generation market cannot be declared competitive based on economic performance. This does not mean that competition is not here or is not coming, but it does indicate the need for a continuing focus on market structure conditions that assure competition.

\section{Reference}

Comnes GA, Belden TN, Kahn EP. The Price of Electricity from Private Power Producers. Stage II: Expansion of Sample and Preliminary Statistical Analysis. Lawrence Berkeley National Laboratory Report No. LBL-36054, 1995. 


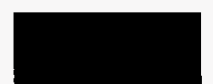

\section{The Cost and Performance of European DSM Programs}

\section{E. Vine}

We examined the experience of European utilities and governments in demandside management (DSM) programs and program evaluation. The findings are the first results from a joint international effort in compiling and analyzing the measured results of energy-efficiency programs in a consistent and comprehensive fashion. Where available, the program results are based on post-program evaluations rather than on unverified program estimates. While the countries and case studies examined are not representative of all of Europe, they are valuable for illustrating the experience of DSM programs occurring in Europe today.

The cost-effectiveness of these programs varied significantly (see Figure). From the utility perspective, the average levelized utility resource cost was $2.0 \mathrm{c} / \mathrm{kWh}$, and from a total resource cost perspective (when participant costs are added to utility costs), the average cost $(3.3 \mathrm{~d} / \mathrm{kWh})$ was close to the measured performance of some DSM programs in the U.S. Weighted by energy savings, the average cost of energy saved by the programs was $1.8 \& / \mathrm{kWh}$.
The actual performance of these programs is uncertain due to the utilities' limited experience in evaluating DSM (especially, energy-efficiency) programs. Many of the programs relied on engineering data and engineering analysis for estimating energy savings, while billing data were used in only a few cases to statistically analyze changes in consumption. In addition to the uncertainty of program results, several of these programs had broad objectives in trying to transform the market of energyefficiency goods and services through information and audit programs, as well as market-pull programs. Consequently, other measures of program performance need to be taken into account, such as the degree to which the energy-efficiency market has been transformed (e.g., greater availability of efficient equipment).

We believe that DSM program results and experience may be transferred from one location to another, if at least two provisions are fulfilled: 1) the data are collected consistently using a standardized data-collection instrument that includes a set of instructions; and 2) the information on the cost and performance of DSM programs is placed in the broader context of the utility and customer environments in each country (e.g., energy prices and rates, market barriers, regulatory incentives and disincentives, motivations for pursuing DSM, the market for energy efficiency, and the extent of privatization and regulation of the power industry). We expect that energyefficiency measures and program delivery systems can be transferred from one country, or one region, to another. Similarly, program evaluation processes and methodologies can also be transferred; however, differences in nomenclature, the level of integration of evaluation in program design and implementation, and the amount of expertise and resources in an organization may limit the amount and type of information that can be transferred. However, these short-term barriers may be overcome in the future as evaluation assumes a more important role.

\section{Reference}

Vine E. International DSM and DSM Program Evaluation: An INDEEP Assessment. Lawrence Berkeley National Laboratory Report No. LBL-36647, 1995.

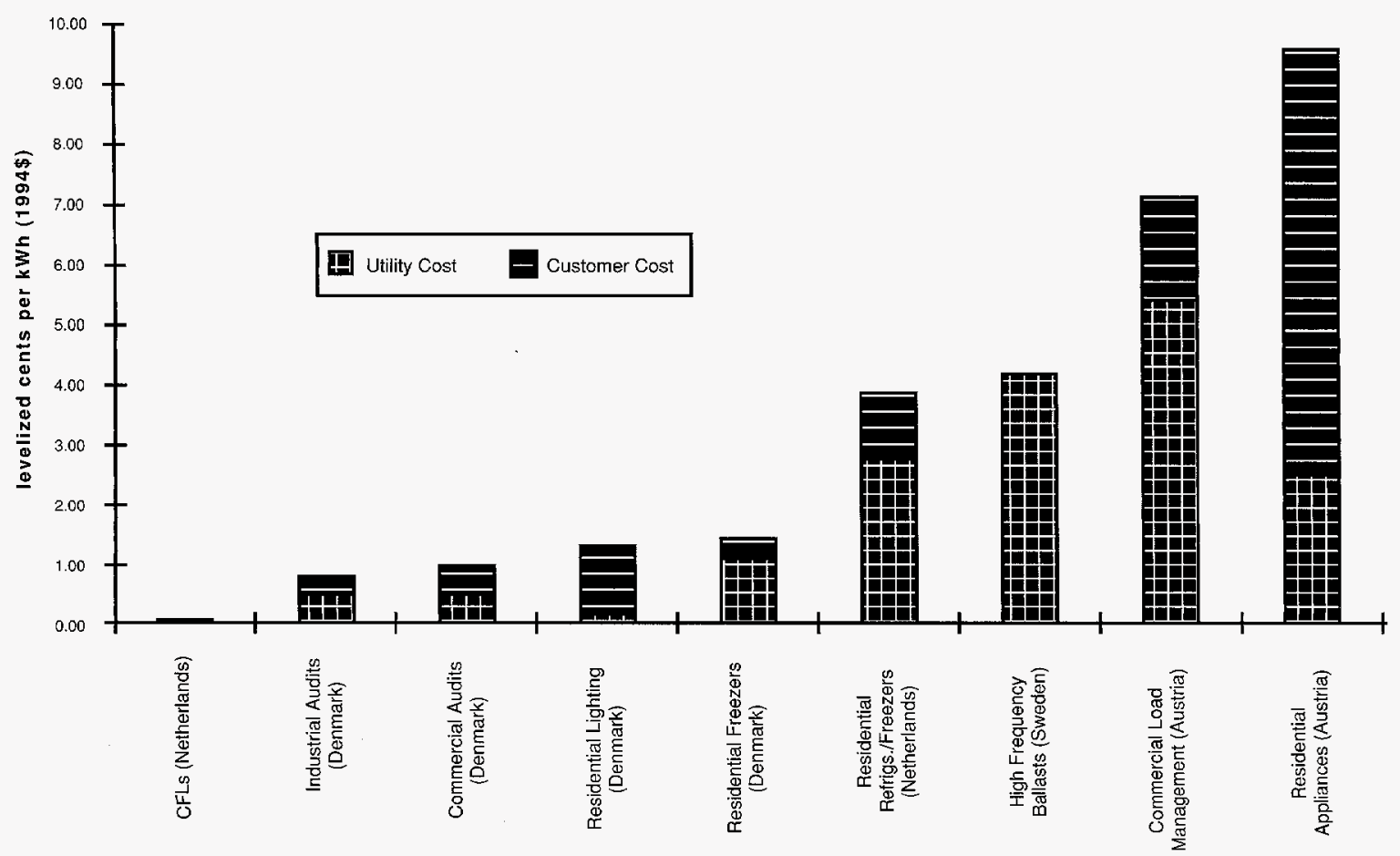

Figure. Total resource cost of savings from selected European DSM programs (CFL = compact fluorescent lamps). 


\section{Analysis of Federal Appliance Efficiency Standards}

J.E. McMahon, B. Atkinson, S. Boghosian, S. Brown, P. Chan, T. Chan, A. DeVuono, D. Fisher, L. Greening, J. Jennings, J. Kollar, J.G. Koomey, M.D. Levine, J. Lin, X. Liu, J. Logan, J. Lutz, S. Mahler, C. Marnay, S.J. Pickle, G. Rosenquist, A. Sanstad, A.O. Sezgen, I. Shukman, S. Stoft, I. Turiel, C. Webber

The Energy Policy and Conservation Act (P.L. 94-163), as amended by the National Energy Conservation Policy Act (P.L. 95-619) and by the National Appliance Energy Conservation Act of 1987 (P.L. 100-12) and by the National Appliance Energy Conservation Amendments of 1988 (P.L. 100-357), provides energyefficiency standards for 12 types of consumer products and authorizes the Secretary of Energy to prescribe amended or new energy standards for 13 types of products.*

Initiated in 1979, LBNL's assessment of the standards is designed to

*The Energy Policy Act of 1992 (P.L. 102-486) adds five products: (14) general-service fluorescent lamps and incandescent reflector lamps, (15) shower heads, (16) faucets, (17) water closets, and (18) urinals, for which test procedures and labels will be developed. This Act sets standard levels for lamps, motors, commercial heating and cooling equipment, and commercial water heaters, and includes a schedule for possible amendments to the standards. evaluate their economic impacts according to the legislated criteria (see Figure).

The economic impact analysis is performed in five major areas:

- Engineering Analysis, which establishes the technical feasibility and product attributes including costs of design options to improve appliance efficiency.

- Consumer Analysis at two levels: national aggregate impacts (forecasts) and impacts on individuals (lifecycle cost analysis). The national aggregate impacts include forecasts of appliance sales, efficiencies, energy use, and consumer expenditures. The individual impacts are analyzed by lifecycle cost, payback periods, and cost of conserved energy, which evaluate the savings in operating expenses relative to increases in purchase price.

- Manufacturer Analysis, which provides an estimate of manufacturers' response to the proposed standards.
Their response is quantified by changes in several measures of financial performance.

- Utility Analysis, which measures the impacts of the altered energyconsumption patterns on electric and gas utilities.

- Environmental Analysis, which estimates changes in emissions of carbon dioxide, sulfur oxides, and nitrogen oxides resulting from reduced energy consumption in the home and at the power plant.

This year, we provided support to DOE in considering a consensus standard for refrigerators and freezers negotiated by manufacturers, energy-efficiency advocates, states, and utilities. We conducted analysis to address issues raised by comments on the March 1994 proposed standards for eight products: room air conditioners, water heaters, mobile home furnaces, direct heating equipment, kitchen ranges and ovens,

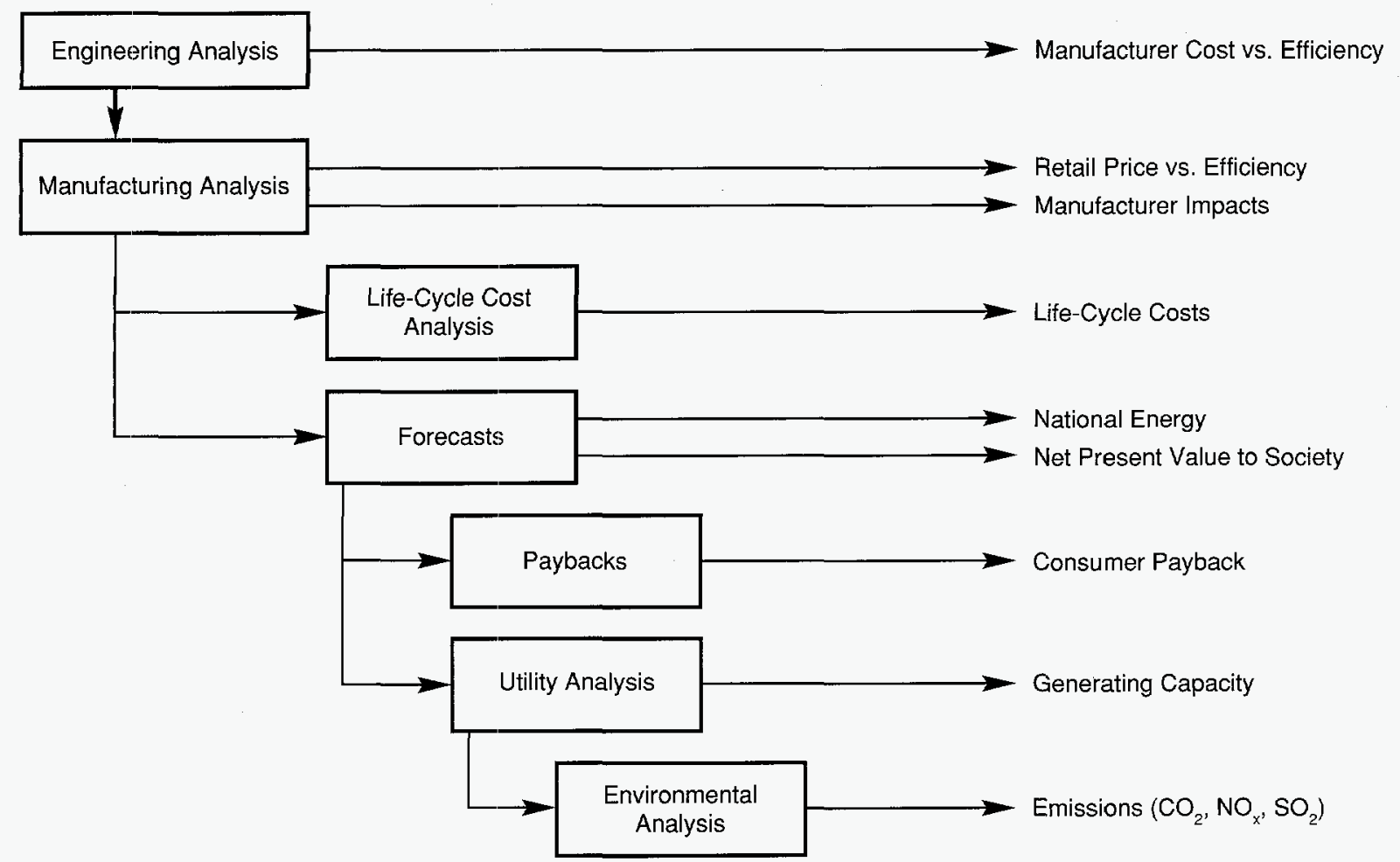

Figure. Analytic framework for the appliance standards analysis. 
pool heaters, televisions, and fluorescent light ballasts. Additional analysis was conducted on possible updates to standards on central air conditioners, heat pumps, furnaces, clothes washers, clothes dryers, and dishwashers.

The Energy Policy Act of 1992 expanded the appliance efficiency program at DOE to include lamps, motors, commercial heating and cooling equipment, and commercial water heating. We performed analyses of possible standards for high-intensity discharge lamps, the four plumbing products, and small electric motors, as well as looked at rating and information programs for luminaires and for office equipment.

For next year, Congress proposed a critical review of the standards process and a temporary halt to rulemakings. We will support the independent critical review, propose improvements to the analysis, implement new processes to conform with findings of the critical review, provide support to DOE by performing technical and economic analyses, as directed, and analyze alternatives to standards. We will document the analysis we completed for room air conditioners, ranges and ovens, ballasts, clothes washers and clothes dryers, water heaters, central air conditioners and heat pumps, dishwashers, highintensity discharge lamps, small motors, and office equipment. We will write a report on an evaluation of the luminaire test and information program.

\section{References}

U.S. Department of Energy, Assistant Secretary for Energy Efficiency and Renewable Energy, Office of Codes and Standards. Technical Support Document: Energy Efficiency Standards for Consumer Products: Refrigerators, Refrigerator-Freezers, and Freezers. Washington, D.C.: U.S. Department of Energy Technical Support Document, DOE-EE-0064, 1995.

Atkinson BA, McMahon JE, Lin J, Fisher DC, Pickle SI, Monforte FA. Modeling U.S. industrial lighting energy consumption and savings potential. In: Proceedings of the ACEEE 1995 Sumer Study on Industrial Energy Efficiency, August 1-4, 1995. Washington, D.C.: American Council for an Energy Efficient Economy, 1995, pp. 577581.

Turiel I, Atkinson BA, Boghosian S, Chan $\mathrm{P}$, Jennings $\mathrm{J}$, Lutz $\mathrm{J}$, McMahon JE, Rosenquist G. Evaluation of Advanced. Technologies for Residential Appliances and Residential and Commercial Lighting. Lawrence Berkeley National Laboratory Report No. LBL-35982, 1995.

\section{Engineering Analyses of Appliance Efficiency Improvements}

\section{Turiel, B. Atkinson, P. Biermayer, S. Boghosian, T. DeVuono, C. Dunham, S. Hakim, J. Logan, J. Lutz, G. Rosenquist}

The economic impacts of appliance efficiency standards depend largely on the relation between cost and energy consumption of a consumer product. Our engineering analysis seeks to identify this cost-consumption relationship for selected appliances.

In 1995 we completed engineering analyses for fluorescent lamp ballasts, room air conditioners, and cooking products. Draft technical reports on these products were completed. We responded to comments on the notice of proposed rulemaking for these products.

Draft analyses of dishwashers, clothes washers, and clothes dryers have been completed. Additionally, analyses of small motors, lighting products, and office equipment are all in progress.

The engineering analysis consists of the following steps: select appliance classes; select baseline units for each class; select design options for each class; and determine the maximum technologically feasible design, the efficiency improvement, and the cost for each option for each class. Data are obtained through contacts with trade organizations and manufacturers, from suppliers of purchased parts and materials, and from computer simulations.

In 1996 we plan to write the draft report documenting the engineering analysis of water heaters, central air conditioning/heat pumps, dishwashers, and laundry products. After peer reviews, we will also revise our report on the analysis of water heaters, fluorescent lamp ballasts, room air conditioners, and ranges/ovens. Work will continue on small motors, lighting products, and office equipment.

\section{References}

Technology and Market Assessment Group. Draft Report on Potential Impact of Possible Efficiency Levels for Fluorescent Lamp Ballasts. Washington, D.C.: U.S. Department of Energy, Office of Codes and Standards, 1996.

Technology and Market Assessment Group. Draft Report on Potential Impact of Alternative Efficiency Levels for Room Air Conditioners. Washington, D.C.: U.S. Department of Energy, Office of Codes and Standards, 1996.

Technology and Market Assessment Group. Draft Report on Potential Impact of Alternative Efficiency Levels for Ranges and Ovens. Washington, D.C.: U.S. Department of Energy, Office of Codes and Standards, 1996. 


\section{Impacts of Water Heater Efficiency Increases: Variability among Households \\ J.D. Lutz, C. Dunham, X. Liu, L. Greening, J.E. McMahon, J. Zeitz, V. Budzyn, Q.T. McGrue}

Energy consumed by residential water heaters accounts for $11 \%$ of the electricity and $24 \%$ of the natural gas consumed in the residential sector in the U.S. However, residential hot water use and the associated energy consumption are not well characterized. Most analyses of national impacts of U.S. energy-efficiency policies use a single national average daily value for hot water use, regardless of the number of people in the household, the presence of hot water-using appliances, or the climate in which the house is located. Studies show that these and other factors influence the amount of hot water used and the amount of energy needed to generate that hot water.

This year we designed a detailed method for analyzing impacts of potential policies or new technologies on this important residential end use (see Figure). The key part of this process is to disaggregate the analysis down to the household level to account for many of the different factors that influence hot water use and the associated energy use.

Two levels of analysis are being undertaken. The first utilizes a Monte Carlo uncertainty model with 6 submodels and 25 equations to calculate the lifecycle cost for water heaters. A range of values, not just a single "typical" value, is associated with each variable in the model to represent the variability among households in the population. The output of this model is the distribution of lifecycle costs for various types of water heaters. We are studying the expected change in costs for cases where a more efficient water heater replaces the existing one, or where the household switches to a different fuel.

The second level of analysis utilizes a more detailed engineering model. This model is applied to approximately 4000 households in the U.S. DOE's Residential Energy Consumption Survey sample that have their own water heaters. The process starts with a "draw" model that predicts hot water use by time of day for each household for eight different types of days per year, i.e., weekend and weekdays for each of the four seasons. The hot water-use pattern for each household, along with information about the water heater, is used in simulation models to calculate direct energy consumption of the water heater as well as the thermal impact on the surrounding space. If the water heater is in conditioned or semiconditioned space, the incremental energy consumption of the space-conditioning equipment caused or avoided because of the water heater is also determined. This interaction is especially important for heat pump water heaters.

Annual operating costs are determined based on local gas, oil and electricity prices. Any installation costs are also calculated. These can be quite large in cases where the water heating fuel is being changed. The remaining lifetime of the water heater in each household is estimated based on age of current water heater, hot water use, thermostat setting, and water quality. These are entered into a consumer choice model to predict what type of water heater each household will purchase when the current one fails.

A weighted sum of the energy consumption by household is calculated to determine the impact on utilities and the environment of different polices that might limit or promote the types and efficiencies of water heaters available. The annual shipments of water heaters will be forecast and impacts on manufacturers also estimated.

Because the analysis is done on a household-by-household basis for a representative sample, the impacts of policy choice, projected technological change, or marketing programs can be estimated for sub-segments of the populations by region or demographics.

Next year we plan to complete analysis for several scenarios of the impacts of possible energy efficiency levels for residential water heaters, with emphasis on fuel switching and the impacts on different segments of the population.

\section{Reference}

Lutz JD, Liu X, McMahon JE, Dunham C, McGrue QT. Modeling Residential Hot Water Use Pattems. Lawrence Berkeley National Laboratory Report No. LBL-37805, 1995.

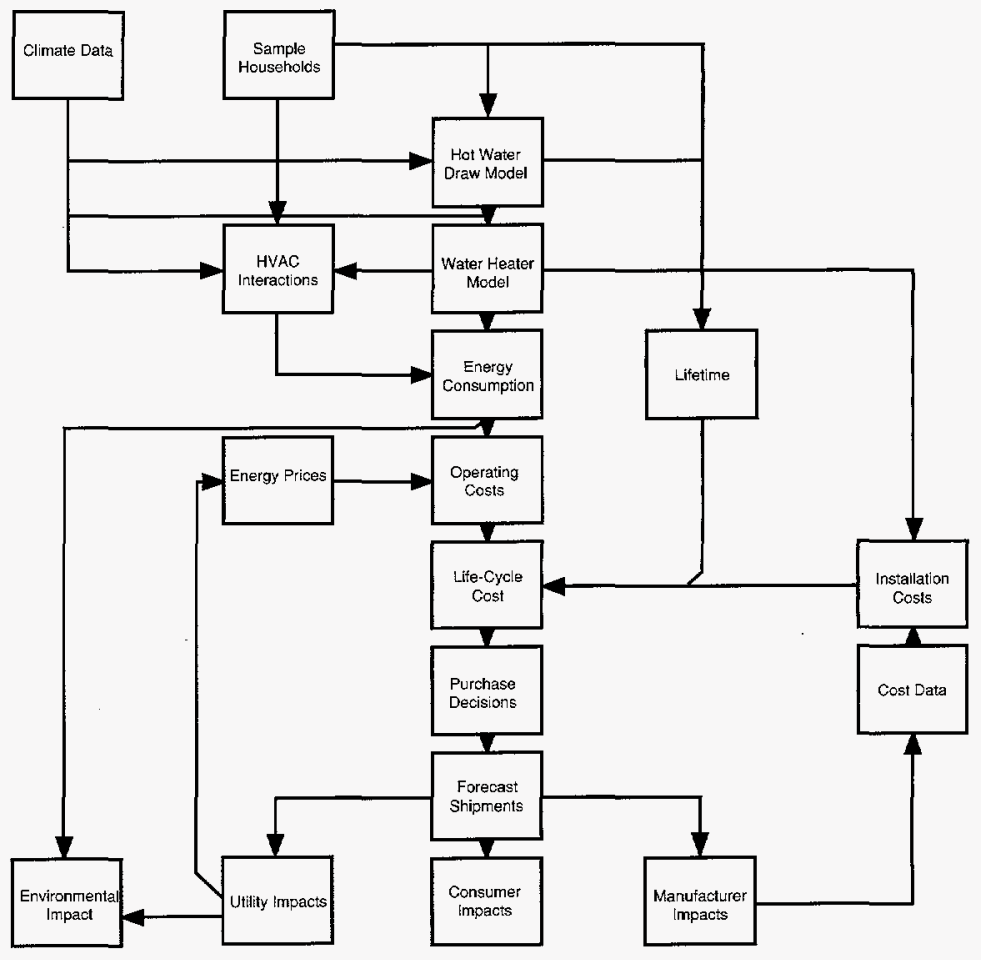

Figure. Schematic flowchart of new methodology for analysis of water heaters. 


\title{
Promoting Water Conservation with State and Local Incentive Programs
}

\author{
C. Dunham, J.D. Lutz, S.J. Pickle, J.E. McMahon
}

Water conservation can benefit a community in many ways. The need for conservation is obvious in areas where water is in short supply. Efficient use of water helps communities meet current supply needs in times of drought and when population growth places pressure on existing supplies. Reducing demand can also protect future water resources by drawing more slowly upon reservoirs and aquifers.

In an effort to promote water conservation, Section 123 of the Energy Policy Act of 1992 (EPACT) requires the Department of Energy to issue recommendations on establishing state and local incentive programs to encourage voluntary consumer replacement of existing water closets, urinals, showerheads, and faucets by purchasing watersaving products meeting EPACT standards. We participated in the process of assessing and drafting the required EPACT recommendations.

The draft recommendations urge state and local authorities working together and with utilities to:

- investigate the cost-effectiveness of voluntary replacement of plumbing fixtures and fittings as an effective component of a water-efficiency incentive program;

- allow utilities to distribute the costs of providing water-saving products by billing at pre-installation rates until devices have been paid for;

- encourage decreased water usage by adjusting rate structures such as increasing block rates or applying seasonal pricing that better reflects marginal costs;

- add additional incentive to rebate programs by making the rebates nontaxable income;

- require municipalities or utilities to exhaust every reasonable and cost-effective method of water conservation before applying for permits to construct new water supply or water treatment systems;

- require high-efficiency water closets, urinals, showerheads, and faucets in new construction and change plumbing codes to incorporate different pipe-sizing needs;
- mandate installation of meters to correctly measure water consumption.

To explore ways in which these recommendations may be realized, we reviewed case studies in New York, California, Texas, and Washington state. Each case study profiled a successful water conservation effort. We selected these states because their water conservation programs included the following elements:

- the inclusion of high-efficiency plumbing products;

- variable and flexible programs, translatable to other states and municipalities around the country, and

- demonstrated reduced water consumption.
The case studies demonstrate some of the ways in which water authorities around the country have synthesized different elements from the preceeding list of recommendations. The cases highlighted are by no means the only successful programs. We also studied and reported on city programs.

\section{Reference}

Dunham C, Lutz JD, Pickle, SJ. Promoting Plumbing Fixture and Fitting Replacement: Recommendations and Review for State and Local Water Resource Authorities. Lawrence Berkeley National Laboratory Report No. LBL-37399, 1995.

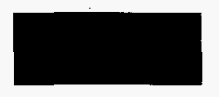

\section{Integrated Modeling of the U.S. Energy Sector Using NEMS} C. Marnay, A. Kast, S.J. Pickle

The National Energy Modeling System (NEMS) is an integrated energyenvironment-economy model of the entire U.S. energy industry. It was designed and built over several years by the U.S. Department of Energy's Energy Information Administration (EIA). NEMS is used by EIA to forecast U.S. energy production, imports, conversion, price, and consumption to the year 2015. These forecasts appear in many EIA publications, including the Annual Energy Outlook (AEO), a document that strongly influences U.S. energy policy and energy-investment decisions. These important public and private decisions have a major impact on the U.S. economy, for which the total annual energy bill is approximately $\$ 500$ billion.

NEMS is comprised of separate modules. Embedded in these modules is sophisticated knowledge about each aspect of the U.S. energy industry. NEMS iterates across these modules to produce equilibrium results for the entire industry.

In an attempt to apply the power of NEMS to current policy and technical issues, the model has been run under assumptions different from those typically used by EIA. The results of one such analysis appear in Figures 1 and 2. In this test, the initial capital cost of wind electricity generation was varied from the $A E O$ value for the year 2010 of $690 \mathrm{~S} / \mathrm{kW}$. The amount of wind-generating capacity that NEMS predicts will be constructed by 2010 appears quite sensitive to this capital cost assumption. If the capital costs of wind generators are cut to half the $A E O$ value, the quantity of constructed wind generation increases five times. As Figure 1 shows, the net effect of this increase is to raise the fraction of total U.S. electrical energy derived from renewable sources from 12 to $14 \%$. Figure 2 shows the environmental benefit of this additional wind generation: total emissions of carbon are reduced by $16 \mathrm{Mt} / \mathrm{yr}$.

We will continue to use NEMS to study energy technology and policy questions. The goal is to use NEMS to conduct simple analyses of the U.S. energy sector not covered in the $A E O$. We will study assumptions that may challenge conventional wisdom or that are beyond the scope of EIA publications. 


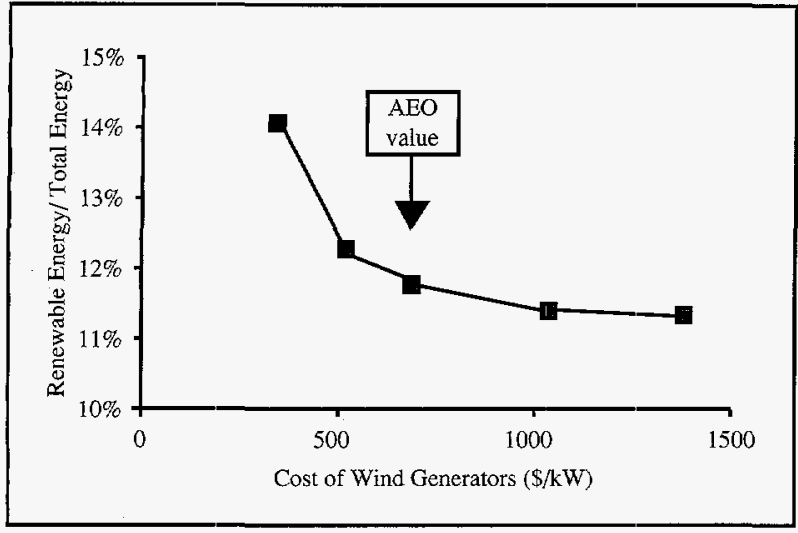

Figure 1. Renewable fraction of electrical energy in 2010.

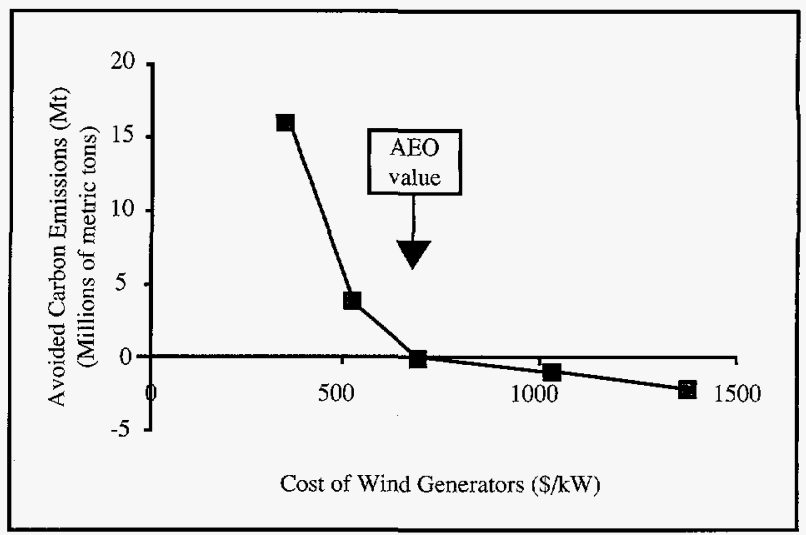

Figure 2. Change in carbon emissions with wind technology cost.

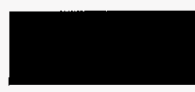

\section{Lifestyle Impacts on Personal Transportation}

L.A. Greening, L. Schipper, W.B. Davis, E. Watt, M.J. Figueroa, R. Gorham, T. Wenzel, P.L. Scholl

During the past year we completed a project that studied the economic and behavioral aspects of personal transportation based on a comparison of published national surveys of the U.S. and a variety of European countries.

The results of this study indicate that the U.S. is distinguished for having the largest share of automobile use. This is not so much because the length of a trip is longer in the U.S. than in European countries (only 10 to $15 \%$ higher), but mainly because the frequency of trips is significantly higher. Our analysis was performed for seven countries: the U.S., West Germany, Sweden, the U.K., the Netherlands, Norway, and Denmark.

Other key findings include that the average weekly distance traveled per person by automobile overshadows that traveled by all other modes, with the automobile accounting for two-thirds of overall travel in all of these countries. The Figure illustrates the differences in distances traveled by purpose by country. It is striking that the distribution of travel by purpose seems to cluster around one-third commuting, one-quarter family business, and the rest free time, except in the U.S., where the share for family business is distinctly higher.

Extending this work, we acquired household transport surveys from four European countries (Sweden, Finland, the U.K., and the Netherlands). We are in the process of performing a comparative analysis of mobility patterns from these countries with those of the U.S. From this study we hope to answer fundamental questions concerning similarities and differences in mobility patterns and associated consumption of energy, as they are affected by economic and social differences such as fuel price, culture, lifestyle, and gender. The results of the national survey comparison will be enhanced by results from a comparison of more detailed survey data from various cities in those countries, particularly Stockholm and Gothenberg in Sweden. Ulti- mately this type of analysis will provide the foundation for modeling candidate government policies for the reduction of vehicle miles traveled and energy consumption such as the "location-efficient mortgage." Analysis of these policies requires disaggregated data to capture subtle differences in consumer response.

Differences in travel patterns are assumed to reflect various economic behaviors, including the selection of vehicle attributes and fuel choices. The

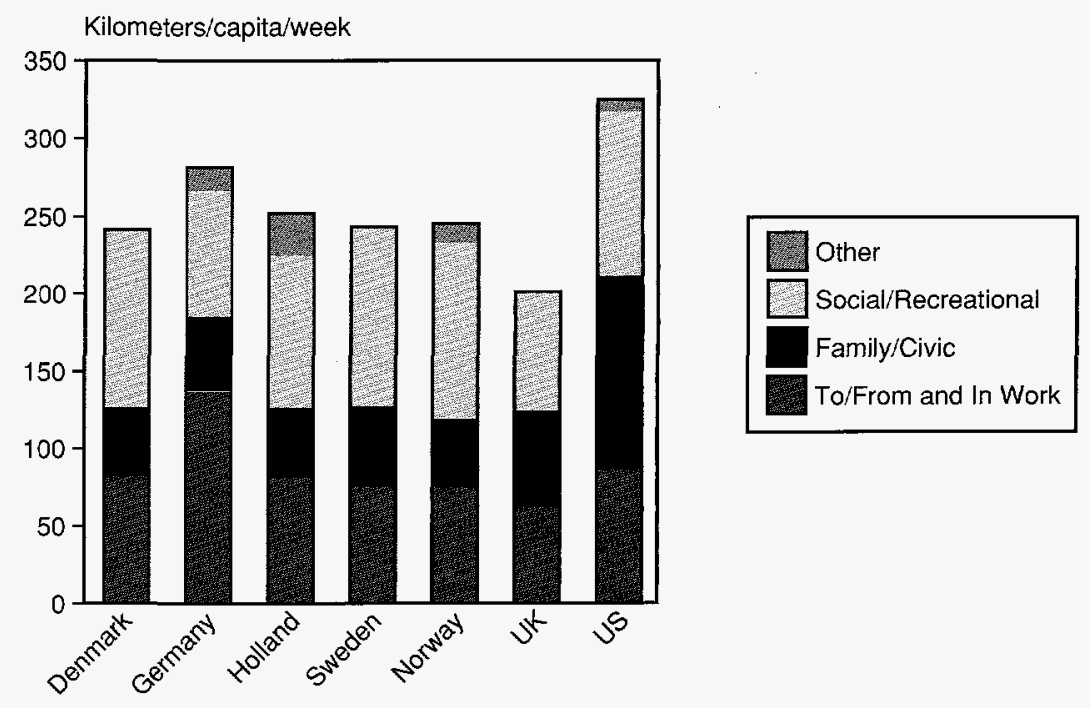

Figure. Travel by purpose in seven countries. 
analysis and modeling effort currently in progress seeks to determine the effects of various socio-demographic differences between and within countries. Three projects consider: 1) differences in sets of vehicle attributes selected by consumers in different European countries; 2) differences in fuel choices, fuel intensity, and number of miles traveled in 11 industrialized countries induced by differences in population densities and other aggregate demographic characteristics; and 3) the distribution across income groups in the U.S. of various costs of owning and driving an automobile, the number of miles driven, and various automobile attributes. The majority of this work is motivated by an interest in better understanding how we might achieve enhanced automotive efficiency.

As a result of this analysis, policies targeted at specific groups within the population may be developed to encourage acquisition of less fuel-intensive vehicles or reduction in vehicle miles traveled. Part of this analysis includes estimating the potential magnitude of errors in population estimates that may arise from the sample design of three travel instruments for the U.S. (National Personal Transportation Survey, Residential Travel Energy Consumption Survey, and the Consumer Expenditure Survey). This will allow an evaluation of the impact from potential under-sampling of critical subgroups of the population by these instruments.

The work on the distribution of fuel costs, vehicle attributes, and number of miles driven is part of an on-going effort to model consumer behavior at the micro or household level. This work makes extensive use of the U.S. Consumer Expenditure Survey, which has collected information on household demographics, household expenditures and income, and vehicle miles traveled by specified vehicle within the household since 1980. This data set has been previously used to estimate differences in gasoline-expenditure patterns between socio-demographic groups. Differences between socioeconomic groups have also been demonstrated in short-run responses to changes in the price of gasoline to the consumer and changes in household income. The results of that demand modeling effort are being used to evaluate the welfare consequences of several levels of candidate gasoline taxes for different groups in the population of the U.S. and are currently being used to evaluate the distributional consequences of: 1) a per gallon tax on gasoline; 2) a per mile tax; 3) a per unit of greenhouse-gas emissions tax; and 4) a per unit of greenhouse-gas emissions tax combined with an emissions-based annual fee.

Other research into consumer behavior is continuing. The CALCARS model developed by the California Energy Commission was added to the policy analysis capabilities during this past summer. As with the previously acquired AUTO model, CALCARS is useful for evaluating the effects of market-based policies intended to encourage the penetration of low emissions or more fuelefficient vehicles. Both models have a nested multinomial logit formulation for the demand component, which forecasts the decisions to purchase as well as utilize vehicles, and a supply component, which forecasts the auto manufacturer's response to changing economic conditions. The AUTO model is calibrated for the entire U.S. CALCARS is formulated for the state of California and explicitly considers alternatively fueled vehicles. As a result, consideration can be given to the impacts of various policy instruments, including subsidies for alternatively fueled vehicles and feebates on consumers' purchases of vehicle stock. The output of both the AUTO and CALCARS models may be combined with various databases of automotive technical and emissions characteristics to evaluate the impacts on the environment. CALCARS is currently being used in the analysis of the ZEV (zero emission vehicle) mandate for the state of California.

During the coming year, as a part of our continuing research on consumer demand for transportation services, a long-run household-level model will be developed from 14 years of Consumer Expenditure Survey data. This model is the natural extension of a short-run model that was estimated at the household level for 1990. This current effort will not only extend the demand analysis in time, but also give consideration to changes in vehicle stock and residence location. Results will be utilized to estimate the welfare impacts of various policies including gasoline, vehicle-milestraveled (vmt) taxes, and pay-as-you-drive insurance schemes. In addition, the U.S. survey comparison work is leading to a long-term concentrated modeling effort using the Nationwide Personal Transportation Survey for 1983 and 1990 and the Consumer Expenditure Survey for 1980 through 1992. This new modeling effort will apply a probit simulator for randomparameter, error components probits, which unlike logits, allow for differing tastes among consumers. Thus, rather than looking at the actions of the average consumer, this model will explicitly model the actions of consumers in different demographic groups, such as consumers at different lifecycle stages, income levels, and levels of educational attainment. In addition, the model will explicitly take into account the influences of trip purpose and travel time in the decisions consumers make about which travel mode to take and which vehicle to buy.

\section{References}

Schipper L, Figueroa MJ, Gorham R. People on the Move: A Comparison of travel patterns in OECDCountries. A Report to the U.S. Department of Transportation. University of California at Berkeley, 1995.

Davis WB, Levine MD, Train K. Effects of Feebates on Vehicle Fuel Economy, Carbon Dioxide Emissions, and Consumer Surplus. U.S. Department of Energy, Office of Policy, DOE/PO-0031, 1995.

Greening L, Jeng HT. Lifecycle analysis of gasoline expenditure patterns. Energy Economics 1994;16(3):217-228.

Greening L, Jeng HT, Formby JP, Cheng, DC. Use of region, life-cycle, and role variables in the short-run estimation of the demand for gasoline and miles travelled. Applied Economics 1995;27:643-656.

Greening L, Schipper L. The differences in welfare loss and greenhouse gas emission reductions across socioeconomic groups in the United States from a Pigouvian tax on gasoline. In: Into the Twenty-First Century: Harmonizing Energy Policy, Environment, and Sustainable Economic Growth, 18th IAEE International Conference Proceedings, July 5-8, 1995. Cleveland, OH: International Association for Energy Economics, pp. 11-20. 


\title{
Research to Support the Development of Energy-Efficient, Low-Polluting Automobiles
}

\author{
M.D. Levine, D. Grether,* D. Hopkins, ${ }^{\dagger}$ T. Wenzel, R. Sawyer, $\neq$ H. Stadler $\neq$
}

The U.S. has embarked on a series of efforts to create an automobile with much greater fuel economy and much lower emissions than current autos. We directed a laboratory-wide effort to contribute to the development of new vehicle technologies. The project focused on expanding existing laboratory expertise in three critical areas:

1) investigation of new power sources for low-nitrogen oxide $\left(\mathrm{NO}_{\mathrm{x}}\right)$ emitting automobiles,

2) creation of microsensors that will be a key component of advanced automobiles, and

3) analysis of the impact of vehicle technologies on urban air quality.

Scientists and regulators are beginning to agree that our worst air quality problems cannot be resolved without achieving significant reductions in $\mathrm{NO}_{x}$ emissions, an ozone precursor. On-road vehicles account for over $30 \%$ of total national $\mathrm{NO}_{x}$ emissions. We pursued two approaches to advance the development of low- $\mathrm{NO}_{x}$ power sources for electric or hybrid electric vehicles: catalytic combustion turbines and zinc/air batteries. Both approaches have the potential of having significant impacts in the intermediate term; however, they have not

\footnotetext{
* Energy \& Environment Division, LBNL.

+ Building Technologies Program, Energy \& Environment Division, LBN/L.

‡ Environmental Research Program, Energy \& Environment Division, LBNL.
}

received adequate attention to date. We have met with high-level representatives of industry and agencies to promote a national research program on catalytic combustion. In addition, we have submitted a proposal to the Electric Power Research Institute to develop bifunctional air electrodes and to test thin zinc/air battery cells.

Sensors are already widely used in today's vehicles. However, we believe that the performance and costeffectiveness of existing sensors could be greatly improved by making them much smaller. This can be done by micro-fabrication (or micro-machining), a process that uses batch-type, thin-film deposition techniques originally developed to manufacture electronic integrated circuits.

At present, micro-machined sensors are already used in automobiles for controlling airbag release and as pressure sensors for various applications. Micro-machining these sensors has led to dramatic reductions in production costs. LBNL's Center for X-Ray Optics has developed a processing capability well suited to fabricating such sensors. The basis of the capability is a technology that combines deep x-ray lithography, micro-electroplating, and molding processes. Sensors and microstructures fabricated by this process can have lateral dimensions as small as 10 micrometers, vertical dimensions less than one millimeter, and submicron tolerances. We completed an assessment of the opportunities for LBNL to develop spe- cific microsensors for application in the next generation of automobiles. The assessment identified major opportunities for automotive microsensors and microactuators; ranked their impact on fuel economy or their effectiveness in measuring emissions; and proposed the best micromachining approach for the highest ranking sensors. Two especially promising opportunities for LBNL are developing microsensors that measure exhaust gas concentrations and that measure mass air flow.

In the third area, we focused on improving the scientific understanding of the level and sources of emissions from current vehicle technologies. Better understanding of the emissions characteristics of current technologies will allow accurate evaluation of the impact of new automotive technologies on air quality. In this area we have:

- analyzed data measured by remote sensing devices to better understand the emissions from malfunctioning vehicles (see next article);

- used tunnel and roadside monitors to measure real world emission levels of nitrous acid (an ozone precursor) and nitrous oxide (a greenhouse gas);

- reviewed the literature on emissions from small engines likely to be used in hybrid electric vehicles; and

- upgraded our capabilities to perform air quality analyses of the Los Angeles Basin and performed simulations of the Basin. 


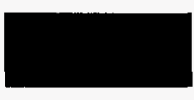

\title{
Real-World Emissions from Model Year 1993, 2000, and 2010 Passenger Cars
}

\author{
M. Ross, ${ }^{*}$ R. Goodwin, ${ }^{*}$ R. Watkins, ${ }^{*}$ M.Q. Wang, ${ }^{\dagger}$ T. Wenzel
}

In spite of great strides in lowering emissions from new vehicles, air quality is far from satisfactory in many major metropolitan areas. The large discrepancy between tested and "realworld" emissions has attracted the attention of legislators and regulators. While manufacturers have been able to meet strict certification-test (Federal Test Procedure, or FTP) standards for new cars, there are two major sources of emissions that are not covered by the current regulatory approach: emissions from driving at speeds and accelerations higher than those specified in the FTP ("off-cycle" emissions), and emissions from cars with malfunctioning emission controls.

These limitations are the main focus of a study at the University of Michigan and LBNL on the real-world average lifetime emissions of conventional cars. The purpose of the study is to determine the sources and quantities of average lifetime real-world emissions from model year (MY) 1993 cars in order to move the focus of analysis and discussion away from the regulatory emissions levels measured in the FTP. In addition, there are three more particular purposes: 1) to provide an overview of emissions to inform discussion of both design priorities and regulatory priorities; 2) to provide a basis for projecting emissions by conventional vehicles of the future, i.e., to enable realistic comparisons with emissions from proposed alternative vehicles; and 3) to advance the art of emissions modeling.

We estimated lifetime emissions from five sources: on-cycle (FTP-like) driving, including cold starts; off-cycle (non-FTP) driving; cars with malfunctioning emission controls; evaporative hydrocarbon (HC) emissions; and upstream sources (fuel extraction, transportation, processing, and distribution). We found that total carbon monoxide (CO) and $\mathrm{HC}$ emissions of MY1993 vehicles are 4 to 5 times the

\footnotetext{
* University of Michigan, Ann Arbor, MI.

t Argonne National Laboratory, Argonne, IL.
}

FTP standards, while those for nitrogen oxides $\left(\mathrm{NO}_{x}\right)$ are about twice the standard (see Figure 1). These totals are consistent with those of the U.S. Environmental Protection Agency's (EPA) emissions factor model, MOBILE5a.

We focused on the two largest sources of real-world emissions: offcycle driving and cars with malfunctioning exhaust emission controls. When high power is required, the onboard computer essentially overrides the emission controls by commanding a rich fuel-air ratio; this results in high $\mathrm{CO}$ emissions. High power driving also increases the temperature in the cylinder, leading to increases in $\mathrm{NO}_{\mathrm{x}}$ emissions. One consequence is that lowpower cars, when one attempts to drive them like high-power cars, are among the worst polluters on the road. EPA's proposed new rules for emissions certification would limit command enrichment in future vehicles.

Our analysis shows that nearly half of the overall $\mathrm{CO}, \mathrm{HC}$, and $\mathrm{NO}_{\mathrm{x}}$ emissions in MY93 cars are due to malfunctioning emission controls. We analyzed a 1991 database of emissions from a large number of California vehicles; the emissions of each car were measured as it was driven past roadside remote sensors. The data indicate that roughly $10 \%$ of 2 - to 5-year old cars have malfunctioning emission controls. We found that the probability of malfunction is strongly dependent on vehicle model, with five less expensive models of Asian manufacture averaging 22\% malfunctions, and all other models averaging $6 \%$. For each of the manufacturers, malfunctions are rare to moderately frequent in mid-price models (such as the Nissan Maxima), but fairly frequent in less-expensive models (such as the Nissan Sentra) as shown in Figure 2.

We examined these data in several ways, as well as compared them with laboratory dynamometer tests of cars driven under real-world conditions, to test the accuracy of the remote sensor data. These cross checks confirmed our result: cars from five models have malfunction probabilities several times those of all other models. We believe that these models suffer from poor initial design and/or flaws during manufacture, and that the responsibility of malfunction emissions is fundamental-

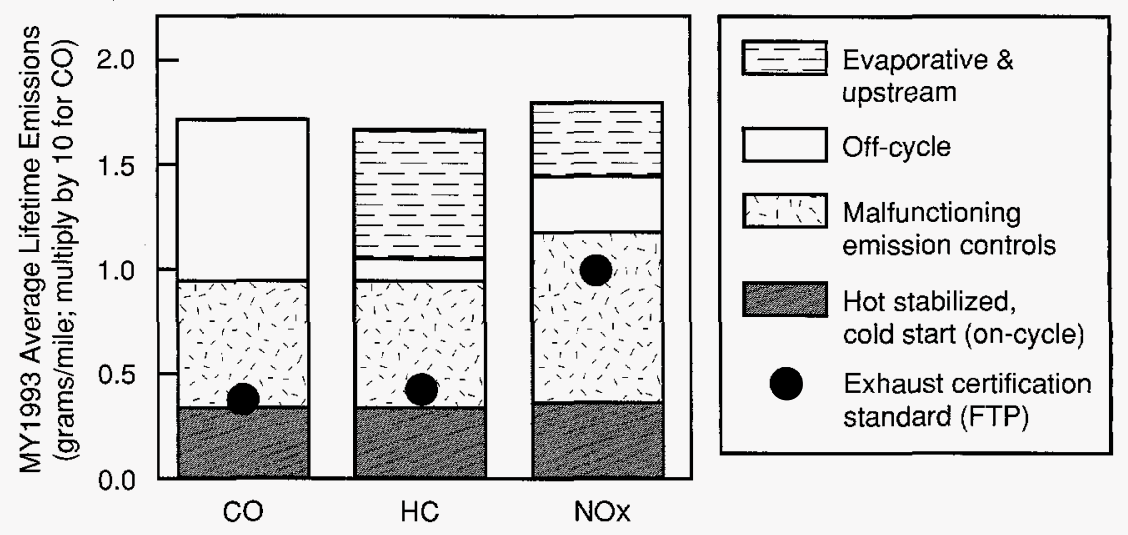

Figure 1. Although on-cycle emissions are below certification standards, total real-world emissions are several times the exhaust standards. 
ly that of the manufacturers, not that of the individual vehicle owner or mechanic. Thus, installation of durable emission controls, using existing technology, on all car models may be more effective in reducing real-world vehicle emissions than vehicle inspection programs or stricter new car exhaust standards.

The probability of malfunction tends to be substantially higher in carbureted than in fuel-injected cars; thus substantial reductions in malfunction emissions are being achieved as a result of the elimination of carbureted fuel systems (which was complete with MY1991). Nevertheless, the probability of malfunction remains high in many fuel-injected models. Figure 3 shows the potential for reducing emissions by improving the design of emission controls. For example, reducing the modelspecific malfunction probability to that of the best quartile of models $(3.5 \%)$ will result in an overall average malfunction probability of $2.6 \%$. This would cut total emissions from fuelinjected cars with malfunctioning emission controls by two-thirds. A testing program that utilizes new data collection tools, such as remote sensing devices and on-board diagnostic instruments, is needed to identify poorly designed models so that steps can be taken to install or design more durable emission controls.

\section{References}

Ross M, Goodwin R, Watkins R, Wang MQ, Wenzel T. Real World Emissions from Model Year 1993, 2000, and 2010 Passenger Cars. Lawrence Berkeley National Laboratory Report No. LBL-37977, 1996.

Wenzel T, Ross M. Emissions from Modern Passenger Cars with Malfunctioning Emissions Controls. Warrendale, PA: Society of Automotive Engineers. SAE Technical Report 960067, 1996.

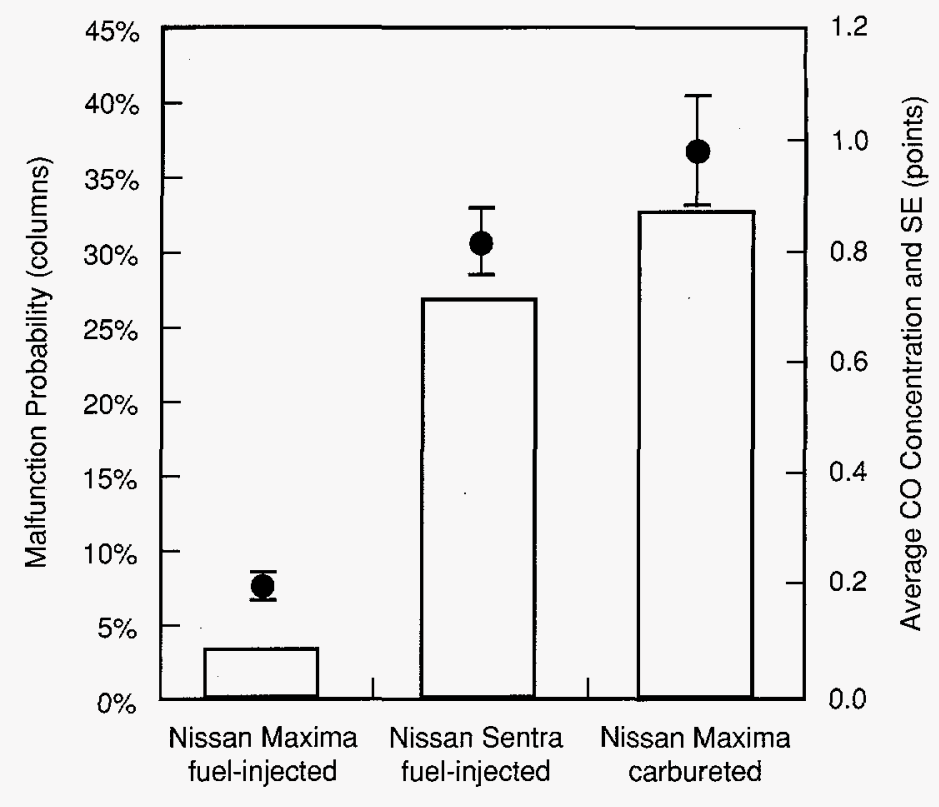

Figure 2. Malfunction probability is strongly dependent on vehicle model and fuel system $(S E=$ standard error $)$.

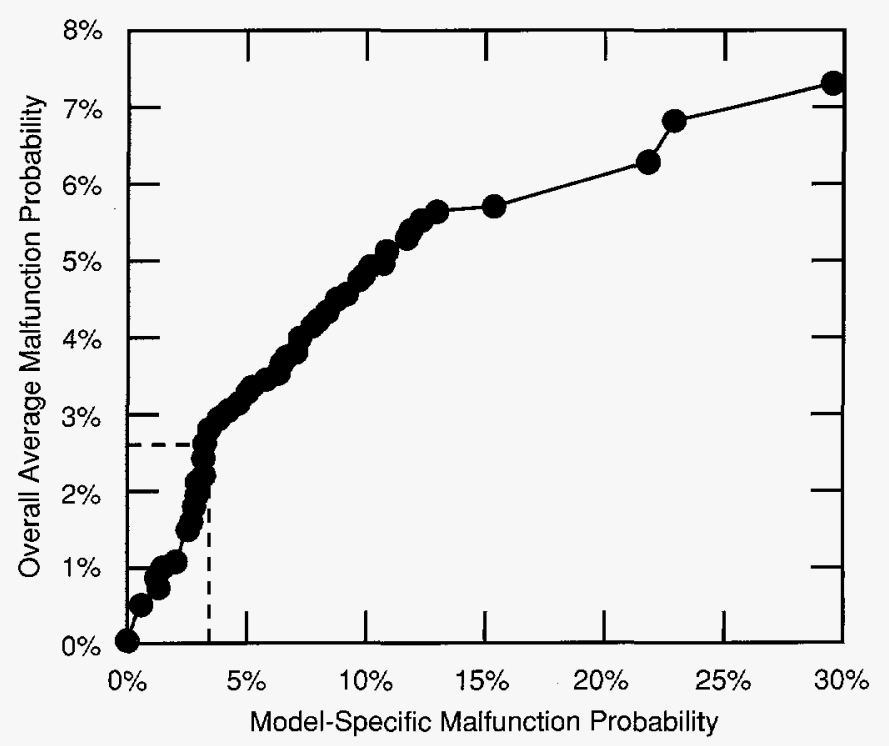

Figure 3. By reducing the malfunction probability to that of the cleanest quartile of car models, manufacturers can substantially reduce the number of malfunctions and real-world emissions. 


\section{Buildings and Their Environment}

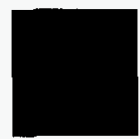

The activities of the buildings groups are diverse: they range from complex analyses of the performance of equipment in U.S. buildings to estimates of the energy performance of groups of buildings. Other work of the buildings groups includes assessing the effects of building materials and vegetation on both the energy consumption and the air quality in urban areas. On another level, large energy using appliances have been analyzed, and the energy use of personal computers has been subjected to scrutiny as part of this past year's activities.
- assessment of urban heat islands

Under the leadership of Hashem. Akbari, we continue to play a national leadership role in the assessment of urban heat islands and investigating measures to mitigate their effects. This year, an important finding, based on the work of Haider Taha, has been that a program of extensive tree planting and the use of high-albedo materials on the roofs of houses and buildings and in the makeup of roadways could improve air quality in Los Angeles more than removing all automobiles from the road.

Other activities of the heat island project have included research on the albedo of materials-including a database for "cool" materials, an assessment of paving materials, measurements of the performance of roofs made of differing materials, and the contributions to the development of standards for "cool" materials-and measurements of different microclimates.

\section{- energy technologies for buildings}

Directing the work on energy technologies for buildings, Joe Huang and colleagues have investigated the design of houses without compressive cooling in moderate California climate zones. Other studies in this area include work

\section{Tomorrow's Home $\$ 250 / y e a r$ energy bill}

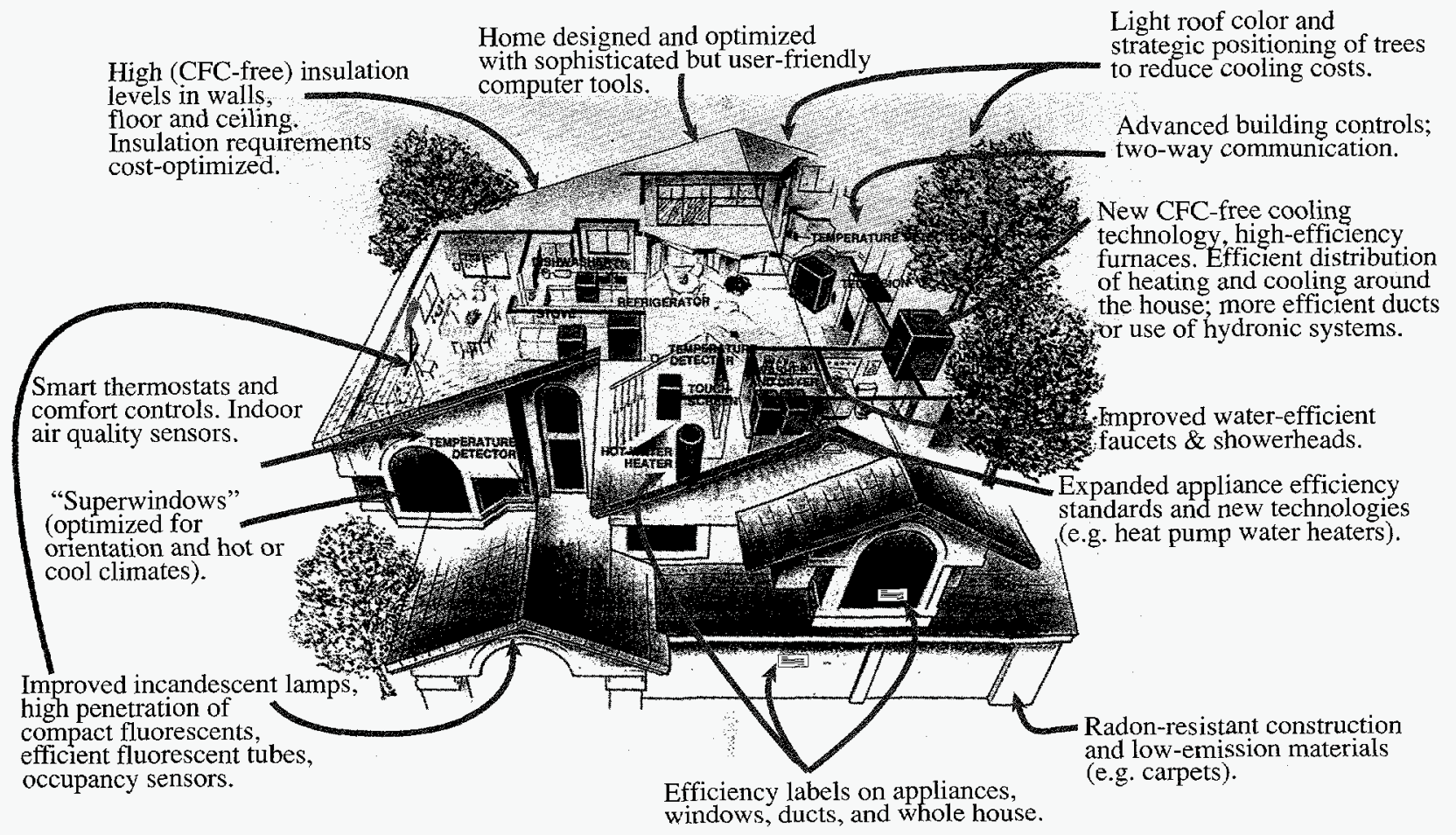


on the use of evaporative cooling and other low-energy cooling strategies in large commercial buildings.

- building commissioning

During the past year Mary Ann Piette initiated an active program exploring the issues involved in building commissioning, including the development of computer tools for commissioning commercial buildings. This work has resulted in a collaborative effort with other researchers in both the Buildings Technology and the Indoor Environment programs within the Energy and Environment Division and also with the Information and Computing Science Division.

- energy performance of residential and commercial buildings

Alan Meier and associates have completed an evaluation of the energy performance of residential buildings in the U.S., another in the series of reports produced over the past 15 years within the building energy compilation and analysis (BECA) activities. In the past year other, separate reports have also been completed on the energy performance of personal. computers as well as ice-makers in domestic refrigerators.

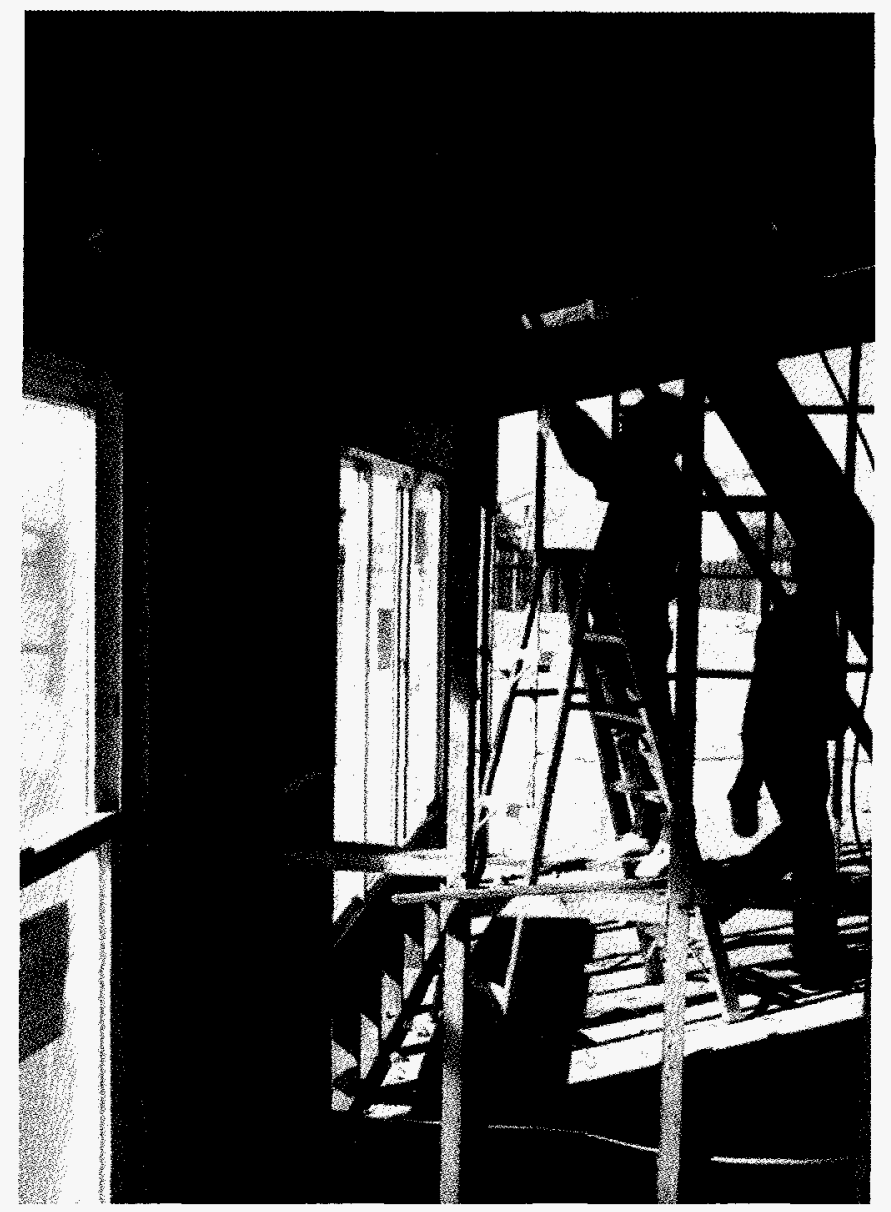

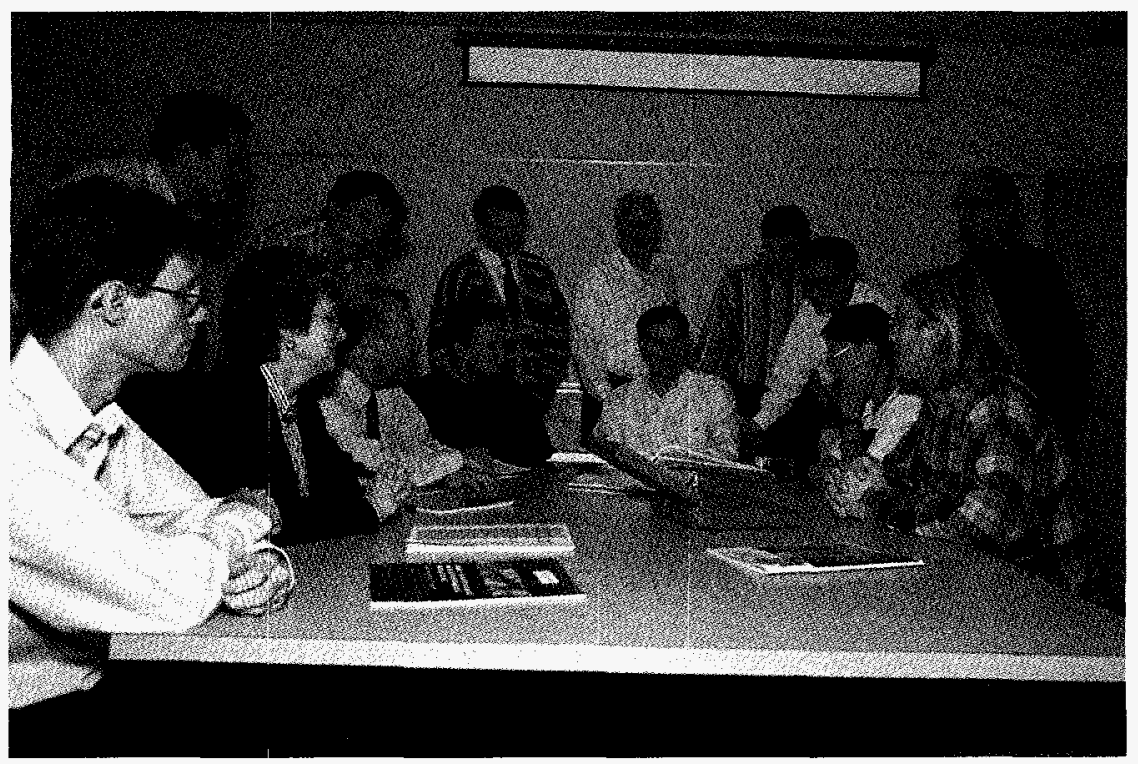




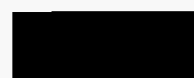

\section{Cooling Our Communities: An Overview of Heat Island Project Activities} H. Akbari

Modern urban areas usually have dark surfaces and less vegetation than their surroundings. Such differences affect the climate, energy use, and habitability of cities. Dark roofs on buildings are heated by the summer sun and raise the summertime cooling demands of buildings. The dark surfaces and reduced vegetation collectively warm the summer air over urban areas, leading to the creation of the summer urban heat island. On a clear summer afternoon, the air temperature in a typical city is about $2.5^{\circ} \mathrm{C}\left(5^{\circ} \mathrm{F}\right)$ hotter than the surrounding rural area. We have found that peak urban electric demand in five American cities (Los Angeles, CA; Washington, D.C.; Phoenix, AZ; Tucson, $\mathrm{AZ}$; and Colorado Springs, $\mathrm{CO}$ ) rises by 2$4 \%$ for each $1^{\circ} \mathrm{C}$ rise in daily maximum temperature above a threshold of 15$20^{\circ} \mathrm{C}$. Thus, the additional air-conditioning use caused by this urban air temperature increase is responsible for $5-10 \%$ of urban peak electric demand.

What can be done to counteract the heat island effect? The Heat Island Project has examined both building- and cityscale effects of the urban surface on energy use and climate. At the building scale, cool roofs reduce air conditioning loads. Numerous experiments on individual buildings in California and Florida show that painting the roof white reduces the air conditioning load between 10 and $50 \%$, depending on the thickness of insulation under the roof. At the community scale, increasing the albedo (solar reflectance) of urban surfaces and planting trees in urban areas can limit or reverse the urban heat island effectively and inexpensively. An estimate of the national impact of cool surfaces and shade trees (combining the cooling effect at the building level and communitywide cooling) is summarized in the Table.

For highly absorptive (low-albedo) surfaces, the difference between the surface and ambient air temperature, may be as high as $50^{\circ} \mathrm{C}\left(100^{\circ} \mathrm{F}\right)$, while for less absorptive (high-albedo) surfaces, such as white paint, the difference is about $10^{\circ} \mathrm{C}$. For this reason, shade trees (i.e., trees that directly shade buildings) and cool surfaces (which absorb little of the incident insolation) are effective means of cooling buildings and reducing energy use.
Through direct shading and evapotranspiration, trees reduce summer cooling energy use in buildings at about $1 \%$ of the capital cost of avoided power plants plus air-conditioning equipment. Cool surfaces are more effective than trees and cost little if color changes are incorporated into routine re-roofing and resurfacing schedules. In addition, the results from lightcolored surfaces are immediate, while it may be ten or more years before a tree is large enough to produce significant energy savings.

Reflective urban surfaces and shade trees also reduce smog. We simulated the cooling achieved by increasing the solar reflectance of roofs and roadways in the Los Angeles Basin. The results show a $2^{\circ} \mathrm{C}\left(4^{\circ} \mathrm{F}\right)$ cooling by noon, when smog is forming rapidly. Putting these results into the Los Angeles smog model then predicts a reduction in population-weighted smog of $10-20 \%$.

The Table describes the potential savings. However, achieving this potential is conditional on receiving the necessary federal support. Programs for planting shade trees already exist, but starting an effective and comprehensive program requires research and material development, wholesale technology transfer and implementation guidelines, and outreach activities. In the following articles we briefly discuss some of the progress in these areas in FY 1995. Taha examines the impact of large-scale albedo and vegetation modifications on ozone air quality in the Los Angeles Basin. Pomerantz et al. present the results of a project to estimate direct energy cost savings from cool roofs in Sacramento, CA. His work is complemented by Taha et al., who present the

Table. Basecase U. S. air-conditioning use and savings potential of cool surfaces and shade trees. We estimate that $20 \%$ of air conditioning can be avoided by the year 2015 .

\begin{tabular}{|c|c|c|c|}
\hline & \multirow{2}{*}{$\begin{array}{c}1995 \\
\text { Basecase }\end{array}$} & \multicolumn{2}{|c|}{2015} \\
\hline & & Basecase & Savings* \\
\hline Electricity (TWh) & 440 & 540 & 108 \\
\hline $\mathrm{Cost}^{\dagger}$ (billion $\$$ ) & 44 & 54 & 11 \\
\hline $\mathrm{CO}_{2}(\mathrm{MtC} \ddagger)$ & 110 & 135 & 27 \\
\hline
\end{tabular}

result of their meteorological modeling and estimating energy impacts of cool surfaces in several U.S. regions. In our field measurement activities, Levinson and Akbari discuss preliminary data on the rate of evapotranspiration from a tree while Smith and Akbari present a study of microclimate variation around a house in a suburban setting. Berdahl et al. discuss a database for cool materials, focusing on roofing materials. Discussion of cool paving materials is presented by Pomerantz et al. Our database activities are complemented by the development of American Society for Testing of Materials (ASTM) standards for measuring solar reflectance and thermal emittance of construction materials and comparing their steady-state surface temperatures, as presented by Akbari.

\section{References}

Akbari H, Davis S, Dorsano S, Huang J, Winnett S (eds.). Cooling Our Communities: A Guidebook on Tree Planting and Light-Colored Surfacing. U.S. Environmental Protection Agency, Office of Policy Analysis, Climate Change Division. Lawrence Berkeley National Laboratory Report No. LBL-31587, 1992.

Akbari $H$, Rosenfeld A, Taha $H$. Summer heat islands, urban trees, and white surfaces. In: Proceedings of American Society of Heating, Refrigeration, and Air Conditioning Engineers, February 10-14, 1990. Atlanta, GA: American Society of Heating, Refrigeration, and Air Conditioning Engineers. Also published as Lawrence Berkeley National Laboratory Report LBL28308, 1990. 


\section{Ozone Air Quality Implications of Large-Scale Albedo and Vegetation Modifications in the Los Angeles Basin}

\section{H. Taha}

Increasing the urban surface albedo (solar reflectance) and urban reforestation are two innovative measures that have the potential to reduce the formation of photochemical smog. Implementing these strategies can reduce regional air temperatures, the need for cooling energy, and associated emissions of oxides of nitrogen from power plants. Lowered air temperatures would also reduce temperaturedependent emissions of reactive organic gases from vegetation, reduce anthropogenic evaporative losses from mobile sources, and slow down the chemical reactions responsible for producing photochemical smog. One region targeted for the implementation of these strategies is the Los Angeles Basin, whose summer mesoscale meteorology and air quality are modeled in this project.

The meteorological and photochemical modeling work performed in this study indicates that implementing high-albedo materials and urban vegetation in the Los Angeles Basin would have a net effect of reducing ozone concentrations (see Figure). For example, if the albedo of roofs is increased by 0.35 and that of pavements by 0.25 , and two trees were added to each house, the domainwide population-weighted exceedance exposure to ozone above the National Ambient Air Quality Standard (120 parts per billion (ppb) ozone) would be decreased by up to $20 \%$ (or more) during a typical summer day in late August.

These improvements in air quality are on the same order of magnitude as those gained from implementing other major strategies, such as mobile source emission control. Based on 1987 emission. inventories, the simulations indicate that the air quality benefits of albedo and vegetation increase strategies are comparable to those of converting all mobile sources operating in 1987 in the Basin to zeroemitting vehicles. 'These findings are for ozone reductions only; removing or converting motor vehicles have several other advantages as well. At this time, this comparison is preliminary since there are uncertainties in the modeling system and emission inventories. These findings will be updated as other episodes are studied and more representative emission inven- tories become available. This study also identified those tree species (hydrocarbon-emitting trees) that should not be planted because they would worsen the air quality.

In its 1994 Air Quality Management Plan the South Coast Air Quality Management District has considered highalbedo materials and urban vegetation as potential strategies for improving the ozone air quality. Our modeling studies are currently paving the way for the development of a RECLAIM equivalent for high-albedo materials and low-emitting urban trees. (RECLAIM is an acronym for the Regional Clean Air Incentive Market, developed for the California. South Coast Air Basin.)

\section{References}

Taha H. Modeling the impacts of increased urban vegetation on the ozone air quality in the South Coast

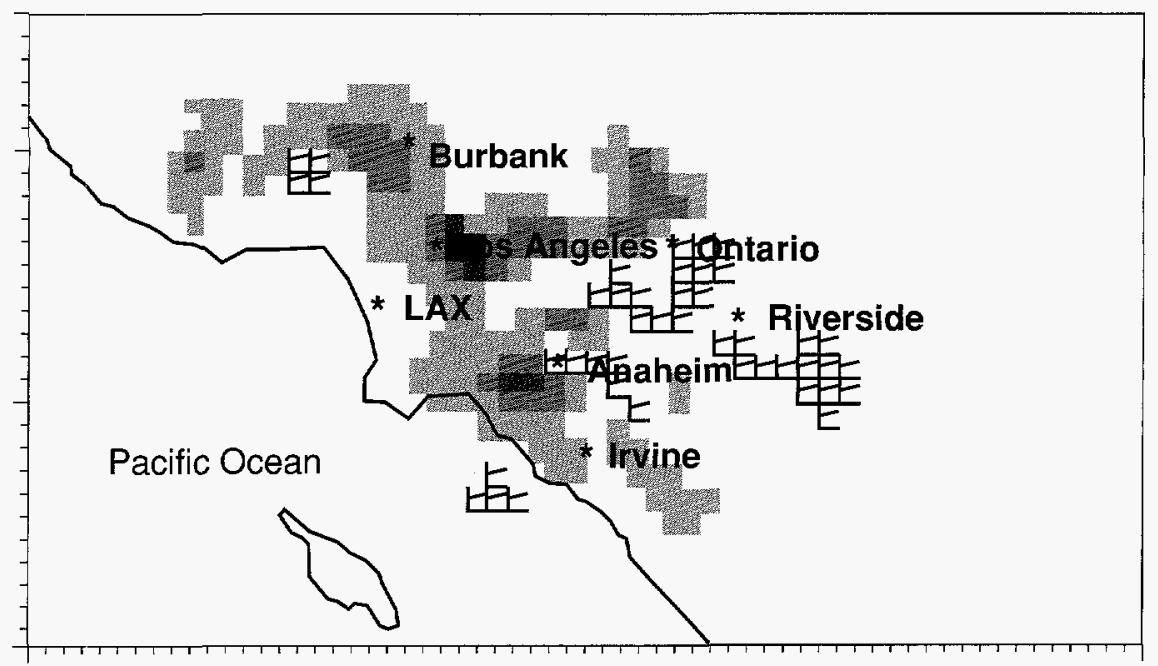

Ozone concentration difference $(\mathrm{ppb})$
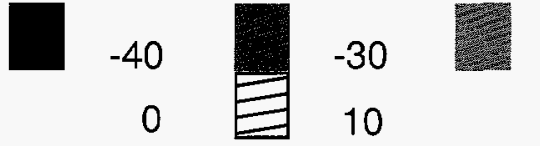

$-20$

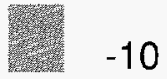

10

20

Figure. Changes in ozone concentrations (ppb) at 3 P.M. on August 27, due to increased vegetation cover in the Los Angeles Basin. The simulations were based on the assumption that between 16 and 20 million trees have been planted in the region. 


\title{
Energy Cost Savings From Cool Roofs in Sacramento, California
}

\author{
M. Pomerantz, H. Akbari, S.J. Konopacki
}

The energy and cost savings that might be achieved by modification of the solar reflectance (albedo) of roofs in Sacramento, CA, was estimated. Heating of the roofs by sunlight is a major load on the air-conditioning systems of buildings in hot, sunny climates. The heating can be reduced by making the roof more reflective of sunlight (increasing albedo). Based on aerial photographs, we estimated the distribution of albedos of roofs of both residential and commercial buildings in Sacramen- to. We observed that they are relatively dark; with available roofing materials they could be made significantly more reflective. Using the DOE-2.1E building energy analysis program, we calculated how much the cooling and heating energy costs of these buildings would change if maximally reflective roofings were installed. This estimate includes the extra heating in winter, which turns out to be small. After summing over the distribution of roof albedos and the building stock, we estimated that at least $\$ 16$ million per year might be saved in Sacramento County if the roofs were changed from their present albedos to a practical maximal value of 0.7 . For residences, this is about $\$ 35$ per year net savings. If the surcharge for highalbedo roofing is less than about $\$ 3.25$ per $\mathrm{m}^{2}$ ( 30 per $\mathrm{ft}^{2}$ ), the savings over the lifetime of the roof will pay for the extra cost. These results will be extended to other U.S. cities in warm regions to obtain an estimate of the savings possible in the entire nation.

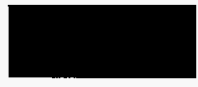

Modeling the Meteorological and Energy Impacts of Urban Heat Island Control in the U.S.

\section{H. Taha, S. Gabersek, S.J. Konopacki}

A mesoscale meteorological modeling study was undertaken to assess the impacts of urban heat island control strategies on urban meteorology and energy use in several U.S. cities. We modeled the impacts of large-scale use of high-albedo (reflective) materials in building and urban surfaces and the impacts of urban reforestation. Nine large regions, about $100000 \mathrm{~km}^{2}$ each, were simulated. For each region, domain-averaged direct and indirect impacts of these strategies on energy use were quantified.

In the past, simulations of the direct (small-scale) effects of heat island control strategies on energy use have been performed on an annual basis using the DOE-2 building energy analysis program. The indirect (urban-scale) effects have been simulated and assessed over much shorter time-scales, e.g., a few days in summer, because mesoscale meteorological models cannot be easily adapted to run for an entire year. In this study, a methodology was developed to extrapolate "episodic" simulations of the indirect effect to include an entire year at each location. This allowed us to account for the direct and indirect impacts of urban heat island mitigation strategies on heating energy use in winter as well as cooling energy use in summer.
The Colorado State University Mesoscale Model (CSUMM) was used to simulate the regional meteorology and its modification. Episodic simulations of a few days at a time were performed for each region. To assess the direct and indirect energy implications of large-scale albedo and vegetation cover modifications, the DOE-2 program was used to simulate four prototypical buildings in each region using weather data generated by the meteorological model.

The mesoscale meteorological modeling results indicate that heat islands in Atlanta, Chicago, and New York may reach $2-3^{\circ} \mathrm{C}$ higher than the suburbs in the afternoon in summer, but only $1.5^{\circ} \mathrm{C}$ higher in Dallas and Phoenix. The Houston, Washington D.C., and Philadelphia heat islands are on the order of $\sim 2^{\circ} \mathrm{C}$, whereas Miami did not appear to have any heat islands, probably due to its coastal, open location. These heat islands were the direct consequences of low vegetation cover, surface moisture, and albedo and higher anthropogenic heating in urban areas. In terms of urban cooling through implementing high-albedo materials and urban forest strategies (combining impacts of reflective materials and trees), this mesoscale modeling study suggests that New York, Philadelphia,
Washington D.C., and Atlanta have the highest potential for cooling (up to $2^{\circ} \mathrm{C}$ reduction in air temperature). Dallas, Chicago, Houston, and Phoenix follow, with temperature reduction of up to $1.5^{\circ} \mathrm{C}$. Miami has the smallest cooling potential, up to $1^{\circ} \mathrm{C}$ reduction. The modeling results also suggest that cities with large surface areas available for modification are the ones that benefit most from heat island mitigation strategies, e.g., New York (see Figure).

Building simulations with the DOE-2 program indicate that energy savings on the order of 3-35\% are attainable with modifications in albedo and vegetation cover. The savings at each location depend on building type and thermal integrity, weather, and other location-specific conditions. Simulations indicate that the percentage of total energy savings attributable to the indirect effects is between $10 \%$ and $40 \%$ (i.e., the direct effects contribute $60 \%$ to $90 \%$ to total savings). However, the indirect effects in these simulations are probably underestimated because the meteorological model simulates conditions in the boundary layer (e.g., above roof level) not in the canopy layer (e.g., under a vegetation stand or within street canyons) where air temperature is more responsive to changes in surface properties. Future work on these mod- 
els should allow us to obtain "belowthe-canopy" estimates of reductions in temperature and, thus, savings in energy use. An important conclusion we reached based on the results of the modeling work is that wintertime penalties in heating energy use are very small or negligible in most cases.

\section{Reference}

Gabersek S, Taha H. A Preliminary Multi-City Assessment of the Impacts of Increased Urban Albedo and Vegetation on Regional Meteorology and Energy Use. Lawrence Berkeley National Laboratory Report No. LBL-37887, 1995.

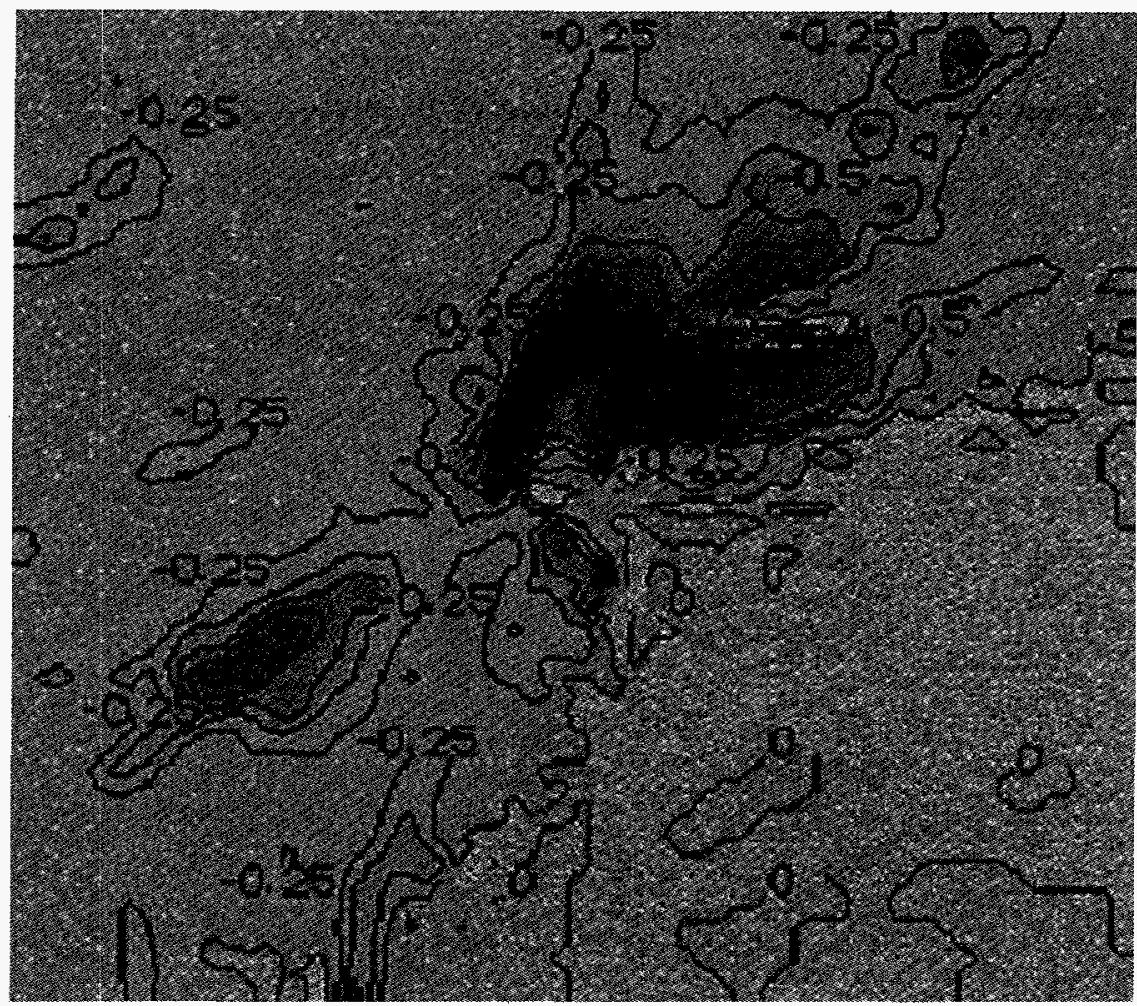

Figure. Simulated cooling $\left({ }^{\circ} \mathrm{C}\right)$ at 3 P.M. on a typical July 25 in the New York modeling region resulting from large-scale use of reflective materials and urban trees. Blue areas indicate a temperature decrease; the darker the blue, the greater the temperature decrease. A large area has cooled by as much as $2^{\circ} \mathrm{C}$ over New York City, Long Island, Newark, and Philadelphia. (Red areas indicate a slight increase in temperature.)

\section{Measurement of the Evapotranspiration Rate of a Tree}

R. Levinson, H. Akbari

Evapotranspiration from a small tree was measured in order to model the performance of a tree as a source of moisture and evaporative cooling in the the summer season. The objective of the project was to determine how the rate at which the tree releases water into the air depends on soil moisture and ambient weather conditions (see Figure 1). Sensitive air temperature sensors were set upand downwind of the tree to measure the extent to which air is cooled as it passes through the tree canopy and evaporates water from the tree's leaves.

A two-meter-high potted Japanese privet tree (with a cross section of $0.6 \mathrm{~m}^{2}$ ) rested on a load cell that weighed the tree, while sensors on the tree, in the soil, and on an adjacent weather tower measured the ambient air temperature, relative humidity, insolation, wind speed, wind direction, soil moisture, sunny leaf temperature, and shaded leaf temperature (see Figure 2). By collecting data at onesecond intervals, events that rapidly perturb the system, such as adding water to the tree soil, could be distinguished from slower events, like evapotranspiration. Correlating the differences in air temperatures measured upstream and downstream of the tree's canopy with the instantaneous wind direction made it possible to investigate slight evapotranspiration-driven air temperature depres- sions that would otherwise be masked by the small errors in air temperature measurements caused by solar heating of temperature sensors.

Preliminary analysis of the data reveals that this small tree transpired 200400 grams of water per hour on summer days, equivalent to a cooling potential of $125-250$ watts $\left(210-420 \mathrm{~W} / \mathrm{m}^{2}\right)$. We estimate that a well-watered typical tree with a canopy diameter of $5 \mathrm{~m}$ could produce 1.4-2.8 tons of cooling per day.

In the coming year, we will analyze these data and develop correlations between the rate of evapotranspiration and ambient conditions. 

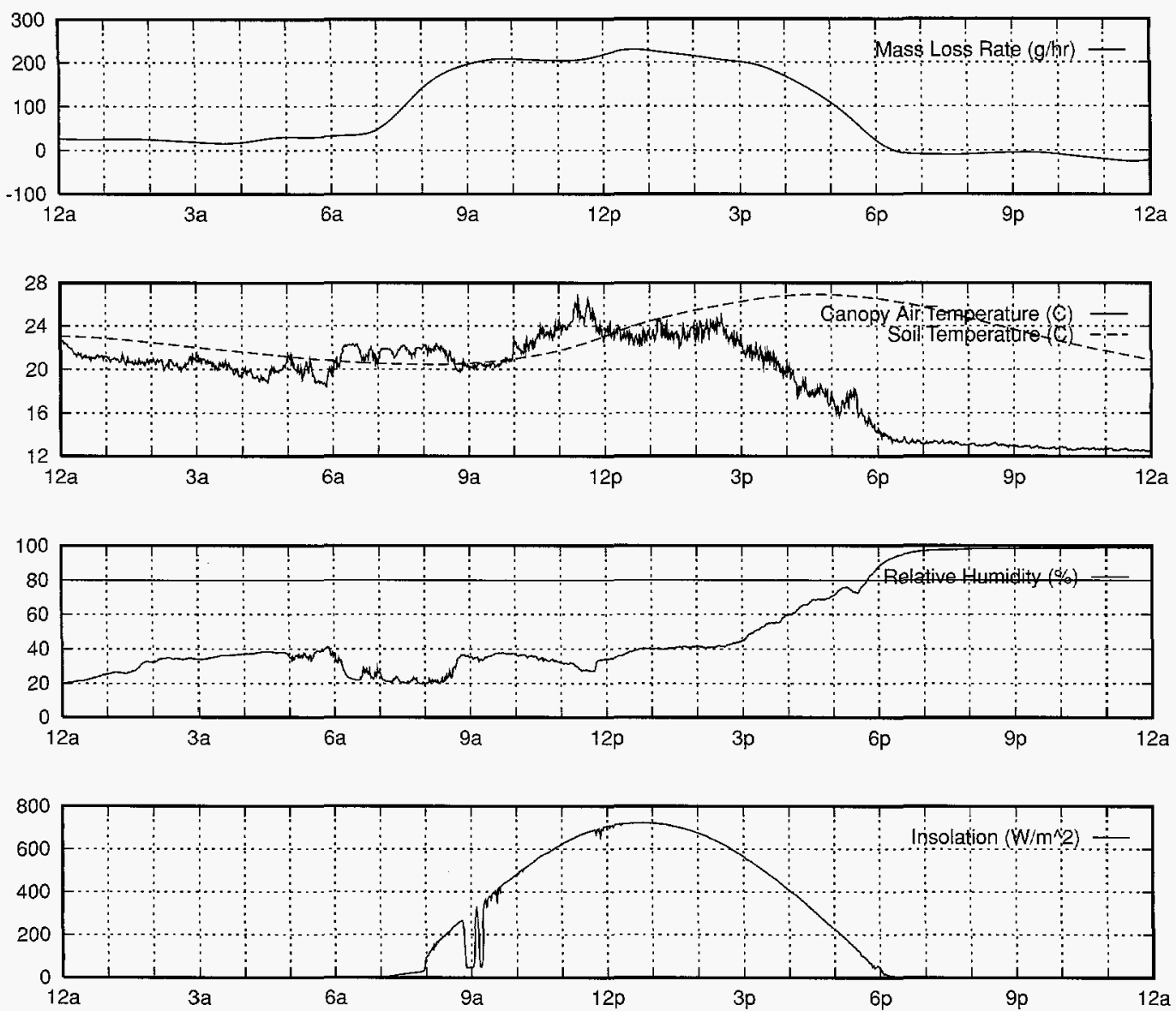

Figure 1. A small potted Japanese privet tree lost water at the rate of $200 \mathrm{~g} / \mathrm{hr}$ on a warm, sunny, and dry afternoon in mid-October.

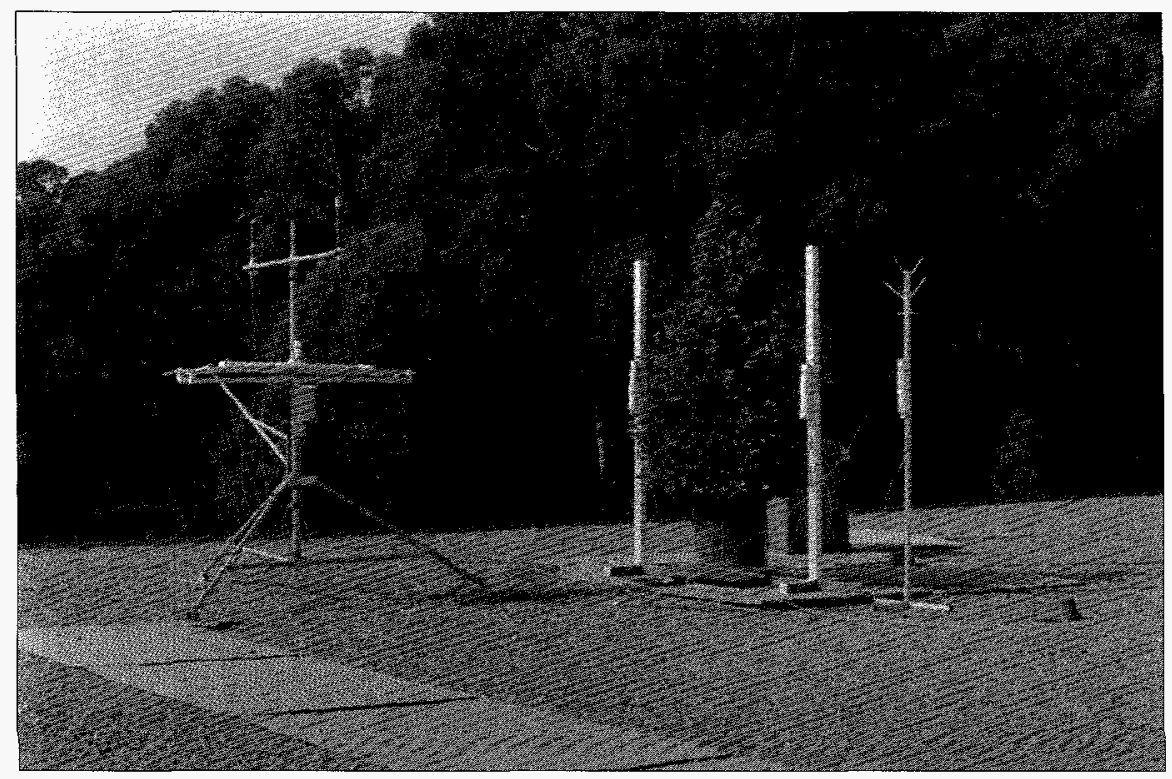

Figure 2. A load cell beneath the tree sensed changes in the tree's mass, while nearby instruments measured air temperatures, humidity, wind speed, and other ambient environmental conditions. The tree and weather station resided on the roof of a building at the Lawrence Berkeley National Laboratory. 


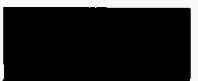

\section{Microclimate Variation in the Suburban Environment}

\author{
C.K. Smith, H. Akbari
}

One focus of research in the Heat Island Project is the use of shade trees and high-albedo surfaces to reduce urban temperatures. In addition to cooling surfaces and structures in their immediate vicinity, such features can contribute to the reduction in air temperature over an entire neighborhood, resulting in a neighborhood-wide or indirect cooling effect.

Experiments to assess the potential magnitude of these indirect effects often compare air temperatures measured near the ground in neighborhoods having different albedos or densities of trees. Necessity dictates the measurements be made at one or a few discrete locations. Yet the urban and suburban environments are filled with man-made and natural features that alter the ambient air temperature in their vicinity, i.e., they give rise to localized or microclimate effects. If discrete air temperature measurements are to reflect an entire neighborhood, the influence of microclimate effects on these measurements must be minimized.

We performed an experiment to monitor ambient air temperature at 18 locations around a suburban residence, from which we identified a multitude of microclimate effects. Temperature data, along with horizontal insolation, relative humidity, and wind speed and direction, were logged every 2.7 seconds for the period September 11 to November 7,1994 .

In the absence of any objective measure of the unperturbed neighborhood climate of the site, we used the spatial average temperature, derived from 13 locations monitored continuously over the course of the experiment. For each location, the difference from the spatial average temperature was taken to be a measure of the microclimate effects.

The microclimate effects at each location followed a diurnal pattern characteristic of the local environment. Fourteen days of temperature-difference data were co-averaged to show a diurnal microclimate profile for each location (Figure).

Locations close to the home wind break; (d) in open yard. showed a daytime peak in their difference profiles, while those near the location of shade trees and away from the home showed a daytime trough. The amplitude of the features reached 2 to $3^{\circ} \mathrm{C}$ on a warm day $\left(25^{\circ} \mathrm{C}\right)$. The vertical offset of the diumal profile was also related to features in the local environment. Nighttime behavior is governed mainly by the view factor (fraction of full sky seen from each location) and the distance from high thermal mass features (such as the home).

Some locations had diurnal difference profiles that peak at about $0^{\circ} \mathrm{C}$ (i.e., the temperature was close to the spatial average). The same locations show a depressed nighttime temperature relative to the spatial average. They have high view factors, are away from surfaces of low reflectivity, and are out of the wind shadows of structures. These are optimal locations for neighborhood temperature measurement.

The sensitivity of the microclimate variations to changes in the overall tem-

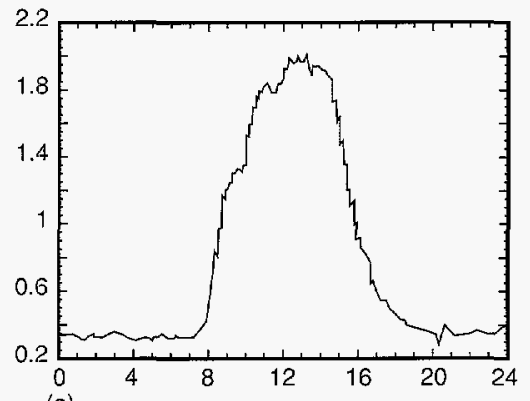

(a)
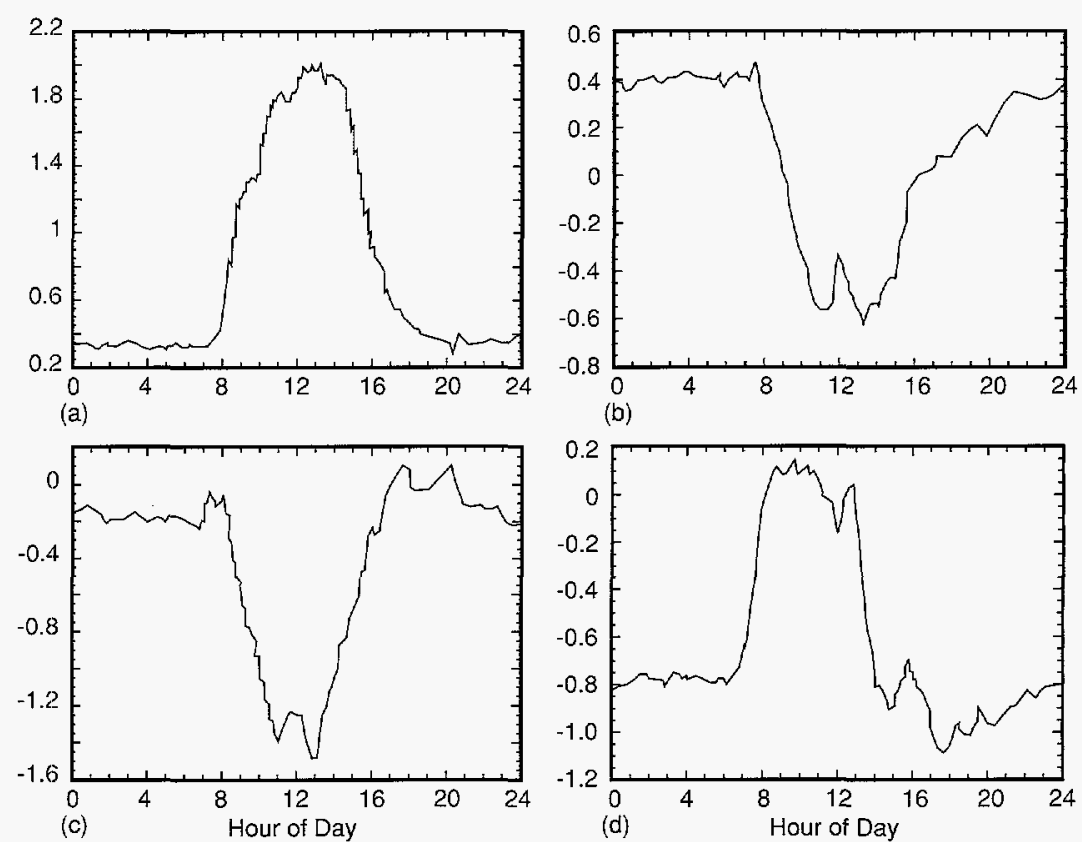

(b)

perature was explored by regressing the daytime extremes of the temperature difference against the maximum daily average temperature. The daily peaks generally became higher and daily troughs became lower by a few tenths of a degree per 10-degree increase in average temperature. Put simply, the microclimate effects that dominate during the day become stronger on a warmer day.

The results of the analysis allowed us to formulate a protocol for minimizing the effects of microclimate variation on neighborhood temperature measurements in the urban and suburban environment. The protocol will be used in designing experiments to assess the impact of indirect cooling effects on urban air temperatures.

\section{Reference}

Smith CK, Akbari H, Bretz S. Microclimate Effects Near the Ground in the Suburban Environment. Lawrence Berkeley National Laboratory Report No. LBL-37876, 1996.

Figure. Diurnal patterns of microclimate variation (expressed as the temperature difference from the average): (a) near house; (b) under large walnut tree; (c) next to redwood 


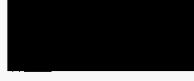

A Database for Cool Materials

P. Berdahl, H. Akbari, L. Gartland, C.K. Smith, F. Yang

To design buildings that can provide comfort with less air-conditioning energy use, we need information about materials that remain cool in the sun. Cool materials that reflect incident solar energy back out to space can also be used to cool entire cities. While it is certainly well known that white materials are useful (and black materials are poor) for these purposes, reliable and accurate information on the "coolness" of construction materials is often lacking. Particularly important are roofing materials. To satisfy the need for better information, a Cool Materials Database is being constructed.

Most common roofing materials absorb solar radiation, reflecting only a small portion of the incident energy. Dark roofs reach peak temperatures of $82^{\circ} \mathrm{C}\left(180^{\circ} \mathrm{F}\right)$ on hot, calm sunny days, Such high temperatures lead to significant heat conduction into the building through the roof insulation and into airconditioning ducts. Roof temperatures are determined primarily by the heat bal- ance at the outer roof surface. High solar reflectance is obviously desirable. In addition, the building designer wishes to enhance heat transfer from the hot roof to the environment, which occurs by thermal emission of infrared radiation and by heat convection.

Solar reflectance values are found in the literature for a few building materials, but the available information is quite limited. Manufacturers, if they measure reflectance at all, often measure the visible reflectance. However, at least half of the energy content of sunlight is in the invisible infrared and ultraviolet portions of the spectrum. The best procedure for measuring solar reflectance in the laboratory is the use of a spectrometer to measure the monochromatic reflectance across the solar spectrum, as is shown for some white roof coatings in the Figure. Then a standard solar spectrum is used as a weighting function to compute the overall fraction of solar energy reflected under typical atmospheric conditions. In our laboratory, we perform these mea-

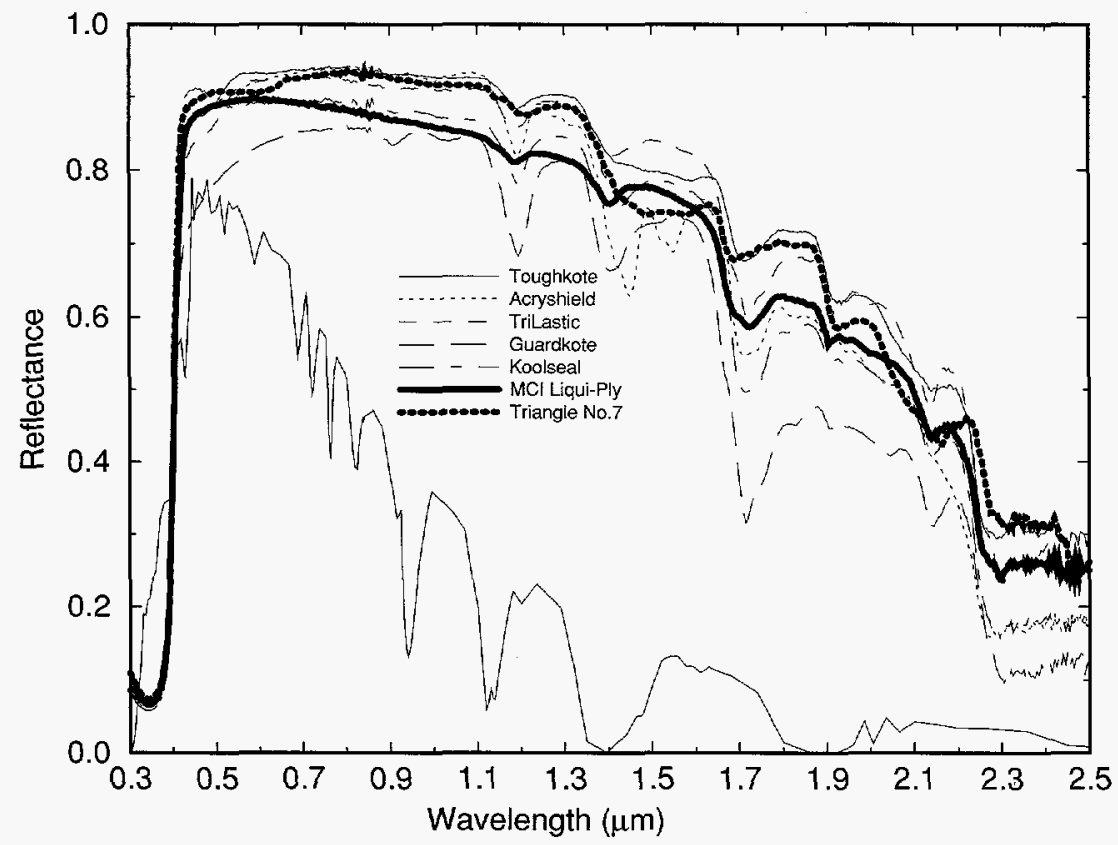

Figure. Spectral reflectance of seven white roof coatings. Also shown is the shape of the solar spectrum (lower curve), which indicates how the solar energy is distributed over wavelength. The overall solar reflectances of these materials are Toughkote, 0.85; Acryshield, 0.83 ; TriLastic, 0.83 ; Guardkote, 0.74; Koolseal, 0.81; MCI, 0.80; and Triangle No. 7, 0.84 . These values are typical for high-quality white roof coatings.

surements with a Perkin-Elmer Lambda 19 US-VIS-NIR spectrometer fitted with a Labsphere integrating sphere.

Infrared emittance values for building materials have not been widely measured. A common strategy for non-metals and metals with opaque coatings is to assume the emittance is independent of wavelength and equal to 0.9 , as is often the case. However, measurements are needed to see how generally this rule of thumb is applicable. Bare metal surfaces and aluminum-pigmented coatings are known to have lower emittances, which also vary with wavelength in the thermal infrared range. We have recently completed the setup of a new instrument, a Spectral Emissonmeter, which permits the determination of spectral emittance from 5 to 40 micrometers wavelength. It consists of a Bruker Instruments IFS 28 Fourier Transform InfraRed (FTIR) spectrometer, fitted with an external port and an external chamber for housing the heated sample under test.

In the next year, an initial version of the Cool Materials Database will be published in paper and electronic forms. It will include tabulations of solar reflectance and infrared emittance of building materials and lists of manufacturers. It will be accompanied by analyses that interpret the data and provide advice for its use. In-house measurements of solar reflectance and infrared emittance will be used to provide data not otherwise available and to allow us to evaluate the data we are able to obtain from other sources.

\section{Reference}

Berdahl P, Bretz S. Preliminary survey of the solar reflectance of cool roofing surfaces. Energy and Buildings, Special Issue on Urban Heat Islands and Cool Communities, 1995 (in press). 


\section{Paving Materials for Heat Island Mitigation}

\section{Pomerantz, H. Taha, A. Chen, A. Rosenfeld ${ }^{+}$}

One of the causes of higher temperatures in cities (compared to their environs) is the absorption of sunlight by dark pavements. In warm climates, this absorption can contribute damage to the environment by adding to airconditioning electrical demand and smog. In this work, the dollar value of potential savings from lighter pavements is estimated.

We examined the effect of paving urban roads, driveways, and walkways with materials that are lighter colored than black asphalt. The lighter color means that the sunlight is reflected rather than absorbed, and so the pavement is cooler. If a pavement is cooler, its lifetime is longer and the environmental damage of disposing of it is lessened. Reflectivity is also a safety factor in visibility at night, and this factor reduces the demand for electric lighting for streets. The drawback of high reflectivity is glare, which may be a limiting consideration. We considered new pavements, which are made of cement concrete; more flexible surfaces, like asphalt concrete; and porous pavements, such as grass pavers. We also reviewed materials for resurfacing existing pavements. We assembled information on the compositions of the materials, their suitabilities for particular applications, and their approximate costs.

We have shown by computer simulation that, if all possible pavements were whitened to an albedo of 0.35 , the cooling of the city would save electricity and reduce smog damage. The present dollar value of these savings in Los Angeles is estimated to be $\$ 1.80 / \mathrm{m}^{2}$ $\left(\$ 0.17 / \mathrm{ft}^{2}\right)$ of pavement. The cost of pavement depends on the amount of material used. If the surface layer is thin enough, its cost may be sufficiently low that the savings from a lighter color would pay for any extra cost. Thus, it may happen that a lighter pavement is overall less costly than a dark one. We illustrate this in the Figure. If the sav-

*Center for Building Science, Energy \& Environment Division, LBNL

${ }^{\dagger}$ Senior Advisor for Energy Efficiency, Office of Energy Efficiency \& Renewable Energy, U.S. DOE. ings is $\$ 1.80 / \mathrm{m}^{2}$, for a $6-\mathrm{mm}(1 / 4$-in.) thick resurfacing, money would be saved, as long as the extra costs of the aggregate and binder are within the triangle to the left of the filled circles. For example, an increase of binder price by $\$ 1.64$ per liter ( $\$ 6.25$ per gallon) and no increase in aggregate price will not increase the pavement cost more than $\$ 1.80 / \mathrm{m}^{2}$. Or, aggregate priced at $\$ 138$ per $\mathrm{Mg}$ ( $\$ 126$ per ton) more than present cost, and no increase in binder price, could be used without exceeding the benefits of the cooler surface. Such aggregate can be quite white and yield a more reflective surface, with no overall extra cost to society. If the pavement is $25 \mathrm{~mm}$ (1 in.) thick, the range of affordable price increases is confined to the area below the line defined by the open squares. The four times thicker surface implies a four times smaller range of affordable price increases.

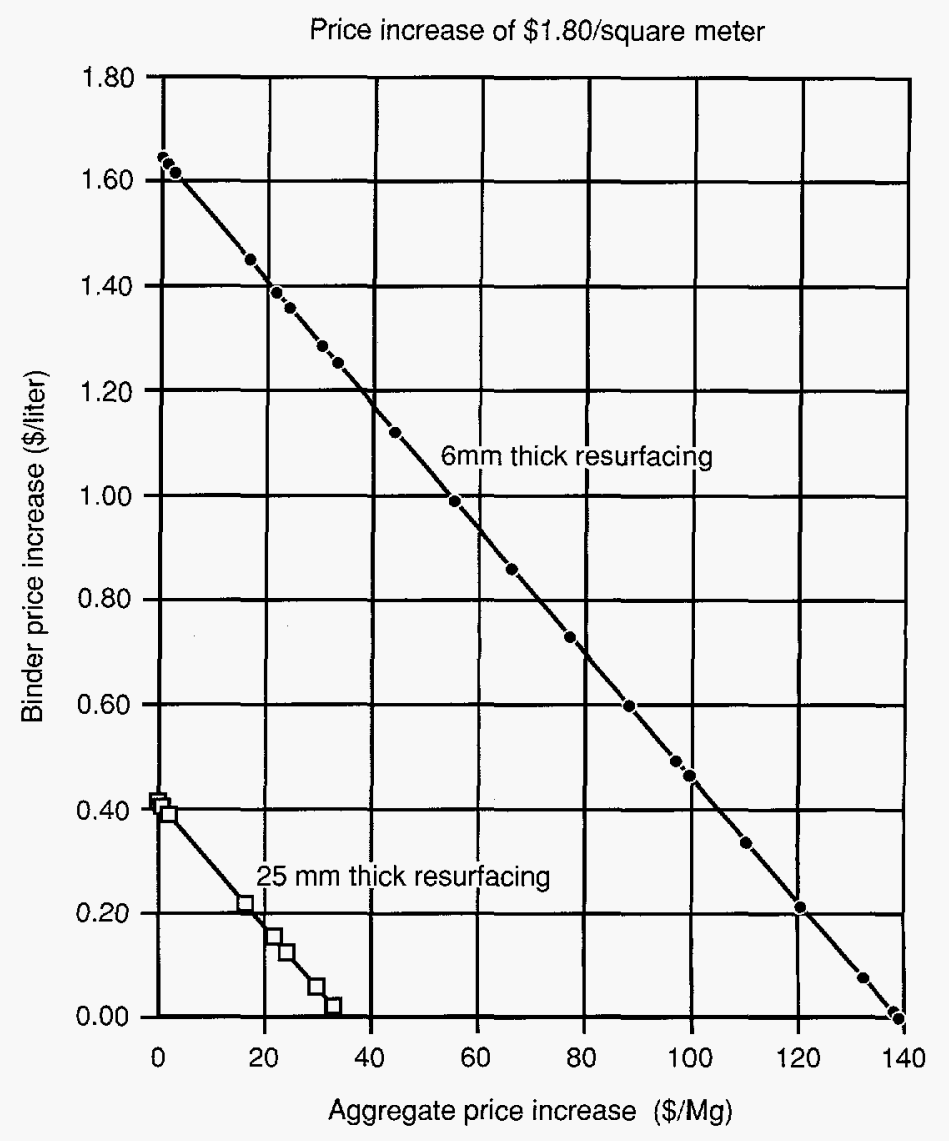

Figure. The savings resulting from a cooler pavement are greater than the extra costs, if the extra costs of the aggregate and binder are within the triangle to the left of the solid line for a 6 - $m m$ thick resurfacing. The savings exceed the extra cost as long as the materials prices are within the triangle to the left of the line for the $25-\mathrm{mm}$ thick resurfacing. 


\section{ASTM Standards for Cool Construction Materials}

\section{H. Akbari}

We have examined the impacts of using cool surfaces (cool roofs and pavements) on reducing the urban air temperature and hence reducing cooling energy use and smog. At the community scale, increasing the solar reflectance of urban surfaces can effectively and inexpensively limit or reverse an urban heat island. An estimate of the national impact of cool surfaces (combining the cooling effect at the building level and community-wide cooling) is summarized in the Table.

Achieving these potential savings, however, is conditional on receiving the necessary federal support. An important step in initiating an effective program in this area is to work with the American Society for Testing of Materials (ASTM) and the industry to create test procedures, ratings, and labels for cool materials. A subcommittee of ASTM E06, on Cool Construction Materials, was formed as part of a national plan to exploit cool construction technology and materials.

In 1994, a group of industry representatives from the public and private sectors, including several ASTM members, attended two workshops on cool construction materials. The group formed the National Committee for the Planning of the Cool Construction Materials Program. One of the major tasks in this National Plan is to develop performance data and standard procedures for the evaluation of cool construction materials.
The subcommittee of E06 was formed as the vehicle to develop standard practices for measuring, rating, and labeling cool construction materials.

The subcommittee has determined that two optical properties (solar reflectance and emissivity) need to be measured in both the laboratory and the field. In response to the lack of standards for field measurements of solar reflectance, the subcommittee has drafted a test method for measuring solar reflectance of the horizontal and lowsloped surfaces. The subcommittee believes that two existing ASTM standards (E 903-Test Method for Solar Absorptance, Reflectance, and Transmittance of Materials Using Integrating Spheres, and E 408-Test Methods for Total Normal Emittance of Surfaces Using Inspec-

Table. Basecase U. S. air-conditioning use and savings potential of cool surfaces. We estimate that $13 \%$ of air conditioning can be avoided by the year 2015 .

\begin{tabular}{|c|c|c|c|}
\hline & \multirow{2}{*}{$\begin{array}{c}1995 \\
\text { Basecase }\end{array}$} & \multicolumn{2}{|c|}{2015} \\
\hline & & Basecase & Savings* \\
\hline Electricity (TWh) & 440 & 540 & 70 \\
\hline $\operatorname{Cost}^{\dagger}$ (billion $\$$ ) & 44 & 54 & 7 \\
\hline $\mathrm{CO}_{2}(\mathrm{MtC})$ & 110 & 135 & 18 \\
\hline
\end{tabular}

* Assuming $1 \mathrm{kWh}$ costs $10<$ in 1994 dollars.

t Potential savings in 20 years when roof resurfacing is completed.

$\mp \mathrm{MtC}=$ million metric tons of carbon.
tion-Meter Techniques) meet the needs for laboratory measurement of these properties.

Another activity of the subcommittee includes developing a Standard Practice for Calculating Solar Reflectance Index of Horizontal and Low-Sloped Surfaces. It is the objective of this standard to define a Solar Reflectance Index (SRI), which measures the relative steady-state temperature of a surface with respect to standard white $(S R I=100)$ and standard black $(S R I=0)$ under standard solar and ambient conditions.

In the coming year, we plan to finalize these standards and develop new ones addressing degradation of solar reflectivity with age and weathering.

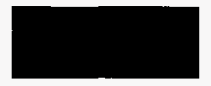

\section{Residential Building Energy Compilations}

\section{A. Meier, B. Pon}

Three related investigations of energy use in homes are underway. One is a broad compilation of field performance of energy-efficient buildings in both warm and cold climates. Its aim is to identify and document the characteristics of buildings that provide high levels of amenities with low energy consumption. The second investigation seeks to quantify the energy savings from ground source heat pumps (GHPs). The third focuses on the energy use of homes in cold climates around the world. The goal is to understand the apparent differences in energy performance due to differences in the method- ology of assessing performance.

The three studies are similar because they require the collection and analysis of large amounts of energy and building characteristics data. They all draw upon a common database containing energy, climate, and physical parameters of the homes. Some of the same buildings are used in all three studies because they are energy-efficient, located in cold climates, and are heated with GHPs. The studies diverge in the treatment of the data.

The first study, the compilation of energy-efficient homes, is a broad effort to show that low-energy homes are not strange or necessarily unconventional structures. Moreover, these buildings achieve low energy use through conventional and reliable technologies, rather than through the efforts or sacrifices of their occupants. This study also seeks to collect data from efficient homes in warm regions, where reducing the cooling requirements is the primary goal.

The second study focuses on the energy use of homes with GHPs. The GHP is a new technology that in theory offers reduced energy use, improved thermal comfort in both winter and summer, and reduced peak loads. 


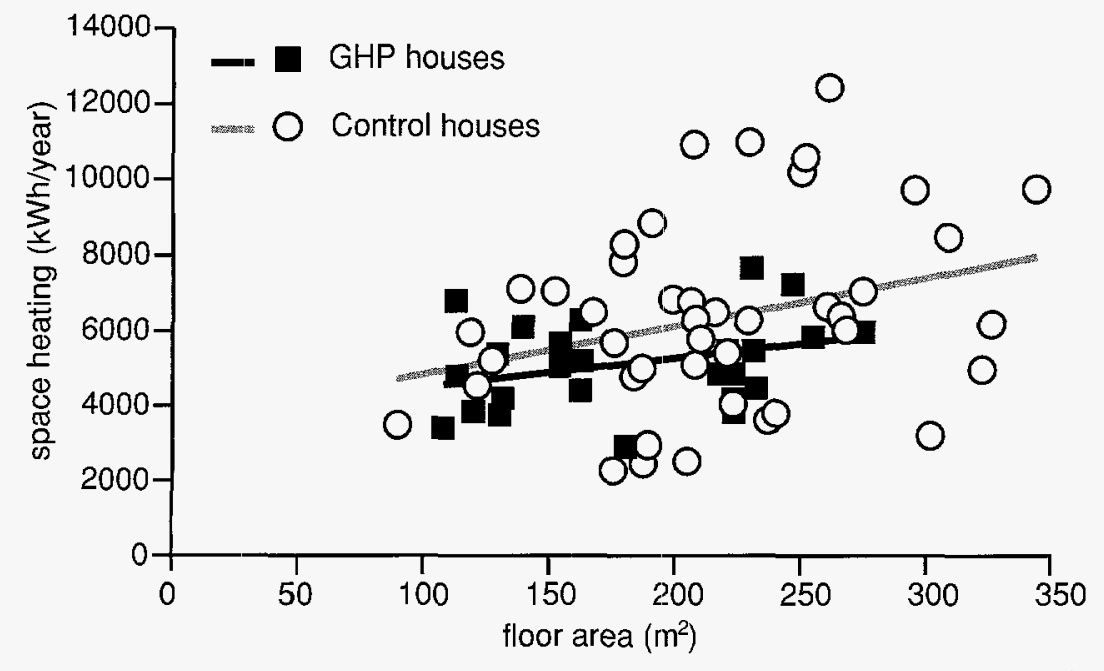

Figure. Space heating energy use of Montana homes with ground source heat pumps and controls.

Homes equipped with GHPs are being built in a tremenclous range of climates, from wintry Montana to semi-tropical Louisiana. Considerable anecdotal evidence suggests that the occupants are happy with both the reduced energy bills and the improved indoor thermal environment, but there is no careful documentation of the energy savings. The Figure shows a comparison of Montana GHP homes with a control group of energy-efficient homes in the same climate region. In spite of the cold climate, space-heating energy (for both groups) is virtually independent of home size. The GHP homes used about $15 \%$ less space-heating energy than the controls-a significant difference, but less than that claimed by advocates of GHPs.

The goal of the third study is to test new indicators of energy efficiency that better capture the home's overall energy efficiency and the levels of services enjoyed by its occupants. In the last 20 years, consumers throughout the world have reduced the energy used for space heating in cold climates. Now the space-heating costs are frequently less than one-third of the entire utility bill, even in near-Arctic climates. At the same time, electricity use in conjunction with space-heating systems (for ventilation and boiler operation) has greatly increased, in addition to the electricity for appliances and water heating. The result is that traditional indicators of residential energy efficiency, based on space heating alone, are increasingly obsolete.

\section{Reference}

Litt B, Meier A. What is a low-energy house? In: Proceedings of the ACEEE Summer Study on Energy Efficiency in Buildings., August 28-September 3, 1994. Vol. 9. Washington, DC: American Council for an Energy Efficient Economy, 1994, pp. 9.213-9.220.

\section{The Cost and Performance of Residential New Construction Programs E. Vine}

New homes determine future housing stock trends and the penetration of innovations in the marketplace. Residential new construction programs are of special interest therefore because they affect both present and future energy use. These programs affect the housing stock directly (by what is actually built) and indirectly (by creating demands for materials and by training builders, contractors, architects, and engineers). Thus, if cost-effective energy-efficiency opportunities are not fully captured by existing codes and standards, they may become "lost opportunities" for society.

In the past year, we evaluated the cost and performance of ten residential new construction programs sponsored by investor-owned utilities in the U.S. Based on evaluations of these programs, we found that many of these programs were in danger of being discontinued because the current inclusion of only direct program effects led to the conclusion that these programs were not cost-effective. The cost of energy saved by nine of the programs ranged from a low of $3.4 \phi / \mathrm{kWh}$ to a high of $34.1 \mathrm{c} / \mathrm{kWh}$ (see Figure). Weighted by energy savings, the average cost of energy saved by the programs was $5.7 \not / \mathrm{kWh}$.

We believe that the cost-effectiveness of residential new construction programs can be improved 1) by promoting technologies and advanced building design practices that significantly exceed state and federal standards; 2 ) by reducing program marketing costs and devel- oping more effective marketing strategies; 3) by recognizing the role of these programs in increasing compliance with existing state building codes; and 4) by allowing utilities to obtain an "energysavings credit" from utility regulators for program spillover (market transformation) impacts. Utilities can also leverage their resources in seizing these opportunities by forming strong and trusting partnerships with the building community and with local and state government.

\section{Reference}

Vine E. Utility Residential New Construction Programs: Going Beyond the Code. Lawrence Berkeley National Laboratory Report No. LBL-36603, 1995. 


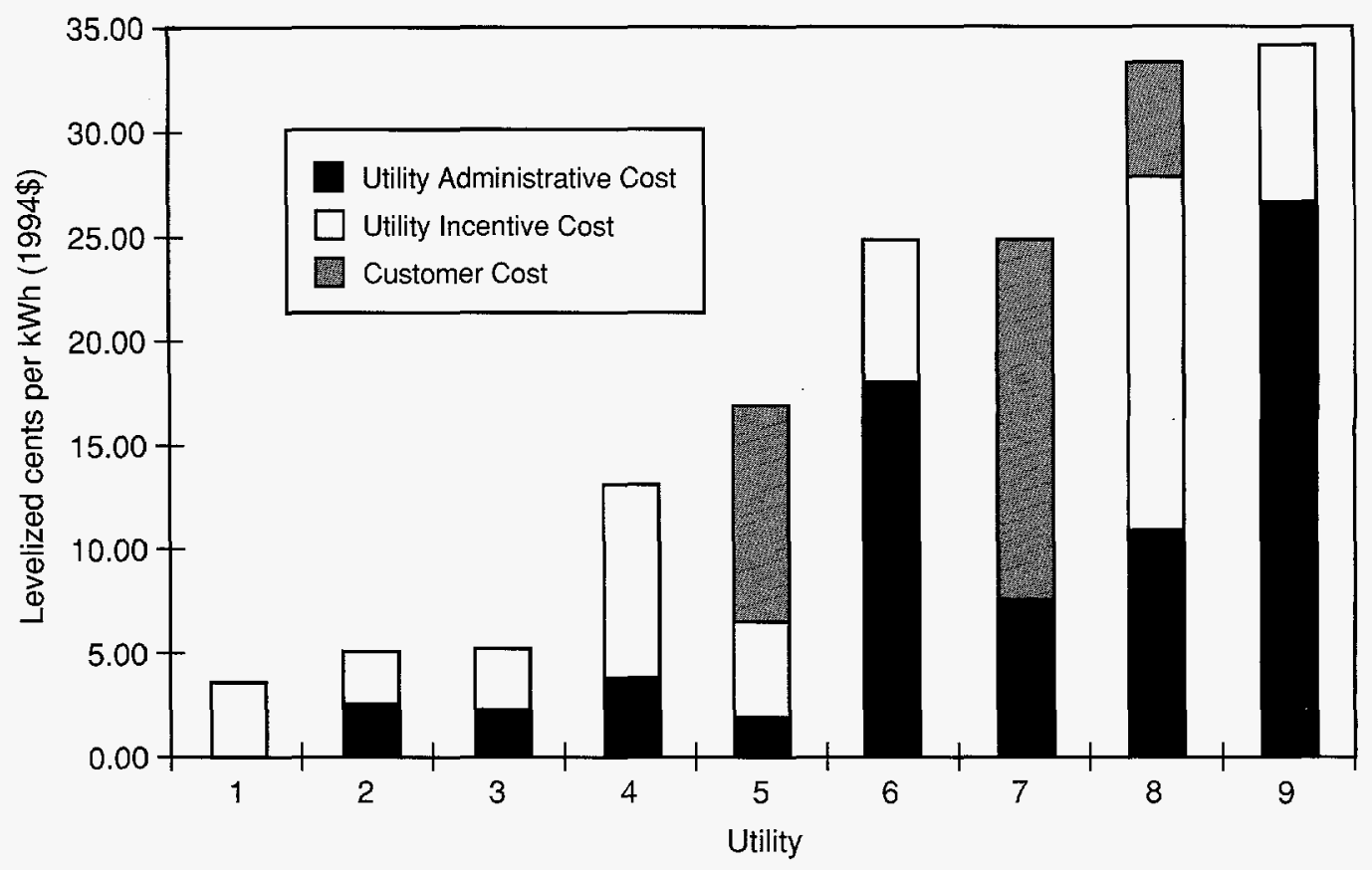

Figure. Total resource cost of residential new construction program energy savings.

\section{Designing Compressorless Houses for California Transition Climates}

\section{J. Huang, G. Loisos, S. Ubbelohde*}

The aim of the multi-year project "Alternatives to Compressive Cooling" is to develop and demonstrate costeffective residential building designs for California transition climates-inland areas between the coast and the Central Valley-where non-compressor cooling is technologically feasible but where the use of mechanical air conditioning is becoming more prevalent.

In July 1995, a design workshop was held at the Pacific Energy Center in San Francisco, which included 20 invited architects, contractors, and students, as well as the entire LBNL research team. The research team summarized its analysis of the cooling needs in the transition climates, stressing the applicability of such alternative cooling strategies as minimizing solar heat gain, increasing the building thermal mass, mechanical and natural ventilation, evaporative cooling, and improved controls. Designers at the workshop divided into four teams to produce designs for four hous-

*Department of Architecture, University of California at Berkeley. ing scenarios: high-density detached, standard lot detached (see Figure), move-up/luxury, and zero lot line housing.

To receive feedback on the thermal performance of their proposed designs, each team was provided with a PCbased design tool that used a spreadsheet program to invoke detailed DOE2 design-day simulations. This tool showed the maximum temperature the proposed designs would reach during the two hottest periods of the year, as well as indicating the need for air conditioning.

Since this tool is easy to use, the teams could fine-tune their designs to maintain indoor comfort at minimum costs.

The workshop produced prototypical building designs that are now being refined with detailed parametric thermal and cost-effectiveness analyses. The final building designs are expected to be finished in the spring of 1996.

\section{References}

Huang YJ, Warner JL, Feustel HE, Treidler B, Winkelmann FC, Buhl WF. Technical Issues Related to the Analysis of Ventilative Cooling Strategies. Lawrence Berkeley National Laboratory Report No. LBID-2088, 1995.

Meldem R, Winkelmann FC. Comparison of DOE-2 with Measurements in the Pala Test Houses. Final Report to CIEE. Lawrence Berkeley National Laboratory, 1995.

Loisos G, Ubbelohde S. Design Workshop. Project Summary to CIEE. University of California, Berkeley, 1995.

Huang YJ, Zhang H. Analysis of Climatic Conditions and Preliminary Assessment of Alternative Cooling Strategies for Houses in California Transition Climate Zones. Lawrence Berkeley National Laboratory Report No. LBL-36177, 1995.

Huang YJ. A Simplified Tool for the Design of Compressorless Houses. Lawrence Berkeley National Laboratory Report No. LBL-38138, 1995. 


\section{Computerized Commissioning Tools for Commercial Buildings}

\section{M.A. Piette, K. Heinemeier, F. Olken, ${ }^{*}$ M. Sherman, ${ }^{\dagger}$ S. Selkowitz ${ }^{\ddagger}$}

Commissioning is a set of processes to ensure that building components and systems are installed and operated in an optimal fashion to meet or exceed design intent. Most buildings are not commissioned in a structured manner, which results in such significant problems as defeated energy-efficiency strategies, incomplete control sequences, and poor documentation on as-operated conditions.

Commissioning costs vary depending on the scope of the commissioning project and the complexity of the building. Our recent analysis of the benefits of commissioning has shown that it is often cost-effective in terms of energy savings alone. Efforts to reduce costs are needed to encourage more widespread use of commissioning processes and techniques.

Computer-based information technology is one approach to address the loss of information that occurs as a building moves from design to operations. We have developed a prototype chiller commissioning tool to assist in the development, customization, execution, and archiving of commissioning plans. This tool was developed as part of the Building Performance Assurance Project to develop Building Life-Cycle Information Systems (BLISS).

Part of the first year's efforts have focused on chiller commissioning, since chillers are the largest single energyusing component in buildings with central plants. As shown in the Figure, the first step in applying the software is to describe the characteristics of the chiller components (chiller size, type, design efficiency, flow rates, and operating temperatures). The software contains a general description of chiller commis-

*Information \& Computing Sciences Division, LBNL.

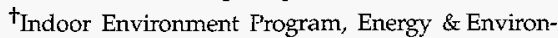
ment Division, LBNL.

‡Building Technologies Program, Energy \& Environment Division, LBNL. sioning activities and a module to record specific test plan methods, customized for a particular building (Step 2). Laptop computers can be used to track changes to test plans and collect data during plan execution (Step 3). Test results are recorded and outstanding issues and deficiences are tracked to ensure that the chiller is fully functional (Step 4). Long-term performance tracking methods are also defined for ongoing evaluation over the life of the building.

Second-year activities will cover four primary areas. First, to evaluate the software's usefulness and value in cutting commissioning costs and improving building performance, we will obtain feedback from commissioning agents. Second, we will expand the tool to be inter-operable with other computer-based building life-cycle information tools. These include such design

$\begin{array}{llll}\text { Step 1 } & \text { Step 2 } & \text { Step 3 } & \text { Step 4 } \\ \text { Describe } & \text { Customize } & \text { Execute } & \text { Record } \\ \text { Components } & \text { Plan } & \text { Tests } & \text { Results }\end{array}$

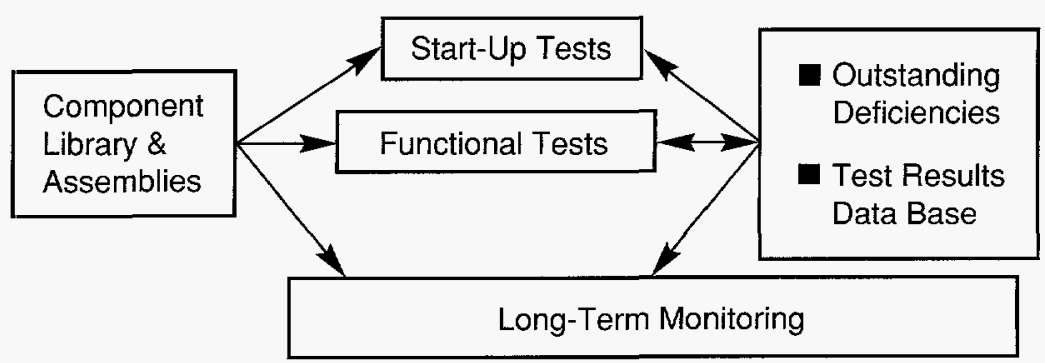

Figure. The four steps of commissioning and the use of a computer-based chiller commissioning tool. tools as PowerDOE and the Building Design Advisor, and model-based performance tracking tools such as a calibrated (equation-based) SPARK model. Third, we will refine the tool based on user comments. Finally, we plan to increase the scope of the software to include additional cooling plant components, such as cooling towers. These improvements will culminate in a prototype cooling plant life-cycle information system.

\section{Reference}

Piette MA, Nordman B, Greenberg S. Commissioning of Energy-Efficiency Measures: Costs and Benefits for 16 Buildings, prepared for the Bonneville Power Administration, Lawrence Berkeley National Laboratory Report No. LBL-36448, 1994. 


\section{Building Performance Evaluation and Tracking Tool} O. Sezgen, B. Smith*

Numerous proxies have traditionally been used to measure the energy performance of heating, ventilating, and air conditioning (HVAC) systems in buildings. These include equipment coefficient of performance (COP) at standard conditions, annual integrated part load efficiency, and seasonal integrated part load efficiency. These proxies describe the performance of a building HVAC system in a limited fashion. More detailed information about performance must involve the dynamic behavior of the HVAC/building variables.

Measured HVAC time-series data are descriptive of the performance, but only under the strict boundary conditions that the building was exposed to during the monitoring (e.g., the weather conditions during monitoring, the control strategies that were applied during the same period, etc.). When one wants to estimate performance under other possible conditions, measured data is of limited use. A dynamic model of the building/HVAC system calibrated to monitored data, on the other hand, can facilitate such estimations.

Our objective in this project was to use a dynamic model of the HVAC system to develop a methodology for carrying the performance-related information from the design phase to the commissioning phase, operations phase, and even a retrofit phase.

In our methodology, during the design phase the HVAC model is built using the design documents and manufacturer-supplied data on equipment performance. At this stage, it is possible to emulate several design options (such as different equipment sizes, efficiencies, etc.), to compare the energy performance of these different options and to feed information back to the design process.

During the commissioning phase, the model built using the design data is calibrated to represent the dynamic behavior of the system as it actually performs. For this purpose, after the acceptance of the building, time-series data on the HVAC variables are used to revise the model parameters. At this point, the emulation results and the real data from the building should be very close.

We developed application software that allows the use of the above calibrated model in numerous ways during the operations and retrofit phases. The Building Performance Evaluation and Tracking Tool can be used for performance tracking, for analysis of different control strategies, and also for the analysis of different options during the retrofit phase.

Using the performance tracking options, data from the building can be compared to benchmark data from other similar buildings, to historic data from the same building during other time periods, or most significantly, to the simulated data using the HVAC model. Deviations in the building data from the simulated data may indicate problems in the HVAC system. The Figure shows the simulated and measured data for the chillers of a case-study building. This project, at least at this stage, is not aimed at pinpointing the source of such problems. In other words, it is not intended to be a diagnostics application, although this is a fertile research area.

Control strategy analysis options facilitate changes to the control logic actually used during the measurement and comparison of the emulated results to the actual measured data. The environmental conditions and the building loads are maintained at the levels that they occurred, but changes are made to the control choices such as temperature set points, or equipment status. Although at this stage, these control strategy analysis options serve as a "what-if" type of analysis facility, capabilities can be expanded to include optimization. In such an application, the tool would come back with the optimal set of choices for all of the control options.

Finally, longer term actions can be analyzed using the retrofit analysis options of the tool. Here, changes that

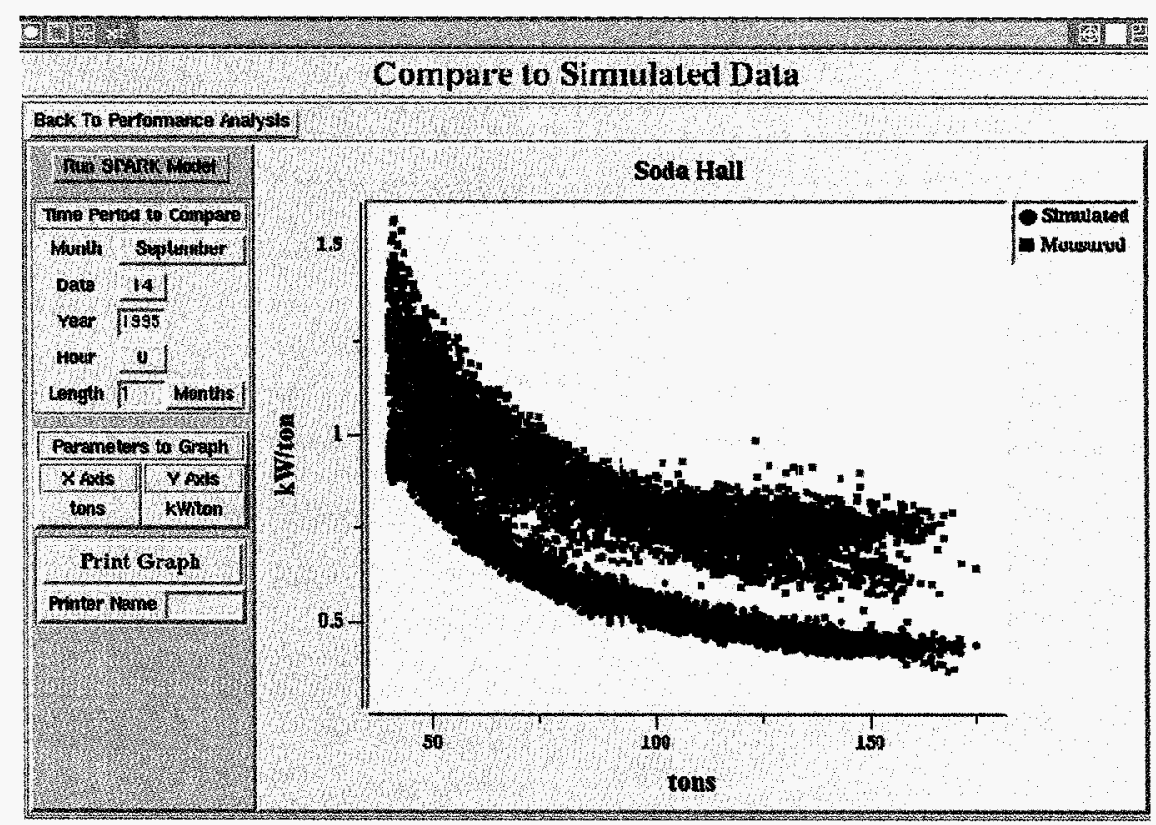

Figure. Measured and simulated data for the chillers of a case-study building. 
would require implementation of new equipment and hardware are analyzed. A typical example would be a chiller replacement project. Using the retrofit analysis options of the tool, one can compare the performance of the overall system under different chiller sizing and efficiency choices.

We used the Simulation Problem Analysis Research Kernel (SPARK) to build our emulation model. SPARK was developed by the Simulation Research Group of LBNL's Building Technologies Program. SPARK can be viewed as an object-based differential/algebraic equa- tion solver. The models are represented as mathematical graphs (as opposed to linear data structures) in SPARK, and this feature facilitates emulation of submodels without substantial changes to the initial model. This is also a crucial feature which facilitates emulations using changes in control strategies.

During the first year of this project, we focused our attention on chillers. This was mainly for demonstration purposes and this setup served as a test bed for the development of the Performance Evaluation and Tracking Tool. Clearly, optimization of chiller perfor- mance cannot be done independent of the effects of such action on the energy performance of the rest of the system. For example, reducing the condenser inlet temperature reduces the chiller electricity use, but increases the energy consumption of the cooling towers. Having demonstrated the concepts on chillers, we are now expanding our models to include first cooling towers and then cooling coils, and possibly the air distribution system.

\section{Measured Energy Savings and Performance of Power-Managed Personal Computers and Monitors}

\section{B. Nordman, M.A. Piette, K. Kinney}

Power-management systems for the vast number of personal computers now in operation could help consumers save as much as $\$ 1$. billion a year in energy costs. Personal computers (PCs) are estimated to use a total of 16 billion $\mathrm{kWh} /$ year of commercial sector electricity. The U.S. Environmental Protection Agency's Energy Star program specifies maximum power demand $(30 \mathrm{~W})$ for computers and monitors when in a "sleep" or inactive mode. To make better estimates of the electricity savings we can expect from power management, we gathered energy-use data from power-managed (Energy Star-compliant) PCs and monitors, audited the power-management features in a sample office area with $34 \mathrm{PCs}$, and reviewed the underlying technology that operates power management. In the audit, we examined whether the power-management features were "enabled," i.e., turned on.

We collected electricity-use measurements of eleven pieces of powermanaged office equipment: three PCs and three monitors in LBNL offices, and five combined PC-monitor systems from several locations around the country. We measured the time the machines spent in primary system operating modes (off, low-, and full-power) and combined these with power measurements to derive hours of use per mode. Energy-savings estimates were derived using three schedules: "as-operated," "standardized" to a typical operating pattern, and the "maximum" achievable savings.

The Figure shows the as-operated and standardized savings for the eleven devices in annual electricity savings and dollar savings at the U.S. average commercial electricity price of $8 c / \mathrm{kWh}$. Asoperated, energy savings for the eleven $\mathrm{PCs}$ and monitors ranged from 0 to 75 $\mathrm{kWh} /$ year; under the standardized operating schedule (device turned on $20 \%$ of nights and weekends), the savings are about $200 \mathrm{kWh} /$ year. Most of the savings are from monitor power management. Measured separately, the monitors are physically larger than those in the combined systems, which explains why the savings for the two categories are similar. As is apparent from the Figure, monitor power management saved considerably more energy in these systems due to higher operating and lower "sleep" power levels.

An audit of several dozen compliant devices found only $11 \%$ of PCs fully enabled and $39 \%$ of monitors properly configured. Further examination of the enabled devices showed that many were not entering low-power modes or were only powering down a few system components and thus achieving only small power savings. In some cases, we determined that the computer network hardware and activity was keeping the PCs "awake."

Changes in technology, rapid turnover of different computer models, and the interactions among hardware and software components make any

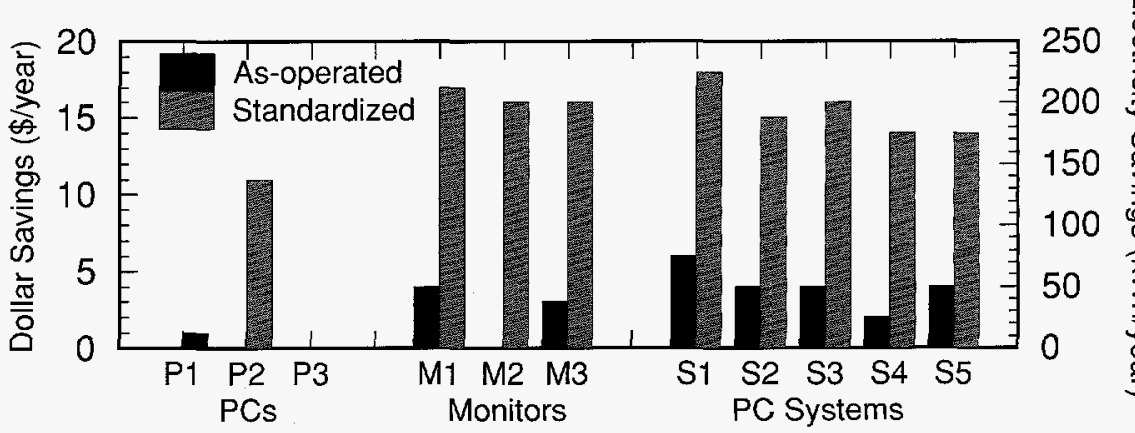

Figure. Energy and dollar savings from PC power management, both as measured and under a standard operating pattern. 
characterization of the potential and actual state of power management in PCs complicated. Confusion among users and support personnel often leads to assumptions that power management is operating when it is not. Similarly, for some users, one bad experience with power management leads to permanent disablement of the feature.

The most critical outstanding research issue is to evaluate the percentage of compliant machines that are enabled and working. As of October 1995, Energy Star PCs and monitors were required to be shipped already enabled, which should increase the percentage of PCs and monitors using power management. Ensuring that these devices routinely enter low-power modes is also important.

The highest priority for increasing energy savings from power management is to target monitors since they are generally easier to configure than are PCs, are less likely to interfere with system operation, and have greater savings for each device. The difficulty of knowing how to configure most PC systems properly is the largest current barrier to achieving the savings potential from power management. Better software controls should greatly alleviate this problem.

\section{Reference}

Piette, MA, Cramer M, Eto J, Koomey J. Office Technology Energy Use and Savings Potential in New York. Lawrence Berkeley National Laboratory Report No. LBL-36752, 1995.

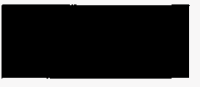

\section{Energy Use of Ice Making in Domestic Refrigerators} A. Meier

Most large domestic refrigerators sold in the United States are equipped with an automatic ice maker or designed so one can be easily added. Field monitoring studies have determined that refrigerators with automatic ice makers consume $7-26 \%$ more electricity than similar models without them. The U.S. Department of Energy (DOE) has an energy test procedure for refrigerators, but it does not include energy use of ice makers. This investigation sought to develop a modified test procedure that would include the electricity consumed by automatic ice makers and other new features.

Designs for automatic ice-making units in different domestic refrigerators are all very similar. The major components are a water reservoir, a motor/cam assembly, an ice mold, ejector blades and a heater, a harvest basket, and a shut-off arm. All residential units make cubes, which are then released through the application of heat. A typical cycle converts $140 \mathrm{~cm}^{3}$ of water into eight crescent-shaped ice "cubes." The elapsed time of one ice-making cycle depends upon the temperature setting of the refrigerator, but most ice makers can produce at least $2000 \mathrm{~g}$ of ice per day.

The automatic ice maker contains several heaters. Not only do they add to the cooling requirements, but they also require more energy than manual iceproduction methods. The largest energy consumer is the mold heater, which typically draws 185 watts. Under maximum ice-harvesting conditions, the total energy devoted to ice making (including chilling and freezing the water) will be about $250 \mathrm{kWh} /$ year, or about $25 \%$ of typical electricity use for these models of refrigerators. Under typical conditions, the additional load will be less.

At the same time, automatic ice making saves energy because the user does not open the freezer door as frequently. Producing $500 \mathrm{~g} /$ day saves roughly two openings per day or about $10 \mathrm{kWh} /$ year.

The Figure shows the results of successive measurements of energy use for four refrigerators (expressed as averages). The first value is the labeled energy consumption as provided by the manufacturers. The second value is the actual DOE test values for each unit, as measured in the laboratory. (This is expected to differ somewhat from the labeled value due to sampling variation.) The third value is the energy use with the modified test that includes the automatic ice maker. After laboratory tests, the units were placed in real kitchens and monitored for two years. The results are summarized in the fourth value. The units were then

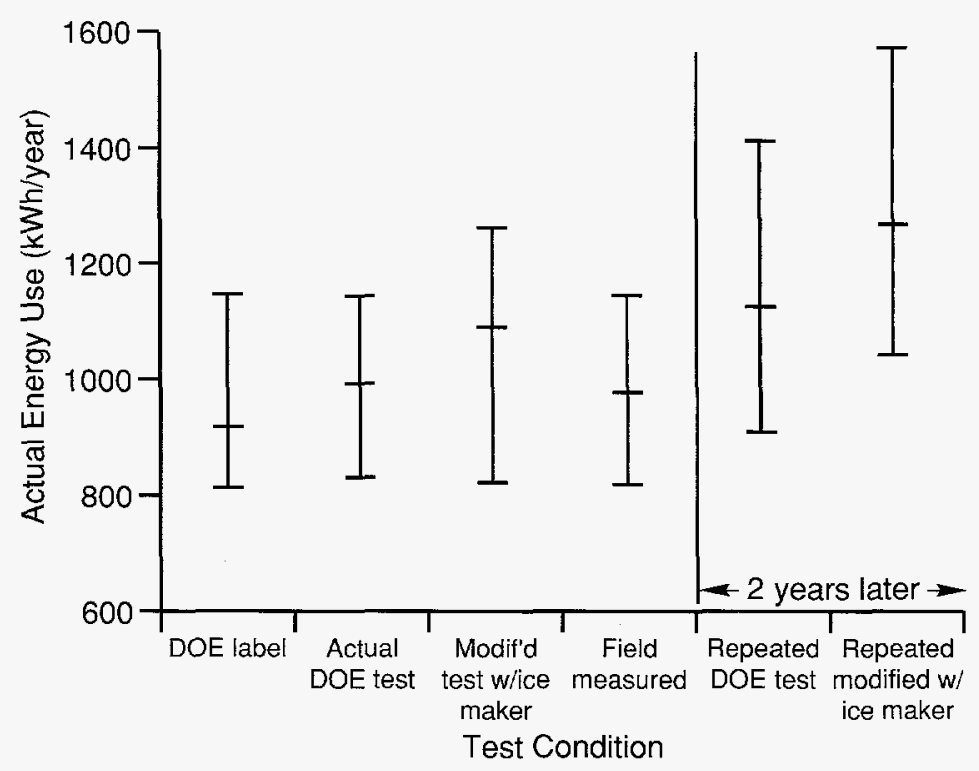

Figure. Energy consumption of four refrigerators in laboratory and field measurements. 
returned to the laboratory and re-tested using both the DOE and modified procedures. These are the fifth and sixth values in the Figure.

The measured increase in energy use due to ice making was roughly $60 \%$ greater than predicted. The range in energy use is probably due to different lengths of mold heater operation. The refrigerators used about $10 \%$ more electricity in actual kitchens than predicted by the conventional DOE test (which is used for the energy label). When the laboratory tests were repeated after two years, the refrigerators experienced $14 \%$ higher energy use.

This modification of the DOE test procedure was relatively easy to undertake. Other modifications to increase its realism, such as for food loading, may be more difficult. Each modification needs to balance the demands for realism with the need to maintain a simple procedure with acceptable accuracy and precision. Careful testing, both in the laboratory and in the field, would also be necessary to ensure that the test applies to all common units.

\section{Reference}

Meier A. Energy Use of Ice Making in Domestic Refrigerators. Lawrence Berkeley National Laboratory Report No. LBL-31976, 1995.

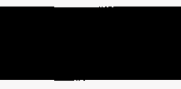

\section{Space-Conditioning Stock}

\section{J. Huang, E. Franconi}

The energy bill for the heating and cooling of commercial buildings is $\$ 40$ billion a year, consuming nearly onetenth of all the energy used in the U.S. The aim of this two-year project is to understand the characteristics of this energy expenditure by quantifying the contributions of major building components (such as roofs, walls, and windows) and end uses (such as lighting or equipment) to these space-conditioning loads (see Figure). This information is
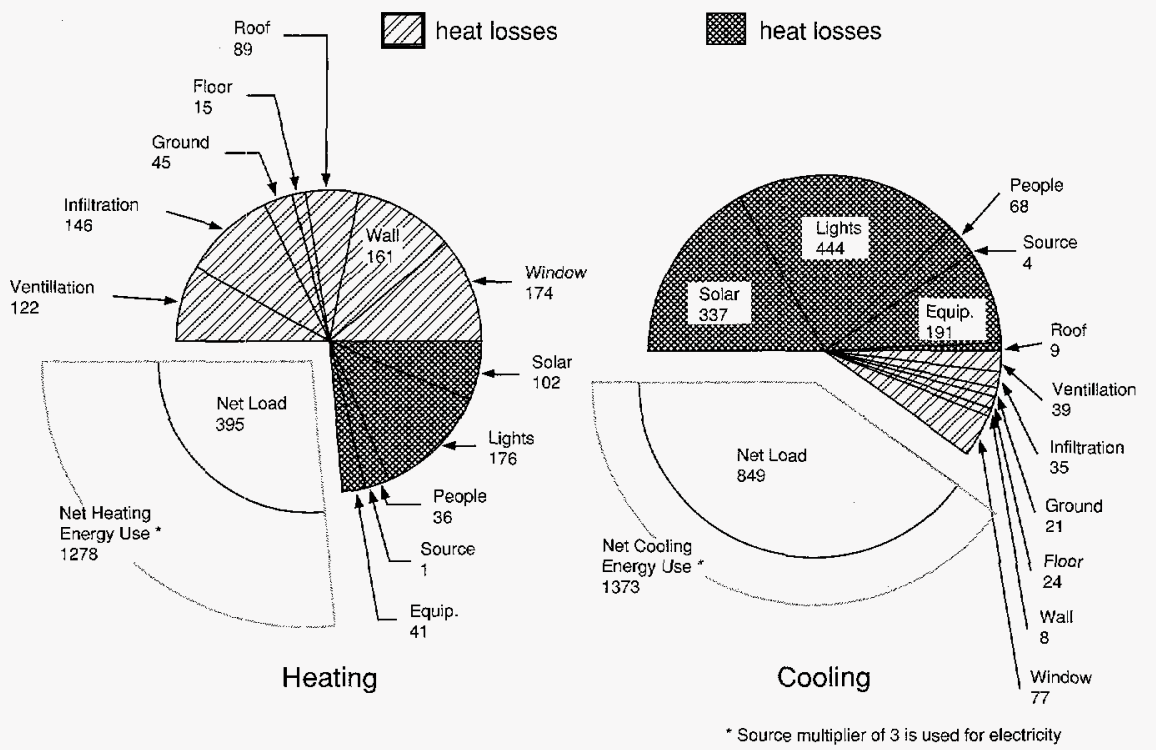

useful for comparing the potentials of different energy conservation strategies, identifying demand-side management opportunities, and allowing DOE to prioritize their building research activities.

The DOE-2 building energy analysis computer program is used to simulate the energy use of a large collection of prototypical commercial buildings developed in previous research efforts. A special procedure was developed to disaggregate the computed loads by

building component and end use. The relationship of the building load to the energy requirement of the space-conditioning system is expressed as System and Plant Factors, which vary greatly depending on the system type, building operations, and climate.

The computed loads and energy use data are combined with building stock information from DOE's Energy Information Agency (EIA) to derive the total energy consumption for each commercial building sector, and then apportion it by building component and end use. The total space-conditioning energy use estimated by this engineering approach agrees within $5 \%$ of that from EIA's Commercial Builaing Energy Consumption Survey (CBECS).

\section{References}

Huang YI, Franconi EM. Commercial Heating and Cooling Loads Component Analysis. Lawrence Berkeley National Laboratory Report No. LBL-37208, 1995.

Huang YJ. Energy Use Characteristics of Prototypical Commercial Buildings. Lawrence Berkeley National Laboratory Report No. LBL-36021, 1995.

Figure. Aggregate component loads for all commercial buildings (petajoules). 


\title{
Estimates of Energy Consumption by Building Type and End Use at Department of Defense Facilities
}

\author{
H. Akbari, S.J. Konopacki
}

End-use Disaggregation Algorithm (EDA) to develop end-use load shapes and intensities for prototypical buildings at the U.S. Department of Defense (DoD) facilities. In EDA, DOE-2 building energy analysis program simulations are reconciled hourly against measured energy consumption to obtain end-use consumption data. The objectives of this project were to : 1) develop an energy database by building type and end use for DoD facilities; and 2) enhance the DoD energy office's ability to track energy use by end use. In the process, we also transferred our analytical methodologies for end-use energy analysis to the U.S. Army's Construction Engineering Research Laboratory.

We initially achieved the objectives at one DoD installation, Fort Hood, Texas. At Fort Hood, the building types include a wide spectrum of commercial and residential buildings: barracks, dining hall, gymnasium, small and large administration, vehicle maintenance, hangar, hospital, warehouse, singlefamily detached, two-plex and four-plex units, and miscellaneous. As many as 11 end uses were developed for each prototype, consisting of nine electric (space cooling, fans/pumps, cooking, miscellaneous/plugs, refrigeration, exterior lighting, interior lighting, process loads, and street lighting) and two gas (space heating and hot water heating). Since, we had only hourly electricity-use data for the entire facility characterized by major electricity-distribution feeders, we reconciled only the electric end uses.

The EDA was applied to ten feeders in Fort Hood, and the results from the analyses of these ten feeders were extrapolated to estimate energy use by end use for the entire installation. Utility billing data for electricity use were used to validate the total energy use as estimated by EDA to within. 5\%, which was attributed to transmission losses. The extrapolation of the EDA results to the entire Fort Hood installation is shown in the Figure, where electricity use and peak power demand are depicted by both building type and end use.
Administration, residential, and the barracks prototypes are the largest consumers of electricity, totaling $250 \mathrm{GWh}$ per year (74\% of Fort Hood's annual consumption of $330 \mathrm{GWh}$ ). Cooling, ventilation, miscellaneous, and indoor lighting consume almost $84 \%$ of total electricity use. The largest contribution to peak power demand is the residential sector $(35 \%, 24 \mathrm{MW}$ out of $70 \mathrm{MW})$, followed by administration buildings $(30 \%)$, and barracks (14\%). For the entire Fort Hood installation, cooling is $54 \%$ of the peak demand ( $38 \mathrm{MW}$ out of 70 MW), followed by interior lighting at $18 \%$, and miscellaneous end uses at $12 \%$.

With existing technologies, energy-efficiency programs can be designed to reduce energy and peak demand use by $20 \%$ with a payback time of less than three years. Such a program at Fort Hood can result in an annual savings of $66 \mathrm{GWh}$ and $14 \mathrm{MW}$.

In the second phase of this project, we are extending the annual energy-use intensitites obtained at Fort Hood to 20 other DoD installations nation-wide, representing all major climatic regions. However, the data available for these other facilities are very limited. Monthly utility electrical use data will be used in place of hourly data, and surveys of building characteristics are not available. We plan to use the Fort Hood prototypes and modify them based on the available data for other installations. Data identifying HVAC system type are virtually non-existent; consequently, fewer building types will be examined.

\section{References}

Akbari H, Konopacki SI. End-use Energy Characterization and Conservation Potentials at DoD Facilities: An Analysis of Electricity Use at Fort Hood, Texas. Lawrence Berkeley National Laboratory Report No. LBL-36974, 1995.

Akbari H. Validation of an algorithm to disaggregate whole-building hourly electrical load into end uses. Energy-The International Journal 1995;20(12):12911301.

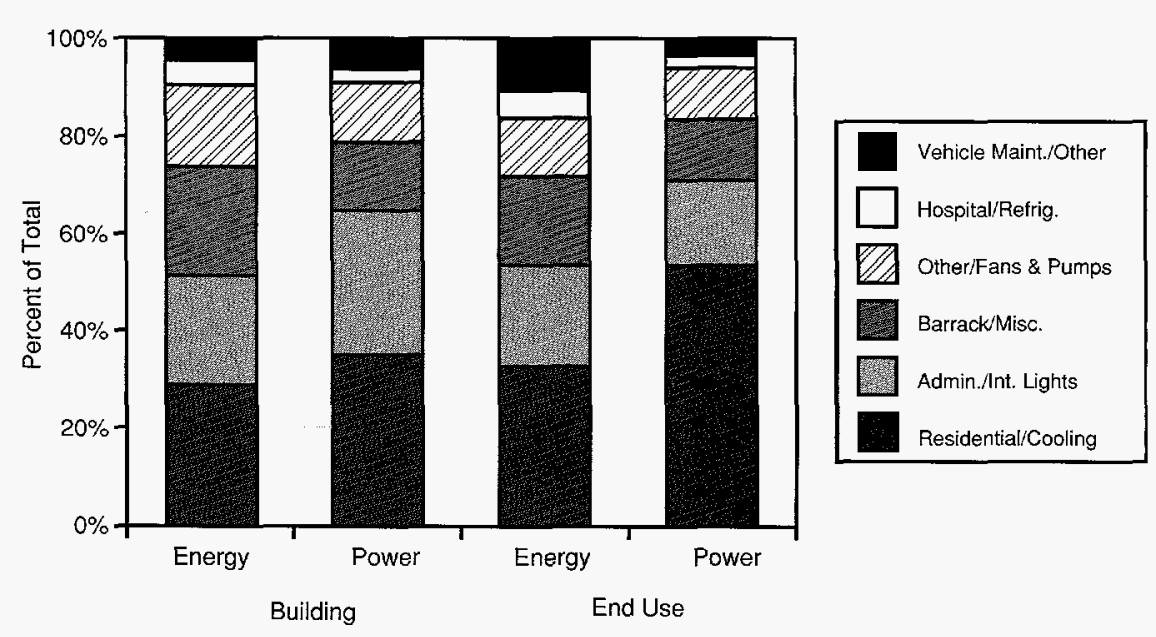

Figure. Percentage of electricity use (330 GWh) and peak power demand (70 MW) by building type and end use at Fort Hood, Texas, for 1993. 


\section{Sponsors}

Support from the following sources was provided through the U.S. Department of Energy under Contract No. DE-AC0376SF00098:

- Assistant Secretary for Energy Efficiency and Renewable Energy, U.S. Department of Energy Office of Federal Energy Management Program

Office of Planning and Assessment Office of Transportation Technologies

Deputy Assistant Secretary for Building Technologies, Office of Building Energy Research Deputy Assistant Secretary for Building Technologies, Office of Codes and Standards Deputy Assistant Secretary for Industrial Technologies, Industrial Energy Efficiency Division Deputy Assistant Secretary for Utilities Technologies, Office of Energy Management

- Assistant Secretary for Fossil Energy, U.S. Department of Energy

Deputy Assistant Secretary for Coal Technology

- Assistant Secretary for Policy, U.S. Department of Energy

Deputy Assistant Secretary for Economic and Environmental Policy

- Office of Energy Research, U.S. Department of Energy

- U.S. Department of Defense, U.S. Army Corps of Engineers, Construction Engineering Research Laboratory

- U.S. Environmental Protection Agency

Office of Policy, Planning, and Evaluation, Office of Policy Analysis, Climate Change Division

Office of Air and Radiation, Office of Atmospheric Programs, Global Change Division

Office of Air and Radiation, Office of Atmospheric Programs, Atmospheric Pollution Prevention Division

Office of Air and Radiation, Office of Atmospheric Programs, Stratospheric Protection Division

- U.S. Agency for International Development, Office of Energy and Infrastructure

- $\mathrm{AB}$ Volvo

- Bonneville Power Administration

- California Institute for Energy Efficiency

- Chevron

- Conoco

- Danish Energy Agency

- Exxon Company International

- Finnish Ministry of Trade and Industry

- International Energy Agency

- LBNL Laboratory-Directed R\&D Program

- National Aeronautics and Space Administration

- New York State Energy Research and Development Authority

- Oak Ridge National Laboratory 
- Pacific Northwest National Laboratory

- Public Service Electric and Gas Company

- Shell International Petroleum Company

- Shell Oil Company (Houston)

- United Nations Environmental Program, Collaborating Centre on Energy and Environment

- University of California, Transportation Center

Additional support for graduate students to work on LBNL projects came from:

- British Petroleum

- General Motors

- Swedish Communications Research Board

- University of California

Energy Institute

Transportation Center 